\section{Pacific Northwest}

National Laboratory

Operated by Battelle for the

U.S. Department of Energy

\title{
2002 Initial Assessments for B-BX-BY Field Investigation Report (FIR): Numerical Simulations
}

\author{
V. L. Freedman \\ M. D. Williams \\ C. R. Cole \\ M. D. White \\ M. P. Bergeron
}

August 2002

Prepared for the U.S. Department of Energy under Contract DE-AC06-76RL01830

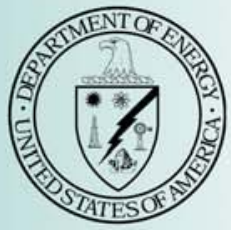




\title{
DISCLAIMER
}

This report was prepared as an account of work sponsored by an agency of the United States Government. Neither the United States Government nor any agency thereof, nor Battelle Memorial Institute, nor any of their employees, makes any warranty, express or implied, or assumes any legal liability or responsibility for the accuracy, completeness, or usefulness of any information, apparatus, product, or process disclosed, or represents that its use would not infringe privately owned rights. Reference herein to any specific commercial product, process, or service by trade name, trademark, manufacturer, or otherwise does not necessarily constitute or imply its endorsement, recommendation, or favoring by the United States Government or any agency thereof, or Battelle Memorial Institute. The views and opinions of authors expressed herein do not necessarily state or reflect those of the United States Government or any agency thereof.

\author{
PACIFIC NORTHWEST NATIONAL LABORATORY \\ operated by \\ BATTELLE \\ for the \\ UNITED STATES DEPARTMENT OF ENERGY \\ under Contract DE-ACO6-76RLO183O
}

Printed in the United States of America

Available to DOE and DOE contractors from the

Office of Scientific and Technical Information,

P.O. Box 62, Oak Ridge, TN 37831-0062;

ph: (865) 576-8401

fax: (865) 576-5728

email: reports@adonis.osti.gov

\footnotetext{
Available to the public from the National Technical Information Service, U.S. Department of Commerce, 5285 Port Royal Rd., Springfield, VA 22161

ph: (800) 553-6847

fax: $(703) 605-6900$

email: orders@ntis.fedworld.gov

online ordering: http://www.ntis.gov/ordering.htm
} 


\title{
2002 Initial Assessments for B-BX-BY Field Investigation Report (FIR): Numerical Simulations
}

\author{
V. L. Freedman \\ M. D. Williams \\ C. R. Cole \\ M. D. White \\ M. P. Bergeron
}

August 2002

Prepared for

the U.S. Department of Energy

under Contract DE-AC06-76RL01830

Pacific Northwest National Laboratory

Richland, WA 99352 


\section{Summary}

Pacific Northwest National Laboratory, supporting CH2MHILL Hanford Group, Inc. (CHG) in their preparation of a Field Investigative Report (FIR) for the Hanford Site Single-Shell Tank (SST) Waste Management Area (WMA) B-BX-BY, executed a suite of numerical simulations of flow and solute transport to predict the performance of surface barriers for reducing long-term risks from potential groundwater contamination at the WMA. The scope and parametric data for these simulations were defined by a CHG Modeling Data Package. This report documents the simulation of 14 cases involving two-dimensional cross sections through the B-BX-BY WMA. Two cross-sections were constructed for this analysis: the first was through the BX WMA from Tanks BX-108 to BX-102 for investigating past leaks; the second was through trench B-38 to simulate discharge from the B trenches. The simulations were used to investigate the impact of surface barriers, water-line leaks, and placement of inventories for the transporting fluid (i.e., water), meteoric recharge and partitioning between the aqueous and sorbed phases. Three transported solutes were considered: uranium-238 (U-238), technetium-99 (Tc-99), and nitrate $\left(\mathrm{NO}_{3}\right)$.

The large quantity of simulation data makes it impractical to reproduce in numerical, graphical or visual form. Therefore, only selected results are presented in this report, and the majority of the data are archived in electronic form. The two principal objectives of this work were to conduct the simulations and analyses using an open scientific approach and to provide modeling results that could be verified and repeated. In partial fulfillment of these objectives, the source code for the STOMP simulator, ancillary utilities coding, input files, simulation output files, and converted results files have been archived in electronic form with sufficient detail so the calculations can be repeated.

All simulations comprised steady flow and transient components, where flow fields developed from the steady flow component were used to initialize the transient simulation. Steady-flow initial conditions were developed by simulating from a unit hydraulic gradient condition to a steady flow condition, dictated by the initial meteoric recharge at the surface, water table elevation, aquifer flux, no-flux vertical boundaries, soiltype zonations and hydrologic properties, and location of impermeable tanks.

The physical domains for the two-dimensional simulations involving the tanks were east-west sections across the BX tank farm WMA from Tank BX-108 to the eastern BX WMA fence line. From the starting conditions outlined above, transient simulations of solute transport for the BX tank farm were executed for a 1000-year period (i.e., year 2000 to 3000) that involved implementing a closure barrier in 2040 and a degraded closure barrier from 2540 to 3000 . Two of the simulations involved analyzing the effect of an interim barrier from 2010 to 2540 . Other simulation cases involved investigating changes in the flow fields in response to the application of water-line leaks, variations in recharge and partitioning coefficient, and inventory placement in the subsurface. For example, the Base Case simulated an initial recharge rate of $100 \mathrm{~mm} / \mathrm{yr}$, and three other cases investigated different recharge rates (50,30, and $10 \mathrm{~mm} / \mathrm{yr})$. Including the Base Case, three cases analyzed the effect of different values of the partitioning coefficient $\left(\mathrm{K}_{\mathrm{d}}=0.6\right.$, 0.1 , and $1.0 \mathrm{~g} / \mathrm{L}$ ). The effect of water-line leaks was examined in two cases. The influ ence of initial contaminant inventory distributions was investigated by considering two different inventory distributions beneath the BX tanks. In both distributions, solute concentrations varied with depth but were uniformly distributed in the horizontal direction. In the Base Case distribution, the inventory was located east of Tank BX-102 and extended to the east BX fence line. In the second distribution, the inventories were centered between Tanks BX-105 and BX-102. 
For the B-38 trench simulations, the start time was 1954, with a discharge to the trench for one year of 378,000 gallons with unit inventory concentrations for sorbing (U-238) and non-sorbing (Tc-99 and $\mathrm{NO}_{3}$ ) species. Two of the trench simula tions included a closure barrier at 2010 and a degraded closure barrier from 2510 to 3000 . A closure barrier schedule analogous to the one used for the BX tank farm was used for the third trench simulation, with a closure barrier at 2040 and a degraded closure barrier from 2540 to 3000. To assess the impact of meteoric recharge in the trench B-38, simulations were executed with unit inventory distributions. The first trench simulation had a recharge rate of $55.4 \mathrm{~mm} / \mathrm{year}$, whereas the latter two had recharge rates of $100 \mathrm{~mm} /$ year. The domain of the two-dimensional trench simulation was from the west to the east fence lines of the B trenches at B-38. The results of the trench simulations were scaled to the disposal inventory of trench B-38 and the total disposal inventory of all eight trenches.

These flow domains were discretized with grid resolutions of $0.5334 \mathrm{~m}(1.75 \mathrm{ft})$ in the horizontal direction and $0.4572 \mathrm{~m}(1.5 \mathrm{ft})$ in the vertical direction, yielding 42,900- to 48,516- node grids. Execution times for these simulations varied from 8 to 48 hours. Mass balance errors were small for all simulations. For example, the maximum mass balance errors for each solute in all fourteen cases were $0.052 \%$ for U-238, $0.415 \%$ for Tc-99, and $0.140 \%$ for $\mathrm{NO}_{3}$.

Simulation results are summarized and supported with line plots and color-scale images. The Results sections of this report begin with descriptions of the techniques and utility programs used to convert the simulation results from the conventional STOMP output format to the forms reported. Results are then presented for each of the cases starting with the coupled vadose-zone and unconfined aquifer simulations followed by the translation of those results for contaminant transport to the remote compliance points through streamtube modeling. The primary emphasis in reporting results was to provide a straightforward summary of the simulations and streamtube modeling using tables, plots, and color-scaled images.

A principal objective of this investigation was to evaluate the effectiveness of interim barriers to the infiltration of meteoric water (from winter precipitation and snowmelt) on the migration of contaminants from previous leak sources from the BX tank farm and B trenches. For the two cases that examined the effect of interim barriers (Cases 2 and 5), the initial peak arrival times and concentrations for Tc-99 and $\mathrm{NO}_{3}$ were similar to the Base Case. This was due to the initial inventory distribution, which contained high concentrations of both Tc-99 and $\mathrm{NO}_{3}$ near the water table. The barrier had little effect on the initial breakthrough because the contaminants had already migrated to the water table before the lower infiltration rates became effective at that depth. By contrast, the interim barrier did have an impact on the inventory in the upper part of the vadose zone. Whereas breakthrough curves for the Base Case showed an additional peak due to a low concentration region in the middle part of the vadose zone, the reduced recharge caused by the interim barrier effectively eliminated the final peak.

Simulations investigating water-line leaks (Cases 3 and 4) demonstrated the highest peak concentrations of the $11 \mathrm{BX}$ cases. In Case 3, the leak at $1 \mathrm{gpm}$ over 20 years had a more significant effect on mobilizing the contaminants than in Case 4 (200,000 gal over five days). This effect is due to the larger volume of water $(525,960 \mathrm{gal})$ released in Case 3. A significant result is the mobilization of U-238. The peak U-238 concentrations in Case 3 were not only the highest and earliest of the 11 cases but were also two orders of magnitude higher than Case 10, which examined the effect of lowering the value of the partitioning coefficient from 0.6 to $0.1 \mathrm{~mL} / \mathrm{g}$.

Overall, simulation results for the BX WMA showed that only a small fraction of the U-238 inventory migrated from the vadose zone in most of the test cases. The main exceptions were the water-line leak 
cases ( 3 and 4) and the low U-238 Kd case (10) mentioned above. For the various recharge rates (Cases 7 , 8, and 9), increasingly smaller fractions of the U-238 inventory migrated from the vadose zone as the recharge rate was decreased. The most signif icant reduction occurred in Case $9(10 \mathrm{~mm} / \mathrm{yr})$, which had a peak U-238 concentration two orders of magnitude less than that of Case 8 (30 mm/yr). Only a one orderof-magnitude decrease in the U-238 peak concentration was noted when recharge was reduced from 100 (Base Case) to $50 \mathrm{~mm} / \mathrm{yr}$ (Case 7), and from $50 \mathrm{~mm} / \mathrm{yr}$ to $30 \mathrm{~mm} / \mathrm{yr}$ (Case 8).

In general, results showed similar peak WMA concentrations for all of the simulations $(<800 \mathrm{pCi} / \mathrm{L}$ for Tc-99 and $<800 \mu \mathrm{g} / \mathrm{L}$ for $\mathrm{NO}_{3}$ ), with the exception of the water-line leak cases. Differences in peak concentrations for Tc-99 and $\mathrm{NO}_{3}$ with different recharge rates were small due to the proximity of a high concentration zone to the water table. These peaks occur early in the simulations in 2000 for all three simulations. However, to examine the effect of the reduced recharge rates in Cases 7-9, the reported peak concentrations in Tables S.1 through S.3 compare concentration differences in the second peak. Although reducing the recharge rate has little impact on the init ial breakthrough of the mobile contaminants, significant reductions in both peak concentrations and arrival times occur for the second peak values. The most significant effect of reducing recharge was delaying the arrival of the peak concentrations to the exclusion and Columbia River boundaries. For example, relative to the Base Case, the arrival of the peak concentrations of the two solutes is delayed an average of 66 years for Tc -99 and an average of 76 years for $\mathrm{NO}_{3}$ when the recharge rate is reduced to $10 \mathrm{~mm} / \mathrm{yr}$ (Case 9).

The Tc-99 and $\mathrm{NO}_{3}$ concentrations used in the initial soil concentration profiles were much smaller than the estimated leak inventories relative to the assumed plume size. To resolve these discrepancies, both Tc-99 and $\mathrm{NO}_{3}$ initial concentration distributions were scaled to yield the same inventory diameter as U-238. This resulted in the same scaling factor for the average BX fence line concentrations for all three contaminants from the cross-section values. Possible reasons for the relatively low Tc-99 profile include 1) the borehole used for the measurements was on the fringe of the Tc-99 plume (<<mean plume concentration), 2) Tc-99 has already migrated to the aquifer (possibly due to artificial recharge such as water-line leaks), and 3) the Tc-99 estimated leak inventory is too high. The concentration profiles for U-238 and $\mathrm{NO}_{3}$ were much closer to their estimated leak inventories for the assumed plume extent.

In the B trench cases, simulations predic ted that the U-238 would not migrate from the vadose zone to the aquifer in the thousand years that were simulated. The simulations also predicted that Tc-99 would appear quickly in the aquifer following the trench discharge in 1954, with peak concentrations occurring around 2020 to 2030. Because unit inventory results were scaled to the estimated Tc-99 discharged to all the B trenches, peak average trench fence line Tc-99 aquifer concentrations ranged from 170 to $550 \mathrm{pCi} / \mathrm{L}$ in the three recharge cases ( 55.4 and $100 \mathrm{~mm} / \mathrm{yr}$ ). The relative breakthrough curves of $\mathrm{NO}_{3}$ were the same as Tc-99 because they were both scaled to the same non-sorbing species based on the estimated inventories. 
Table S.1. Percentage of Predicted Peak U-238 Aqueous Concentrations and Arrival Times Relative to Base Case (Case 1); percent values calculated based on peak concentration values that appear in Table 4.2

\begin{tabular}{|c|c|c|c|c|}
\hline $\begin{array}{l}\text { U-238 } \\
\text { Conc. }\end{array}$ & $\begin{array}{c}\text { Cross Section } \\
(\%)\end{array}$ & $\begin{array}{c}\text { Average Fence Line } \\
(\%)\end{array}$ & $\begin{array}{c}\text { Exclusion Boundary } \\
(\%)\end{array}$ & $\begin{array}{l}\text { Columbia } \\
\text { River }\end{array}$ \\
\hline Case 1 & 100 & 100 & 100 & $-{ }^{(a)}$ \\
\hline Case 2 & 12 & 12 & 11 & - \\
\hline Case 3 & $2.7 \mathrm{E}+07$ & $2.7 \mathrm{E}+07$ & $5.4 \mathrm{E}+06$ & - \\
\hline Case 4 & 350 & 350 & 320 & - \\
\hline Case 5 & 50 & 49 & 50 & - \\
\hline Case 6 & 7 & 7 & 6 & - \\
\hline Case 7 & 13 & 13 & 12 & - \\
\hline Case 8 & 3 & 3 & 2 & - \\
\hline Case 9 & 0.04 & 0.04 & 0.02 & - \\
\hline Case 10 & $6.4 \mathrm{E}+05$ & $6.4 \mathrm{E}+05$ & $2.1 \mathrm{E}+04$ & (b) \\
\hline Case 11 & 5 & 5 & 7 & - \\
\hline \multicolumn{5}{|c|}{ Unit Inventory } \\
\hline Case 12 & - & - & - & - \\
\hline Case 13 & - & - & - & - \\
\hline Case 14 & - & - & - & - \\
\hline
\end{tabular}

Table S.2. Percentage of the Predicted Peak Tc-99 Aqueous Concentrations and Arrival Times Relative to Base Case (Case 1); percent values calculated based on the peak concentration values that appear in Table 4.3

\begin{tabular}{|c|c|c|c|c|}
\hline $\begin{array}{l}\text { Tc-99 } \\
\text { Conc. }\end{array}$ & $\begin{array}{c}\text { Cross Section } \\
(\%)\end{array}$ & $\begin{array}{c}\text { Average Fence Line } \\
(\%)\end{array}$ & $\begin{array}{c}\text { Exclusion Boundary } \\
(\%)\end{array}$ & $\begin{array}{c}\text { Columbia River } \\
(\%)\end{array}$ \\
\hline Case 1 & 100 & $100 \%$ & 100 & 100 \\
\hline Case 2 & 99 & 99 & 88 & 66 \\
\hline Case 3 & $2.1 \mathrm{E}+03$ & $2.1 \mathrm{E}+03$ & 569 & 206 \\
\hline Case 4 & 250 & 250 & 150 & 115 \\
\hline Case 5 & 87 & 87 & 84 & 86 \\
\hline Case 6 & 87 & 87 & 79 & 59 \\
\hline Case 7 & $54^{(\mathrm{a})}$ & $54^{(\mathrm{a})}$ & 53 & 51 \\
\hline Case 8 & $34^{(\mathrm{a})}$ & $34^{(\mathrm{a})}$ & 34 & 35 \\
\hline Case 9 & $13^{(\mathrm{a})}$ & $13^{(\mathrm{a})}$ & 13 & 15 \\
\hline Case 10 & 100 & 100 & 100 & 100 \\
\hline Case 11 & 100 & 100 & 100 & 100 \\
\hline \multicolumn{5}{|c|}{ Unit Inventory } \\
\hline Case 12 & 100 & 100 & 100 & 100 \\
\hline Case 13 & 340 & 330 & 330 & 290 \\
\hline Case 14 & 620 & 620 & 610 & 560 \\
\hline
\end{tabular}


Table S.3. Percentage of the Predicted Peak $\mathrm{NO}_{3}$ aqueous concentrations and arrival times relative to the Base Case (Case 1); percent values calculated based on the peak concentration values that appear in Table 4.4

\begin{tabular}{|l|r|r|r|r|}
\hline $\mathrm{NO}_{3}$ Conc. & Cross Section & $\begin{array}{c}\text { Average } \\
\text { Fence Line }\end{array}$ & $\begin{array}{r}\text { Exclusion } \\
\text { Boundary }\end{array}$ & Columbia River \\
\hline Case 1 & $100 \%$ & $100 \%$ & $100 \%$ & $100 \%$ \\
Case 2 & $100 \%$ & $100 \%$ & $100 \%$ & $93 \%$ \\
Case 3 & $1.4 \mathrm{E}+03 \%$ & $1.4 \mathrm{E}+03 \%$ & $351 \%$ & $195 \%$ \\
Case 4 & $290 \%$ & $280 \%$ & $150 \%$ & $120 \%$ \\
Case 5 & $94 \%$ & $94 \%$ & $91 \%$ & $95 \%$ \\
Case 6 & $94 \%$ & $94 \%$ & $91 \%$ & $89 \%$ \\
Case 7 & $54 \%{ }^{(\mathrm{a})}$ & $54 \%^{(\mathrm{a})}$ & $61 \%$ & $76 \%$ \\
Case 8 & $34 \%{ }^{(\mathrm{a})}$ & $34 \%$ & $40 \%$ & $59 \%$ \\
Case 9 & $13 \% \%^{(\mathrm{a})}$ & $13 \%{ }^{(\mathrm{a})}$ & $15 \%$ & $27 \%$ \\
Case 10 & $100 \%$ & $100 \%$ & $100 \%$ & $100 \%$ \\
Case 11 & $100 \%$ & $100 \%$ & $100 \%$ & $100 \%$ \\
\hline \multicolumn{5}{|c|}{ Unit Inventory } \\
\hline Case 12 & $100 \%$ & $100 \%$ & $100 \%$ & $100 \%$ \\
Case 13 & $340 \%$ & $340 \%$ & $330 \%$ & $290 \%$ \\
Case 14 & $620 \%$ & $620 \%$ & $610 \%$ & $560 \%$ \\
\hline
\end{tabular}

(a) Actual cross-section percent value is $\sim 95 \%$; actual average fence line percent values are $\sim 98 \%$. Both peaks occur in 2000 due to initial conditions near the water table. Values in table represent changes in peak concentrations due to variations in meteoric recharge. 


\section{Contents}

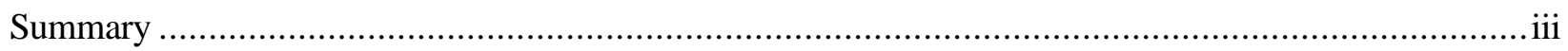

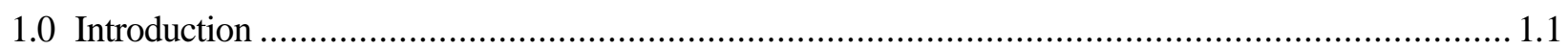

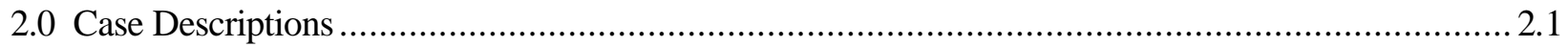

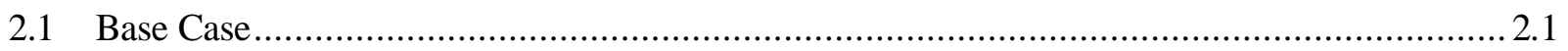

2.2 Interim Barrier Alternative and No Water-Line Leaks..................................................... 2.1

2.3 No Interim Barrier and Water-Line Leak (1 gpm for 20 years)..................................... 2.3

2.4 No Interim Barrier and Water-Line Leak (200,000 gal over five days) ............................. 2.3

2.5 Shifted Inventory Distribution and No Interim Barrier ................................................ 2.3

2.6 Shifted Inventory Distribution with Interim Barrier ........................................... 2.3

2.7 Base Case with 50 mm/yr Meteoric Recharge.................................................................. 2.3

2.8 Base Case with 30 mm/yr Meteoric Recharge.......................................................... 2.4

2.9 Base Case with $10 \mathrm{~mm} / \mathrm{yr}$ Meteoric Recharge......................................................... 2.4

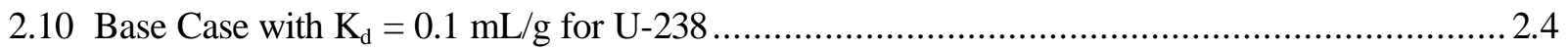

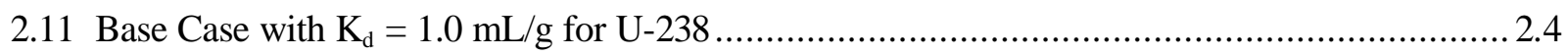

2.12 B-38 Trench with 55.4 mm/yr Meteoric Recharge .................................................... 2.4

2.13 B-38 Trench with 100.0 mm/yr Meteoric Recharge ................................................ 2.4

2.14 B-38 Trench with Delayed Closure Barrier with 100.0 mm/yr Meteoric Recharge ................. 2.5

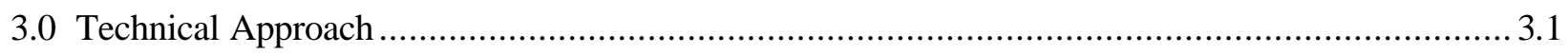

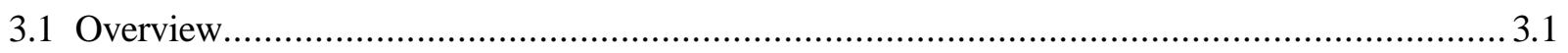

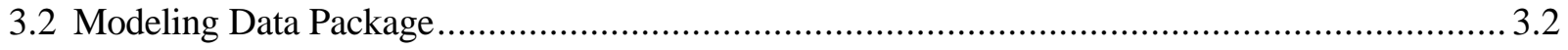

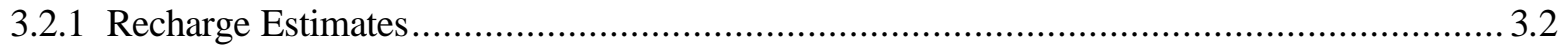

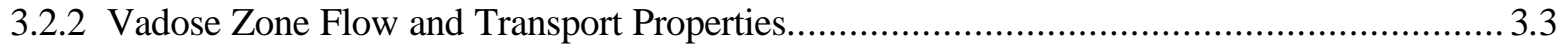

3.2.3 Stochastic Model for Macroscopic Anisotropy ............................................................ 3.4

3.2.4 Bulk Density and Distribution Coefficient ............................................................... 3.6

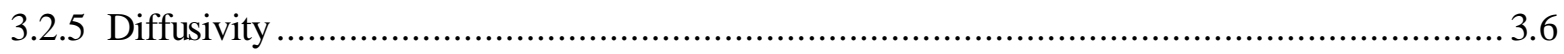

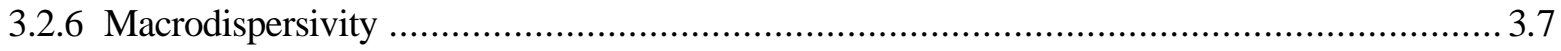

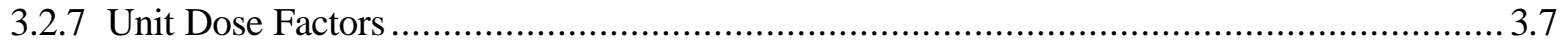

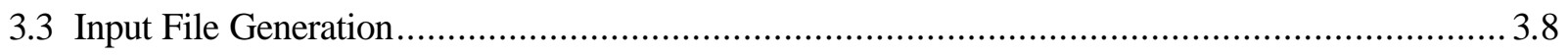

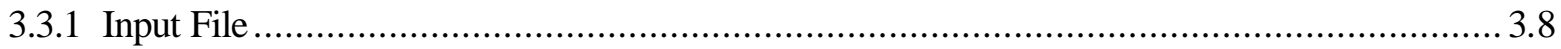

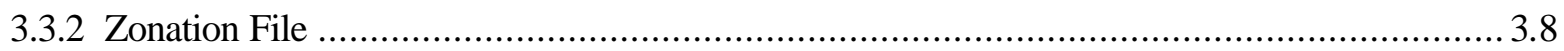

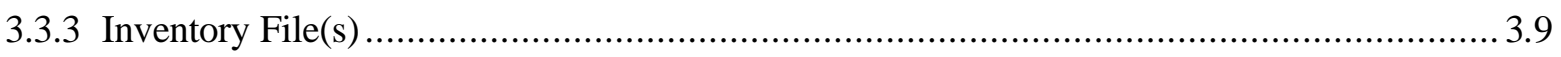

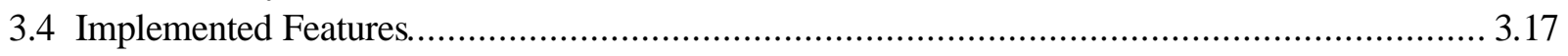

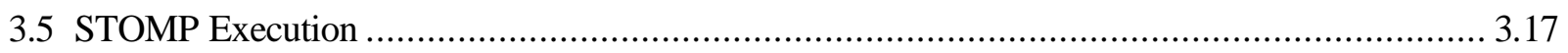

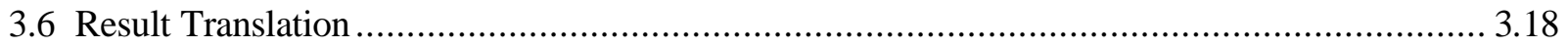

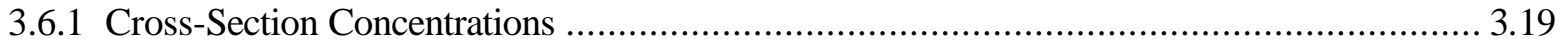

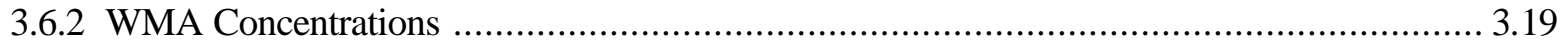

3.6.3 Cross-Section Scale Factors................................................................................. 3.20

3.6.4 Trench Fence Line Concentrations ..................................................................... 3.21

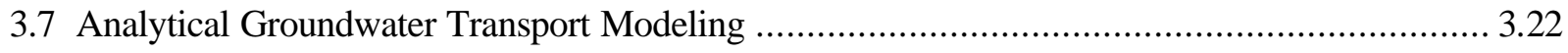




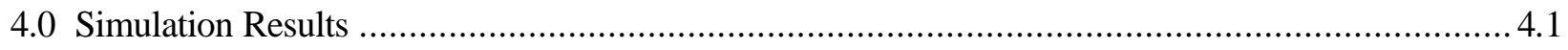

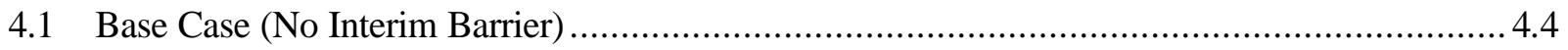

4.2 Interim Barrier Alternative and No Water-Line Leaks............................................... 4.6

4.3 No Interim Barrier and Water-Line Leak (1 gpm for 20 years)..................................... 4.7

4.4 No Interim Barrier and Water-Line Leak (200,000 gal over five days) .............................. 4.9

4.5 Shifted Inventory Distribution and No Interim Barrier .......................................... 4.10

4.6 Shifted Inventory Distribution with Interim Barrier ............................................ 4.10

4.7 Base Case with 50 mm/yr Meteoric Recharge............................................................ 4.11

4.8 Base Case with 30 mm/yr Meteoric Recharge........................................................... 4.13

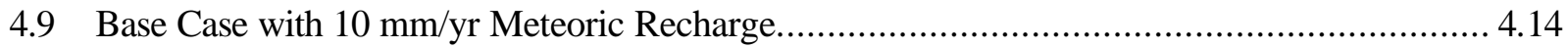

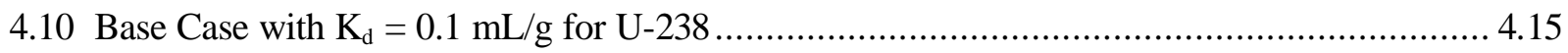

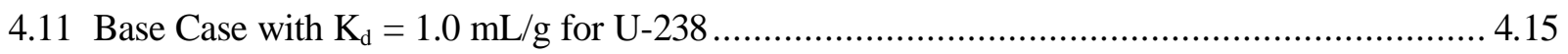

4.12 B-38 Trench with 55.4 mm/yr Meteoric Recharge .................................................... 4.16

4.13 B-38 Trench with 100.0 mm/yr Meteoric Recharge ............................................... 4.17

4.14 B-38 Trench with Delayed Closure Barrier and 100 mm/yr Meteoric Recharge ................... 4.18

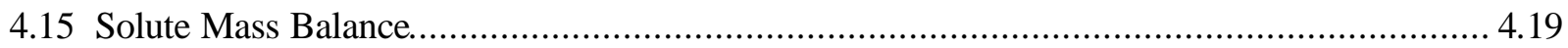

5.0 Numerical Groundwater Transport Modeling Results ................................................... 5.1

5.1 Numerical Model Description ............................................................................... 5.1

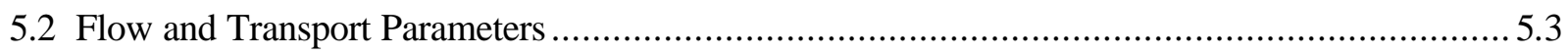

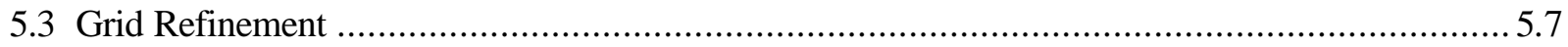

5.4 Modeling Results_-Transport from BX Tank Farm and B-38 Trench.................................. 5.7

5.5 Result Comparisons_-Analytical Versus Numerical Models ............................................ 5.9

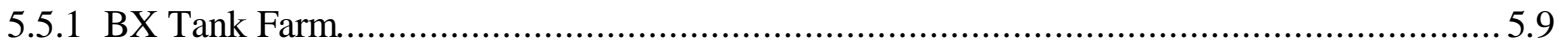

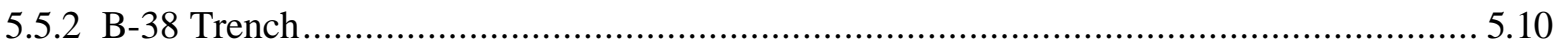

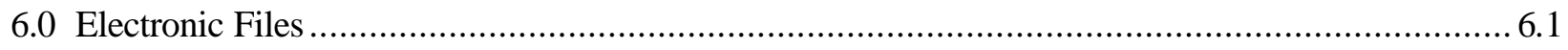

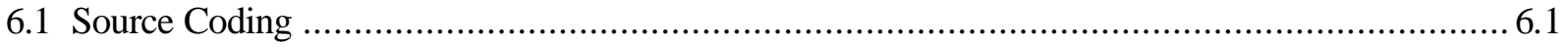

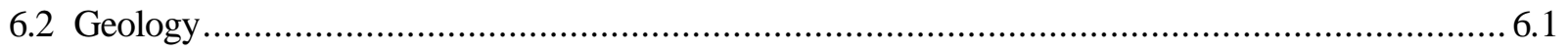

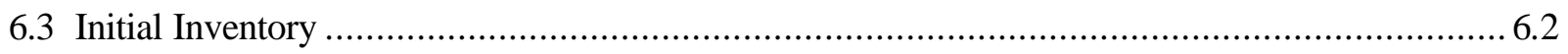

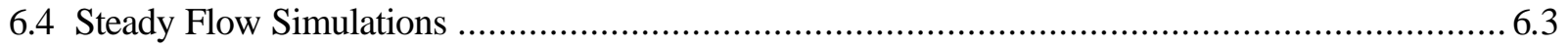

6.5 Coupled Vadose Zone and Unconfined Aquifer Modeling ............................................. 6.3

6.6 Analytical Groundwater Transport Modeling .............................................................. 6.4

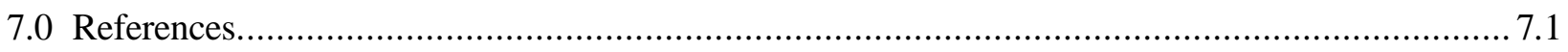

Appendix A: BX Saturation and Concentration Distributions ............................................. A.1

Appendix B: B Trench Saturation and Concentration Distributions .......................................... B.1

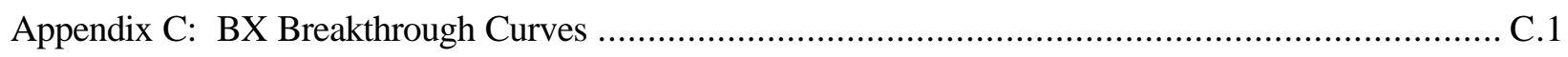

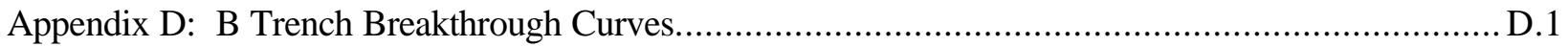

Appendix E: Electronic Data ................................................................. inside back cover 


\section{Figures}

3.1 Rock/Soil Zonation Used for Cross Sections BX-108-BX-102 and Trench B-38.................... 3.9

3.2 Rock/Soil Zonation for Cross Sections BX-108-BX-102 and Trench B-38 ......................... 3.10

3.3 U-238 Concentration Profile for Initial Conditions in STOMP and the Corresponding Reported Inventory

3.4 Tc-99 Concentration Profile for Initial Conditions in STOMP and the Corresponding Reported Inventory

3.5 $\quad \mathrm{NO}_{3}$ Concentration Profile for Initial Conditions in STOMP and the Corresponding Reported Inventory ......

3.6a U-238 Concentrations in Aqueous Phase Only ......................................................... 3.16

3.6b U-238 Concentrations in Total Aqueous and Sorbed Phase Concentrations

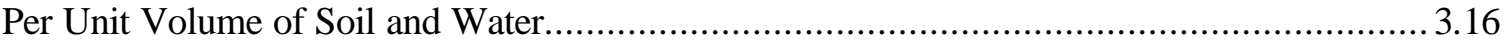

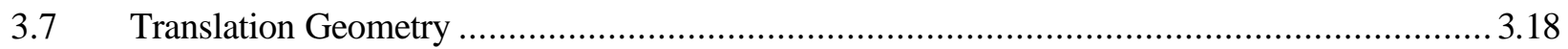

5.1 Simulated Versus Observed Heads for all Observations Through Time in

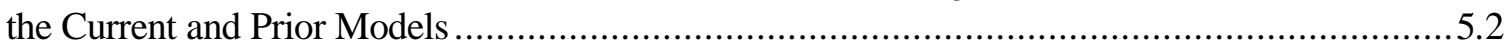

5.2 Map of SGM Hydrogeologic Units Containing the Water Table in March 1999 .....................5.5

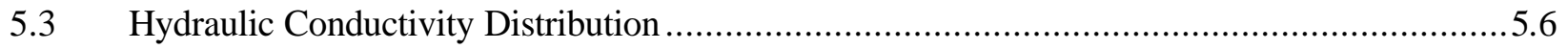

5.4 Coarse Composite Analysis Grid with Plume in Year 2340 ........................................... 5.8

5.5 Composite SGM Results for Case 1 Illustrating Plan-View Concentration Contours at Peak Arrival Times for the Exclusion Boundary and Columbia River............................. 5.11

5.6 Composite SGM Results for Case 12, Illustrating Plan-View Concentration Contours at Peak Arrival Times for the Exclusion Boundary and Columbia River.

\section{Tables}

S.1 Percentage of Predicted Peak U-238 Aqueous Concentrations and Arrival Times

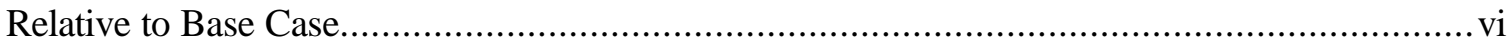

S.2 Percentage of the Predicted Peak Tc-99 Aqueous Concentrations and Arrival Times

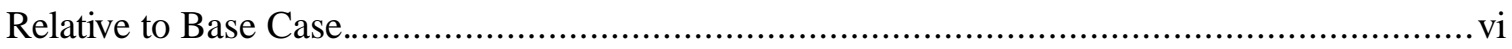

S.3 Percentage of the Predicted Peak $\mathrm{NO}_{3}$ Aqueous Concentrations and Arrival Times

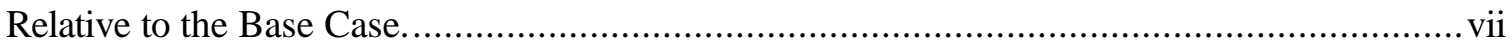

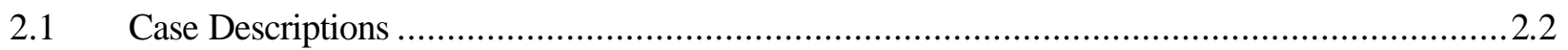

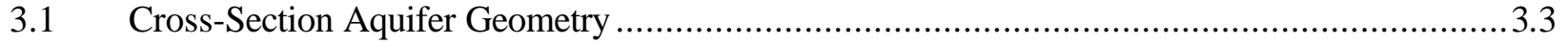

$3.2 \quad$ Streamtube Aquifer Geometry ............................................................................ 3.3

3.3 Composite van Genuchten-Mualem Parameters for Various Strata at BX Tank Farms ..............3.4

3.4 Macroscopic Anisotropy Parameters Based on Polmann Equations for Strata at the B-BX-BY WMA 
3.5 Effective Parameter Estimates for the Product of Bulk Density and

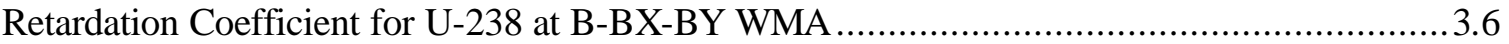

3.6 Nonreactive Macrodispersivity Estimates for Strata at B-BX-BY WMA ............................... 3.7

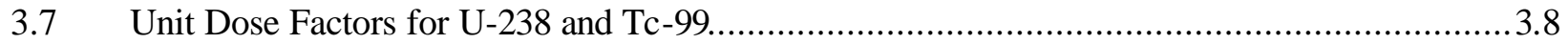

Initial Inventory Distribution Schedule ..................................................................... 3.14

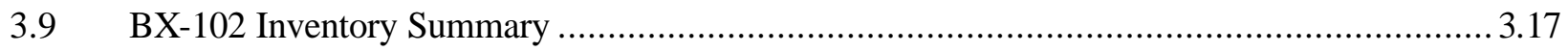

3.10 B-38 Trench Case Inventory Summary................................................................... 3.17

3.11 Calculated Plan View Areas of 2-D Plume Geometries for BX-108 to BX-102

Concentration Profiles and Inventory and Scale Factors ............................................ 3.21

3.12 Concentration Scale Factors for BX WMA from BX-108 to BX-102 Cross-Section

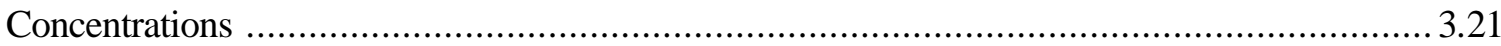

3.13 Concentration Scale Factors for B Trench WMA from Unit Inventory Cross-Section

Concentrations

3.14 Distance to Compliance Point, Groundwater Velocity, and Travel Time

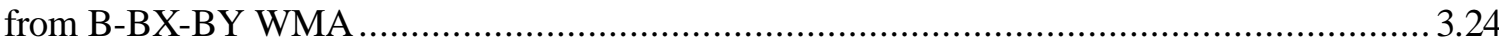

3.15 Analytical Groundwater Transport Modeling Properties............................................. 3.24

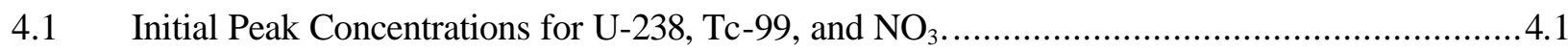

4.2 Predicted Peak U-238 Aqueous Concentrations and Arrival Time Summary........................4.2

4.3 Predicted Peak Tc-99 Aqueous Concentrations and Arrival Time Summary ........................4.3

4.4 Predicted Peak $\mathrm{NO}_{3}$ Aqueous Concentrations and Arrival Time Summary...........................4.4

4.5 STOMP Mass Balance for U-238............................................................................. 4.20

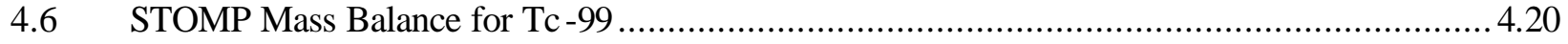

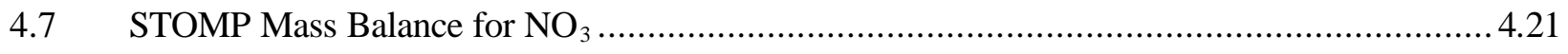

5.1 Maximum Tc-99 Concentration at Compliance Points for Base Case ................................ 5.10

5.2 Maximum Tc-99 Concentration at Compliance Points for B-38 Trench

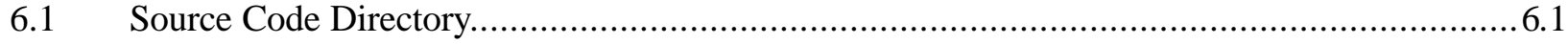

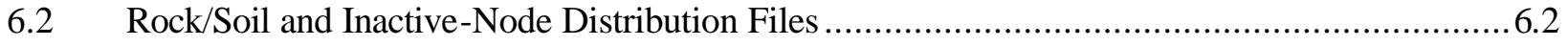

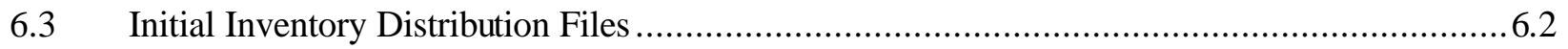

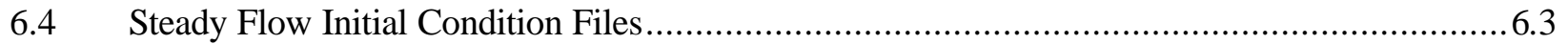

6.5 Coupled Vadose Zone and Unconfined Aquifer Modeling Files........................................6.4

6.6 Analytical Groundwater Transport Modeling Files.................................................... 6.5 


\subsection{Introduction}

The U.S. Department of Energy (DOE) is charged with cleaning up sites where the subsurface environment has been contaminated with dangerous constituents. Included among these sites are four of the seven Hanford Site single-shell tank (SST) Waste Management Areas (WMA), referred to as S-SX, B-BX-BY, $\mathrm{T}$, and TX-TY. In keeping with its charge, DOE has initiated a corrective action program that will address the impacts of previous and potential future leaks and releases of wastes from tanks at these four WMAs on the vadose zone environment. The Tank Farm Vadose Zone Project, a component of DOE's overall corrective action program, has begun a series of field investigations at the B-BX-BY WMA that are made necessary by the Tri-Party Agreement (TPA) (TPA M-45-98-03) (Ecology et al. 1989). Under TPA Milestone M-45-55-T01, DOE is required to submit to the Washington State Department of Ecology a Field Investigative Report (FIR) for WMA B-BX-BY. This report considers interim corrective measures (ICMs) such as surface covers or barriers (Haass 1999). This work investigates through numerical simulation the performance of proposed ICMs with respect to their impact on reducing long-term risks from potential groundwater contamination at the B-BX-BY WMA.

The modeling approach used in this study at the B-BX-BY WMA is similar to the S-SX FIR modeling report (White et al. 2001). The specific objectives of the numerical assessment are to quantify the risks posed by past tank releases if no ICMs are implemented and to determine the degree to which implementation of selected ICMs will decrease those risks. The assessments of this investigation focus specifically on impacts to groundwater resources (i.e., the concentration of contaminants in the groundwater) and long-term risk to human health associated with groundwater use. The evaluations consider the extent of contamination within the vadose zone, movement of contaminants through the vadose zone to the groundwater, and movement of contaminants through the groundwater to points of compliance. By providing quantitative comparisons among ICM concepts, the results from this evaluation may impact current operations or future decisions on retrieval of tank waste and closure of the B-BX-BY WMA.

This report documents initial investigations performed via numerical simulation of contaminant migration beneath the BX WMA and the calculation of associated risks at points of compliance. The report is divided into sections that generally follow the overall simulation procedures. First, the objectives are summarized, followed by a list of the numerical simulations that were executed. Next we describe the process of converting the data provided in the Modeling Data Package (MDP) into input files for the STOMP simulator. Much of this discussion relies on the reader having access to the STOMP guide documents and focuses on the correlation between the MDP and STOMP input cards. This discussion also includes descriptions of converting geologic cross sections into two-dimensional soil distribution maps and initial inventory data into distributions of dissolved contaminant concentrations. Three new capabilities that were initially implemented into the STOMP simulator for the S-SX FIR modeling (White et al. 2001) were also used in this investigation: 1) saturation-dependent permeability anisotropy (i.e., Polmann model), 2) solutesoil-dependent enhanced macrodispersivity, and 3) Courant number limiter (i.e., multiple transport time stepping). Implementation of these capabilities into the STOMP simulator is described, as is a short summary of the code compilation and execution on workstations operating under Linux.

The scope and data required to perform the numerical simulations are documented in the MDP (Khaleel et al. 2001) provided by CH2M HILL Hanford Group, Inc. The numerical simulations were executed with the STOMP simulator ((White and Oostrom 2000a,b) and consider the distribution of 
contaminants presently in the vadose zone, the migration of those contaminants to the groundwater under the influence of surface barriers, the further migration of contaminants through the groundwater to the point(s) of compliance, and the types of human activities at the points of compliance. As specified by the data package, three contaminant species (U-238, Tc-99, and $\mathrm{NO}_{3}$ ), representing the range of mobile and immobile constituents, were considered in these analyses. All simulations were executed on two-dimensional grids that represented cross sections traversing three SSTs within the BX WMA and B trenches. Initial contaminant inventories were developed for the BX-HH' cross section in accordance with the MDP. Grid resolutions for all simulations were $0.5334 \mathrm{~m}(1.75 \mathrm{ft})$ horizontally and $0.4572 \mathrm{~m}(1.5 \mathrm{ft})$ vertically. The vadose zone was modeled as an aqueous-gas porous media system where transport through the gas phase was neglected. All simulations used the infinite dilution assumption for coupling fluid flow and contaminant transport.

The principal objective for these investigations was executing the simulations specified in the MDP using widely accepted, scientifically based computational software and reporting the generated results. To promote an open exchange of scientific knowledge and ideas, the software used in this study will be made available, upon request, to the U.S. government and its contractors. To ensure the capability to repeat these simulations in the future, the source coding, input files, and output files have been stored in electronic form and will also be made available to the U.S. government and its contractors. Although Battelle - Pacific Northwest Division maintains a copyright on the STOMP simulator, the U.S. government retains a paid-up, nonexclusive, irrevocable worldwide license to reproduce, prepare derivative works, and perform and display publicly by or for the U.S. government, including the right to distribute to other U.S. government contractors. Numerical simulation of contaminant migration through the vadose zone and unconfined aquifer beneath the B-BX-BY WMA required the conversion information in the MDP into electronic input that could be interpreted by the STOMP simulator, execution of the software, and translation of the simulation output into graphical form for reporting. This report documents these three steps and summarizes the simulation results for each of the 13 cases executed based on the methods of the S-SX Modeling Report (White et al. 2001).

Inventory estimates were considered a critical parameter of these analyses. Concentration measurements used to develop initial distributions were taken from recently collected data on U-238, Tc-99, and $\mathrm{NO}_{3}$ from a borehole near Tank BX-102 as documented in the MDP. Using results from vadose zoneaquifer simulations, concentration profiles in two dimensions were then scaled to the estimated leak inventory for the WMA and its compliance points. Two principal assumptions of the investigation are that no additional contaminant releases will occur in the future and that water-line leaks from the existing piping in the B-BX-BY WMA have been addressed and resolved. Two simulation cases, however, did consider water-line leaks in the vicinity of Tank BX-102.

For simulations that considered surface barriers at the BX tank farm, interim barriers were assumed to become effective in 2010 and closure barriers in 2040. For the B-38 trench simulations, no interim barriers were used and the closure barrier became effective in 2010 in two simulations and 2040 in a third. Surface barriers were expected to reduce significantly the infiltration of meteoric water and delay the arrival of contaminants at the water table. The curved surface of the tank dome, impermeable tank wall, and water shedding by these surfaces were modeled in these simulations. Because of this water shedding, soils between tank surfaces were predicted to have higher water contents than sediments outside the tank. The sedimentary soils were assumed to have moisture-dependent anisotropy, where the ratio of horizontal to vertical relative permeability was defined as a function of the soil saturation. 
Two-dimensional cross sections were used to simulate fluid flow and contaminant transport through the vadose zone and groundwater. Two representations of west-east cross sections through the B-BX-BY WMA were considered: 1) cross section BX-HH' through Tanks BX-108, -105, and -102 and 2) the trench area of the BX-HH' cross section west of Tank BX-111. In this report, these cross sections are referred to by tank sequence or trench.

Each transient simulation was preceded by a steady flow simulation to establish initial conditions. Steady-flow conditions were established using a constant surface recharge of meteoric water and fixing the aquifer flux across the cross section. No solute transport was considered during the steady flow simulations. Transient simulations involved both fluid flow and solute transport. The transient simulation started with the steady flow conditions flow field and responded to changes in meteoric recharge caused by barrier emplacements. Two simulations additionally considered water-line leaks. The incoming aquifer water flux remained fixed throughout the transient simulation. The transient solute transport simulations conducted for each cross section generated a breakthrough curve (BTC) (a plot of dissolved solute concentration versus time) at the compliance boundaries (groundwater outflow region) of the B-BX-BY WMA. Solute concentrations at the compliance points were converted into dose estimates using conversion factors (Khaleel et al. 2001).

Fluid flow within the vadose zone was described using the Richard's equation, whereas contaminant transport was described using the conventional advective-dispersive transport equation with an equilibrium linear sorption coefficient formulation (i.e., $\mathrm{K}_{\mathrm{d}}$ formulation). Stratigraphic information for the cross sections was based on the studies of Lindsey and Reynolds (2001) and the MDP (Khaleel et al. 2001). These cross-sections include dipping strata, and when combined with the Polmann (1990) model for anisotropy in relative permeability for unsaturated soils, allows the simulator to model the enhanced spreading at the fine- to coarse-grained interfaces and the increased downslope movement of water along these interfaces.

Modeling parameters used to describe soil-moisture retention, phase relative permeability, saturated hydraulic conductivity (intrinsic permeability), and bulk density (porosity) for individual strata were based on data collected from 200 Area soils (Khaleel et al. 2001). For each stratum (soil type) defined on the cross-section stratigraphy, the small-scale laboratory measurements were scaled spatially upward to obtain equivalent horizontal and vertical unsaturated hydraulic conductivities as a function of mean tension (Khaleel et al. 2001). This scaling technique yields a mathematical expression describing macroscopic anisotropy in the unsaturated hydraulic conductivity as a function of mean tension for each stratum. Arithmetic averaging of van Genuchten parameters (van Genuchten 1980) was used to define the soil-moisture retention function for each stratum. Where multiple soil samples were unavailable for a given stratum, data were used from soil samples taken from the same stratum. Hydraulic properties were determined from laboratory measurements of soil moisture retention and unsaturated hydraulic conductivity when available. This approach avoided extrapolating unsaturated hydraulic conductivities (van Genuchten 1980; Mualem 1976) to dry conditions based on a saturated conductivity estimate (Khaleel et al. 1995). To reflect field conditions, laboratory data were corrected for the presence of any gravel fraction in the sediment samples (Khaleel and Relyea 1997).

In keeping with the approach taken for modeling fluid flow, solute transport properties for bulk density, diffusivity, and dispersivity were specified for each stratum. Contaminant mobility was defined through an equilibrium linear sorption coefficient. The geochemical environment beneath the B-BX-BY WMA was probably influenced by tank fluid chemistry at the time of the leak. Available data suggest that the most severe changes in the geochemical environment have occurred in the soils underlying and surrounding 
Tank BX-102 due to wastes discharged or leaked into the subsurface. Uncertainty remains about the linear sorption coefficient and the applicability of a linear-sorption model for U-238. As a result, a range of empirical sorption values was used in the modeling to assess the migration behavior of U-238. There is little doubt, however, that the linear sorption coefficient $\left(K_{d}\right)$ for Tc-99 is close to $0 \mathrm{~mL} / \mathrm{g}$ in Hanford sediments. This low $\mathrm{K}_{\mathrm{d}}$, coupled with its long half-life $\left(2.03 \times 10^{5} \mathrm{yr}\right)$, allows Tc-99 to migrate long distances in both the vadose zone and groundwater, posing a threat to groundwater quality for a long time.

Initial conditions for soil-moisture (expressed in terms of capillary pressure) and solute concentration were needed to initiate transient flow and transport simulations. Initial soil moisture was established through steady flow simulations. Steady flow simulations are pseudo-transient simulations that proceed from some soil moisture distribution with constant boundary conditions until steady flow conditions are reached. In establishing the steady flow soil moisture profiles, constant recharge was used as the boundary condition along the ground surface, and a constant water flux was imposed for the aquifer. For the twodimensional domain, vertical surfaces were considered zero-flux boundaries. Initial conditions for solute concentrations were based on contaminant profiles, assumed lateral extent, and inventory estimates for U-238, Tc-99 and $\mathrm{NO}_{3}$ using a uniform lateral distribution model (Khaleel et al. 2001).

Because the results between two- and three-dimensional cross sections showed good agreement for the S-SX FIR (White et al. 2001), two-dimensional west-to-east cross sections through the B-BX-BY WMA were used for modeling fluid flow and solute transport. The simulation domain extended horizontally past the WMA boundaries and vertically from the ground surface to $5 \mathrm{~m}(34.5 \mathrm{ft})$ below the water table at a depth of about $77 \mathrm{~m}(252 \mathrm{ft})$ below ground surface. 


\subsection{Case Descriptions}

The flow and solute transport simulations executed were specified in the MDP (Khaleel et al. 2000). This suite of simulations investigates the need for ICMs (e.g., surface barriers) and the sensitivity of water-line leaks, recharge, sorption, and initial inventory placement on solute transport. Two-dimensional cross sections, representing east-west transects through the BX tank farms and B trenches, were used for the computational domains. For the BX tank farm, the following simulations were conducted for cross sections BX-108, -105, and -102:

- Inventory distribution east of Tank BX-102 (Cases 1-4 and 7-11)

- Inventory distribution centered between Tanks BX-105 and BX-102 (Cases 5 and 6)

- Interim barriers (Cases 2 and 6)

- Water-line leaks (Cases 3 and 4)

- Variations in recharge rates (Cases 7, 8, and 9)

- Variations in U-238 $\mathrm{K}_{\mathrm{d}}$ (Cases 10 and 11).

For $\mathrm{B}$ trench, the following simulations were conducted for the $\mathrm{B}-38$ cross section west of the $\mathrm{BX}$ tank farm:

- Variations in recharge rates (Cases 12 and 13)

- Closure barrier schedule analogous to the one used for the BX tank farm cases (Case 14).

Simulations were executed for a period of compliance of 1000 years. The cases are summarized in Table 2.1 and described in the sections that follow.

\subsection{Base Case}

This scenario involves simulating flow and transport for the cross section through Tanks BX-108, -105 , and -102 , considering an initial recharge rate of $100 \mathrm{~mm} / \mathrm{yr}$, no waterline leak, no interim barrier, a closure barrier at year 2040, a linear partitioning coefficient of $0.6 \mathrm{~mL} / \mathrm{g}$ for U-238, and an inventory distribution that extends east from Tank BX-102 to the east fence line boundary.

\subsection{Interim Barrier Alternative and No Water-Line Leaks}

This scenario involves simulating flow and transport for the cross section through Tanks BX-108, -105 , and -102 , considering initial recharge rate of $100 \mathrm{~mm} / \mathrm{yr}$, placement of an interim barrier by 2010, a closure barrier at year 2040 (i.e., the interim barrier replaced by the closure barrier), no water-line leak, a linear partitioning coefficient of $0.6 \mathrm{~mL} / \mathrm{g}$ for U-238, and an inventory distribution that extends east from Tank BX-102 to the east fence line boundary. 
Table 2.1. Case Descriptions

\begin{tabular}{|c|c|c|c|c|c|c|c|}
\hline Case & Description & $\begin{array}{l}\text { Interim } \\
\text { Barrier }\end{array}$ & $\begin{array}{l}\mathrm{K}_{\mathrm{d}} \mathrm{U}-238 \\
(\mathrm{~mL} / \mathrm{g})\end{array}$ & \multicolumn{4}{|c|}{ Recharge Rate History (mm/yr) } \\
\hline \multicolumn{2}{|c|}{ Tank Cases (BX-108-BX-102 Cross Section) } & & & \multicolumn{4}{|c|}{ Time $^{(\mathrm{a})}(\mathrm{yr})$} \\
\hline & & & & $2000-2010$ & $2010-2040$ & $2040-2540$ & $2540-3000$ \\
\hline 1 & Base case (no action alternative) & no & 0.6 & 100 & 100 & 0.1 & 3.5 \\
\hline 2 & Interim barrier alternative & yes & 0.6 & 100 & 0.5 & 0.1 & 3.5 \\
\hline 3 & Water line leak (1 gpm for $20 \mathrm{yr})$ & no & 0.6 & $100+$ leak & $100+$ leak $^{(b)}$ & 0.1 & 3.5 \\
\hline 4 & Water line leak (200,000 gal over 5 days) & no & 0.6 & $100+$ leak $^{(\mathrm{c})}$ & 100 & 0.1 & 3.5 \\
\hline 5 & Shifted inventory & no & 0.6 & 100 & 100 & 0.1 & 3.5 \\
\hline 6 & Shifted inventory with interim barrier & yes & 0.6 & 100 & 0.5 & 0.1 & 3.5 \\
\hline 7 & Base case with $50 \mathrm{~mm} / \mathrm{yr}$ recharge & no & 0.6 & 50 & 50 & 0.1 & 3.5 \\
\hline 8 & Base case with $30 \mathrm{~mm} / \mathrm{yr}$ recharge & no & 0.6 & 30 & 30 & 0.1 & 3.5 \\
\hline 9 & Base case with $10 \mathrm{~mm} / \mathrm{yr}$ recharge & no & 0.6 & 10 & 10 & 0.1 & 3.5 \\
\hline 10 & Base case with $\mathrm{U}-238 \mathrm{~K}_{\mathrm{d}}=0.1$ & no & 0.1 & 100 & 100 & 0.1 & 3.5 \\
\hline 11 & Base case with U-238 $\mathrm{K}_{\mathrm{d}}=1.0$ & no & 1.0 & 100 & 100 & 0.1 & 3.5 \\
\hline \multicolumn{2}{|c|}{ Trench Cases (B-38 Cross Section) } & & & \multicolumn{4}{|c|}{$\operatorname{Time}^{(\mathrm{d})}(\mathrm{yr})$} \\
\hline & & & & $1954-2010$ & $2010-2510$ & 2510 & 3000 \\
\hline 12 & B-38 trench with $55.4 \mathrm{~mm} / \mathrm{yr}$ recharge & no & 0.6 & 55.4 & 0.1 & & \\
\hline \multirow[t]{3}{*}{13} & B-38 trench with $100 \mathrm{~mm} / \mathrm{yr}$ recharge & no & 0.6 & 100 & 0.1 & & \\
\hline & & & & \multicolumn{4}{|c|}{ Time $^{(\mathrm{e})}(\mathrm{yr})$} \\
\hline & & & & $1954-2040$ & $2040-2540$ & \multicolumn{2}{|c|}{$2540-3000$} \\
\hline 14 & B-38 trench with delayed closure barrier & no & 0.6 & 100 & 0.1 & \multicolumn{2}{|c|}{3.5} \\
\hline \multicolumn{8}{|c|}{$\begin{array}{l}\text { (a) At } 2010 \text {, in Cases } 2 \text { and } 6 \text {, an interim barrier is placed over the tanks, thereby reducing recharge. At } 2040 \text { (in all cases) a closure barrier is placed over the } \\
\text { tanks, and at } 2540 \text { the closure barrier degrades, thereby increasing recharge. } \\
\text { (b) Leak continues through } 2020 . \\
\text { (c) Leak occurs over five days in year } 2000 \text {. } \\
\text { (d) At } 2010 \text { a closure barrier is placed over the trench, and at } 2510 \text { the closure barrier degrades, thereby increasing recharge. } \\
\text { (e) At } 2040 \text { a closure barrier is placed over the trench, and at } 2540 \text { the closure barrier degrades, thereby increasing recharge (same as tank Base-Case schedule) }\end{array}$} \\
\hline
\end{tabular}




\subsection{No Interim Barrier and Water-Line Leak (1 gpm for 20 years)}

This scenario involves simulating flow and transport for the cross section through Tanks BX-108, -105 , and -102 , considering an initial recharge rate of $100 \mathrm{~mm} / \mathrm{yr}$, water-line leak ( $1 \mathrm{gpm}$ for 20 years) for BX-102 only, no interim barrier until closure at year 2040, a linear partitioning coefficient of $0.6 \mathrm{~mL} / \mathrm{g}$ for U-238, and an inventory distribution that extends east from Tank BX-102 to the east fence line boundary. The water line leak occurs east of Tank BX-102 over a 4.57-m (15-ft) radius at the elevation of the top of the tank dome. Because the water line leak causes a rapid migration of the contaminants, the domain for this simulation only is extended $30.5 \mathrm{~m}(100 \mathrm{ft})$ so that the contaminants do not come into contact with the domain boundary.

\subsection{No Interim Barrier and Water-Line Leak (200,000 gal over five days)}

This scenario involves simulating flow and transport for the cross section through tanks BX-108, -105 , and -102 , considering initial recharge rate of $100 \mathrm{~mm} / \mathrm{yr}$, water-line leak (200,000 gallons in 5 days) for BX-102 only, no interim barrier until closure at year 2040, a linear partitioning coefficient of $0.6 \mathrm{~mL} / \mathrm{g}$ for U-238, and an inventory distribution that extends east of Tank BX-102 to the east fence line boundary. The water line leak occurs east of Tank BX-102 over a 4.57-m (15-ft) radius at the elevation of the top of the tank dome.

\subsection{Shifted Inventory Distribution and No Interim Barrier}

This scenario involves simulating flow and transport for the cross section through tanks BX-108, -105 , and -102 , considering an initial recharge rate of $100 \mathrm{~mm} / \mathrm{yr}$, no water-line leak, no interim barrier until closure at year 2040, a linear partitioning coefficient of $0.6 \mathrm{~mL} / \mathrm{g}$ for U-238, and an inventory distribution that is centered between Tanks BX-105 and -102.

\subsection{Shifted Inventory Distribution with Interim Barrier}

This scenario involves simulating flow and transport for the cross section through tanks BX-108, 105, and -102, considering an initial recharge rate of $100 \mathrm{~mm} / \mathrm{yr}$, placement of an interim barrier at year 2010, a closure barrier at year 2040 (i.e., the interim barrier replaced by the closure barrier), no water-line leak, a linear partitioning coefficient of $0.6 \mathrm{~mL} / \mathrm{g}$ for U-238, and an inventory distribution that is centered between Tanks BX-105 and -102.

\subsection{Base Case with $50 \mathrm{~mm} / \mathrm{yr}$ Meteoric Recharge}

This scenario involves simulating flow and transport for the cross section through Tanks BX-108, -105 , and -102 , considering an initial recharge rate of $50 \mathrm{~mm} / \mathrm{yr}$, no water-line leak, no interim barrier until closure at year 2040, a linear partitioning coefficient of $0.6 \mathrm{~mL} / \mathrm{g}$ for U-238, and an inventory distribution that extends east from Tank BX-102 to the east fence line boundary. 


\subsection{Base Case with 30 mm/yr Meteoric Recharge}

This scenario involves simulating flow and transport for the cross section through Tanks BX-108, -105 , and -102 , considering initial recharge rate of $30 \mathrm{~mm} / \mathrm{yr}$, no water-line leak, no interim barrier until closure at year 2040, a linear partitioning coefficient of $0.6 \mathrm{~mL} / \mathrm{g}$ for U-238, and an inventory distribution that extends east from Tank BX-102 to the east fence line boundary.

\subsection{Base Case with $10 \mathrm{~mm} / \mathrm{yr}$ Meteoric Recharge}

This scenario involves simulating flow and transport for the cross section through Tanks BX-108, -105 , and -102 , considering an initial recharge rate of $10 \mathrm{~mm} / \mathrm{yr}$, no water-line leak, no interim barrier until closure at year 2040, a linear partitioning coefficient of $0.6 \mathrm{~mL} / \mathrm{g}$ for U-238, and an inventory distribution that extends east from Tank BX-102 to the east fence line boundary.

\subsection{Base Case with $K_{d}=0.1 \mathrm{~mL} / \mathrm{g}$ for $\mathrm{U}-238$}

This scenario involves simulating flow and transport for the cross section through Tanks BX-108, --105 , and -102 , considering an initial recharge rate of $100 \mathrm{~mm} / \mathrm{yr}$, no interim barrier until closure at year 2040, a linear partitioning coefficient $\left(\mathrm{K}_{\mathrm{d}}\right)$ of $0.1 \mathrm{~mL} / \mathrm{g}$ for $\mathrm{U}-238$, and an inventory distribution that extends east from Tank BX-102 to the east fence line boundary.

\subsection{Base Case with $K_{d}=1.0 \mathrm{~mL} / \mathrm{g}$ for $\mathrm{U}-238$}

This scenario involves simulating flow and transport for the cross section through Tanks BX-108, -105 , and -102 , considering an initial recharge rate of $100 \mathrm{~mm} / \mathrm{yr}$, no interim barrier until closure at year 2040, a linear partitioning coefficient $\left(\mathrm{K}_{\mathrm{d}}\right)$ of $1.0 \mathrm{~mL} / \mathrm{g}$ for $\mathrm{U}-238$, and an inventory distribution that extends east from Tank BX-102 to the east fence line boundary.

\subsection{B-38 Trench with 55.4 mm/yr Meteoric Recharge}

This scenario involves simulating flow and transport for a cross section west of Tank BX-111, considering an initial recharge rate of $55.4 \mathrm{~mm} / \mathrm{yr}$, a 378,000-gal leak in 1954, no water-line leak, no interim barrier until closure at year 2010, and a unit inventory distribution for a sorbed species (U-238, $\mathrm{K}_{\mathrm{d}}$ $=0.6 \mathrm{~mL} / \mathrm{g}$ ) and a nonsorbing species $\left(\mathrm{Tc}-99\right.$ and $\left.\mathrm{NO}_{3}\right)$. The unit inventory results are also scaled to the $\mathrm{U}-238, \mathrm{Tc}-99$, and $\mathrm{NO}_{3}$ inventory estimates for trench B-38 and all of the B trenches.

\subsection{B-38 Trench with $100.0 \mathrm{~mm} / \mathrm{yr}$ Meteoric Recharge}

This scenario involves simulating flow and transport for a cross section west of Tank BX-111, considering initial recharge rate of $100 \mathrm{~mm} / \mathrm{yr}$, a 378,000-gal leak in 1954, no interim barrier until closure at year 2010, and a unit inventory distribution for a sorbed species (e.g., U-238, $\mathrm{K}_{\mathrm{d}}=0.6 \mathrm{~mL} / \mathrm{g}$ ) and a 
nonsorbing species (e.g., Tc-99 and $\mathrm{NO}_{3}$ ). The unit inventory results are also scaled to the U-238, Tc-99, and $\mathrm{NO}_{3}$ inventory estimates for trench $\mathrm{B}-38$ and all of the $\mathrm{B}$ trenches.

\subsection{B-38 Trench with Delayed Closure Barrier with 100.0 mm/yr Meteoric Recharge}

This scenario involves simulating flow and transport for a cross section west of Tank BX-111, considering an initial recharge rate of $100 \mathrm{~mm} / \mathrm{yr}$, a 378,000-gal leak in 1954, no interim barrier until closure at year 2040, and a unit inventory distribution for a sorbed species (e.g., U-238, $\mathrm{K}_{\mathrm{d}}=0.6 \mathrm{~mL} / \mathrm{g}$ ) and a nonsorbing species (e.g., Tc-99 and $\mathrm{NO}_{3}$ ). The unit inventory results are also scaled to the U-238, Tc-99, and $\mathrm{NO}_{3}$ inventory estimates for trench B-38 and all of the B trenches. 


\subsection{Technical Approach}

A multistep approach was used to execute the simulations described in the modeling data package. In brief, the approach involved converting information in the data package to a suite of input files, executing the STOMP simulator, translating the simulation results into graphical form, and determining solute concentrations and doses at the compliance points. This section provides an overview and then more extensive review of these steps. In the discussions that follow, MDP refers to the modeling data package (Khaleel et al. 2001).

\subsection{Overview}

Three types of input are files defined in a STOMP simulation: 1) a simulation control and material definition file, 2) a soil zonation file, and 3) an inventory file for each solute species. Modeling input data stored in these files were developed from the modeling data package in conjunction with the discretization of the physical domain. Physical domains were east-west two-dimensional cross sections in the BBX-BY WMA. The physical domain was discretized using a Cartesian grid with uniform horizontal and vertical spacings of $0.5334 \mathrm{~m}(1.75 \mathrm{ft})$ and $0.4572 \mathrm{~m}(1.5 \mathrm{ft})$, respectively.

Graphical representations of geologic interpretations and engineered structures in the BX WMA subsurface (Khaleel et al. 2001, Appendix B) were converted to zonation maps based on the Cartesian discretization of the physical domain. Tabular data describing the initial distribution of the three contaminants of concern (i.e., U-238, Tc-99, and $\mathrm{NO}_{3}$ ) were interpolated onto the computational domain. Hydrologic properties, as defined in the MDP, for each of five identified soil types were converted to input in the form of STOMP input cards. Transport property data for the three contaminants and five soiltype combinations were converted to input in the form of STOMP input cards. The conceptual model was then completed by converting boundary conditions and sources, as specified in the MDP, into input in the form of STOMP input cards, specifying execution controls and requesting output data.

Time-varying surface recharge and water-line leaks required a transient flow solution to be executed with the solute transport calculations. The transient flow and transport simulations were initiated using a steady flow solution to the boundary-value problem using the initial boundary values. This approach neglects time variations in surface recharge prior to the simulation start. The steady flow initial condition was generated with a simulation to steady flow conditions. This simulation did not involve solute transport and was executed as a transient simulation from a unit-gradient initial condition to a steady flow condition that honored the surface recharge and unconfined aquifer flux. The steady flow and transient simulations were executed on a Linux workstation. For compatibility between platforms, the input, zonation, and inventory files were maintained as ASCII formatted files.

Simulation results were written to three types of output files: 1) a reflected input and reference node file, 2) a series of plot files, and 3) a surface-flux file. The reflected input and reference node file contains a translation of the input file(s), as interpreted by the simulator (e.g., with unit conversions), and a time sequence of the simulation history and chosen variables (e.g., aqueous pressure, moisture content, solute concentrations, Darcy fluxes) at selected grid locations. Plot files contain variable data for all grid points at selected simulation times. These files are used to generate color-scaled plots and animations through 
Tecplot. $^{(1)}$ A utility program, PlotTec, is used to translate STOMP plot files into Tecplot-formatted input files. Surface-flux files contain rate and integral information about fluxes crossing user-defined internal or external boundaries. Solute fluxes and aqueous fluxes at the downgradient domain boundary, within the groundwater, are used to calculate average solute concentrations and source rates at the first compliance point at the east fence in the B trench and BX WMA. Surface-flux files are also used to generate rate and integral plots of solutes exiting the computational domain and entering the groundwater. A utility program, Surcalc, was used to translate STOMP surface-flux files into formatted input files suitable for plotting.

Aquifer breakthrough curves or solute concentrations as a function of time at the compliance points outside the B-BX-BY WMA boundary were computed by extrapolating solute concentrations exiting the STOMP computational domain. An analytical solution to the advection-dispersion equation for solute transport through a saturated porous media in three dimensions was used, following the approach described by Baetslé (1969) and documented in Domenico and Schwartz (1990). This approach assumes solute originates at a point source as a series of slugs released over time, where the method of superposition is used to integrate the slug releases. The solute mass from each slug migrates from the point source by advective-dispersive transport in a steady, uniform flow field. As the solute mass is transported advectively with the flow, it spreads longitudinally and transversely via hydrodynamic dispersion and molecular diffusion. The mass flux of solute, used as input, was computed from the stomp surface file output for mass flux exiting the $5 \mathrm{~m}$ aquifer at the east side of the domain. Aquifer recharge along the groundwater flow path was neglected in translating solute concentrations to the compliance points.

\subsection{Modeling Data Package}

Meteoric recharge and parameters for vadose zone flow and transport were provided in the MDP. Additional data on aquifer parameters and dimensions are summarized in Tables 3.1 and 3.2. Selected data are repeated in this section.

\subsubsection{Recharge Estimates}

Portions of the B-BX-BY tank farm surfaces are covered with gravel to prevent vegetative growth and provide radiation shielding for site workers. Bare gravel surfaces, however, enhance net infiltration of meteoric water compared to undisturbed, naturally vegetated surfaces. Between tanks, infiltration is further enhanced by the effect of percolating water being diverted by the impermeable sloping surface of the tank domes. Recharge estimates used in this investigation are shown in Table 2.1.

(a) Tecplot, Version 8.0, Amtec Engineering, Inc., Bellevue, WA. 
Table 3. 1. Cross-Section Aquifer Geometry

\begin{tabular}{|l|l|l|}
\hline \multicolumn{1}{|c|}{ Parameter } & \multicolumn{1}{|c|}{ Value } & \multicolumn{1}{c|}{ Reference } \\
\hline Aquifer Hydraulic Conductivity & $1,615 \mathrm{~m} /$ day & FY 2000 Hanford Site \\
Effective Porosity & 0.30 & Groundwater Monitoring Report \\
Hydraulic Gradient & 0.00014 & (Bergeron and Wurstner 2000, \\
Groundwater Velocity & $0.8 \mathrm{~m} /$ day & Table A.2) \\
Aquifer Thickness & $5 \mathrm{~m}$ & MDP (Khaleel et al. 2001) \\
\hline
\end{tabular}

Table 3. 2. Streamtube Aquifer Geometry

\begin{tabular}{|c|c|c|}
\hline Parameter & Value & Reference \\
\hline $\begin{array}{l}\text { BX WMA fence line width } \\
\text { B trench WMA fence line width }\end{array}$ & $\begin{array}{l}183 \mathrm{~m}(600 \mathrm{ft}) \\
198 \mathrm{~m}(650 \mathrm{ft})\end{array}$ & $\begin{array}{l}\text { MDP (Khaleel et al. 2001, } \\
\text { Figure 1) }\end{array}$ \\
\hline $\begin{array}{l}\text { Distance to exclusion boundary } \\
\text { Travel time to exclusion } \\
\text { boundary } \\
\text { Mean velocity to exclusion } \\
\text { boundary }\end{array}$ & $\begin{array}{c}4.6 \mathrm{~km} \\
40 \mathrm{yr} \\
115 \mathrm{~m} / \mathrm{yr}\end{array}$ & $\begin{array}{l}\text { VAM3D Simulation Travel } \\
\text { Markers (Law et al. 1996; Lu } \\
\text { 1996) }\end{array}$ \\
\hline $\begin{array}{l}\text { Distance to river boundary } \\
\text { Travel time to river boundary } \\
\text { Mean velocity to river boundary }\end{array}$ & $\begin{array}{c}16 \mathrm{~km} \\
260 \mathrm{yr} \\
61.5 \mathrm{~m} / \mathrm{yr}\end{array}$ & $\begin{array}{l}\text { VAM3D Simulation Travel } \\
\text { Markers (Law et al. 1996; Lu } \\
\text { 1996) }\end{array}$ \\
\hline
\end{tabular}

\subsubsection{Vadose Zone Flow and Transport Properties}

Upscaled values of parameters for fluid flow and solute transport for the vadose zone were used in these investigations. Details for computing upscaled parameters are provided in Khaleel et al. (2001). Fluid flow parameters for the vadose zone include soil moisture retention characteristics and saturated hydraulic conductivity. Solute transport parameters include bulk density, diffusivity, sorption coefficients, and macrodispersivity. Table 3.3 lists the composite, fitted van Genuchten-Mualem (van Genuchten 1980) parameters for various strata at the B-BX-BY tank farms. Note that the material type numbers are identical to those indicated in the MDP Appendix B. 
Table 3.3. Composite van Genuchten-Mualem Parameters for Various Strata at the BX Tank Farms (Khaleel et al. 2001, Appendix B)

\begin{tabular}{|l|c|c|c|c|c|c|c|}
\hline Strata/Material Type & $\begin{array}{c}\text { Number of } \\
\text { Samples }\end{array}$ & $\theta_{\mathrm{s}}$ & $\theta_{\mathrm{r}}$ & $\begin{array}{c}\alpha \\
1 / \mathrm{cm}\end{array}$ & $\mathrm{n}$ & $l$ & $\begin{array}{c}\mathrm{K}_{\mathrm{s}} \\
\mathrm{cm} / \mathrm{s}\end{array}$ \\
\hline Backfill (1) & 10 & 0.1380 & 0.0100 & 0.0210 & 1.3740 & 0.5 & $5.60 \mathrm{e}-04$ \\
Sand H2 (2) & 12 & 0.3819 & 0.0443 & 0.117 & 1.6162 & 0.5 & $9.88 \mathrm{e}-05$ \\
Gravelly Sand H1 (3) & 11 & 0.2126 & 0.0032 & 0.0141 & 1.3730 & 0.5 & $2.62 \mathrm{e}-04$ \\
Gravelly Sand H3 (4) & 8 & 0.2688 & 0.0151 & 0.0197 & 1.4194 & 0.5 & $5.15 \mathrm{e}-04$ \\
Hanford-Ringold/ & 4 & 0.4349 & 0.0665 & 0.0085 & 1.8512 & 0.5 & $2.40 \mathrm{e}-04$ \\
Plio-Pleistocene (5) & 8 & 0.2688 & 0.0151 & 0.0197 & 1.4194 & 0.5 & $1.87 \mathrm{e}-01$ \\
Aquifer & \multicolumn{7}{|r}{} \\
\hline
\end{tabular}

\subsubsection{Stochastic Model for Macroscopic Anisotropy}

Variable, tension-dependent anisotropy provides a framework for upscaling small-scale, laboratory measurements to the effective (i.e., upscaled) properties for the large-scale tank farm vadose zone. A stochastic model (Polmann 1990) was used to evaluate tension-dependent anisotropy for sediments at the B-BX-BY WMA; details are in Khaleel et al. (2001, Appendix C). The following is a brief description of the variable anisotropy model used in this investigation.

Yeh et al. (1985) analyzed steady unsaturated flow through heterogeneous porous media using a stochastic model; parameters such as hydraulic conductivity were treated as random variables rather than deterministic quantities. The Gardner (1958) relationship was used by Yeh et al. (1985) to describe unsaturated hydraulic conductivity as a function of saturated hydraulic conductivity and tension according to Equation (3.1)

$$
K(\psi)=K_{s} \exp (-\beta \psi)
$$

where $\mathrm{K}$ is the unsaturated hydraulic conductivity, $\mathrm{K}_{\mathrm{S}}$ is the saturated hydraulic conductivity, $\psi$ is the tension, and $\beta$ is a fitting parameter. Equation (3.1) can be written as shown in Equation (3.2). This form is referred to as the log-linear model:

$$
\ln K(\psi)=\ln K_{S}-\beta \psi
$$

because the log of the hydraulic conductivity is linearly related to the tension through a constant slope. A constant slope, however, is often inadequate for describing $\operatorname{InK}(\psi)$ over the range of tension of interest for field applications. As an alterative, $\beta$ can be approximated locally by straight lines over a range of tensions. The $\mathrm{InK}_{\mathrm{S}}$ term can then be derived by extrapolating the local slopes to zero tension.

Using a linear correlation model between the zero-tension intercept and $\beta$, Polmann (1990) presented a generalized model that accounts for the cross-correlation of the local soil property (i.e., InK $K_{S}$ and $\beta$ ) residual fluctuations. Compared with the uncorrelated $\mathrm{InK}_{\mathrm{S}}$ and $\beta$ model, partial correlation of the 
properties was shown to have a significant impact on the magnitude of the effective parameters derived from the stochastic theory. The Polmann (1990) equations for deriving the effective parameters are shown in Equations (3.3) through (3.6):

$$
\begin{aligned}
& \langle\operatorname{LnK}\rangle=\left\langle\operatorname{LnK} \mathrm{S}_{\mathrm{s}}\right\rangle-\mathrm{A}\langle\psi\rangle-\frac{\sigma_{\mathrm{LnKS}}^{2} \lambda\left[\mathrm{p}-\mathrm{p}^{2}\langle\psi\rangle-\zeta^{2}\langle\psi\rangle\right]}{(1+\mathrm{A} \lambda)} \\
& \sigma_{\mathrm{LnK}}^{2}=\frac{\sigma_{\mathrm{LnKS}}^{2}\left\lfloor(1-p\langle\psi\rangle)^{2}+\zeta^{2}\langle\psi\rangle^{2}\right\rfloor}{(1+\mathrm{A} \lambda)} \\
& K_{\mathrm{h}}^{\text {eq }}=\exp \left\lfloor\langle\operatorname{LnK}\rangle+\frac{\sigma_{\text {LnK }}^{2}}{2}\right\rfloor \\
& K_{\mathrm{V}}^{\text {eq }}=\exp \left\lfloor\langle\operatorname{LnK}\rangle-\frac{\sigma_{\mathrm{LnK}}^{2}}{2}\right\rfloor
\end{aligned}
$$

where

$\sigma_{\mathrm{LnK}}^{2}$ is the variance of log unsaturated conductivity

$\langle\psi\rangle$ is the mean tension

$\sigma_{\text {LnKs }}^{2}$ is the variance of $\operatorname{lnK} s$

$\left\langle L n K_{S}\right\rangle$ is the mean of $\ln K_{S}$

$p$ is the slope of the $\beta$ versus $I n K_{s}$ regression line

$\zeta=\frac{\sigma_{\delta}}{\sigma_{\text {LnKs }}}$

$\sigma_{\delta}$ is the standard deviation of the residuals in the $\beta$ versus $I n K_{S}$ regression

A is the mean slope, $\beta$, for $\ln K_{S}$ versus $\psi$

$\lambda$ is the vertical correlation lengths for $\operatorname{lnK}_{S}$

$\mathrm{K}_{\mathrm{h}}^{\mathrm{eq}}$ is the equivalent unsaturated horizontal hydraulic conductivity

$\mathrm{K}_{\mathrm{V}}^{\mathrm{eq}}$ is the equivalent unsaturated vertical hydraulic conductivity.

Macroscopic anisotropy parameter estimates for the strata at the B-BX-BY WMA are listed in Table 3.4. Details on these parameters and their derivation are included in Khaleel et al. (2001, Appendix C) and White et al. (2001). 
Table 3.4. Macroscopic Anisotropy Parameters Based on Polmann Equations for Strata at the B-BX-BY WMA (Khaleel et al. 2001, Appendix B)

\begin{tabular}{|l|c|c|c|c|c|c|c|}
\hline Strata/Material Type & $\begin{array}{c}\text { Number of } \\
\text { Samples }\end{array}$ & $\left\langle\operatorname{LnK}_{\mathrm{S}}\right\rangle$ & $\sigma_{\text {LnKs }}^{2}$ & $\mathrm{p}$ & $\zeta$ & $\begin{array}{c}\lambda \\
(\mathrm{cm})\end{array}$ & $\mathrm{A}$ \\
\hline Backfill (1) & 10 & -15.76 & 3.56 & $-1.1 \mathrm{e}-4$ & $1.84 \mathrm{e}-4$ & 30 & 0.00371 \\
Sand H2 (2) & 12 & -14.59 & 1.50 & $-7.2 \mathrm{e}-4$ & $6.55 \mathrm{e}-4$ & 50 & 0.00620 \\
Gravelly Sand H1 (3) & 11 & -14.85 & 1.94 & $-2.6 \mathrm{e}-4$ & $2.50 \mathrm{e}-4$ & 30 & 0.00368 \\
Gravelly Sand H3 (4) & 8 & -15.30 & 1.83 & $-5.6 \mathrm{e}-4$ & $5.16 \mathrm{e}-4$ & 50 & 0.00415 \\
Hanford-Ringold/ & 4 & -10.43 & 1.01 & $-2.4 \mathrm{e}-3$ & $9.34 \mathrm{e}-4$ & 50 & 0.0104 \\
Plio-Pleistocene (5) & & & & & & \\
\hline
\end{tabular}

\subsubsection{Bulk Density and Distribution Coefficient}

Both bulk density $\left(\rho_{b}\right)$ and the distribution coefficient $\left(K_{d}\right)$ estimates were needed to calculate retardation factors for different solute species. The effective, large-scale estimate for the product $\rho_{b} K_{d}$ was considered to be the average of the product of small-scale laboratory measurements for bulk density and distribution coefficient (Gelhar 1993). Effective large-scale estimates of bulk density, distribution coefficient, and their product for U-238 are listed in Table 3.5 for the five strata samples. The average $\rho_{b}, E\left[\rho_{b}\right]$ estimates were based on data in Khaleel et al. (2001). The $K_{d}$ estimates for U-238 were based on Kaplan and Serne (1999) data for undisturbed sediments. The distribution coefficients for the remaining solutes (i.e., Tc-99 and $\mathrm{NO}_{3}$ ) were estimated to be zero.

Table 3.5. Effective Parameter Estimates for the Product of Bulk Density and Retardation Coefficient for U-238 at B-BX-BY WMA

\begin{tabular}{|l|c|c|c|}
\hline \multicolumn{1}{|c|}{ Strata/Material } & $\mathrm{K}_{\mathrm{d}}$ & $\mathrm{E}\left[\rho_{\mathrm{b}}\right]$ & $\mathrm{E}\left[\rho_{\mathrm{b}} \mathrm{K}_{\mathrm{d}}\right]$ \\
\hline Backfill (1) & $0.6 \mathrm{~mL} / \mathrm{g}$ & 1.94 & 0.59 \\
Sand H2 (2) & $0.6 \mathrm{~mL} / \mathrm{g}$ & 1.76 & 1.04 \\
Gravelly Sand H1 (3) & $0.6 \mathrm{~mL} / \mathrm{g}$ & 2.07 & 1.24 \\
Gravelly Sand H3 (4) & $0.6 \mathrm{~mL} / \mathrm{g}$ & 1.94 & 1.17 \\
Hanford-Ringold/ & $0.6 \mathrm{~mL} / \mathrm{g}$ & 1.65 & 0.98 \\
Plio-Pleistocene (5) & $0.6 \mathrm{~mL} / \mathrm{g}$ & 1.94 & 1.17 \\
Aquifer & & \\
\hline
\end{tabular}

\subsubsection{Diffusivity}

It was assumed that the effective, large-scale diffusion coefficients for all strata at the B-BX-BY WMA were a function of volumetric moisture content and could be expressed using the Millington and Quirk (1961) empirical relation, as shown in Equation 3.7: 


$$
D_{e}(\theta)=D_{0} \frac{\theta^{10 / 3}}{\theta_{s}^{2}}
$$

where $D_{e}$ is the effective diffusion coefficient of an ionic species, $D_{0}$ is the molecular diffusion coefficient for the species in water, $\theta$ is the water content, and $\theta_{\mathrm{S}}$ is the saturated water content. The molecular diffusion coefficient for all species in pore water was assumed to be $2.5 \mathrm{e}-5 \mathrm{~cm}^{2} / \mathrm{s}$ (Kincaid et al. 1995).

\subsubsection{Macrodispersivity}

An extended review is provided in Appendix C of Khaleel et al. (2001) on the rationale for vadose zone macrodispersivity estimates. Macrodispersivity estimates were needed for both reactive (U-238) and nonreactive (Tc-99 and $\mathrm{NO}_{3}$ ) species. Macrodispersivity estimates for the nonreactive species are listed in Table 3.6.

The net effect of species sorption is to retard the migration through geologic media. Soil sorption is a function of the species and soil properties and varies spatially with soil properties (Gelhar 1993; Talbott and Gelhar 1994). Stochastic analysis results for macrodispersivity enhancement for the five strata are presented in Appendix C of Khaleel et al. (2000) for the reactive species (U-238). In this analysis, the unsaturated hydraulic conductivities were evaluated at a tension of $100 \mathrm{~cm}$ via the fitted van GenuchtenMualem relation. The macrodispersivity enhancement ranged from 1.06 for sandy sediments to about 2.24 for Plio-Pleistocene (silty) sediments.

Table 3.6. Nonreactive Macrodispersivity Estimates for Strata at B-BX-BY WMA

\begin{tabular}{|l|c|c|c|c|}
\hline \multicolumn{1}{|c|}{ Strata/Material } & $\sigma^{2}{ }_{\text {lnK }}$ & $\begin{array}{c}\text { Correlation } \\
\text { Length } \lambda, \mathrm{cm}\end{array}$ & $\mathrm{A}_{\mathrm{L}}, \mathrm{cm}$ & $\mathrm{A}_{\mathrm{T}}, \mathrm{cm}$ \\
\hline Backfill (1) & 4.54 & 30 & $\sim 150$ & 15 \\
Sand H2 (2) & 4.60 & 30 & $\sim 150$ & 15 \\
Gravelly Sand H1 (3) & 3.19 & 30 & $\sim 100$ & 10 \\
Gravelly Sand H3 (4) & 4.95 & 30 & $\sim 100$ & 10 \\
Hanford-Ringold/ & 0.92 & 30 & $\sim 50$ & 5 \\
Plio-Pleistocene (5) & 4.95 & 30 & $\sim 100$ & 10 \\
Aquifer & & & \\
\hline
\end{tabular}

\subsubsection{Unit Dose Factors}

Unit dose factors needed to convert U-238 and Tc-99 concentrations in the groundwater to a radiation dose, based on a drinking water consumption scenario of $730 \mathrm{~L} / \mathrm{yr}$, are listed in Table 3.7. 
Table 3.7. Unit Dose Factors for U- 238 and Tc-99 (Rittmann 1999)

\begin{tabular}{|c|c|}
\hline Radionuclide & Dose Factor \\
\hline U-238 & $0.196 \mathrm{mrem}$ per $\mathrm{pCi} / \mathrm{L}$ \\
Tc-99 & $0.00107 \mathrm{mrem}$ per $\mathrm{pCi} / \mathrm{L}$ \\
\hline
\end{tabular}

\subsection{Input File Generation}

Three types of input files were used to drive the STOMP simulator: 1) a simulation control file and material definition (input), 2) a soil zonation file (zonation), and 3) initial solute inventory files (inventory). All input files were written and stored in ASCII text format. The simulation control and material definition input files were assembled using a conventional text editor, whereas the zonation and inventory files were generated with utility programs.

\subsubsection{Input File}

As described in the STOMP User's Guide (White and Oostrom 2000a), the input file is divided into cards that group common data (e.g., solution control, hydraulic properties, output control, boundary conditions). The input files for the simulated cases will be provided in electronic form (see Section 6).

\subsubsection{Zonation File}

The zonation file is an ordered listing (i.e., I,J,K indexing) of integers that identify the rock/soil type for every grid cell in the computational domain. Inactive nodes are assigned an integer value of zero, and rock/soil types are assigned numbers in accordance with the ordered listing of rock/soil types in the Rock/ Soil Zonation Card. For example, for the Base Case simulation an integer value of one in the zonation file refers to sandy gravel, and a value of three refers to Plio-Pleistocene. Zonation files for the executed simulations were generated for the B-BX-BY cross section shown in Figure 3.1 (also shown in MDP, Appendix B). Color delineated images of the zonation files for the two cross sections, BX-108 to BX-102 and the B-38 trench, are shown in Figure 3.2.

These files were generated from digitized versions of the geologic cross sections for the B-BX-BY WMA (Figure 3.1) using the GeoSTOMP utility software. Written in Fortran 77, GeoSTOMP was designed to read STOMP grid cards and geologic well data or geologic interpretations and translate those data into a zonation file. GeoSTOMP assumes that the rock/soil type assigned to a computational grid cell is strictly dependent on the interpolated rock/soil type at the geometric centroid of the grid cell. The source code for GeoSTOMP and the accompanying input and output files will be included in Appendix E, provided on a CD with this report. A second utility, TankSTOMP, is used to define the tank domains within the zonation file. This utility converts tank geometric data into inactive nodes in the zonation file. As with GeoSTOMP, grid cells are considered to be within the tank domain if the geometric centroid of the grid cells falls within the tank volume. The source code for TankSTOMP and accompanying input and output files is included in Appendix E. 


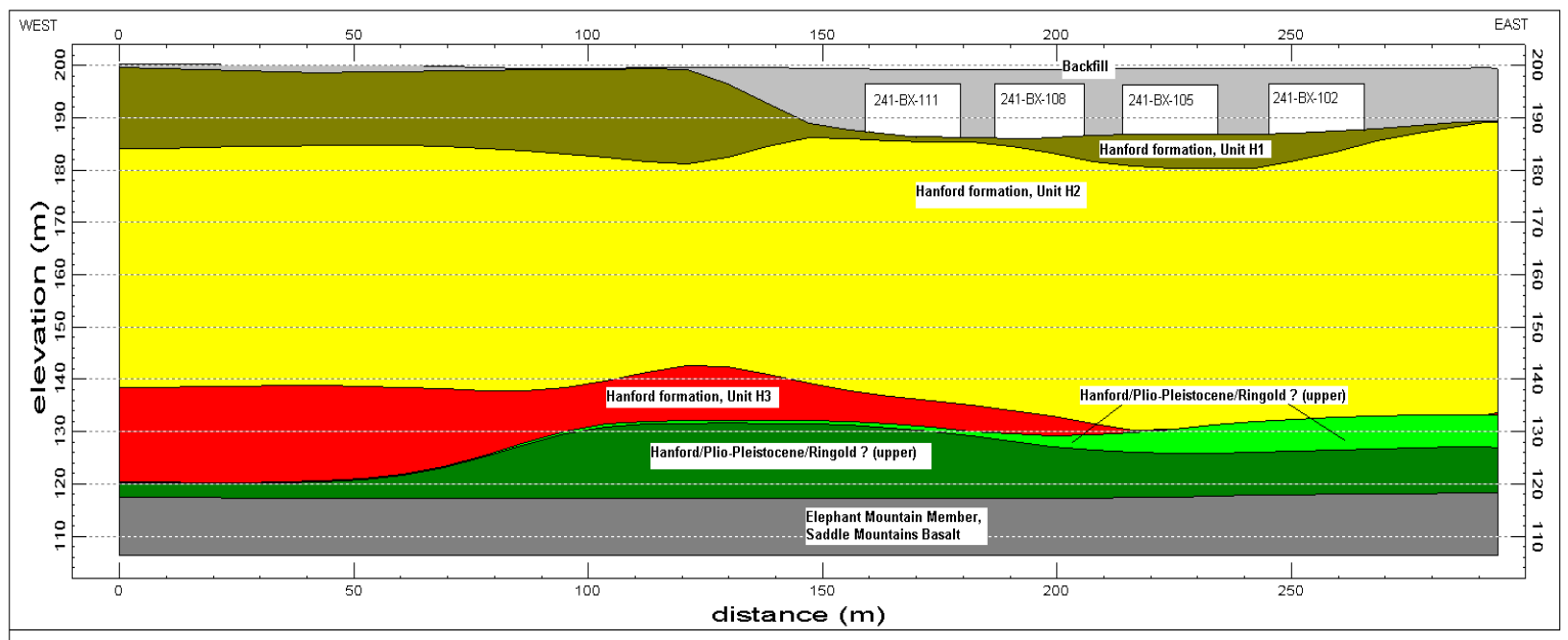

West-East Cross-Section, 241-BX Tank Farm

Figure 3.1. Rock/Soil Zonation Used for Cross Sections BX-108-BX-102 (distance $\sim 180$ to $300 \mathrm{~m}$ ) and Trench B-38 (distance $\sim 20$ to $70 \mathrm{~m}$ )

Cross section BX-HH', containing Tanks BX-108, -105 and -102 (Figure 3.2a), was modeled using a

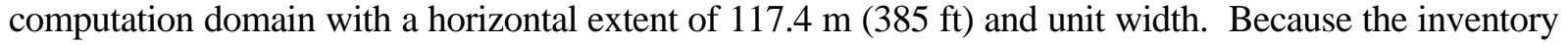
was emplaced at areas east of the BX-108 tank, the westernmost tank, BX-111, was not included in the domain. To avoid boundary effects when the domain terminated at the east fence line, the geology shown at the eastern edge of the BX cross section was extended by $4.57 \mathrm{~m}(15 \mathrm{ft})$. From cross section BX-HH', a second domain west of Tank BX-111 was developed to model flow and transport in trench B-38. The horizontal extent of this cross section was $109.9 \mathrm{~m}(306.5 \mathrm{ft})$ and the width was $3.05 \mathrm{~m}(10 \mathrm{ft})$, (see Figure 3.2b) and represents the area west of the tanks in Figure 3.1. The geology for both of these cross sections is a primarily layered system created by alluvial deposition, with a more permeable gravely sand strata that forms the foundation for the tank bottoms.

\subsubsection{Inventory File(s)}

Inventory files were used to initialize the solute concentrations across the computational domain. These files contained ordered listings (using I,J,K indexing) of initial solute concentrations for every grid cell in the computational domain. A unique inventory file was developed for each combination of solute species and initial inventory distribution. A utility program called InvSTOMP was used to convert tabulated values of contaminant concentrations, as reported in the MDP into inventory files. InvSTOMP reads an input file that contains a description of the computational domain (formatted as a STOMP grid card), the distribution of rock/soil types (formatted as a STOMP rock/soil zonation card) and the solute concentration distributions. 

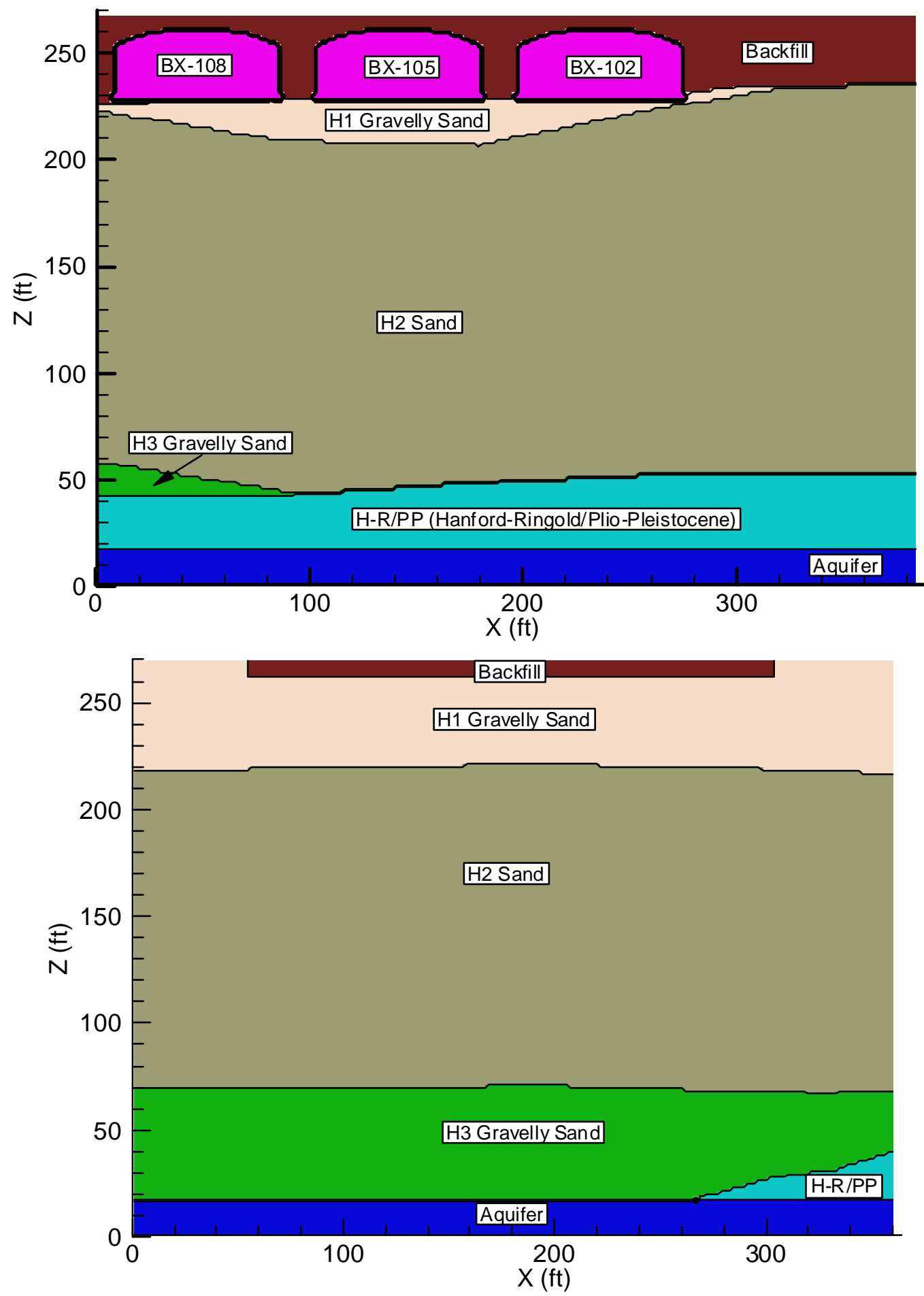

Figure 3.2. Rock/Soil Zonation for Cross Sections BX-108-BX-102 (top) and Trench B-38 (bottom) 


\subsubsection{Inventory Distribution}

For the B-38 trench simulations, only U-238 and Tc-99 were included in the STOMP simulations as $\mathrm{NO}_{3}$ was scaled from the nonsorbing Tc-99 results. In contrast to the BX tank farm simulations, the B-38 trench simulations assumed no inventory was initially present in the subsurface. Instead, these contaminants were simulated as discrete sources of unit inventory discharged to the trench at the beginning of the simulation in 1954. The results of these simulations were scaled to the B-38 trench inventory and that of all the trenches (see Table 3.3).

For the BX tank farm, the vadose zone inventory estimates of U-238, Tc-99 and $\mathrm{NO}_{3}$ were based on soil samples collected from a borehole located near Tank BX-102 as reported in the MDP. Only one inventory distribution was used for each species in the BX tank farm, but it was placed in two different locations in the subsurface. For the Base Case and its variants, the inventory profiles was located east of Tank BX-102 and extended to the east BX fence line. In the alternate inventory scenario, the inventory profile maintained the same horizontal extent, but the profile was centered between Tanks BX-105 and BX-102. For both inventory placements, the inventory distribution was assumed to be laterally uniform, and extended over the same distance of $27.9 \mathrm{~m}$ (91.5 ft), which was the distance between Tank BX-102 and the east BX fence line.

Because the borehole concentrations for Tc-99 and $\mathrm{NO}_{3}$ were low relative to the total estimated leak inventory, these concentrations were scaled according to the method outlined in Section 3.6 to maintain a plume extent similar to U-238. Initial inventory distributions used in the STOMP numerical simulations were scaled concentrations. However, for the discussion that follows, the inventory distribution honors the concentration per gram of soil by depth reported in the MDP (Appendix D). Thus, the data presented in this section represent the unscaled initial inventory distributions for both Tc-99 and $\mathrm{NO}_{3}$.

To determine the inventory profiles, concentrations measured at discrete depths were assigned to nodes in the computation domain corresponding to the midpoint of the sample interval. Because the sampling intervals for Tc-99 and $\mathrm{NO}_{3}$ were larger than the distance between nodes in the computational domain, nodes that did not correspond to a sample depth were assigned interpolated values of concentration. These concentrations were determined with a linear interpolation scheme, using the nearest measured concentrations above and below nodes not corresponding to a measurement depth. For example, the vertical distance between nodes in the computational node was $0.46 \mathrm{~m}(1.5 \mathrm{ft})$, whereas the largest distance between samples for Tc-99 was $9.96 \mathrm{~m}$ (32.7 ft). Instead of assigning zero concentrations to nodes falling within the 9.96-m (32.7-ft) interval, these nodes were assigned interpolated values of concentration.

By contrast, the sampling interval for U-238 was more frequent and, in many instances, smaller than the vertical distance between nodes (e.g., $0.15 \mathrm{~m}[0.5 \mathrm{ft}]$ ). Laboratory analyses reported several soil samples with U-238 concentrations below the minimum detection level. When this occurred, a zero concentration was assigned at the corresponding depth. Thus, the U-238 profile differed from those of the Tc-99 and $\mathrm{NO}_{3}$ inventories in that it contained zero values of concentrations throughout its profile. However, similar to the estimates for the Tc-99 and $\mathrm{NO}_{3}$ inventories, concentrations were interpolated when the distance between nodes was smaller than the sampling interval. 
Figures 3.3 to 3.5 demonstrate how the reported inventories from the laboratory analyses translated to the computational grid for a one-dimensional slice through the domain. The solid line in Figure 3.3 traces the initial inventory in STOMP for species U-238, whereas the reported inventories are shown with a solid marker. Several areas of the plot show that markers lie between the reported inventory symbols, indicating regions of interpolated concentrations. By contrast, Figure 3.3 shows areas where the reported inventory sampling intervals were smaller than the node spacing. For example, concentrations were measured at $29.7 \mathrm{~m}(98.2 \mathrm{ft})$ and $30.4 \mathrm{~m}(99.6 \mathrm{ft})$. Because the elevation at the node was closer to $29.9 \mathrm{~m}$ $(98.2 \mathrm{ft})$ than $30.4 \mathrm{~m}(99.6 \mathrm{ft})$, the concentration assigned to this node corresponded to measurements at $29.9 \mathrm{~m}(98.2 \mathrm{ft})(113.26 \mathrm{pCi} / \mathrm{g})$, rather than $30.4 \mathrm{~m}(99.6 \mathrm{ft})(211.59 \mathrm{pCi} / \mathrm{g})$.

Figure 3.3 also demonstrates a correlation between reported U-238 concentrations that were less than the minimum detection level and the zero concentrations InvSTOMP assigned to nodes in the computational domain. This differs from the Tc-99 and $\mathrm{NO}_{3}$ concentration profiles in Figures 3.4 and 3.5, in which zero concentrations are only assigned to nodes at the endpoints of the plume. Similar to the U-238 profile, areas of the plots for Tc-99 and $\mathrm{NO}_{3}$ also illustrate interpolated concentration values. These appear in regions where markers on the solid lines lie between the values indicated for the reported inventory.

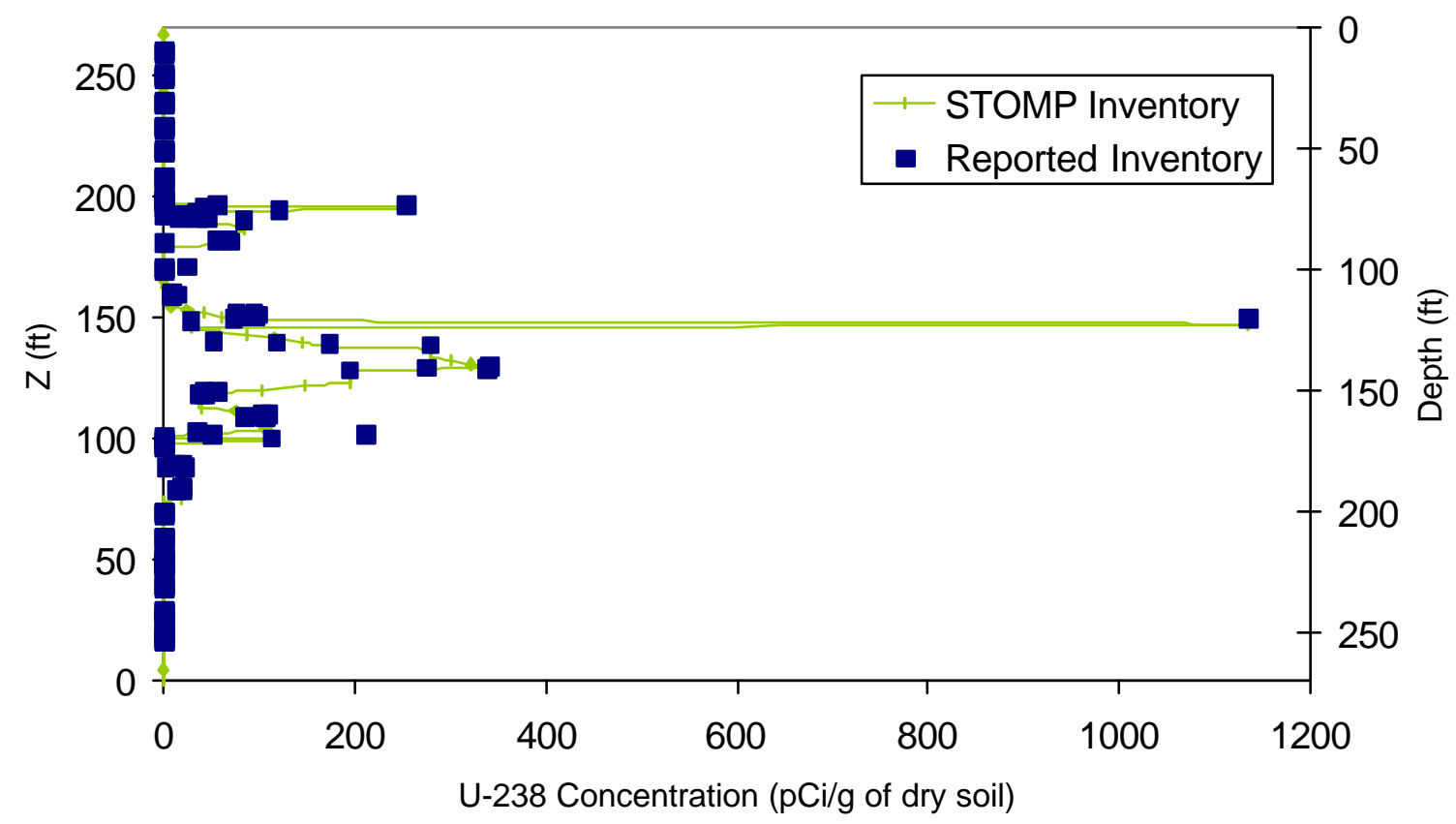

Figure 3. 3. U-238 Concentration Profile for Initial Conditions in STOMP and the Corresponding Reported Inventory 


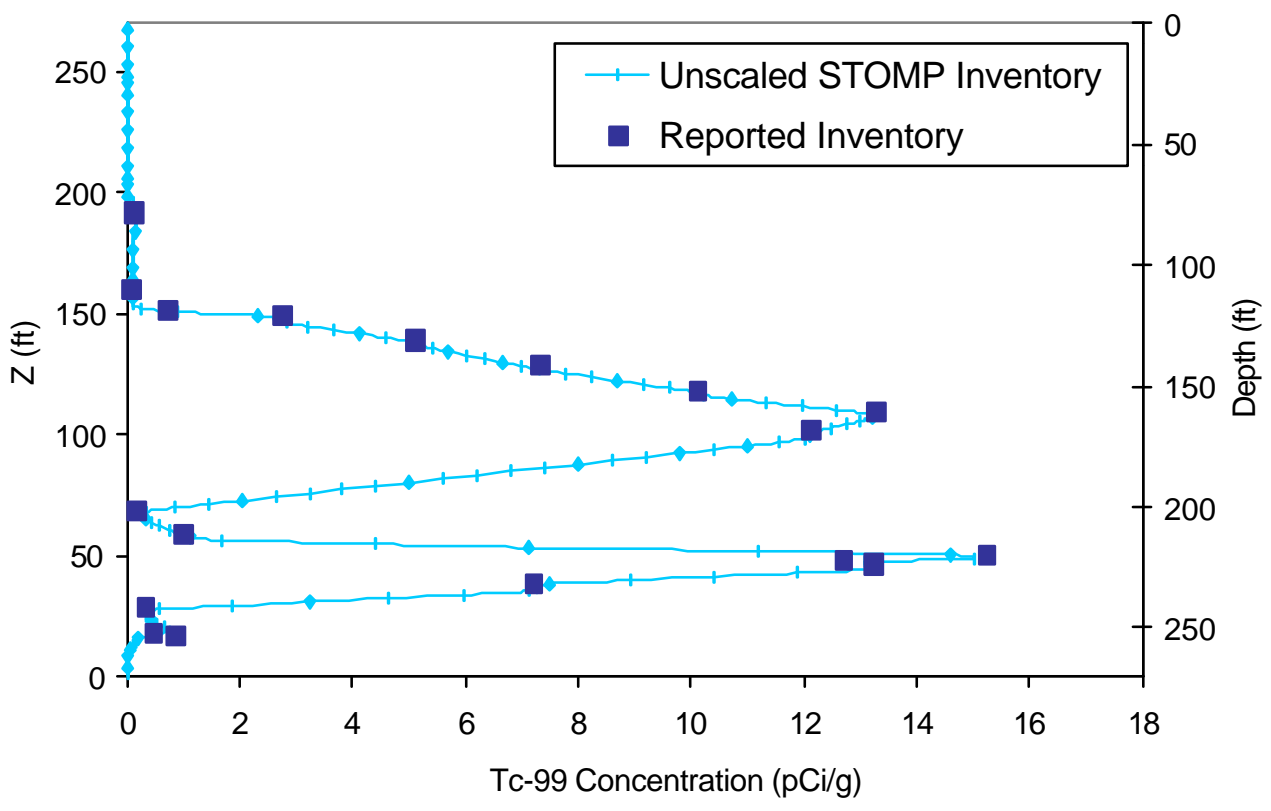

Figure 3. 4. Tc-99 Concentration Profile for Initial Conditions in STOMP and the Corresponding Reported Inventory

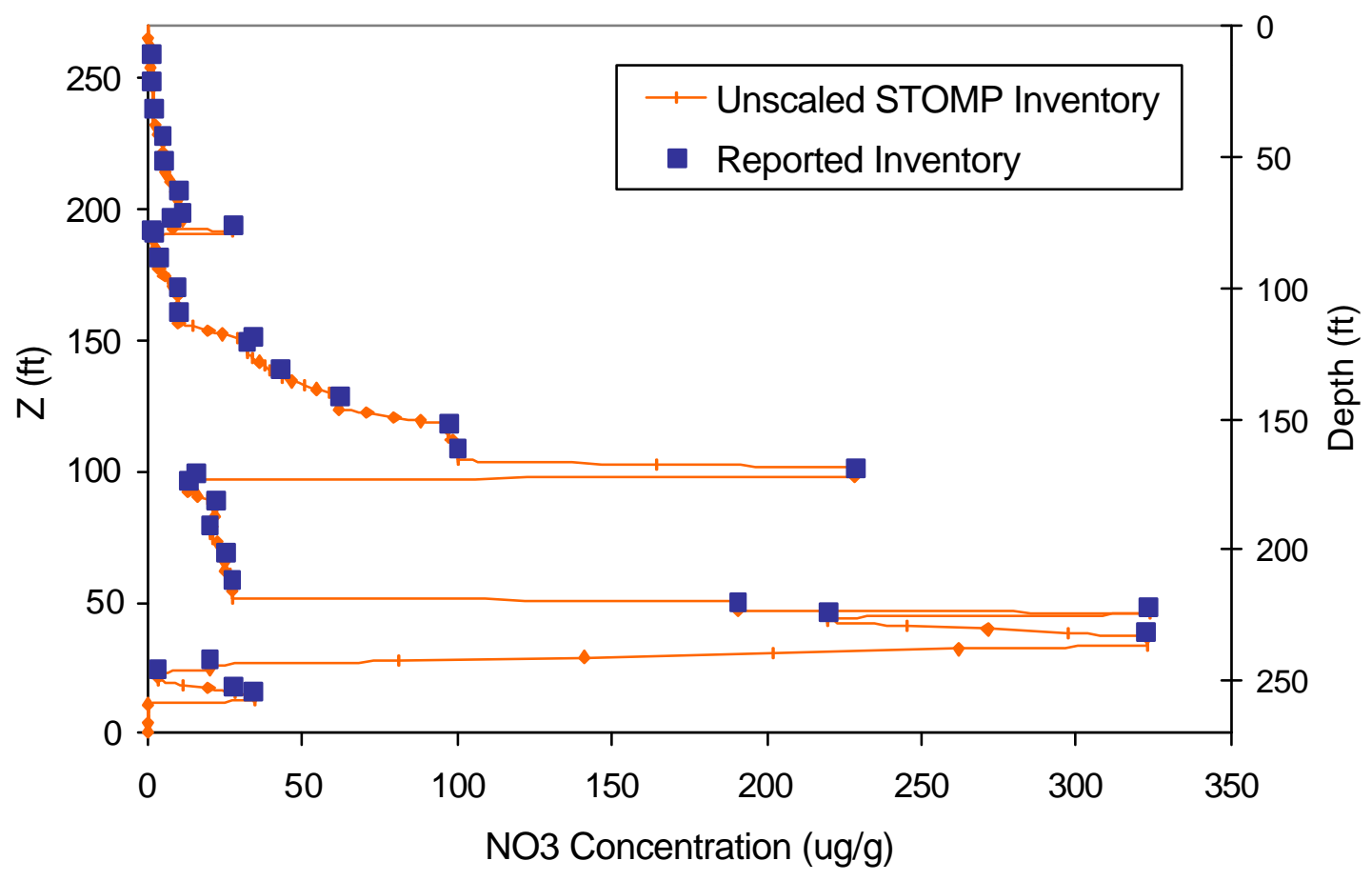

Figure 3. 5. $\mathrm{NO}_{3}$ Concentration Profile for Initial Conditions in STOMP and the Corresponding Reported Inventory 


\subsubsection{Inventory Distribution Maps}

Color-scaled images of the initial inventories are shown in Appendixes A and B. For the inventory east of Tank BX-102, the initial inventory distributions are shown in Figures A.2 (a) (total U-238), A.3(a) (aqueous phase U-238), A.4(a) (aqueous phase Tc-99) and A.5(a) (aqueous phase $\mathrm{NO}_{3}$ ). For the alternate inventory distribution centered between Tanks BX-105 and BX-102, the initial concentration distributions are shown in Figures A.15 (a) (total U-238), A.16(a) (aqueous phase U-238), A.17(a) (aqueous phase Tc-99) and A.18(a) (aqueous phase $\mathrm{NO}_{3}$ ). For the B-38 trench, the color-scaled images in Appendix B show the inventory distribution after one year of simulation [B.3-5(a) and B.10-13(a)]. The relationship between initial inventory distribution and simulation cases is shown in Table 3.8.

Table 3.8. Initial Inventory Distribution Schedule

\begin{tabular}{|c|c|c|}
\hline Simulation Case & Inventory Distribution & Appendix A Figures \\
\hline 1. Base Case (no action alternative) & East of BX-102 to BX fence line & A.2(a), A.3(a), A.4(a), A.5(a) \\
\hline 2. Interim Barrier & East of BX-102 to BX fence line & A.2(a), A.3(a), A.4(a), A.5(a) \\
\hline $\begin{array}{l}\text { 3. Water-Line Leak } \\
\text { (1 gpm for } 20 \mathrm{yr})\end{array}$ & East of BX-102 to BX fence line & A.2(a), A.3(a), A.4(a), A.5(a) \\
\hline 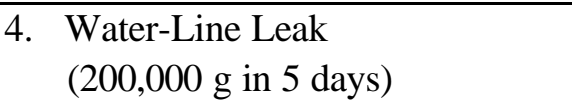 & East of BX-102 to BX fence line & A.2(a), A.3(a), A.4(a), A.5(a) \\
\hline 5. No Action Alternative & $\begin{array}{l}\text { Centered between BX-105 and } \\
\text { BX-102 }\end{array}$ & $\begin{array}{l}\text { A.15(a), A.16(a), A.17(a), } \\
\text { A.18(a) }\end{array}$ \\
\hline 6. Interim Barrier & $\begin{array}{l}\text { Centered between BX-105 and } \\
\text { BX-102 }\end{array}$ & $\begin{array}{l}\text { A.15(a), A.16(a), A.17(a), } \\
\text { A.18(a) }\end{array}$ \\
\hline 7. Base Case $(50 \mathrm{~mm} / \mathrm{yr})$ & East of BX-102 to BX fence fine & A.2(a), A.3(a), A.4(a), A.5(a) \\
\hline 8. Base Case $(30 \mathrm{~mm} / \mathrm{yr})$ & East of BX-102 to BX fence line & A.2(a), A.3(a), A.4(a), A.5(a) \\
\hline 9. Base Case $(10 \mathrm{~mm} / \mathrm{yr})$ & East of BX-102 to BX fence line & A.2(a), A.3(a), A.4(a), A.5(a) \\
\hline 10. Base Case $\left.\left(\mathrm{K}_{\mathrm{d}}{ }^{238} \mathrm{U}\right)=0.1 \mathrm{~mL} / \mathrm{g}\right)$ & East of BX-102 to BX fence line & A.31(a), A.32(a), A.4(a), A.5(a) \\
\hline 11. Base Case $\left.\left(\mathrm{K}_{\mathrm{d}}{ }^{238} \mathrm{U}\right)=1.0 \mathrm{~mL} / \mathrm{g}\right)$ & East of BX-102 to BX fence line & A.33(a), A.34(a), A.4(a), A.5(a) \\
\hline 12. Trench $(55.4 \mathrm{~mm} / \mathrm{yr})$ & Unit inventory $\left({ }^{238} \mathrm{U}\right.$ and $\left.{ }^{99} \mathrm{Tc}\right)$ & B.3(a), B.4(a), and B.5(a) \\
\hline 13. Trench $(100 \mathrm{~mm} / \mathrm{yr})$ & Unit inventory $\left({ }^{238} \mathrm{U}\right.$ and $\left.{ }^{99} \mathrm{Tc}\right)$ & B.10(a), B.11(a), and B.12 (a) \\
\hline 14. Trench $(100 \mathrm{~mm} / \mathrm{yr})$ & Unit inventory $\left({ }^{238} \mathrm{U}\right.$ and $\left.{ }^{99} \mathrm{Tc}\right)$ & B.10(a), B.11(a), and B.12 (a) \\
\hline
\end{tabular}

Species inventories provided in the modeling data package were expressed in soil concentration (e.g., $\mu \mathrm{g} / \mathrm{g}$ soil, $\mathrm{pCi} / \mathrm{g}$ soil). These concentrations were converted to aqueous phase concentrations based on the soil bulk density (i.e., from grain density and porosity) and the initial saturation. Initial saturations were determined using the steady-state saturation distribution simulated in STOMP for the different recharge rates. The aqueous concentrations are calculated as

$$
c_{\ell}=\frac{c_{s} \rho_{s}\left(1-n_{T}\right) y_{\ell}}{s_{\ell} n_{D}}
$$


where $C_{\ell}$ is the aqueous-phase concentration, $C_{S}$ is the soil concentration, $\rho_{S}$ is the soil grain density, $n_{T}$ is the total porosity, $s_{\ell}$ is the aqueous-phase saturation, and $n_{D}$ is the diffusive porosity. The product of $s_{\ell}$ and $n_{D}$ represents the moisture content. For all of the numerical simulations in the B-BX-BY WMA, it was assumed that diffusive porosities were equal to the total porosities of the media. In Equation 3.8, $\mathrm{y}_{\ell}$ represents the equilibrium fraction of solute in the aqueous phase and is given as

$$
\mathrm{y}_{\ell}=\frac{\mathrm{s}_{\ell} n_{\mathrm{D}}}{\tilde{n}_{\mathrm{s}} K_{\mathrm{d}}\left(1-n_{\mathrm{T}}\right)+\mathrm{s}_{\ell} n_{\mathrm{D}}}
$$

where $K_{d}$ is the partition coefficient. Thus, for the nonsorbed Tc-99 and $\mathrm{NO}_{3}$ species, $\mathrm{y}_{\ell}$ is equal to 1 because the first term in the denominator is equal to zero $\left(K_{d}=0\right)$. By contrast, for U-238 $\left(K_{d}=\right.$ $0.6 \mathrm{~mL} / \mathrm{g}), \mathrm{y}_{\ell}$ has a value between zero and one because it represents the fraction of the contaminant in the aqueous phase over the total amount in both the aqueous and sorbed phases.

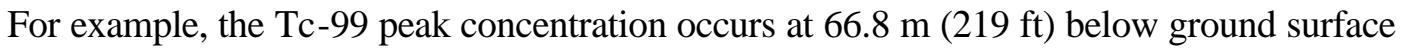
(Figure 3.4) and has a reported soil concentration $\left(C_{S}\right)$ of $15.2 \mathrm{pCi} / \mathrm{g}$. In this region, the saturation $\left(\mathrm{S}_{\ell}\right)$ is 0.449 , and both the diffusive $\left(n_{D}\right)$ and total $\left(n_{T}\right)$ porosities are equal to 0.435 . Because Tc-99 is not sorbed, $\mathrm{y}_{\ell}$ is equal to 1 . Thus, assuming a grain density $\left(\rho_{\mathrm{s}}\right)$ of $2.65 \mathrm{~g} / \mathrm{cm}^{3}$, the aqueous concentration $\left(\mathrm{C}_{\ell}\right)$ of Tc-99 is computed as

$$
\mathrm{C}_{\ell}=\frac{15.2 * 2.65 *(1-0.435) * 1}{0.449 * 0.435}=\left(116.52 \mathrm{pCi} / \mathrm{cm}^{3}\right) * 1000 \mathrm{~cm}^{3} / \mathrm{L}=1.16 \times 10^{5} \mathrm{pCi} / \mathrm{L}
$$

For sorbed species, $\mathrm{C}_{\ell}$ is calculated in the same way as the nonsorbed species, but $\mathrm{y}_{\ell}$ has a value less

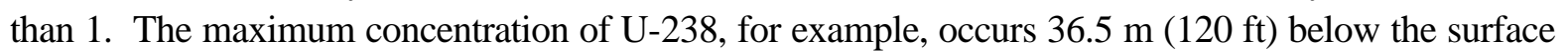
(Figure 3.3) and has a $C_{S}=1135 \mathrm{pCi} / \mathrm{g}$. In this region, $\mathrm{n}_{\mathrm{D}}$ and $\mathrm{n}_{\mathrm{T}}$ are equal to 0.382 , and $\mathrm{s}_{\ell}=0.558$. Assuming a $\mathrm{K}_{\mathrm{d}}=0.6 \mathrm{~mL} / \mathrm{g}$ (Base Case) and $\rho_{\mathrm{S}}=2.65 \mathrm{~g} / \mathrm{cm}^{3}, \mathrm{y}_{\ell}$ is calculated as

$$
\mathrm{y}_{\ell}=\frac{0.558 * 0.382}{2.65 * 0.6(1-0.382)+0.558 * 0.382}=0.178
$$

which represents the fraction of solute in the aqueous phase. The aqueous concentration of U-238 is then calculated from Equation 3.8:

$$
\mathrm{C}_{\ell}=\frac{1135^{*} 2.65 *(1-0.382) * 0.178}{0.558 * 0.382}=\left(1552.0 \mathrm{pCi} / \mathrm{cm}^{3}\right)^{*} 1000 \mathrm{~cm}^{3} / \mathrm{L}=1.55 \times 10^{6} \mathrm{pCi} / \mathrm{L}
$$

In this example, the majority of U-238 exists in the sorbed phase, as indicated by the low fractional value of $\mathrm{y}_{\ell}$. 
The effect of U-238 partitioning is shown in Figure 3.6a and b, which reports the U-238 inventory in concentration per liter for the aqueous phase, and for the total concentration per unit volume of soil and water for both the aqueous and sorbed phases. These profiles represent the initial concentration distributions for the Base Case scenario, where the value of the partition coefficient is $0.6 \mathrm{~mL} / \mathrm{g}$. Because these plots illustrate the effect of partitioning on the initial inventory distribution, the shape of the profile is identical to the U-238 total concentration presented in Figure 3.3.

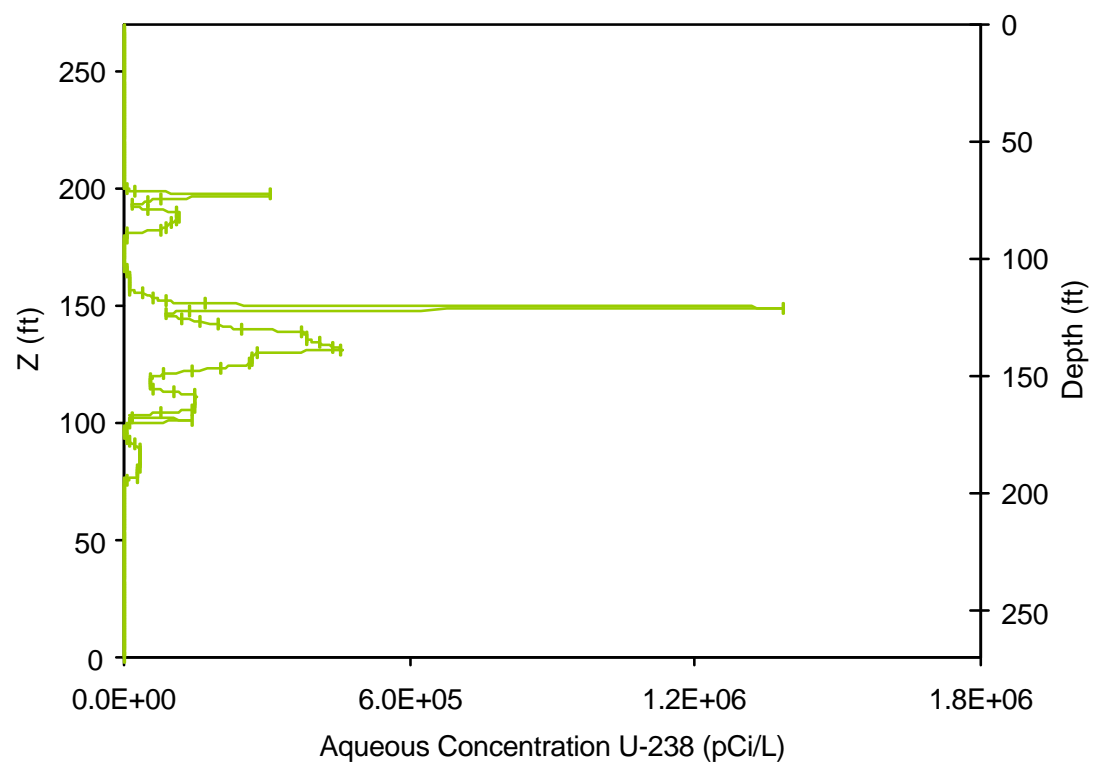

Figure 3. 6a. U-238 Concentrations in Aqueous Phase Only

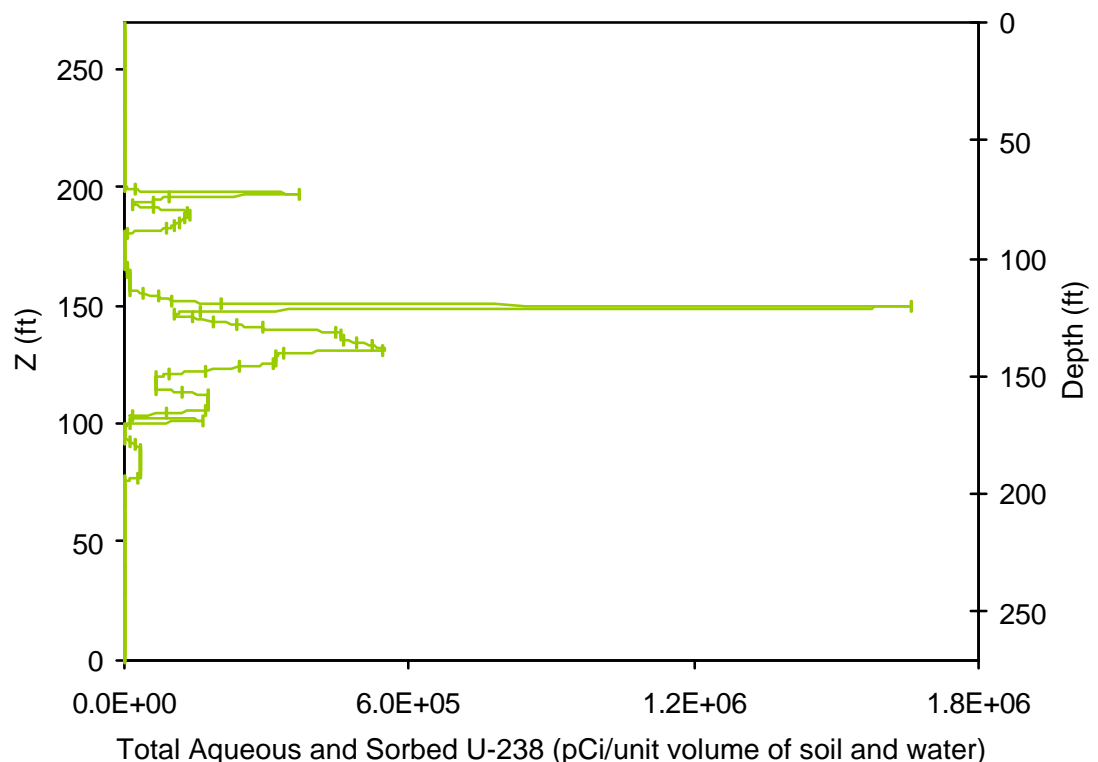

Figure 3. 6b. U-238 Concentrations in Total Aqueous and Sorbed Phase Concentrations per Unit Volume of Soil and Water 
The concentration profiles presented in Figures 3.2 to 3.4 represent the total inventories at each node for a one-dimensional column. To determine the total inventory for each species in the domain, the mass $\left(\mathrm{NO}_{3}\right)$ or $\mathrm{Ci}(\mathrm{U}-238$ and Tc-99) at each node is summed for both the aqueous and sorbed phases. The total inventories computed by STOMP for a two-dimensional domain are compared with the estimated losses reported in the MDP (Appendix D) in Tables 3.8 and 3.9. Note that the cross-section inventories reported in Table 3.8 are from the upscaled Tc-99 and $\mathrm{NO}_{3}$ concentrations described in Section 3.6. Also shown in Tables 3.8 and 3.9 are the two-dimensional inventories used in the STOMP simulations as well as the three-dimensional scale factors used for the WMA and compliance boundaries. The details of the scaling method are outline in Section 3.6.

Table 3.9. BX-102 Inventory Summary

\begin{tabular}{|c|c|c|c|}
\hline Solute & Reported Leak Inventory & $\begin{array}{c}\text { Cross Section } \\
\text { Inventory }\end{array}$ & WMA Scale Factor \\
\hline $\mathrm{U}-238$ & $3.15 \mathrm{Ci}$ & $4.31 \times 10^{-2} \mathrm{Ci}$ & 73 \\
$\mathrm{Tc}-99$ & $4.37 \mathrm{Ci}$ & $6.01 \times 10^{-2} \mathrm{Ci}$ & 73 \\
$\mathrm{NO}_{3}$ & $13,100 \mathrm{~kg}$ & $1.79 \times 10^{2} \mathrm{~kg}$ & 73 \\
\hline
\end{tabular}

Table 3.10. B-38 Trench Case Inventory Summary

\begin{tabular}{|l|c|c|c|}
\hline & $\begin{array}{c}\mathrm{U}-238 \\
(\mathrm{Ci})\end{array}$ & $\begin{array}{c}\text { Tc-99 } \\
(\mathrm{Ci})\end{array}$ & $\begin{array}{c}\mathrm{NO}_{3} \\
(\mathrm{~kg})\end{array}$ \\
\hline Unit Inventory & 1.0 & 1.0 & 1.0 \\
B-38 Trench & $1.58 \times 10^{-2}$ & $1.84 \times 10^{-2}$ & $.32 \times 10^{5}$ \\
All B Trenches (8) & 1.49 & 8.31 & $1.93 \times 10^{6}$ \\
\hline
\end{tabular}

\subsection{Implemented Features}

For the S-SX field investigation (White et al. 2001), the STOMP simulator, as documented in White and Oostrom (2000a, 2000b) and Nichols et al. (2000), was modified to extend its capabilities for modeling saturation dependent anisotropy, enhanced macrodispersivity, and specialized Courant number control. These features are also implemented for the B-BX-BY WMA simulations described in this report. For a detailed description of these features, refer to White et al. (2001).

\subsection{STOMP Execution}

The reported simulations were executed on Linux workstations. All executables were generated from a single source code, which is readable and available in electronic form (Section 6). Executing the simulator required two steps: 1) compiling the source code with a parameters definition file and 2) executing the compiled code on a workstation or personal computer. The executable forms of the STOMP simulator for these investigations were generated using the default level of optimization for each compiler. STOMP was coded following ASCII Fortran 77 protocols and yielded no warning or error messages during compilation. The size of the computational domains ( 40,000 nodes) necessitates the use of a 
conjugate gradient linear system solver with a compact storage scheme for the Jacobian matrix. The STOMP simulator uses the SPLIB solver (Bramley and Wang 1995) for sparse linear systems for solutions implementing conjugate gradient solvers. The SPLIB solver is a collection of libraries that must be assembled on the executing computer and linked to the STOMP simulator during compilation. The SPLIB files and instructions necessary to complete the compilation and execution of the STOMP simulator will be available in electronic form (Section 6).

\subsection{Result Translation}

For these investigations, the STOMP simulator reads in a series of input files and generates an output file, surface flux file, and a series of plot files. As described previously, the STOMP output file contains reflected data from the input files, simulation progression information, and reference-node output. The output files were only used for verification and simulation tracking. Input, output, and surface-flux files are located in the simulation case directories and will be available in electronic format (Section 6).

Concentration and dose calculations were made using STOMP output values for solute mass and water mass fluxes from the 5-m-thick aquifer on the downgradient side (east) of the cross section. These data were recorded in the STOMP surface file. With the appropriate scale factors, these data were used to calculate 1) the cross-section concentrations, 2) average fence line concentrations, and 3) WMA solute mass fluxes for use as sources in aquifer models such as analytic aquifer streamtube models and threedimensional numerical hydrogeologic models to predict concentrations at the distal compliance points.

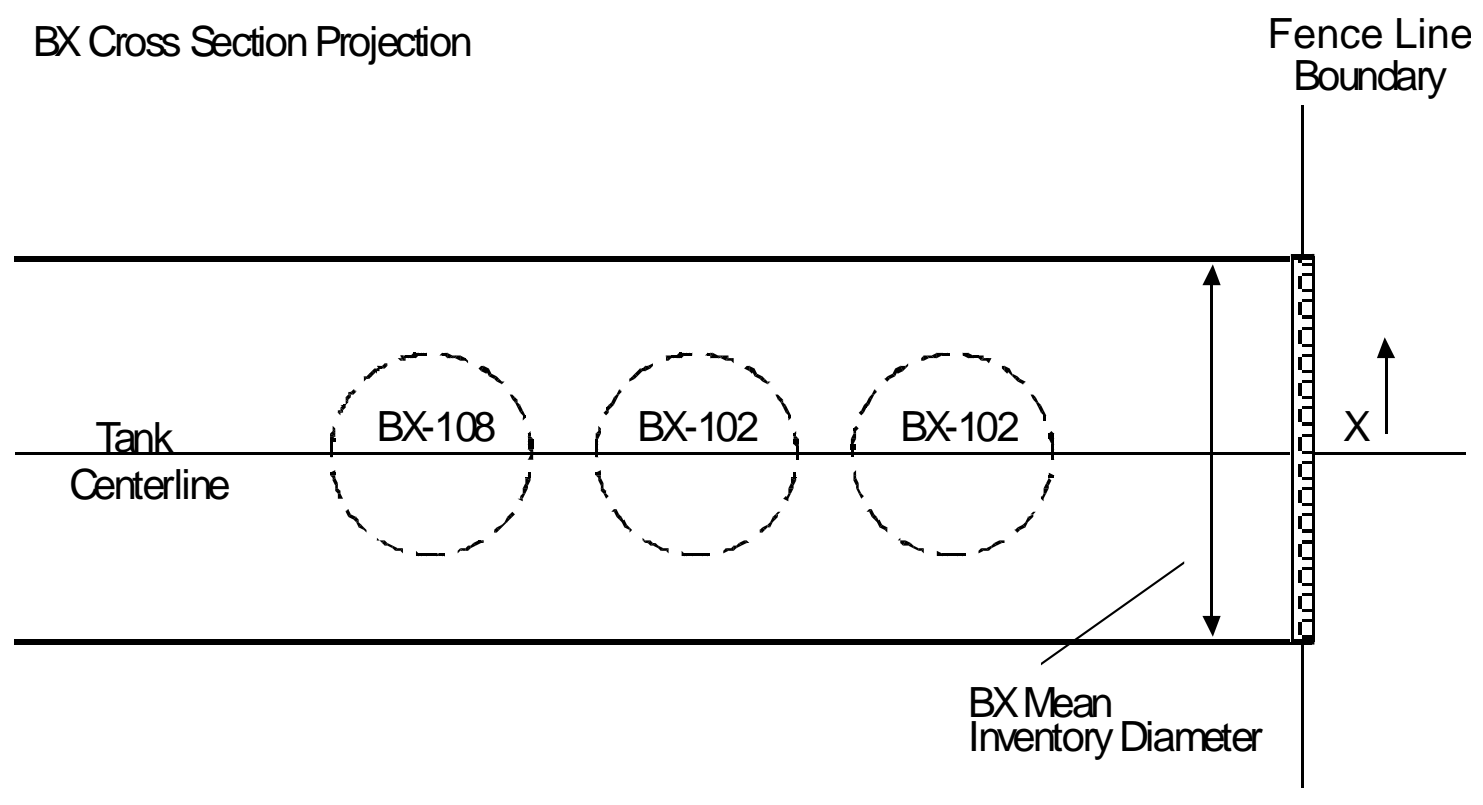

Figure 3.7. Translation Geometry 
Flux surfaces were defined for the downgradient, vertical boundary in the unconfined aquifer at the east fence line, which represent the cross section values (i.e., the BX fence line for the tank simula tions, or the trench fence line for the trench simulations). The surface flux output for this surface includes the aqueous volumetric flux rate and integral, and the solute flux rate and integral crossing the surface (i.e., exiting the computational domain through the unconfined aquifer). Surface flux output was converted to breakthrough curves at the $\mathrm{BX}$ and trench fence lines and provided input to the streamtube model. These conversions were executed with the utility program Surfcalc.c.

The two-dimensional simulations executed in this investigation yielded solute mass flux and concentration at the BX fence line boundary along the tank centerlines for the cross section, as shown in Figure 3.7. For the trench simulations, solute mass flux and concentrations were determined for the trench fence line. Translation of the centerline solute mass flux or concentration to an average value across the fence line boundaries is outlined below.

\subsubsection{Cross-Section Concentrations}

Cross-section concentrations were initially calculated from the mass fluxes by the following equation:

$$
\mathrm{C}_{\mathrm{xsect}}=\mathrm{S}_{\mathrm{mf}} / \mathrm{W}_{\mathrm{mf}}
$$

where $\mathrm{S}_{\mathrm{mf}}$ is the solute mass flux (pCi /yr or $\mu \mathrm{g} / \mathrm{yr}$ ), and $\mathrm{W}_{\mathrm{mf}}$ is the water mass flux (L/yr). These concentrations were later scaled to match the total inventory estimate. The procedure is outlined in Section 3.6.3.

\subsubsection{WMA Concentrations}

For the BX-108 to BX-102 cross section, the initial lateral extent of all the concentration profiles were explicitly set to span the distance from the east edge of Tank BX-102 to the WMA fence line, $27.9 \mathrm{~m}(91.5 \mathrm{ft})$ based on the MDP. Integrating the vertical concentration data from the borehole near BX-102 over this distance yielded a fixed inventory for the unit width 0.31-m (1-ft) cross section. This calculated two-dimensional inventory was expanded to a cylindrical volume large enough to account for the total inventory estimate. This was accomplished by multiplying the cross-section solute mass flux by a scale factor $\left(\mathrm{S}_{\mathrm{wma}}\right)$ given as

$$
\mathrm{S}_{\mathrm{wma}}=\mathrm{Inv}_{\text {total }} / \mathrm{Inv}_{\mathrm{xsect}}
$$

where $\operatorname{Inv}_{\text {total }}$ is the total estimated leak inventory ( $\mathrm{Ci}$ or $\mathrm{kg}$ ) and $\mathrm{Inv}_{\mathrm{xsect}}$ represents the initial inventory in the cross section ( $\mathrm{Ci}$ or $\mathrm{kg}$ ). Note that this approach differs from the one used in the S-SX FIR modeling (White et al. 2001). In the S-SX approach, the lateral extent of the concentrations profiles in the cross section was calculated based on estimated leak inventories at specific depth intervals to fit a cylindrical geometry. 


\subsubsection{Cross-Section Scale Factors}

Table 3.11 shows the two-dimensional calculated plan-view sizes of circular plumes using each of the concentration profiles and inventory estimates from the MDP. In the first column of the table, the total concentration value is obtained by integrating the vertical concentration data from the borehole near $\mathrm{BX}-102$; it represents the total inventory present in a unit width $[0.31 \mathrm{~m}(1-\mathrm{ft})]$ cross section. The second column of Table 3.11 is the diameter (d) that is required to convert the two-dimensional unit width inventory in column 1 to a three-dimensional plume that matches the total estimated leak inventories and is given as

$$
\operatorname{Inv}_{\mathrm{xsect}} \mathrm{A}=\operatorname{Inv}_{\text {total }}
$$

where $\mathrm{A}=\pi(\mathrm{d} / 2)^{2}$ and is the area of a circular plume. For example, the total unit width concentration for Tc-99 is $3.96 \times 10^{-5} \mathrm{Ci} / \mathrm{ft}^{2}$. Because the total estimated inventory for Tc-99 is $4.37 \mathrm{Ci}$, then a plume diameter of $375 \mathrm{ft}$ is necessary to obtain a total leak inventory of $4.37 \mathrm{Ci}\left[3.96 \times 10^{-5} \mathrm{Ci} / \mathrm{ft}^{2} \times \pi(375 \mathrm{ft} / 2)^{2}=\right.$ $4.37 \mathrm{Ci}]$.

For U-238, the calculated diameter of $28.0 \mathrm{~m}(92 \mathrm{ft})$ closely matches the distance from the east edge of Tank BX-102 to the WMA fence line [27.9 m (91.5 ft)]. This distance is less than the calculated diameters for both the $\mathrm{NO}_{3}$ inventory, $53.9 \mathrm{~m}(177 \mathrm{ft})$ and the Tc-99, $114 \mathrm{~m}(375 \mathrm{ft})$ inventories. If the diameter of the plume is assumed to be close to the distance between the eastern edge of Tank BX-102 and the WMA fence line (i.e., $27.9 \mathrm{~m}$ [91.5 ft]), the discrepancy can be attributed to one or more of the following factors. First, it is possible that the concentrations measured were below the plume average in the borehole (i.e., the samples were taken in a low-concentration area). Second, due to the mobility of Tc-99 and $\mathrm{NO}_{3}$, it is also possible that a large quantity of the inventory has already been transported out of the vadose zone and into the aquifer, possibly due to artificial recharge (e.g., waterline leaks). A third possibility is that the estimated leak inventory estimates are too high.

In this analysis, it is assumed that the inventory leak estimates are correct and that the concentrations measured were below the plume average. Hence, the borehole concentration data for Tc-99 and $\mathrm{NO}_{3}$ were scaled based on the calculated U-238 inventory diameter of $27.9 \mathrm{~m}(92 \mathrm{ft})$. The scaling factors were calculated as

$$
S_{x \text { sect }}=\left(\frac{\text { Inv }_{\text {total }}}{A \operatorname{Inv_{xsect}}}\right)
$$

and are shown in Table 3.11. For example, the cross-sectional area for a circular plume with a diameter

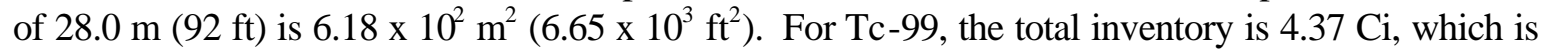
divided by the product of the concentration per unit area data and the area. The resulting scale factor is 16.6. The $\mathrm{NO}_{3}$ inventory was scaled with the same method and the scale factor. The U-238 data were not scaled in this step since the calculated inventory diameter was close to the diameter used for the twodimensional simulations. However, the U-238 data were previously scaled from the single borehole measurements in the MDP by a factor of 2 based on geophysical measurements in surrounding boreholes. 
Table 3.11. Calculated Plan View Areas of 2-D Plume Geometries for BX-108 to BX-102 Concentration Profiles and Inventory and Their Scale Factors Based on Mean Inventory Diameter of $28.0 \mathrm{~m}(92 \mathrm{ft})$

\begin{tabular}{|c|c|c|c|c|c|c|}
\hline Solute & \multirow{2}{*}{$\begin{array}{c}\text { Unscaled Inventory } \\
\text { per Unit Area }\left(\mathrm{ft}^{2}\right)\end{array}$} & \multicolumn{2}{|c|}{$\begin{array}{c}\text { Unscaled Circular Plume } \\
\text { Diameter (plan view) } \\
(\text { plan view) }\end{array}$} & \multicolumn{2}{|c|}{$\begin{array}{c}\text { Cross-Section } \\
\text { Concentration } \\
(\mathrm{m})\end{array}$} & \multicolumn{2}{|c|}{$\begin{array}{c}\text { Scaled Circular Plume } \\
\text { Diameter (plan view) } \\
(\mathrm{ft})\end{array}$} \\
\hline $\mathrm{U}-238$ & $4.47 \mathrm{E}-04 \mathrm{Ci}$ & 28 & 92 & 1 & 28 & 92 \\
$\mathrm{Tc}-99$ & $3.96 \mathrm{E}-05 \mathrm{Ci}$ & 114 & 375 & 16.66 & 28 & 92 \\
$\mathrm{NO}_{3}$ & $5.32 \mathrm{E}-01 \mathrm{~kg}$ & 54 & 177 & 3.66 & 28 & 92 \\
\hline
\end{tabular}

\subsubsection{Trench Fence Line Concentrations}

The average fence line solute concentration $\left(\mathrm{C}_{\mathrm{wma}}\right)$ was calculated for each solute by

$$
\mathrm{C}_{\mathrm{wma}}=\mathrm{C}_{\mathrm{xsect}} \frac{\text { Inv }_{\text {total }} / \text { Inv }_{\mathrm{x} \mathrm{sect}}}{\mathrm{W}_{\text {fenceline }} / \mathrm{W}_{\mathrm{xsect}}}
$$

where $\mathrm{W}_{\text {fenceline }}$ is the fence line width ( $\mathrm{ft}$ or $\mathrm{m}$ ) and $\mathrm{W}_{\mathrm{xsect}}$ is the cross-section width ( $\mathrm{ft}$ or $\mathrm{m}$ ). As shown in Equation 3.15, the aquifer water flux was upscaled from the cross section for use in calculating the average fence line solute concentrations. The cross-section water flux (per unit width) was multiplied by the fence line length to calculate the aquifer water flux for the WMA. Assuming a uniform groundwater flux at the WMA, the water flux scaling is a function of the width of the fence line and the cross-section width. The scaled WMA solute flux is divided by the scaled WMA water flux to yield the average fence line aqueous solute concentration for each species. This calculation is based on aqueous concentrations.

The resulting concentration scale factors for the BX cross-section results are shown in Table 3.12. Because the cross-section concentrations were scaled to the same mean inventory diameter, the WMA concentration scale factor is the same for all three solutes.

Table 3.12. Concentration Scale Factors for BX WMA from BX-108 to BX-102 Cross-Section Concentrations

\begin{tabular}{|c|c|}
\hline Solute & $\begin{array}{c}\text { WMA Concentration } \\
\text { Scale Factor }\end{array}$ \\
\hline U-238 & 0.122 \\
Tc-99 & 0.122 \\
$\mathrm{NO}_{3}$ & 0.122 \\
\hline
\end{tabular}

Although unit inventories were assumed for the B trenches, the trench WMA mass fluxes and concentrations were determined by the same method. For the WMA mass flux, the cross section mass flux was multiplied by the inventory for each case. Similarly, the trench cross-section concentrations were determined by multiplying the cross-section concentrations by the inventory of the case. To calculate the average fence line concentrations, the scaled WMA mass fluxes were divided by the aquifer 
water flux at the trench fence line (198 m [650 ft] long). Note that for aquifer water flux scaling, the width (y-dimension) of the STOMP trench cross section was $3.05 \mathrm{~m}(10 \mathrm{ft})$, whereas the width of the BX-108 to BX-102 cross section was $0.30 \mathrm{~m}(1 \mathrm{ft})$. The resulting concentration scale factors for the $\mathrm{B}$ trench cross section are shown in Table 3.13.

Table 3.13. Concentration Scale Factors for B Trench WMA from Unit Inventory Cross-Section Concentrations

\begin{tabular}{|c|c|c|c|}
\hline Solute & $\begin{array}{c}\text { Unit Trench Inventory } \\
\text { Case Trench } \\
\text { WMA Concentration } \\
\text { Scale Factor }\end{array}$ & $\begin{array}{c}\text { B-38 Trench Inventory } \\
\text { Case Trench } \\
\text { WMA Concentration } \\
\text { Scale Factor }\end{array}$ & $\begin{array}{c}\text { All } 8 \text { Trenches Inventory } \\
\text { Case Trench } \\
\text { WMA Concentration } \\
\text { Scale Factor }\end{array}$ \\
\hline $\mathrm{U}-238$ & $1.54 \mathrm{e}-2$ & $2.43 \mathrm{e}-4$ & $2.29 \mathrm{e}-2$ \\
$\mathrm{Tc}-99$ & $1.54 \mathrm{e}-2$ & $2.83 \mathrm{e}-4$ & $1.28 \mathrm{e}-1$ \\
$\mathrm{NO}_{3}$ & $1.54 \mathrm{e}-2$ & $2.03 \mathrm{e}+3$ & $2.97 \mathrm{e}+4$ \\
\hline
\end{tabular}

\subsection{Analytical Groundwater Transport Modeling}

An instantaneous point source model (Baetslé 1969) was used to calculate the concentration of contaminant species originating at the B-BX-BY WMA and monitored in the model at two remote compliance points along the groundwater flow path. The two compliance points are located at 1) the 200 Area exclusion boundary ( $1.25 \mathrm{~km}[0.78 \mathrm{mi}]$ east of the $200 \mathrm{E}$ Area), and 2) at the Columbia River (see Table 3.13). The distance to each compliance point along the groundwater flow path was based on streamlines derived from the VAM3D site-wide groundwater models of Law et al. (1996) and Lu (1996). Steady flow conditions, water table maps, and streamlines generated from the VAM3D simulation are reported by Khaleel et al. (2000). The analytical groundwater model assumed transport from a point source from a series of solute slugs and considers longitudinal and horizontal transverse dispersion, molecular diffusion, and first-order decay. The method of superposition was used to integrate the individual slug sources. The instantaneous point source model for a three dimensional space, as reported by Domenico and Schwartz (1990), is shown in Equation (3.16):

$$
C(x, y, z, t)=\left[\frac{C_{0} V_{0}}{\left(8(\pi t)^{3 / 2}\left(D_{x} D_{y} D_{z}\right)^{1 / 2}\right.}\right] \exp \left[-\frac{\left(x-v t^{2}\right)}{4 D_{x} t}-\frac{y^{2}}{4 D_{y} t}-\frac{z^{2}}{4 D_{z} t}-\lambda t\right]
$$

where $C(x, y, z, t)$ is the solute concentration as a function of position and time (pCi/L or $\mu \mathrm{g} / \mathrm{L}), \mathrm{C}_{0} \mathrm{~V}_{0}$ is the instantaneous source of solute mass ( $p C i$ or $\mu g$ ), $D_{x}, D_{y}, D_{z}$ are spatial components of the hydrodynamic dispersion coefficient $\left(\mathrm{m}^{2} / \mathrm{yr}\right), x, y, z$ are spatial distances from the solute source $(\mathrm{m}), \mathrm{t}$ is the time (yr), $\lambda$ is the solute species radioactive decay half-life (yr), and $\mathrm{V}$ is the pore-water velocity ( $\mathrm{m} / \mathrm{yr}$ ). 
The spatial components of hydrodynamic dispersion coefficients include dispersive and diffusive elements, according to Equation (3.17):

$$
D_{i}=\alpha_{i} v+D_{m} \text { for } i=x, y, z
$$

where $\alpha_{i}$ is the dispersivity $(\mathrm{m})$, and $\mathrm{D}_{\mathrm{m}}$ is the molecular diffusion coefficient $\left(\mathrm{m}^{2} / \mathrm{yr}\right)$.

Material property maps for the three elemental layers of the VAM3D site-wide groundwater model (SGM) are reported in Khaleel et al. (2001). Hydraulic properties for each of the 18 soil zones identified in the VAM3D SGM, including hydraulic conductivity in the north-south, east-west, and vertical directions, specific storage, and porosity are also reported in Khaleel et al. (2001). The VAM3D SGM assumed equal values for the north-south and east-west hydraulic conductivity and a vertical conductivity one order of magnitude less than the horizontal components. Specific storage was assumed constant across the site at $1 . e-61 / \mathrm{m}$, and porosities were either 0.1 or 0.25 .

Distances and travel times from the B-BX-BY WMA to the two compliance points were derived from streamline results from steady-state VAM3D unconfined aquifer flow simulations of the Hanford Site (Lu 1996). The simulation results were taken from "post-Hanford" or future conditions representing the water table at the Site without the impact of unconfined aquifer discharges from the project. Results of the VAM3D simulated hydraulic heads and streamlines are shown in Figures 15 and 19 in Lu (1996). Two streamlines are analyzed from Figure 19 (Lu 1996) starting at the B-BX-BY WMA to determine the unconfined aquifer path length to the river. Travel markers indicating 20-year intervals on the streamlines were used to estimate the travel time to the river from the B-BX-BY WMA. One streamline initially goes north from the B-BX-BY WMA through the gap between Gable Mountain and Gable Butte and then travels east to the Columbia River. The second (and shorter) streamline goes directly east to the river south of Gable Mountain. Since these had dramatically different lengths and travel times to the Columbia River, only values for the second (shorter) streamline was used in this analytical streamtube analysis (Table 3.13). Other groundwater flow simulations of the Hanford Site and Hanford Site monitoring data have shown the potential for groundwater flow that goes northward through the Gable Mountain/Gable Butte gap. These pathlines were not considered in this analysis and may be transient in nature from the extensive artificial recharge on the Hanford Site. Results from the shorter path length provide conservative estimates.

The concentration at compliance points is calculated by a Fortran code (disp.f) that implements the instantaneous pulse equation. Input to the model is read from two separate files. The distance from the source zone to each compliance point in the longitudinal (x direction) and groundwater velocity for each successive interval is listed in Table 3.14. The distances reported in Table 3.14 represent the longitudinal distance $x$ of Eq. (3.13) and (3.14). Values for the $y$ and $z$ directions are assigned values of zero signifying that the point of observation was along the longitudinal centerline. The other parameters used by the first input file (runpoint.csh) in the analytical groundwater model are listed in Table 3.15. 
Table 3.14. Distance to Compliance Point, Groundwater Velocity, and Travel Time from B-BX-BY WMA

\begin{tabular}{|l|c|c|c|}
\hline \multicolumn{1}{|c|}{ Compliance Point } & Distance, $\mathrm{m}$ & Velocity, $\mathrm{m} / \mathrm{yr}$ & Time, $\mathrm{yr}$ \\
\hline Exclusion Boundary & 4,600 & 115 & 40 \\
Columbia River & 16,000 & 61.5 & 260 \\
\hline
\end{tabular}

Table 3.15. Analytical Groundwater Transport Modeling Properties

\begin{tabular}{|l|l|}
\hline \multicolumn{1}{|c|}{ Parameter } & \multicolumn{1}{c|}{ Value } \\
\hline Horizontal dispersivity & $3.05 \mathrm{~m}$ \\
Vertical dispersivity & $0.01 \mathrm{~m}$ \\
Longitudinal dispersivity & $30.5 \mathrm{~m}$ \\
Molecular diffusion & $0.079 \mathrm{~m}^{2} / \mathrm{yr}$ \\
U-238 half-life & $4,460,000,000 \mathrm{yr}$ \\
U-238 unit dose factor & $0.196 \mathrm{mrem} / \mathrm{pCi} / \mathrm{L}$ \\
Tc-99 half-life & $213,000 \mathrm{yr}$ \\
Tc-99 unit dose factor & $0.00107 \mathrm{mrem} / \mathrm{pCi} / \mathrm{L}$ \\
\hline
\end{tabular}

The second input file provided solute mass flux across the B-BX-BY WMA as a function of time for the three species (U-238, Tc-99, and $\mathrm{NO}_{3}$ ). The concentration at each compliance point is calculated for a time series of solute release events using linear superposition of Equation (3.13) for each release event. The 1000-year period for the BX tank analysis, between years 2000 and 3000, was modeled using 1000 uniformly spaced solute release events. For the trench analysis, the time period was 1046 years, between years 1954 and 3000, and was modeled using 1046 uniformly spaced solute release events. Radiological decay of the nonradioactive species $\left(\mathrm{NO}_{3}\right)$ was omitted. 


\subsection{Simulation Results}

Reported simulation results are focused on key fluid flow and solute transport behavior, mass balance errors, and breakthrough curves at the first compliance point (B-BX-BY WMA boundary). The term total concentration is used in the following discussion to describe the total aqueous and sorbed phase concentrations per unit volume of soil and water. Peak aqueous concentration, time to peak concentration, and initial aqueous concentrations are summarized. The maximum initial aqueous concentrations based on the inventory estimates of Khaleel et al. (2001) are presented for comparison with the computed peak aqueous concentrations.

Saturations and inventory profiles for the BX-108 to BX-102 cross section are shown in Appendix A. Their breakthrough curves for the various cases are presented in Appendix C. Saturations and inventory profiles for the B trench simulations are presented in Appendix B, and their breakthrough curves are shown in Appendix D. Translation of the breakthrough curve results to the downgradient compliance points using analytical groundwater streamtube modeling is described in Section 5. These results, as well as the peak initial concentrations, are summarized in Tables 4.1 through 4.4.

Concentration decreases computed by the analytical groundwater transport modeloccur through longitudinal, transverse horizontal, and transverse vertical dispersion as well as molecular diffusion and radioactive decay. The first streamline segment extended from the BX fence line to the 200 Area exclusion boundary, and the second extended from the BX fence line to the Columbia River.

Simulation results were written to 1) reference node, 2) plot file, and 3) surface flux output. The data in this section focus on key flow and transport behavior, mass balance errors, and breakthrough curves at the compliance points (i.e., BX WMA). For more complete analyses, electronic copies of the reference node, plot file, and surface flux outputs will be available for each simulation case and cross section in STOMP simulator output format and converted Tecplot formats (Section 6).

Table 4.1. Initial Peak Concentrations for U-238, Tc-99, and $\mathrm{NO}_{3}$

\begin{tabular}{|c|c|c|c|}
\hline Case & $\begin{array}{c}\text { U-238 } \\
(\mathrm{pCi} / \mathrm{L})\end{array}$ & $\begin{array}{c}\text { Tc-99 } \\
(\mathrm{pCi} / \mathrm{L})\end{array}$ & $\begin{array}{c}\mathrm{NO}_{3} \\
(\mu \mathrm{g} / \mathrm{L})\end{array}$ \\
\hline 1 & $1.404 \times 10^{6}$ & $1.919 \times 10^{5}$ & $8.920 \times 10^{6}$ \\
\hline 2 & $1.404 \times 10^{6}$ & $1.919 \times 10^{5}$ & $8.920 \times 10^{6}$ \\
\hline 3 & $1.404 \times 10^{6}$ & $1.919 \times 10^{5}$ & $8.920 \times 10^{6}$ \\
\hline 4 & $1.404 \times 10^{6}$ & $1.919 \times 10^{5}$ & $8.920 \times 10^{6}$ \\
\hline 5 & $1.424 \times 10^{6}$ & $2.209 \times 10^{5}$ & $9.329 \times 10^{6}$ \\
\hline 6 & $1.424 \times 10^{6}$ & $2.209 \times 10^{5}$ & $9.618 \times 10^{6}$ \\
\hline 7 & $1.493 \times 10^{6}$ & $2.108 \times 10^{6}$ & $8.920 \times 10^{6}$ \\
\hline 8 & $1.540 \times 10^{6}$ & $2.242 \times 10^{6}$ & $1.018 \times 10^{\prime}$ \\
\hline 9 & $1.605 \times 10^{6}$ & $2.515 \times 10^{6}$ & $1.156 \times 10^{7}$ \\
\hline 10 & $1.420 \times 10^{6}$ & $1.919 \times 10^{5}$ & $8.920 \times 10^{6}$ \\
\hline 11 & $9.379 \times 10^{5}$ & $1.919 \times 10^{5}$ & $8.920 \times 10^{6}$ \\
\hline 12 (unit inv) & $6.388 \times 10^{5}$ & $6.968 \times 10^{5}$ & $6.968 \times 10^{2}$ \\
\hline 14 (unit inv) & $6.353 \times 10^{5}$ & $6.935 \times 10^{5}$ & $6.935 \times 10^{2}$ \\
\hline
\end{tabular}


Table 4.2. Predicted Peak U-238 Aqueous Concentrations and Arrival Time Summary

\begin{tabular}{|c|c|c|c|c|c|c|c|c|}
\hline $\begin{array}{l}\text { U-238 } \\
\text { Conc. }\end{array}$ & \multicolumn{2}{|c|}{ Cross Section } & \multicolumn{2}{|c|}{$\begin{array}{l}\text { Average Fence } \\
\text { Line }\end{array}$} & \multicolumn{2}{|c|}{$\begin{array}{l}\text { Exclusion } \\
\text { Boundary }\end{array}$} & \multicolumn{2}{|c|}{ Columbia River } \\
\hline$(\mathrm{pCi} / \mathrm{L})$ & Time & Conc. & Time & Conc. & Time & Conc. & Time & Conc. \\
\hline Case 1 & 2149 & $8.50 \mathrm{E}-01$ & 2147 & $1.04 \mathrm{E}-01$ & 2395 & $3.49 \mathrm{E}-02$ & - & - \\
\hline Case 2 & 2999 & $9.96 \mathrm{E}-02$ & 2999 & $1.21 \mathrm{E}-02$ & 2999 & $3.80 \mathrm{E}-03$ & - & - \\
\hline Case 3 & 2008 & $2.31 \mathrm{E}+04$ & 2008 & $2.82 \mathrm{E}+03$ & 2237 & $1.87 \mathrm{E}+02$ & - & - \\
\hline Case 4 & 2075 & $2.99 \mathrm{E}+00$ & 2075 & $3.65 \mathrm{E}-01$ & 2333 & $1.10 \mathrm{E}-01$ & - & - \\
\hline Case 5 & 2284 & 4.22E-01 & 2283 & $5.14 \mathrm{E}-02$ & 2521 & $1.74 \mathrm{E}-02$ & - & - \\
\hline Case 6 & 2999 & $6.06 \mathrm{E}-02$ & 2999 & 7.39E-03 & 2999 & 2.23E-03 & - & - \\
\hline Case 7 & 2999 & $1.08 \mathrm{E}-01$ & 2999 & $1.32 \mathrm{E}-02$ & 2999 & 4.09E-03 & - & - \\
\hline Case 8 & 2999 & $2.48 \mathrm{E}-02$ & 2999 & $3.02 \mathrm{E}-03$ & 2999 & $7.80 \mathrm{E}-04$ & - & - \\
\hline Case 9 & 2999 & $3.72 \mathrm{E}-04$ & 2999 & $4.53 \mathrm{E}-05$ & 2999 & $5.98 \mathrm{E}-06$ & - & - \\
\hline Case 10 & 2063 & $5.44 \mathrm{E}+02$ & 2063 & $6.63 \mathrm{E}+01$ & 2139 & $7.43 \mathrm{E}+00$ & 2552 & $2.91 \mathrm{E}+00$ \\
\hline Case 11 & 2999 & 4.43E-02 & 2999 & $5.39 \mathrm{E}-03$ & 2999 & $2.40 \mathrm{E}-03$ & - & - \\
\hline \multicolumn{9}{|c|}{ Unit Inventory } \\
\hline Case 12 & - & - & - & - & - & - & - & - \\
\hline Case 13 & - & - & - & - & - & - & - & - \\
\hline Case 14 & - & - & - & - & - & - & - & - \\
\hline \multicolumn{9}{|c|}{ B-38 Trench } \\
\hline Case 12 & - & - & - & - & - & - & - & - \\
\hline Case 13 & - & - & - & - & - & - & - & - \\
\hline Case 14 & - & - & - & - & - & - & - & - \\
\hline \multicolumn{9}{|c|}{ All Trenches } \\
\hline Case 12 & N/A & N/A & - & - & - & - & - & - \\
\hline Case 13 & N/A & N/A & - & - & - & - & - & - \\
\hline Case 14 & N/A & N/A & - & - & - & - & - & - \\
\hline
\end{tabular}


Table 4.3. Predicted Peak Tc-99 Aqueous Concentrations and Arrival Time Summary (DWL 900 pCi/L)

\begin{tabular}{|c|c|c|c|c|c|c|c|c|}
\hline Tc-99 & \multicolumn{2}{|c|}{ Cross Section } & \multicolumn{2}{|c|}{ Average Fence Line } & \multicolumn{2}{|c|}{ Exclusion Boundary } & \multicolumn{2}{|c|}{ Columbia River } \\
\hline$(\mathrm{pCi} / \mathrm{L})$ & Time & Conc. & Time & Conc. & Time & Conc. & Time & Conc. \\
\hline Case 1 & 2048 & $6.65 \mathrm{E}+03$ & 2048 & $8.05 \mathrm{E}+02$ & 2087 & $5.31 \mathrm{E}+01$ & 2300 & $2.27 \mathrm{E}+01$ \\
\hline Case 2 & 2015 & $6.58 \mathrm{E}+03$ & 2015 & $7.97 \mathrm{E}+02$ & 2056 & $4.67 \mathrm{E}+01$ & 2283 & $1.49 \mathrm{E}+01$ \\
\hline Case 3 & 2002 & $1.40 \mathrm{E}+05$ & 2002 & $1.69 \mathrm{E}+04$ & 2042 & $3.02 \mathrm{E}+02$ & 2262 & $4.68 \mathrm{E}+01$ \\
\hline Case 4 & 2007 & $1.67 \mathrm{E}+04$ & 2007 & $2.02 \mathrm{E}+03$ & 2049 & $7.84 \mathrm{E}+01$ & 2283 & $2.62 \mathrm{E}+01$ \\
\hline Case 5 & 2017 & $5.79 \mathrm{E}+03$ & 2017 & $7.02 \mathrm{E}+02$ & 2091 & $4.46 \mathrm{E}+01$ & 2303 & $1.95 \mathrm{E}+01$ \\
\hline Case 6 & 2017 & $5.78 \mathrm{E}+03$ & 2017 & $7.00 \mathrm{E}+02$ & 2058 & $4.21 \mathrm{E}+01$ & 2283 & $1.34 \mathrm{E}+01$ \\
\hline Case 7 & 2028 & $3.59 \mathrm{E}+03^{(\mathrm{a})}$ & 2028 & $4.35 \mathrm{E}+02^{(\mathrm{a})}$ & 2069 & $2.80 \mathrm{E}+01$ & 2300 & $1.15 \mathrm{E}+01$ \\
\hline Case 8 & 2043 & $2.27 \mathrm{E}+03^{(\mathrm{a})}$ & 2043 & $2.75 \mathrm{E}+02^{(\mathrm{a})}$ & 2084 & $1.82 \mathrm{E}+01$ & 2310 & $8.01 \mathrm{E}+00$ \\
\hline Case 9 & 2109 & $8.33 \mathrm{E}+02^{(\mathrm{a})}$ & 2109 & $1.01 \mathrm{E}+02^{(\mathrm{a})}$ & 2149 & $6.78 \mathrm{E}+00$ & 2370 & $3.39 \mathrm{E}+00$ \\
\hline Case 10 & 2048 & $6.65 \mathrm{E}+03$ & 2048 & $8.05 \mathrm{E}+02$ & 2087 & $5.31 \mathrm{E}+01$ & 2300 & $2.27 \mathrm{E}+01$ \\
\hline Case 11 & 2048 & $6.65 \mathrm{E}+03$ & 2048 & $8.05 \mathrm{E}+02$ & 2087 & $5.31 \mathrm{E}+01$ & 2300 & $2.27 \mathrm{E}+01$ \\
\hline \multicolumn{9}{|c|}{ Unit Inventory } \\
\hline Case 12 & 2036 & $1.31 \mathrm{E}+03$ & 2036 & $2.02 \mathrm{E}+01$ & 2077 & $1.46 \mathrm{E}+00$ & 2301 & $6.74 \mathrm{E}-01$ \\
\hline Case 13 & 2025 & $4.39 \mathrm{E}+03$ & 2025 & $6.75 \mathrm{E}+01$ & 2065 & $4.75 \mathrm{E}+00$ & 2288 & $1.98 \mathrm{E}+00$ \\
\hline Case 14 & 2052 & $8.11 \mathrm{E}+03$ & 2052 & $1.25 \mathrm{E}+02$ & 2090 & $8.90 \mathrm{E}+00$ & 2307 & $3.76 \mathrm{E}+00$ \\
\hline \multicolumn{9}{|c|}{ B-38 Trench } \\
\hline Case 12 & 2036 & $2.41 \mathrm{E}+01$ & 2036 & $3.71 \mathrm{E}-01$ & 2077 & $2.69 \mathrm{E}-02$ & 2301 & $1.24 \mathrm{E}-02$ \\
\hline Case 13 & 2025 & $8.08 \mathrm{E}+01$ & 2025 & $1.24 \mathrm{E}+00$ & 2065 & 8.74E-02 & 2288 & $3.64 \mathrm{E}-02$ \\
\hline Case 14 & 2052 & $1.49 \mathrm{E}+02$ & 2052 & $2.30 \mathrm{E}+00$ & 2090 & $1.64 \mathrm{E}-01$ & 2307 & $6.92 \mathrm{E}-02$ \\
\hline \multicolumn{9}{|c|}{ All Trenches } \\
\hline Case 12 & N/A & N/A & 2036 & $1.69 \mathrm{E}+02$ & 2077 & $1.21 \mathrm{E}+01$ & 2301 & $5.60 \mathrm{E}+00$ \\
\hline Case 13 & N/A & N/A & 2025 & $5.61 \mathrm{E}+02$ & 2065 & $3.95 \mathrm{E}+01$ & 2288 & $1.65 \mathrm{E}+01$ \\
\hline Case 14 & N/A & N/A & 2052 & $1.04 \mathrm{E}+03$ & 2090 & $7.40 \mathrm{E}+01$ & 2307 & $3.12 \mathrm{E}+01$ \\
\hline
\end{tabular}


Table 4.4. Predicted Peak $\mathrm{NO}_{3}$ Aqueous Concentrations and Arrival Time Summary (DWL 45,000 $\mu \mathrm{g} / \mathrm{L}$ )

\begin{tabular}{|c|c|c|c|c|c|c|c|c|}
\hline $\begin{array}{c}\mathrm{NO}_{3} \\
\text { Conc }\end{array}$ & \multicolumn{2}{|c|}{ Cross Section } & \multicolumn{2}{|c|}{ Average Fence Line } & \multicolumn{2}{|c|}{ Exclusion Boundary } & \multicolumn{2}{|c|}{ Columbia River } \\
\hline$(\mu \mathrm{g} / \mathrm{L})$ & Time & Conc. & Time & Conc. & Time & Conc. & Time & Conc. \\
\hline Case 1 & 2012 & $3.69 \mathrm{E}+04$ & 2012 & $4.51 \mathrm{E}+03$ & 2053 & $2.54 \mathrm{E}+02$ & 2279 & $7.14 \mathrm{E}+01$ \\
\hline Case 2 & 2012 & $3.69 \mathrm{E}+04$ & 2012 & $4.50 \mathrm{E}+03$ & 2053 & $2.53 \mathrm{E}+02$ & 2276 & $6.63 \mathrm{E}+01$ \\
\hline Case 3 & 2002 & $5.06 \mathrm{E}+05$ & 2002 & $6.17 \mathrm{E}+04$ & 2042 & $8.92 \mathrm{E}+02$ & 2262 & $1.39 \mathrm{E}+02$ \\
\hline Case 4 & 2006 & $1.05 \mathrm{E}+05$ & 2006 & $1.28 \mathrm{E}+04$ & 2047 & $3.88 \mathrm{E}+02$ & 2272 & $8.42 \mathrm{E}+01$ \\
\hline Case 5 & 2000 & $3.46 \mathrm{E}+04$ & 2000 & $4.22 \mathrm{E}+03$ & 2055 & $2.32 \mathrm{E}+02$ & 2280 & $6.76 \mathrm{E}+01$ \\
\hline Case 6 & 2000 & $2.46 \mathrm{E}+04$ & 2000 & $4.22 \mathrm{E}+03$ & 2055 & $2.31 \mathrm{E}+02$ & 2277 & $6.32 \mathrm{E}+01$ \\
\hline Case 7 & 2023 & $2.01 \mathrm{E}+04^{(\mathrm{a})}$ & 2023 & $2.45 \mathrm{E}+03^{(\mathrm{a})}$ & 2064 & $1.56 \mathrm{E}+02$ & 2288 & $5.44 \mathrm{E}+01$ \\
\hline Case 8 & 2036 & $1.26 \mathrm{E}+04^{(\mathrm{a})}$ & 2036 & $1.54 \mathrm{E}+03^{(\mathrm{a})}$ & 2077 & $1.01 \mathrm{E}+02$ & 2301 & $4.23 \mathrm{E}+01$ \\
\hline Case 9 & 2091 & $4.65 \mathrm{E}+03^{(\mathrm{a})}$ & 2091 & $5.68 \mathrm{E}+02^{(\mathrm{a})}$ & 2131 & $3.81 \mathrm{E}+01$ & 2353 & $1.91 \mathrm{E}+01$ \\
\hline Case 10 & 2012 & $3.69 \mathrm{E}+04$ & 2012 & $4.51 \mathrm{E}+03$ & 2053 & $2.54 \mathrm{E}+02$ & 2279 & $7.14 \mathrm{E}+01$ \\
\hline Case 11 & 2012 & $3.69 \mathrm{E}+04$ & 2012 & $4.51 \mathrm{E}+03$ & 2053 & $2.54 \mathrm{E}+02$ & 2279 & $7.14 \mathrm{E}+01$ \\
\hline \multicolumn{9}{|c|}{ Unit Inventory } \\
\hline Case 12 & 2036 & $1.31 \mathrm{E}+00$ & 2036 & $2.02 \mathrm{E}-02$ & 2077 & $1.46 \mathrm{E}-03$ & 2301 & $6.74 \mathrm{E}-04$ \\
\hline Case 13 & 2025 & $4.39 \mathrm{E}+00$ & 2025 & $6.76 \mathrm{E}-02$ & 2065 & $4.75 \mathrm{E}-03$ & 2288 & $1.98 \mathrm{E}-03$ \\
\hline Case 14 & 2052 & $8.11 \mathrm{E}+00$ & 2052 & $1.25 \mathrm{E}-01$ & 2090 & $8.90 \mathrm{E}-03$ & 2307 & $3.76 \mathrm{E}-03$ \\
\hline \multicolumn{9}{|c|}{ B-38 Trench } \\
\hline Case 12 & 2036 & $1.73 \mathrm{E}+05$ & 2036 & $2.67 \mathrm{E}+03$ & 2077 & $1.93 \mathrm{E}+02$ & 2301 & $8.90 \mathrm{E}+01$ \\
\hline Case 13 & 2025 & $5.79 \mathrm{E}+05$ & 2025 & $8.93 \mathrm{E}+03$ & 2065 & $6.27 \mathrm{E}+02$ & 2288 & $2.61 \mathrm{E}+02$ \\
\hline Case 14 & 2052 & $1.07 \mathrm{E}+06$ & 2052 & $1.65 \mathrm{E}+04$ & 2090 & $1.17 \mathrm{E}+03$ & 2307 & $4.96 \mathrm{E}+02$ \\
\hline \multicolumn{9}{|c|}{ All Trenches } \\
\hline Case 12 & N/A & N/A & 2036 & $3.90 \mathrm{E}+04$ & 2077 & $2.82 \mathrm{E}+03$ & 2301 & $1.30 \mathrm{E}+03$ \\
\hline Case 13 & N/A & N/A & 2025 & $1.30 \mathrm{E}+05$ & 2065 & $9.17 \mathrm{E}+03$ & 2288 & $3.82 \mathrm{E}+03$ \\
\hline Case 14 & N/A & N/A & 2052 & $2.41 \mathrm{E}+05$ & 2090 & $1.72 \mathrm{E}+04$ & 2307 & $7.26 \mathrm{E}+03$ \\
\hline
\end{tabular}

\subsection{Base Case (No Interim Barrier)}

The Base Case (Case 1) simulation investigated solute transport through the B-BX-BY WMA considering natural surface infiltration, with no water-line leaks and no interim surface barriers but with a closure barrier at year 2040. The closure barrier degrades after 500 years (see Table 2.1 for recharge rates used in these simulations). This simulation was initialized using a steady flow solution defined by the upper surface recharge rate of $100 \mathrm{~mm} / \mathrm{yr}$ and a specified flux in the unconfined aquifer. Ambient flow in the saturated zone was from west to east. For U-238, the value of the partition coefficient $\left(\mathrm{K}_{\mathrm{d}}\right)$ was $0.6 \mathrm{~mL} / \mathrm{g}$, and this was used to determine the partitioning between the solid (sorbed) and aqueous phases for U-238. Reported total concentrations include the total amount of uranium in both the sorbed and 
aqueous phases. The aqueous concentrations, however, do not include U-238 mass sorbed to the subsurface materials. Inventories of the three contaminant species were initialized using a laterally uniform distribution pattern. Plot-file output for this simulation was generated at the years 2000, 2010, $2040,2100,2200,2300,2400,2540,2600,2800$, and 3000 and includes values for the saturation (i.e., $\theta / \theta_{\mathrm{S}}$, where $\theta$ is the moisture content and $\theta_{\mathrm{S}}$ is the saturated moisture content), aqueous pressure, moisture content, and concentration for the three solute species. The moisture field for these simulations remains unchanged from the initial steady flow field until the year 2040, when the closure barrier becomes effective.

The saturation field is dependent on the surface recharge, hydrologic parameters, soil distribution, and impermeable structures (e.g., SSTs). The steady flow saturation field for the BX-108 to BX-102 cross section with $100 \mathrm{~mm} / \mathrm{yr}$ of meteoric recharge is shown in Appendix A, Figure A.1. In Figure A.1(a), the initial saturation field shows the impacts of the tanks on the moisture content distribution in the subsurface. For example, higher than ambient saturations occur above and between the tanks and lower than ambient saturations occur just below the tanks. In 2040 a closure barrier was assumed to be active, which lowered the meteoric recharge from $100 \mathrm{~mm} / \mathrm{yr}$ to $0.1 \mathrm{~mm} / \mathrm{yr}$. In 2540, assuming some degradation in the closure barrier, the meteoric recharge was increased to $3.5 \mathrm{~mm} / \mathrm{yr}$. The final saturation field at 3000 years is shown in Figure A.1(b). Due to the reduction in surface recharge, the saturation field dried and the impact of the impermeable tanks on the saturation was reduced. The regions directly beneath the tanks showed lower variability in saturation. The variations in surface recharge had the greatest impact on saturations in the region between tanks within the backfill material and the soils immediately below the bottom level of the tanks. The Hanford-Ringold/Plio-Pleistocene soil showed the least amount of change in saturation with the variation in surface recharge, and the water table level showed little variation with the rate of surface recharge.

Color-scaled images of the initial and final solute concentrations for the three mobile species (U-238, Tc-99 and $\mathrm{NO}_{3}$ ) are shown in Figures A.2 through A.5. Both total and aqueous concentrations are reported for U-238 (Figures A.2 and A.3, respectively). The total concentration is the sum of both the aqueous and sorbed phase concentrations per unit volume of soil and water. For Tc-99 (Figure A.4) and $\mathrm{NO}_{3}$ (Figure A.5), however, only aqueous concentrations are reported because they do not sorb to subsurface materials.

A comparison of the inventory profiles for both aqueous and total U-238 concentrations shows that the downward migration of U-238 in the subsurface is limited by sorption to the solid phase. Peak concentrations differ by approximately $15 \%$ between the initial and final profiles and are still confined to the vadose zone. By contrast, the Tc-99 and $\mathrm{NO}_{3}$ inventory profiles show significant downward movement. In both contaminant profiles, the initial vertical distributions show multiple peaks, whereas their final distributions show only a single peak concentration. A comparison of peak concentrations and mass balances between initial and final time steps show a reduction of approximately $97 \%$ from their initial values for both Tc-99 and $\mathrm{NO}_{3}$.

Solute mass flux and aqueous concentration breakthrough curves for the BX WMA simulations are shown in Appendix $\mathrm{C}$ for the three solute species (U-238, Tc-99, and $\mathrm{NO}_{3}$ ). Peak arrival times and peak aqueous concentrations are summarized in Tables 4.1 to 4.4 for the WMA boundary from the STOMP results. Tables 4.2 to 4.4 also summarize the peak arrival times and peak aqueous concentrations for the 
two other compliance points (exclusion and river) based on the results of the analytical aquifer streamtube model (see Section 5 for description). The mass flux results and aqueous concentration breakthrough curve results are discussed below for each species.

For the Base Case, only a small portion $(\approx 0.2 \%)$ of the U-238 inventory has migrated from the vadose zone by the end of the simulation at year 3000. As shown in Figure C.1(a), the cumulative U-238 inventory that has left the WMA boundary is $6.5 \times 10^{9} \mathrm{pCi}$, compared to an initial inventory of $3.15 \mathrm{x}$ $10^{12} \mathrm{pCi}$ (as shown in Table 3.8). Aqueous U-238 concentrations are also very low ( $\left.<1 \mathrm{pCi} / \mathrm{L}\right)$. The initial arrival of low concentrations of U-238 at the WMA boundary does not occur until 2050, with the peak predicted concentration occurring about 50 years later. The predicted U-238 concentrations remain relatively close to the peak concentration for the rest of the simulation with a slight decreasing trend.

Tc-99 mass flux and aqueous concentration breakthrough curves are shown in Figure C.2 for the Base Case. Arrival of the Tc-99 at the WMA boundary occurs shortly after the simulation start due to the location of the initial concentration profile in the vadose zone and simulated nonsorbing behavior of the solute. Almost all of the Tc-99 inventory has migrated from the vadose zone at year 2200, with only residual amounts remaining afterwards. The peak mass flux and concentrations also occurs shortly after the beginning of the simulation. These breakthrough curves have a distinct trimodal shape of approximately the same magnitude, which is caused by low concentration gap in the initial Tc-99 vadose zone distribution [see Figure A.4(a)]. Note that the initial spike in the breakthrough curve occurs at year 2000 and is not easily discerned in Figure C.2.

$\mathrm{NO}_{3}$ mass flux and aqueous concentration breakthrough curves are shown in Figure C.3 for the Base Case. Similar to the predicted Tc-99, the predicted $\mathrm{NO}_{3}$ also arrives quickly at the WMA boundary from the start of the simulation and most of the mass has migrated from the vadose zone by $2200 . \mathrm{The}^{\mathrm{N} O}$ breakthrough curves are also trimodal, but the last peak is only about 1/3 the size of the initial peak value. This is also caused by the initial vertical distribution of $\mathrm{NO}_{3}$ in the vadose zone [see Figure A.5 (a)]. Similar to Figure C.2, the initial spike in the breakthrough curve occurs at year 2000 and is not easily discerned in Figure C.3.

Based on the initial depth distributions of Tc-99 and $\mathrm{NO}_{3}$ from the MDP and the interpolation process used to discretize these profiles, both solutes were present below the water table at the start of the transient run. This resulted in an early breakthrough of these solutes at year 2000 due to the high velocities present in the aquifer. Although present in all of the BX tank farm simulations, this initial spike in the solute breakthrough curves is not easily discerned in the plots in Appendix C.

\subsection{Interim Barrier Alternative and No Water-Line Leaks}

The Barrier Alternative and No Water-Line Leaks (Case 2) simula tion investigated solute transport through the BX tank farms considering natural surface infiltration, with no water-line leaks and closure barrier at year 2040. This simulation differs from the Base Case simulation in that an interim surface barrier was implemented between the years 2010 and 2040. This simulation was initialized using a steady flow solution defined by the upper surface recharge rate of $100 \mathrm{~mm} / \mathrm{yr}$ and a specified flux in the unconfined aquifer. Inventories of the three contaminants were initialized using the laterally uniform distribution pattern as in the Base Case scenario. Plot-file output for this simulation was generated for the 
same output times as the Base Case and includes the same ouput variables. The initial moisture field for these simulations remained unchanged from the initial steady flow until the year 2010, when the interim barrier becomes effective.

The steady flow saturation field for the BX-108 to BX-102 cross section with $100 \mathrm{~mm} / \mathrm{yr}$ of meteoric recharge and interim barrier is shown in Appendix A, Figure A.1. In Figure A.6, the final saturation field shows that the impact of the interim closure barrier has a moisture distribution similar to the Base Case.

For all three contaminants shown in Figures A.7 to A.8, the aqueous concentrations are higher than in the Base Case. For example, the peak aqueous concentration for U-238 is increased by $11 \%$ relative to the Base Case, whereas a greater than two-fold increase in peak concentration occurs for $\mathrm{NO}_{3}$ and a fivefold increase for Tc-99. Changes in the vertical migration are similar for all of the solutes. At 3000

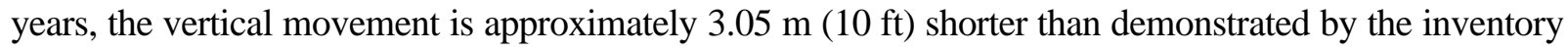
profiles of the Base Case scenario.

Predicted solute mass flux and aqueous concentration breakthrough curves are shown for Case 2 in Appendix C, Figures C.5 through C.8 for U-238, Tc-99, and $\mathrm{NO}_{3}$, respectively. While the initial arrival of all of the solutes in Case 2 are similar to the Base Case until about 2050, the reduced recharge from the interim barrier has a significant impact on the solute mass flux and aqueous concentrations after this time. The cumulative mass of U-238 that has left the vadose zone is approximately one order of magnitude less than the Base Case by the end of the simulation (although the amount is very low in both cases). The U-238 concentrations, while low in this case, show a continuous increase throughout the entire simulation period with the peak concentration occurring at the end.

The peak arrival times and concentrations for Tc-99 and $\mathrm{NO}_{3}$ are earlier and lower in this interim barrier case relative to the Base Case. This is due to the initial inventory distribution, which shows high concentrations of both Tc-99 and $\mathrm{NO}_{3}$ near the water table. The barrier has little effect on the initial breakthrough because the contaminants have already migrated to the water table before the lower infiltration rates have become effective at that depth. For the inventory present in the upper part of the vadose zone, the interim barrier has a significant impact on contaminant transport. While both the Tc-99 and $\mathrm{NO}_{3}$ breakthrough curves were distinctly trimodal in the Base Case, the reduced recharge caused by the interim barrier has eliminated the third, slightly higher peak.

Table 4.3 may be deceptive in assessing the impact of the interim barrier on Tc-99 concentrations given the earlier arrival time and similar concentration to the Base Case. Both simulations yield very similar results up to 2025 . After that, the Base Case then has an additional, slightly higher Tc-99 peak at 2048. The reduced recharge of the interim barrier case eliminated this last peak.

\subsection{No Interim Barrier and Water-Line Leak (1 gpm for 20 years)}

The No Barrier and Water-Line Leak (Case 3) simulation investigated solute transport through the BX tank farm cross section considering natural surface infiltration and a closure barrier at year 2040 . This simulation differs from the Base Case in that a water-line leak occurs east of Tank BX-102 at the level of the top surface of the tank. The water-line leak was modeled as a point source of water (1 gal per minute over 20-years) spread over a 9.14-m (30-ft) diameter. This simulation was initialized using a 
steady flow solution defined by the upper surface recharge rate of $100 \mathrm{~mm} / \mathrm{yr}$ and a specified flux in the unconfined aquifer. Inventories of the three contaminant species were initialized using the laterally uniform distribution pattern. Plot-file output for these simulations was generated at years 2000, 2010, 2020, 2030, 2040, 2100, 2200, 2300, 2400, 2540, 2600, 2800, and 3000 and includes values for saturation, aqueous pressure, moisture content, and concentration for the three solute species.

Preliminary simulations showed that the waterline leak caused a rapid migration of the contaminants.

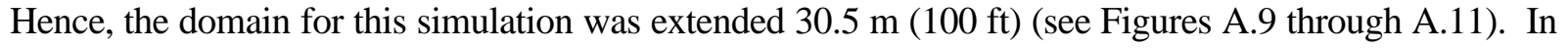
this way, the contaminants were able to migrate laterally without coming into contact with the boundary, which avoided an artificial vertical acceleration of the contaminants.

The flow environment following the leak event is shown in Figure A.9(a) at year 2020, and the final saturation distribution is shown in Figure A.9(b), year 3000. After 20 years, Figure A.9(a) demonstrates a significantly higher saturation distribution relative to the Base Case. The region east of Tank BX-102 and the area beneath it are nearly fully saturated. An increase in saturation is also noted between the tanks, which demonstrate larger areas of higher saturations relative to the Base Case. This indicates that flow from the water-line leak has also migrated to the drier areas beneath the tanks. After 1000 years, Figure A.9 (b) shows that despite the fact that the leak-water has descended into the domain, the final saturation distribution is nearly equal to the Base Case shown in Figure A.1(b).

Significant differences in the inventory profiles relative to the Base Case are noted in the color-scaled images of the final solute concentrations for U-238 (both aqueous and total), Tc-99, and $\mathrm{NO}_{3}$ (Figures A.10-A.11). The most notable effect of the water line leak is in the location of all three contaminant

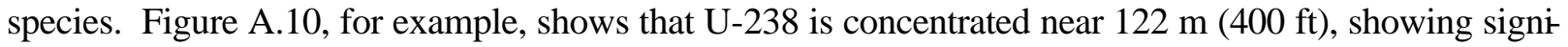
ficantly more lateral movement relative to the Base Case. Both Tc-99 and $\mathrm{NO}_{3}$ (Figure A.11) also show similar migration patterns and have migrated even farther than the U-238. Both Tc-99 and $\mathrm{NO}_{3}$ are concentrated near the exit boundary, but both show a region of lower concentration beneath Tanks $\mathrm{BX}-105$ and BX-102. The transport of the mobile species in the upper region of the vadose zone is delayed because of the shift in the hydraulic gradient, which pushes the plumes upgradient of the exit boundary. For the mobile species located in the lower region of the vadose zone, their transport is accelerated relative to the Base Case due to increased saturations. Because U-238 sorbs to subsurface materials, it is less affected by the shift in hydraulic gradient.

Predicted solute mass flux and aqueous concentration breakthrough curves are shown for Case 3 in Figures C.9-C.12 for U-238, Tc-99, and $\mathrm{NO}_{3}$. The large volume of water discharged in this simulation resulted in this case having the highest solute mass flux and concentrations than any of the other cases. The peak concentrations were also much earlier, even for U-238. Peak concentrations for U-238 were four orders of magnitude greater than the Base Case and occurred early in the simulation. Additionally, more than $85 \%$ of the U-238 inventory had migrated from the vadose zone at year 2030. For Tc-99, the peak concentrations were more than 20 times greater than the Base Case and occurred within the first few years of the simulation. Similarly for $\mathrm{NO}_{3}$, peak concentrations occurred within a few years of the start of the simulation and were nearly 14 times greater than the Base Case. 


\subsection{No Interim Barrier and Water-Line Leak (200,000 gal over five days)}

The No Barrier and Water-Line Leak (Case 4) simulation investigated solute transport through the BX tank farm cross section considering natural surface infiltration and a closure barrier at year 2040. Although Case 4 has a larger leak rate than Case 3, Water-Line Leak, the quantity of water entering the domain is higher in Case 3 (1.05 x 10 $0^{7}$ gal over 20 years) than in Case 4 ( $2 \times 10^{5}$ gal over five days). Similar to Case 3, the leak occurs east of Tank BX-102 at the level of the top surface of the tank and extends over a 9.14-m (30-ft) diameter. The water-line leak was modeled as a point source of water (1 gal

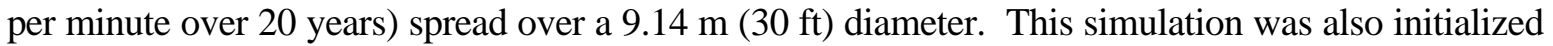
using a steady flow solution defined by the upper surface recharge rate of $100 \mathrm{~mm} / \mathrm{yr}$ and a specified flux in the unconfined aquifer. Inventories of the three contaminant species were initialized using the laterally uniform distribution pattern. Plot-file output for these simulations was generated at 2000, 2000.01389, $2010,2020,2030,2040,2100,2200,2300,2400,2540,2600,2800$, and 3000 and includes values for the saturation, aqueous pressure, moisture content, and concentration for the three solute species.

The flow environment following the leak event is shown in Figure A.12 (a) at year 2000 plus five days, and the final saturation distribution is shown in Figure A.12 (b), year 3000. After five days of simulation, the region east of Tank BX-102 is fully saturated, as well as the region above the leak and to the west. This saturation distribution demonstrates that the release of a large volume of water in a short time period has caused ponding to occur, which corresponded to very high values of pressure. Although ponding may occur with a large waterline leak, the lack of drainage permitted by the selected soil properties in this simulation may have caused an unrealistic migration of the excess leak water. Because water ponded up against the upper boundary of the domain, it migrated in a westward direction above the tank domains. Contrary to the 1-gpm leak case over a 20-year time period (Case 3), a shift in hydraulic gradient did not occur in the region beneath the tanks.

After 1000 years of simulation, Figure A.9(b) also shows that in the region beneath Tank BX-102 and to the east the saturations are nearly identical to the final saturation distribution for the Base Case. Although a large volume of water was input into the system, it occurred over a relatively short time period, and, with time, drained from the system.

The shapes of the final concentration distributions for each of the contaminants shown in Figures A.13-A.14 are similar to those demonstrated by the Base Case [Figures A.2(b), A.3(b) A.4(b), and A.5(b)]. However, increase in saturations has caused a slightly accelerated transport out of the domain. For example, in the year 3000, peak $\mathrm{NO}_{3}$ concentrations decrease by nearly 50\%, whereas the peak Tc-99 concentrations decrease by $60 \%$. The leak water effect on U-238 is less notable because of its sorption to the aquifer materials.

Predicted solute mass flux and aqueous concentration breakthrough curves are shown for Case 4 in Figures C.13-C.16 for U-238, Tc-99, and $\mathrm{NO}_{3}$. As mentioned previously, the predicted pressures for this simulation were very large due to the high water flux rate specified resulting in a complete saturation of the upper zone and a wide lateral zone of spreading. Additional work is needed to verify whether this result is reasonable, given the soil properties, or if more permeable soil properties are required for the backfill layer used for the leak. While the peak concentrations of all the solutes are greater than the Base Case, they are significantly smaller than the values predicted for the other water-leak case (Case 3). 
For U-238 in Case 4, the peak concentrations are 3.5 times the Base Case, but the percentage of U-238 inventory that has migrated from the vadose zone is still very low (less than $0.5 \%$ of the initial specified value). The Tc-99 and $\mathrm{NO}_{3}$ peaks are trimodal, but the second peaks are narrower and about 2.5 times higher than the Base Case. The final Tc-99 and $\mathrm{NO}_{3}$ peaks are about the same as the Base Case.

\subsection{Shifted Inventory Distribution and No Interim Barrier}

The Alternate Inventory Distribution and No Barrier (Case 5) simulation investigated solute transport through BX tank farms considering natural surface infiltration with no water-line leaks and a closure barrier at year 2040. This simulation differs from the Base Case in that the initial concentration distribution was shifted so it was centered between Tanks BX-105 and BX-102. This simulation was initialized using a steady flow solution defined by the upper surface recharge rate of $100 \mathrm{~mm} / \mathrm{yr}$ and a specified flux in the unconfined aquifer. Plot-file output for these simulations was generated at 2000, 2010, 2040, 2100, 2200, 2300, 2400, 2540, 2600, 2800, and 3000 and includes values for the saturation, aqueous pressure, moisture content, and concentration for the three solute species. The moisture field for these simulations remains unchanged from the initial steady flow field until 2040, when the closure barrier becomes effective.

In general, the saturations immediately beneath the tanks are lower than the saturations in the region east of Tank BX-102, whereas the saturations between the tanks are generally higher, as shown in the initial saturation field in Figure A.1(a). However, the depth of the saturation increases is limited, and thus has only a minor effect on the concentration profiles shown in Figures A.15-A.18. For all three contaminants, the shape of the contaminant plumes in the year 3000 differs from those of the Base Case due to the differences in the saturation distributions. Peak concentrations also differ in the two cases due to dilution effects. For U-238 the effect is most pronounced, whereas for $\mathrm{Tc}-99$ and $\mathrm{NO}_{3}$ the impact is not as great because they are distributed at a greater depth in the subsurface.

Predicted solute mass flux and aqueous concentration breakthrough curves are shown for Case 5 in Figures C.17-C.20 for U-238, Tc-99, and $\mathrm{NO}_{3}$. For Case 5, the U-238 peak concentration was approxi mately half of the Base Case, and the initial arrival time was similar. Peak concentrations for Tc-99 and $\mathrm{NO}_{3}$ were about $10 \%$ lower than the Base Case with similar shapes and arrival times. The Tc -99 and $\mathrm{NO}_{3}$ pulses had slightly longer tailings.

Based solely on distance to the compliance boundaries, it is expected that the arrival times for all three of the contaminants would be longer than those of the Base Case. However, the areas beneath the tank farm in the shifted concentration profile and the Base Case profile differ in their initial saturation distribution. As shown in Figure A.1(a), saturations are higher between Tanks BX-105 and BX-102 than in the area east of Tank BX-102. This causes greater mobility of the contaminants and a similarity in the initial breakthrough times relative to the Base Case. Because of shadowing beneath the tanks, the saturations are lower in these regions, which decreases contaminant mobility. Thus, tailing is longer for the mobile species relative to the Base Case.

\subsection{Shifted Inventory Distribution with Interim Barrier}

The Shifted Inventory Distribution and Barrier (Case 6) simulation investigated solute transport through the BX tank farms considering natural surface infiltration, an interim barrier, no water-line leaks, 
and closure barrier at year 2040. This simulation differs from the Base Case simulation in that an interim surface barrier was implemented between the years 2010 and 2400, and a shifted distribution was used for the initial inventory. Similar to Case 5, the Alternate Inventory Distribution shifted the initial inventory of the Base Case so that it was centered between Tanks BX-105 and BX-102. This simulation was initial ized using a steady flow solution defined by the upper surface recharge rate of $100 \mathrm{~mm} / \mathrm{yr}$ and a specified flux in the unconfined aquifer. Plot-file output for this simulation was generated at years 2000, 2010, 2040, 2100, 2300, 2400, 2540, 2600, 2800, and 3000 and includes values for saturation, aqueous pressure, moisture content, and concentration for the four solute species. The moisture field for these simulations remains unchanged from the initial steady flow field until the year 2010, when the interim barrier becomes effective.

The steady flow saturation field for the BX-108 to BX-102 cross section with $100 \mathrm{~mm} / \mathrm{yr}$ of meteoric recharge and interim barrier is the same as Case 2 (Figure A.6). As discussed, the final saturation field in that figure shows the saturation distribution as nearly equal to the Base Case. For all three contaminants shown in Figures A.19-A.20, the aqueous concentrations are higher than Case 5 (shifted inventory, no interim barrier). For example, peak aqueous concentration for U-238 is increased by $12 \%$ relative to Case 5, whereas a two-fold increase in peak concentration occurs for $\mathrm{NO}_{3}$ and a greater than three-fold increase for Tc-99. These differences occur because the interim barrier has caused a reduction in the water flux through the vadose zone. Contrary to Case 2 results, the depth at which the mobile species are present at year 3000 is similar to the no interim barrier case. For immobile phases, however, there is a

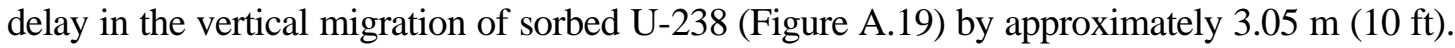

Predicted solute mass flux and aqueous concentration breakthrough curves are shown for Case 6 in Figures C.21 through C.24 for U-238, Tc-99, and $\mathrm{NO}_{3}$. For Case 6, the U-238 peak concentration and mass flux were more than an order of magnitude lower than the Base Case. Tc-99 and $\mathrm{NO}_{3}$ peak concentrations were about $10 \%$ less than the Base Case. The third peaks seen in the Base Case were not present for the mobile solutes and the second pulse had longer tailing. The remaining inventory at the end of the simulation was about $10 \%$ of the initial inventory for Tc-99, and $15 \%$ for $\mathrm{NO}_{3}$.

Similar to Case 2, the interim barrier has little effect on the initial breakthrough because the contaminants have already entered the water table before the reduced recharge rate has impacted their transport. While the initial arrival times and shapes of the breakthrough curves for the solutes for Case 6 were similar to Case 2, the predicted concentrations were lower. This occurs because the higher saturations between Tanks BX-105 and BX-102 dilute the contaminant concentrations more than in the area east of Tank BX-102. Concentrations were about $10 \%$ lower for Tc-99 and $\mathrm{NO}_{3}$ than in Case 2, and approximately $33 \%$ lower for U-238.

\subsection{Base Case with $50 \mathrm{~mm} / \mathrm{yr}$ Meteoric Recharge}

Case 7 is the Base Case with 50-mm/yr meteoric recharge simulation investigated solute transport through the BX cross section considering natural surface infiltration, with no water-line leaks and no interim surface barriers but with a closure barrier at year 2040. This simulation, in conjunction with Cases 1,8 , and 9, forms a sensitivity study on the effect of the initial meteoric recharge rate on the migration of solutes to the B-BX-BY WMA boundary. The simulation in this case was initialized using a steady flow solution defined by the upper surface recharge rate of $50 \mathrm{~mm} / \mathrm{yr}$ and a specified flux in the 
unconfined aquifer. Inventories of the three contaminant species were initialized using the same laterally uniform distribution pattern as in the Base Case. Plot-file output for these simulations was generated at years 2000, 2010, 2040, 2100, 2300, 2400, 2540, 2600, 2800, and 3000 and includes values for the saturation, aqueous pressure, moisture content, and concentration for the three solute species. The moisture field for these simulations remains unchanged from the initial steady flow field until the year 2040, when the closure barrier becomes effective.

The steady flow saturation field for the BX-108 to BX-102 cross section with $50 \mathrm{~mm} / \mathrm{yr}$ of meteoric recharge is shown in Figure A.21(a). This field shows a significant variation from that of the $100-\mathrm{mm} / \mathrm{yr}$ meteoric recharge case [Figure A.1(a)]. The most notable impact is in the region beneath the tanks, in the $\mathrm{H} 1$ gravelly sand, where on average, the saturations are 5 to $10 \%$ lower than in the Base Case. There is also a reduction in saturation in the $\mathrm{H} 2$ sand unit just beneath the tanks, although to a lesser extent. The saturation distribution shown in Figure A.21(b) after 1000 years, however, is similar to the Base Case [Figure A.1(b)].

Changes in the peak initial concentrations (see Table 4.1) result from the lower initial moisture content. Significant changes in the final peak concentrations are demonstrated in Figures A.22 and A.23. The peak Tc-99 and $\mathrm{NO}_{3}$ solute concentrations increased four- and two-fold, respectively, whereas U-238 peak solute concentrations increased by $8 \%$. The corresponding change in the total U-238 peak concentration profile was $13 \%$ because when lower saturations occur in the subsurface, the partitioning into the sorbed phase is greater, which retards even further the vertical migration of the U-238 plume.

Predicted solute mass flux and aqueous concentration breakthrough curves are shown for Case 7 in Figures C.25-C.28 for U-238, Tc-99, and $\mathrm{NO}_{3}$, respectively. Peak concentrations and mass fluxes for U-238 are approximately an order of magnitude lower than the Base Case due to the reduced recharge rate. U-238 arrived initially at a slightly later time. The predicted peak cross section and WMA aquifer concentrations for Tc-99 and $\mathrm{NO}_{3}$ (see Tables 4.3 and 4.4) occur during the first year of the simula tion due to the initial inventory distribution, which contained high concentrations of Tc-99 and $\mathrm{NO}_{3}$ in the vadose zone and near the water table. These values are only about $10 \%$ less than the peak concentrations reported for the Base Case and correspond to the initial spike at year 2000 in the breakthrough curves.

A comparison of the breakthrough curves for this simulation with the Base Case shows that further reducing the recharge rate has a significant effect on the last peak of the curves but little effect on the first peak. For example, in the Base Case the first peak that occurs in year 2000 is lower than the two subsequent peaks. In Case 7, however, the peak concentrations for Tc-99 and $\mathrm{NO}_{3}$ are significantly lower (approximately half the value of the Base Case) after the initial peak value occurs in year 2000. Although the breakthrough curve for the $\mathrm{NO}_{3}$ Base Case was trimodal, the third peak for $\mathrm{NO}_{3}$ is absent in this simulation. Because the effect of the reduced recharge rate is only seen at later times due to the initial contaminant distribution in the vadose zone, only the second peaks of the breakthrough curves are reported in Tables 4.3 and 4.4 so the effect of reduced meteoric recharge can be made. For both Tc-99 and $\mathrm{NO}_{3}$, a greater inventory remained within the domain at the end of the simulation $(<10 \%$ for Tc-99 and $5 \%$ for $\mathrm{NO}_{3}$ ). 


\subsection{Base Case with $30 \mathrm{~mm} / \mathrm{yr}$ Meteoric Recharge}

Case 8, the Base Case with $30 \mathrm{~mm} / \mathrm{yr}$ meteoric recharge simulation, investigated solute transport through the BX cross section in the B-BX-BY WMA considering natural surface infiltration, with no water-line leaks and no interim surface barriers but with a closure barrier at year 2040. These simulations, along with those from Cases 1, 7, and 9, form a sensitivity study on the effect of meteoric recharge on the migration of solutes to the B-BX-BY WMA boundary. The simulations in this case were initialized using a steady flow solution defined by the upper surface recharge rate of $30 \mathrm{~mm} / \mathrm{yr}$ and a specified flux in the unconfined aquifer. Inventories of the three contaminant species were initialized using the laterally uniform distribution pattern from the Base Case scenario. Plot-file output for these simulations was generated at years 2000, 2010, 2040, 2100, 2300, 2400, 2540, 2600, 2800, and 3000 and includes values for saturation, aqueous pressure, moisture content, and concentration of the three solute species. The moisture field for these simulations remains unchanged from the initial steady flow field until the year 2040, when the closure barrier becomes effective.

The steady flow saturation field for the BX-108 to BX-102 cross section with $30 \mathrm{~mm} / \mathrm{yr}$ of meteoric recharge is shown in Figure A.24(a). This field shows a significant variation from that of the 100-mm/yr meteoric recharge case [Figure A.1(a)]. Most notable is the overall reduction in saturation and the increase in shadowing beneath the tanks. Lowering the initial meteoric recharge to $30 \mathrm{~mm} / \mathrm{yr}$ continued the trends established in lowering the recharge from 50 to $100 \mathrm{~mm} / \mathrm{yr}$. For example, peak concentrations shown in the inventory profiles in Figures A.25 and A.26 show that a decrease in saturation increases aqueous concentrations (also see Table 4.1). Similar to the $50 \mathrm{~mm} / \mathrm{yr}$ recharge case, sorbed phase U-238 concentrations increased more than the aqueous concentration and plume movement is retarded with respect to the $100 \mathrm{~mm} / \mathrm{yr}$ and $50 \mathrm{~mm} / \mathrm{yr}$ recharge cases.

Predicted solute mass flux and aqueous concentration breakthrough curves are shown for Case 8 in Figures C.29-C.232 for U-238, Tc-99, and $\mathrm{NO}_{3}$. Peak concentrations and mass fluxes for U-238 are approximately 1.5 orders of magnitude lower than the Base Case due to the reduced recharge rate. The initial arrival of U-238 was slightly later, with the peak concentration occurring at the end of the simulation. The predicted peak cross section and WMA aquifer concentrations for Tc-99 and $\mathrm{NO}_{3}$ (Tables 4.3 and 4.4) occur during the first year of the simulation. This is due to the initial inventory distribution, which contained high concentrations of both Tc-99 and $\mathrm{NO}_{3}$ in the vadose zone near the water table. These values are only about $10 \%$ less than the peak concentrations reported for the Base Case and corresponded to the initial spike at year 2000 in the breakthrough curves.

A comparison of the breakthrough curves for this simulation with the Base Case shows that reducing the recharge rate even further has a significant impact on the last peak of the curves. Similar to the other reduced recharge cases, the peak concentrations for Tc-99 and $\mathrm{NO}_{3}$ are significantly reduced after the initial peak value occurs in year 2000. For example, these later pulses occur later and are of a longer duration. Peak concentrations for Tc-99 and $\mathrm{NO}_{3}$ were about one-third of their initial values and arrived much later than the Base Case. Whereas a 50\% reduction in recharge was sufficient to eliminate the last peak for only $\mathrm{NO}_{3}$ in Case 7 , the $70 \%$ reduction in recharge in this simulation eliminated the final peak for Tc-99 as well. Because the effect of the reduced recharge rate is only seen at later times due to the initial contaminant distribution in the vadose zone, only the second peaks of the breakthrough curves are reported in Tables 4.3 and 4.4 so that the effect of reduced meteoric recharge can be made. For both 
solutes, these later pulses were more spread out in time, and a substantial quantity of Tc-99 and $\mathrm{NO}_{3}$ inventory remained at the end of the simulation ( $18 \%$ for Tc-99 and $15 \%$ for $\mathrm{NO}_{3}$ ).

\subsection{Base Case with $10 \mathrm{~mm} / \mathrm{yr}$ Meteoric Recharge}

The Base Case with 10- $\mathrm{mm} / \mathrm{yr}$ meteoric recharge simulation (Case 9) investigated solute transport through the BX-108 to BX-102 cross section, considering natural surface infiltration with no waterline leaks and no interim surface barriers but with a closure barrier at year 2040. This simulation, in conjunction with those from Cases 1,7 , and 8 , form a sensitivity study on the effect of meteoric recharge on the migration of solutes to the B-BX-BY WMA boundary. The simulations in this case were initialized using a steady flow solution defined by the upper surface recharge rate of $10 \mathrm{~mm} / \mathrm{yr}$ and a specified flux in the unconfined aquifer. Inventories of the three contaminant species were initialized using the same laterally uniform distribution pattern used in the Base Case. Plot-file output for these simulations was generated at years 2000, 2010, 2040, 2100, 2300, 2400, 2540, 2600, 2800, and 3000 and includes values for the saturation, aqueous pressure, moisture content, and concentration for the three solute species. The moisture field for these simulations remains unchanged from the initial steady flow field until the year 2040, when the closure barrier becomes effective.

The steady flow saturation field for the BX cross section with $10 \mathrm{~mm} / \mathrm{yr}$ of meteoric recharge is shown in Figure A.27(a). Compared with the steady flow saturation fields for 100-, 50-, and 30- $\mathrm{mm} / \mathrm{yr}$ [Figures A.1(a), A.21, and A.24], the saturation field at $10 \mathrm{~mm} / \mathrm{yr}$ shows only a small amount of shadowing from the tanks and only slight moisture increases between the tanks. As in the other reduced recharge cases, the saturation distribution at year 3000 [Figure A.27(b)] is similar to the Base Case.

Peak concentrations shown in the inventory profiles in Figures A.28 and A.29 show that a decrease in saturation increases aqueous concentrations. However, contrary to the other reduced recharge cases, the plumes are more elongated and the delay in vertical movement more pronounced even for the mobile contaminants. For sorbed U-238, the vertical migration of the plume is delayed even more than in the other reduced recharge cases.

Predicted solute mass flux and aqueous concentration breakthrough curves are shown for Case 9 in Figures C.33-C.36 for U-238, Tc-99, and $\mathrm{NO}_{3}$, respectively. For this very low initial recharge case, the predicted U-238 mass flux and concentrations were more than three orders of magnitude lower than the Base Case. Initial U-238 arrivals were much later than the Base Case, and the peak concentration occurred at the end of the simulation. This is due to the initial inventory distribution, which contained high concentrations of both Tc-99 and $\mathrm{NO}_{3}$ in the vadose zone near the water table. These values are only about $10 \%$ less than the peak concentrations reported for the Base Case and corresponded to the initial spike at year 2000 in the breakthrough curves.

Similar to the other reduced recharge cases, the peak concentrations for Tc-99 and $\mathrm{NO}_{3}$ are significantly reduced after the initial peak value occurs in year 2000. A comparison of the breakthrough curves for this simulation with the Base Case and the other reduced recharge cases ( 7 and 8 ) shows that arrival times are delayed, and longer tailings result with a further reduction in recharge. Excluding the initial spike of contaminant that occurs because of the high concentration zone near the water table, the peak concentrations of Tc-99 and $\mathrm{NO}_{3}$ were about $10 \%$ of the values for the Base Case. Because the effect of 
the reduced recharge rate is only seen at later times due to the initial contaminant distribution in the vadose zone, only the second peaks of the breakthrough curves are reported in Tables 4.3 and 4.4, so the effect of reduced meteoric recharge can be determined. A substantial quantity of Tc-99 and $\mathrm{NO}_{3}$ inventory also remained in the vadose zone at the end of the simulation $\left(50 \%\right.$ for Tc-99 and $30 \%$ for $\left.\mathrm{NO}_{3}\right)$.

\subsection{Base Case with $K_{d}=0.1 \mathrm{~mL} / \mathrm{g}$ for $\mathrm{U}-238$}

The Base Case with a $\mathrm{K}_{\mathrm{d}}=0.6 \mathrm{~mL} / \mathrm{g}$ for U-238 (Case 10) investigated solute transport through the BX-108 to BX-102 cross section considering natural surface infiltration with no water-line leaks and no interim surface barriers but with a closure barrier at year 2040. This simulation, in conjunction with those from Cases 1 and 11, form a sensitivity study on the effect of the magnitude of the partitioning coefficient on the migration of U-238 to the B-BX-BY WMA boundary. The simulations in this case were initialized using a steady flow solution defined by the upper surface recharge rate of $100 \mathrm{~mm} / \mathrm{yr}$ and a specified flux in the unconfined aquifer. Inventories of the three contaminant species were initialized using the same laterally uniform distribution pattern used in the Base Case. Plot-file output for these simulations was generated at years 2000, 2010, 2040, 2100, 2300, 2400, 2540, 2600, 2800, and 3000 and includes values for the saturation, aqueous pressure, moisture content, and concentration for the three solute species. The moisture field for these simulations remains unchanged from the initial steady flow field until 2040, when the closure barrier becomes effective.

Color-scaled images of the initial and final solute concentrations for U-238 are shown in Figures A.30 (total) and A.31 (aqueous). A comparison of the inventory profiles for both aqueous and total U-238 concentrations shows that, when the $\mathrm{K}_{\mathrm{d}}$ value is reduced from 0.6 to $0.1 \mathrm{~mL} / \mathrm{g}$, the downward migration of U-238 in the subsurface is accelerated. Initial aqueous phase U-238 concentrations are higher than those in the Base Case. With le ss U-238 present in the sorbed phase, the aqueous concentrations of U-238 increase. For example, peak aqueous phase U-238 concentrations differ by approximately $200 \%$ relative to the Base Case. The increased mobility of U-238 with a lower $\mathrm{K}_{\mathrm{d}}$ results in U-238 exiting the modeled domain at a faster rate.

Predicted solute mass flux and aqueous concentration breakthrough curves are shown for Case 10 in Figures C.37 and C.38 for U-238. The lower $\mathrm{K}_{\mathrm{d}}$ value for U-238 in Case 10 results in much more U-238

migrating from the vadose zone to the aquifer. While the initial arrival of U-238 occurs at about the same time as the Base Case, the magnitude of the mass flux and peak concentrations are about 650 times greater in Case 10 due to the increased mobility. The predicted breakthrough curves for U-238 show a single peak with very long tailing up to the end of the simulation. While there is still a substantial amount of U-238 inventory in the vadose zone at the end of the simulation, the simulation predicted that about one-third of the inventory has migrated into the aquifer based on the cumulative mass flux. For both Tc-99 and $\mathrm{NO}_{3}$, the breakthrough curves were identical to the Base Case, which is the expected result.

\subsection{Base Case with $K_{d}=1.0 \mathrm{~mL} / \mathrm{g}$ for $\mathrm{U}-238$}

The Base Case with a $\mathrm{K}_{\mathrm{d}}=0.6 \mathrm{~mL} / \mathrm{g}$ for U-238 (Case 11) investigated solute transport through the BX-108 to BX-102 cross section considering natural surface infiltration, with no water-line leaks and no interim surface barriers but with a closure barrier at year 2040. This simulation, in conjunction with those from Cases 1 and 10, form a sensitivity study on the effect of the magnitude of the partitioning coefficient 
on the migration of U-238 to the B-BX-BY WMA boundary. The simulations in this case were initialized using a steady flow solution defined by the upper surface recharge rate of $100 \mathrm{~mm} / \mathrm{yr}$ and a specified flux in the unconfined aquifer. Inventories of the three contaminant species were initialized using the same laterally uniform distribution pattern used in the Base Case. Plot-file output for these simulations was generated at years 2000, 2010, 2040, 2100, 2300, 2400, 2540, 2600, 2800, and 3000 and includes values for the saturation, aqueous pressure, moisture content, and concentration for the three solute species. The moisture field for these simulations remains unchanged from the initial steady flow field until 2040, when the closure barrier becomes effective.

Color-scaled images of the initial and final solute concentrations for U-238 are shown in Figures A.32 (total) and A.33 (aqueous). A comparison of the inventory profiles for both aqueous and total U-238 concentrations shows that when the $\mathrm{K}_{\mathrm{d}}$ value is increased from 0.6 to $1.0 \mathrm{~mL} / \mathrm{g}$, the downward migration of U-238 in the subsurface is retarded. Initial peak aqueous concentrations are lower than in the Base Case due to partitioning. At year 3000, the concentrations of U-238 are higher than in the Base Case due to the slower rate of migration.

Predicted solute mass flux and aqueous concentration breakthrough curves are shown for Case 11 in Figures C.39 and C.40 for U-238, Tc-99, and $\mathrm{NO}_{3}$. The larger $\mathrm{K}_{\mathrm{d}}$ for U-238 significantly reduces the amount of U-238 migrating from the vadose zone to the aquifer. The initial arrival time of U-238 is about the same as the Base Case ,and the concentration increases throughout the simulation. Peak U-238 concentrations are about one-half the peak concentrations predicted for the Base Case and occur at the end of the simulation. For both Tc-99 and $\mathrm{NO}_{3}$, the breakthrough curves were identical to the Base Case, which is the expected result.

\subsection{B-38 Trench with 55.4 mm/yr Meteoric Recharge}

The B-38 trench simulation investigated solute transport through a cross section west of Tank BX-111, considering natural infiltration at $55.4 \mathrm{~mm} / \mathrm{yr}$, no interim barrier, and a closure barrier by 2010 . A 378,000-gal leak containing a unit inventory distribution for U-238 and Tc-99 occurred over the entire width of the trench in 1954. This simulation, Case 12, forms a sensitivity study on the effect of meteoric recharge on the migration of solutes to the trench fence line. This simulation was initialized using a steady flow solution defined by the upper surface recharge rate of $55.4 \mathrm{~mm} / \mathrm{yr}$ and a specified flux in the unconfined aquifer. Ambient flow in the saturated zone was from west to east in the domain. The value of the partition coefficient $\left(\mathrm{K}_{\mathrm{d}}\right), 0.6 \mathrm{~mL} / \mathrm{g}$, was used to determine the partitioning between the solid (sorbed) and aqueous phases for U-238. Plot-file output for these simulations was generated at years 1954, 1955, 2000, 2010, 2110, 2210, 2310, 2410, 2510, 2700, and 3000 and includes values for saturation, aqueous pressure, moisture content, and concentration for the three solute species.

The saturation field is dependent on the surface recharge, hydrologic parameters, and soil distribution. The steady flow saturation field in 1954 for the trench B-38 cross section with $55.4 \mathrm{~mm} / \mathrm{yr}$ of meteoric recharge is shown in Figure B.1. In Figure B.1(a), the initia 1 saturation field shows the impacts of the trench structure on the moisture content distribution in the subsurface. Lower than ambient saturations occur at the corners of the trench. In 2010 a closure barrier was assumed to be active, which lowered the meteoric recharge from $100 \mathrm{~mm} / \mathrm{yr}$ to $0.1 \mathrm{~mm} / \mathrm{yr}$. In 2510, assuming some degradation in the closure barrier, the meteoric recharge was increased to $3.5 \mathrm{~mm} / \mathrm{yr}$. 
The saturation field in 1955 is shown in Figure B.2(a), one year after the 378,000-gal discharge into

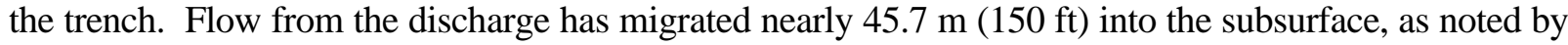
the elevated saturations $(>0.80)$ in the region beneath the trench. This saturation field contrasts sharply with the final saturation field at year 3000, shown in Figure B.2(b). Due to the drainage of the initial discharge and the reduction in surface recharge caused by the closure barrier, the saturation field has dried. The region directly beneath the trench shows lower variability in saturation.

Color-scaled images of the initial and final solute concentrations for the two contaminant species (U-238 and Tc-99) are shown in Figures B.3 through B.7. The total and aqueous concentrations for U-238 (Figures B.3 and B.4, respectively) show that the vertical migration of U-238 is limited significantly by sorption to the subsurface materials as well as to the closure barrier in 2010. In fact, the majority of the U-238 plume is concentrated in the $\mathrm{H} 2$ sand and backfill units, and none of the U-238 has exited the domain. By contrast, the time-series Tc-99 concentration profiles in Figures B.5-B.7 show that Tc-99 does enter the groundwater and migrates from the domain. However, the closure barrier has had a profound effect on Tc-99 migration. As noted in Figure B.5, the Tc-99 plume is largely concentrated in the $\mathrm{H} 1$ gravelly sand unit and has quickly migrated through the $\mathrm{H} 2$ sand unit immediately beneath the trench. With the closure barrier becoming effective in year 2010, Figure B.6 shows that the Tc-99 transport has been considerably delayed, even at year 2210. At year 3000 (Figure B.7), much of the Tc-99 is still present in the vadose zone materials.

Predicted solute mass flux and aqueous concentration breakthrough curves are shown for Case 12 in Figures D.1 through D.3 for Tc-99 and $\mathrm{NO}_{3}$. Because this simulation did not predict any U-238 migration from the vadose zone during the time that was simulated, the mass flux and concentration figures for U-238 were omitted. Scaled results using the inventories for trench B-38 are shown in Figures D.4 through D.6, and scaled results using the inventories for all eight trenches are shown in Figures D.7-D.9.

As noted in Section 3, both Tc-99 and $\mathrm{NO}_{3}$ results were scaled from the unit inventory release of a nonsorbing solute. Therefore, the breakthrough curves and relative results for Tc-99 and $\mathrm{NO}_{3}$ are identical. The Tc-99/NO $\mathrm{NO}_{3}$ mass flux and concentration breakthrough curves have single peaks at year 2050 and long tails that extend the duration of the simulation (year 3000). The simulation predicted about $40 \%$ of the inventory migrated from the vadose zone by the end of the time period.

\subsection{B-38 Trench with $100.0 \mathrm{~mm} / \mathrm{yr}$ Meteoric Recharge}

The second B-38 simulation (Case 13) investigated solute transport through a cross section west of BX-111, considering natural infiltration only at $100 \mathrm{~mm} / \mathrm{yr}$, no interim barrier, and a closure barrier in 2010. Like the previous trench simulation (Case 12), a 378,000-gal leak containing a unit inventory distribution of U-238 and Tc-99 occurred over the entire width of the trench in 1954. Except for the recharge, all other conditions were the same as Case 12. Plot-file output for this simulation was generated at years 1954, 1955, 2000, 2010, 2110, 2210, 2310, 2410, 2510, 2700, and 3000 and includes values for saturation, aqueous pressure, moisture content, and concentrations for the three solute species.

The steady flow saturation field in 1954 for the trench B-38 cross section with $100 \mathrm{~mm} / \mathrm{yr}$ of meteoric recharge is shown in Figure B.8. Relative to Case $12(55.4 \mathrm{~mm} / \mathrm{yr}$ meteoric recharge), the increase in meteoric recharge has increased saturation in all of the geologic units, though there are no significant 
differences in the water table elevation. Saturations are significantly higher so the impact of the trench structure on the moisture content is not noted in the saturation distribution. Similar to Case 12, the 378,000-gal release in 1954 had a significant impact on the saturation distribution (Figure B.9a, year 1955), by increasing the saturations beneath the trench to greater than $80 \%$. Like Case 12, this saturation field contrasts sharply with the final saturation field at 3000 years shown in Figure B.9 (b). Due to the drainage of the initial discharge and the reduction in surface recharge caused by the closure barrier, the saturation field has dried and shows little variability in saturation.

Only small differences in the U-238 aqueous and total concentration distributions (Figures B.10 and B.11) are noted in Case 12. Peak concentrations are lower because of dilution, and the increased recharge has caused a subsequent acceleration in U-238 transport. However, the vertical migration of U-238 is still severely limited and largely confined to the $\mathrm{H} 2$ sand unit even after 3000 years of simulation.

The Tc-99 concentration profiles shown in Figures B.12 through B.15 show a pattern similar to the lower recharge scenario presented in Case 12. The implementation of the closure barrier in 2010 significantly delays Tc-99 transport. However, peak concentrations are lower than Case 12. Transport out of the system is also accelerated due to the increased saturations of the domain.

Predicted solute mass flux and aqueous concentration breakthrough curves are shown for Case 13 in Figures D.10 through D.12 for Tc-99 and $\mathrm{NO}_{3}$. Because this simulation did not predict any U-238 migration from the vadose zone during the time simulated, the mass flux and concentration figures for U-238 were omitted. Scaled results using the inventories for trench B-38 are shown in Figures D.13 through D.15. Scaled results using the inventories for all eight trenches are shown in Figures D.16 through D.18.

As noted in Section 3, both Tc-99 and $\mathrm{NO}_{3}$ results were scaled from the unit inventory release of a non-sorbing solute. Therefore, the breakthrough curves and relative results for Tc-99 and $\mathrm{NO}_{3}$ are identical. Due to the increase in recharge, the Tc-99/ $\mathrm{NO}_{3}$ mass flux and concentration breakthrough curves had single peaks that were slightly earlier than those in Case 12 and peak concentrations that were more than three times higher. They also had long tailings that extended the duration of the simulation (year 3000). The simulation predicted about $70 \%$ of the Tc-99 and $\mathrm{NO}_{3}$ inventory migrated from the vadose zone by the end of the time period.

\subsection{B-38 Trench with Delayed Closure Barrier and $100 \mathrm{~mm} / \mathrm{yr}$ Meteoric Recharge}

The third B-38 trench simulation investigated solute transport through a cross section west of Tank BX-111, considering natural infiltration only at $100 \mathrm{~mm} / \mathrm{yr}$, no interim barrier, and a closure barrier in 2040. In this simulation (Case `14), the year the closure barrier is emplaced is the same as in BX tank simulations (Cases 1-11). Like the previous trench simulations (Cases 12 and 13), a 378,000-gal leak containing a unit inventory distribution for U-238 and Tc-99 occurred over the entire width of the trench in 1954. With the exception of the closure barrier implementation in 2040, all other conditions were the same as in Case 13. Plot-file output for this simulation was generated at years 1954, 1955, 2000, 2010, 2110, 2210, 2310, 2410, 2510, 2700, and 3000 and includes values for saturation, aqueous pressure, moisture content, and concentration for the three solute species. 
The final saturation distribution for the B-38 cross section with $100 \mathrm{~mm} / \mathrm{yr}$ of meteoric recharge and a delayed closure barrier is shown in Figure B.15. Relative to Case 13 (100 mm/yr meteoric recharge and a closure barrier in 2010), the delay in the closure barrier has not had a significant impact on moisture content distribution. However, the delay has had an effect on solute concentrations and transport. For example, the U-238 plume is more diffuse than in Case 13 and has migrated a few feet deeper into the profile, as shown in Figure B.16 for year 3000. For mobile species Tc-99, the effect is more pronounced. Figures B.17 and B.18 show that the delay in the closure barrier has accelerated the transport of Tc-99 to the water table. For example, in year 2110 [Figure B.17(a)], the upper boundary of the Tc-99 plume is approximately $48.8 \mathrm{~m}$ (160 ft) above the water table, whereas in Case 13, it is approximately $54.9 \mathrm{~m}$ (180 ft) above the water table. The effect of the closure barrier is noted in both simulations. The upper boundary of the plume in year 3000 for both the delayed closure barrier and Case 13 is $45.7 \mathrm{~m}$ (150 ft).

Predicted solute mass flux and aqueous concentration breakthrough curves are shown for Case 14 in Figures D.19-D.21 for Tc-99 and $\mathrm{NO}_{3}$. Because this simulation did not predict any U-238 migration from the vadose zone for the time period simulated, the mass flux and concentration figures for U-238 were omitted. Scaled results using the inventories for trench B-38 are shown in Figures D.22 through D.24. Scaled results using the inventories for all eight trenches are shown in Figures D.25 through D.27.

As noted in Section 3, both Tc-99 and $\mathrm{NO}_{3}$ results were scaled from the unit inventory release of a nonsorbing solute. Therefore, the breakthrough curves and relative results for Tc-99 and $\mathrm{NO}_{3}$ are identical. Due to the increase in recharge from the delay in implementing the closure barrier, the Tc-99/NO mass flux and concentration breakthrough curves had peak concentrations that were more than six times higher than Case 12 and 1.8 times higher than Case 13. This simulation predicted about $92 \%$ of the Tc-99 and $\mathrm{NO}_{3}$ inventory migrated from the vadose zone by the end of the time period.

\subsection{Solute Mass Balance}

Mass balance checks were performed on the three solutes (U-238, Tc-99 and $\mathrm{NO}_{3}$ ) for each simulation case, using the expression shown in Equation (4.1):

$$
\mathrm{m}_{\text {error }}=\frac{\mathrm{m}_{\text {initial }}-\mathrm{m}_{\text {final }}-\mathrm{m}_{\text {exit }}}{\mathrm{m}_{\text {initial }}}
$$

where $m_{\text {error }}$ is the mass balance error in percent, $m_{\text {initial }}$ is the initial solute inventory computed from the STOMP plot-file output at year $2000, \mathrm{~m}_{\mathrm{final}}$ is the final solute inventory computed from the STOMP plot-file output at year 3000 , and $m_{\text {exiting }}$ is the integrated solute inventory leaving the computation domain computed from the STOMP surface-flux output. STOMP computed the initial solute masses by integrating the solute concentrations over the flow domain. The solute mass leaving the computational domain through the aquifer was determined using surface-flux output on the eastern side of the domain. The surface-flux output provided both the solute-flux rate and integral. Other than solving the solute mass conservation equations, the STOMP simulator contains no algorithms for correcting local or global mass. Therefore, mass balance errors represent the actual mass balance errors from the conservation equations. Expressed as percent error, mass balance errors were small, as shown in Tables 4.5, 4.6, and 4.7 for $\mathrm{U}-238$, Tc-99, and $\mathrm{NO}_{3}$, respectively. 
Table 4.5. STOMP Mass Balance for U-238

\begin{tabular}{|c|c|c|c|c|}
\hline U-238 $(\mathrm{pCi})$ Case & Initial & Final & Exit & $\%$ Error \\
\hline 1 & $4.311 \mathrm{E}+10$ & $4.302 \mathrm{E}+10$ & $8.661 \mathrm{E}+07$ & $2.2 \mathrm{E}-04$ \\
2 & $4.311 \mathrm{E}+10$ & $4.310 \mathrm{E}+10$ & $9.105 \mathrm{E}+06$ & $2.2 \mathrm{E}-04$ \\
3 & $4.311 \mathrm{E}+10$ & $1.622 \mathrm{E}+09$ & $4.152 \mathrm{E}+10$ & $-7.2 \mathrm{E}-02$ \\
4 & $4.311 \mathrm{E}+10$ & $4.291 \mathrm{E}+10$ & $1.984 \mathrm{E}+08$ & $6.3 \mathrm{E}-05$ \\
5 & $4.311 \mathrm{E}+10$ & $4.306 \mathrm{E}+10$ & $4.804 \mathrm{E}+07$ & $1.3 \mathrm{E}-04$ \\
6 & $4.311 \mathrm{E}+10$ & $4.311 \mathrm{E}+10$ & $4.966 \mathrm{E}+06$ & $7.9 \mathrm{E}-05$ \\
7 & $4.311 \mathrm{E}+10$ & $4.310 \mathrm{E}+10$ & $9.497 \mathrm{E}+06$ & $6.6 \mathrm{E}-06$ \\
8 & $4.311 \mathrm{E}+10$ & $4.311 \mathrm{E}+10$ & $1.474 \mathrm{E}+06$ & $6.0 \mathrm{E}-05$ \\
9 & $4.311 \mathrm{E}+10$ & $4.311 \mathrm{E}+10$ & $1.044 \mathrm{E}+04$ & $2.1 \mathrm{E}-04$ \\
10 & $4.311 \mathrm{E}+10$ & $2.768 \mathrm{E}+10$ & $1.543 \mathrm{E}+10$ & $-1.9 \mathrm{E}-03$ \\
11 & $4.311 \mathrm{E}+10$ & $4.311 \mathrm{E}+10$ & $4.416 \mathrm{E}+06$ & $2.0 \mathrm{E}-04$ \\
12 & $1.000 \mathrm{E}+12$ & $1.000 \mathrm{E}+12$ & $0.000 \mathrm{E}+00$ & $0.00 \mathrm{E}+00$ \\
13 & $1.000 \mathrm{E}+12$ & $1.000 \mathrm{E}+12$ & $0.000 \mathrm{E}+00$ & $0.00 \mathrm{E}+00$ \\
14 & $1.000 \mathrm{E}+12$ & $1.000 \mathrm{E}+12$ & $0.000 \mathrm{E}+00$ & $0.00 \mathrm{E}+00$ \\
\hline
\end{tabular}

Table 4.6. STOMP Mass Balance for Tc -99

\begin{tabular}{|c|c|c|c|c|}
\hline Tc-99 (pCi) Case & Initial & Final & Exit & $\%$ Error \\
\hline 1 & $6.013 \mathrm{E}+10$ & $8.726 \mathrm{E}+08$ & $5.926 \mathrm{E}+10$ & $-5.85 \mathrm{E}-03$ \\
2 & $6.013 \mathrm{E}+10$ & $6.167 \mathrm{E}+09$ & $5.396 \mathrm{E}+10$ & $3.33 \mathrm{E}-05$ \\
3 & $6.013 \mathrm{E}+10$ & $8.647 \mathrm{E}+03$ & $5.993 \mathrm{E}+10$ & $3.33 \mathrm{E}-01$ \\
4 & $6.013 \mathrm{E}+10$ & $3.394 \mathrm{E}+08$ & $5.979 \mathrm{E}+10$ & $1.00 \mathrm{E}-02$ \\
5 & $6.045 \mathrm{E}+10$ & $1.683 \mathrm{E}+09$ & $5.878 \mathrm{E}+10$ & $-2.39 \mathrm{E}-02$ \\
6 & $6.045 \mathrm{E}+10$ & $8.623 \mathrm{E}+09$ & $5.183 \mathrm{E}+10$ & $-1.93 \mathrm{E}-02$ \\
7 & $6.013 \mathrm{E}+10$ & $4.805 \mathrm{E}+09$ & $5.533 \mathrm{E}+10$ & $1.96 \mathrm{E}-03$ \\
8 & $6.013 \mathrm{E}+10$ & $1.060 \mathrm{E}+10$ & $4.953 \mathrm{E}+10$ & $4.99 \mathrm{E}-05$ \\
9 & $6.013 \mathrm{E}+10$ & $2.719 \mathrm{E}+10$ & $3.294 \mathrm{E}+10$ & $9.98 \mathrm{E}-05$ \\
10 & $6.013 \mathrm{E}+10$ & $8.726 \mathrm{E}+08$ & $5.926 \mathrm{E}+10$ & $-5.85 \mathrm{E}-03$ \\
11 & $6.013 \mathrm{E}+10$ & $8.726 \mathrm{E}+08$ & $5.926 \mathrm{E}+10$ & $-5.85 \mathrm{E}-03$ \\
12 & $1.000 \mathrm{E}+12$ & $6.026 \mathrm{E}+11$ & $3.979 \mathrm{E}+11$ & $-3.00 \mathrm{E}-05$ \\
13 & $1.000 \mathrm{E}+12$ & $3.012 \mathrm{E}+11$ & $6.993 \mathrm{E}+11$ & $3.00 \mathrm{E}-05$ \\
14 & $1.000 \mathrm{E}+12$ & $8.450 \mathrm{E}+10$ & $9.160 \mathrm{E}+11$ & $-2.00 \mathrm{E}-05$ \\
\hline
\end{tabular}


Table 4.7. STOMP Mass Balance for $\mathrm{NO}_{3}$

\begin{tabular}{|c|c|c|c|c|}
\hline $\mathrm{NO}_{3}(\mu \mathrm{g})$ Case & Initial & Final & Exit & $\%$ Error \\
\hline 1 & $1.790 \mathrm{E}+11$ & $6.473 \mathrm{E}+09$ & $1.722 \mathrm{E}+11$ & $1.40 \mathrm{E}-01$ \\
2 & $1.790 \mathrm{E}+11$ & $2.172 \mathrm{E}+10$ & $1.571 \mathrm{E}+11$ & $9.64 \mathrm{E}-02$ \\
3 & $1.790 \mathrm{E}+11$ & $2.579 \mathrm{E}+07$ & $1.778 \mathrm{E}+11$ & $6.42 \mathrm{E}-01$ \\
4 & $1.790 \mathrm{E}+11$ & $3.418 \mathrm{E}+09$ & $1.754 \mathrm{E}+11$ & $6.08 \mathrm{E}-02$ \\
5 & $1.795 \mathrm{E}+11$ & $9.172 \mathrm{E}+09$ & $1.704 \mathrm{E}+11$ & $-1.65 \mathrm{E}-02$ \\
6 & $1.795 \mathrm{E}+11$ & $2.678 \mathrm{E}+10$ & $1.528 \mathrm{E}+11$ & $-5.31 \mathrm{E}-02$ \\
7 & $1.790 \mathrm{E}+11$ & $1.821 \mathrm{E}+10$ & $1.605 \mathrm{E}+11$ & $1.46 \mathrm{E}-01$ \\
8 & $1.790 \mathrm{E}+11$ & $3.118 \mathrm{E}+10$ & $1.478 \mathrm{E}+11$ & $6.70 \mathrm{E}-04$ \\
9 & $1.790 \mathrm{E}+11$ & $6.313 \mathrm{E}+10$ & $1.158 \mathrm{E}+11$ & $2.23 \mathrm{E}-04$ \\
10 & $1.790 \mathrm{E}+11$ & $6.473 \mathrm{E}+09$ & $1.722 \mathrm{E}+11$ & $1.40 \mathrm{E}-01$ \\
11 & $1.790 \mathrm{E}+11$ & $6.473 \mathrm{E}+09$ & $1.722 \mathrm{E}+11$ & $1.40 \mathrm{E}-01$ \\
12 & $1.000 \mathrm{E}+09$ & $6.026 \mathrm{E}+08$ & $3.979 \mathrm{E}+08$ & $-3.00 \mathrm{E}-05$ \\
13 & $1.000 \mathrm{E}+09$ & $3.012 \mathrm{E}+08$ & $6.993 \mathrm{E}+08$ & $3.00 \mathrm{E}-05$ \\
14 & $1.000 \mathrm{E}+09$ & $8.450 \mathrm{E}+07$ & $9.160 \mathrm{E}+08$ & $-2.00 \mathrm{E}-05$ \\
\hline
\end{tabular}




\subsection{Numerical Groundwater Transport Modeling Results}

To check the analytical groundwater transport results in Section 4, simulations were run using a threedimensional numerical aquifer model of the Hanford Site for two cases. The cases selected represented two important assessment scenarios: 1) the BX tank farm Base Case (Case 1) and 2) the B-38 trench Case Unit Inventory Release (Case 12). While the analytic model was used to predict concentrations of for three constituents, U-238, Tc-99, and $\mathrm{NO}_{3}$, the numerical model simulations were conducted only for Tc-99. Model comparisons were made at three locations that included the source (BX and trench fence lines) and the exclusion and river boundaries.

The Hanford Site-Wide Groundwater Model (SGM) is the three-dimensional numerical groundwater flow and contaminant transport process model used in this study for comparison with the analytical model results. The SGM is a three-dimensional finite element model based on the Coupled Fluid, Energy, and Solute Transport (CFEST-96) code (Gupta et al. 1987; Gupta 1997). This model and its conceptual basis are fully described in Wurstner et al. (1995) and Cole et al. (1997). They were most recently used in the Hanford Site Composite Analysis (Cole et al. 1997; Kincaid et al. 1998; Bergeron et al. 2001) and ILAW Performance Assessment (Bergeron and Wurstner 2000; Mann et al. 2001). Cole et al. (2001) contains a complete discussion of the uncertainties in the conceptual model as they are currently understood.

Section 5.1 describes the SGM model that was implemented in this analysis. Sections 5.2 and 5.3 describe the flow and transport parameters and grid refinement procedure. In Section 5.4 the numerical modeling results are described, followed by a comparison of results for the numerical and analytical models in Section 5.5.

\subsection{Numerical Model Description}

Although a CFEST SGM was also used in the S-SX FIR analysis, the groundwater model used in this analy sis (current model) is different from that model (White et al. 2001). The conceptual model described in White et al. (2001) is the same as the one used in this report; however, the current model is calibrated within an uncertainty framework (Cole et al. 2001). By recalibrating the prior model, significant improvements enabled it to simulate historical trends in water table changes over the entire Site (Cole et al. 2001). These improvements are noted in the residual plots shown in Figure 5.1, which demonstrate smaller differences between observed and simulated water levels (i.e., lower residuals) in the current model than in the prior model calibration.

Another significant difference between the SGM used in the S-SX FIR effort and the current work is that the S-SX FIR was run as a steady-state flow with a transient transport. This setup represented future "Post-Hanford" conditions with no artificial recharge. Because the simulated sources from the B trenches and BX tank farm in this current effort have earlier arrival times at the water table, a transient flow and transport simulation was required that included the artificial recharge water source terms from Hanford operations.

A complete description of the current model development and its calibration is contained in Cole et al. (2001). In brief, the development of the current model included an extended calibration period dataset for transient head inverse modeling. This data set included new estimates of artificial discharges, river 
a)

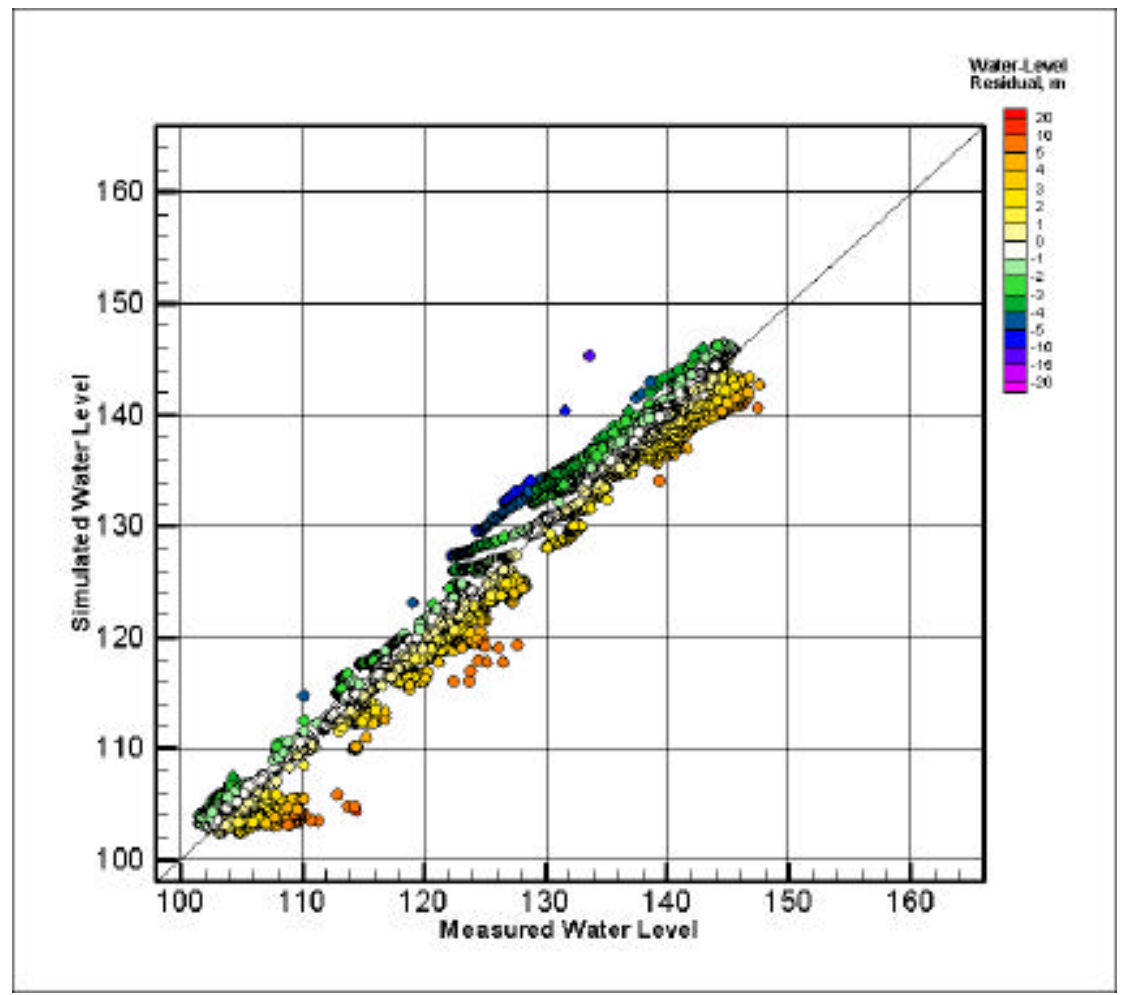

b)

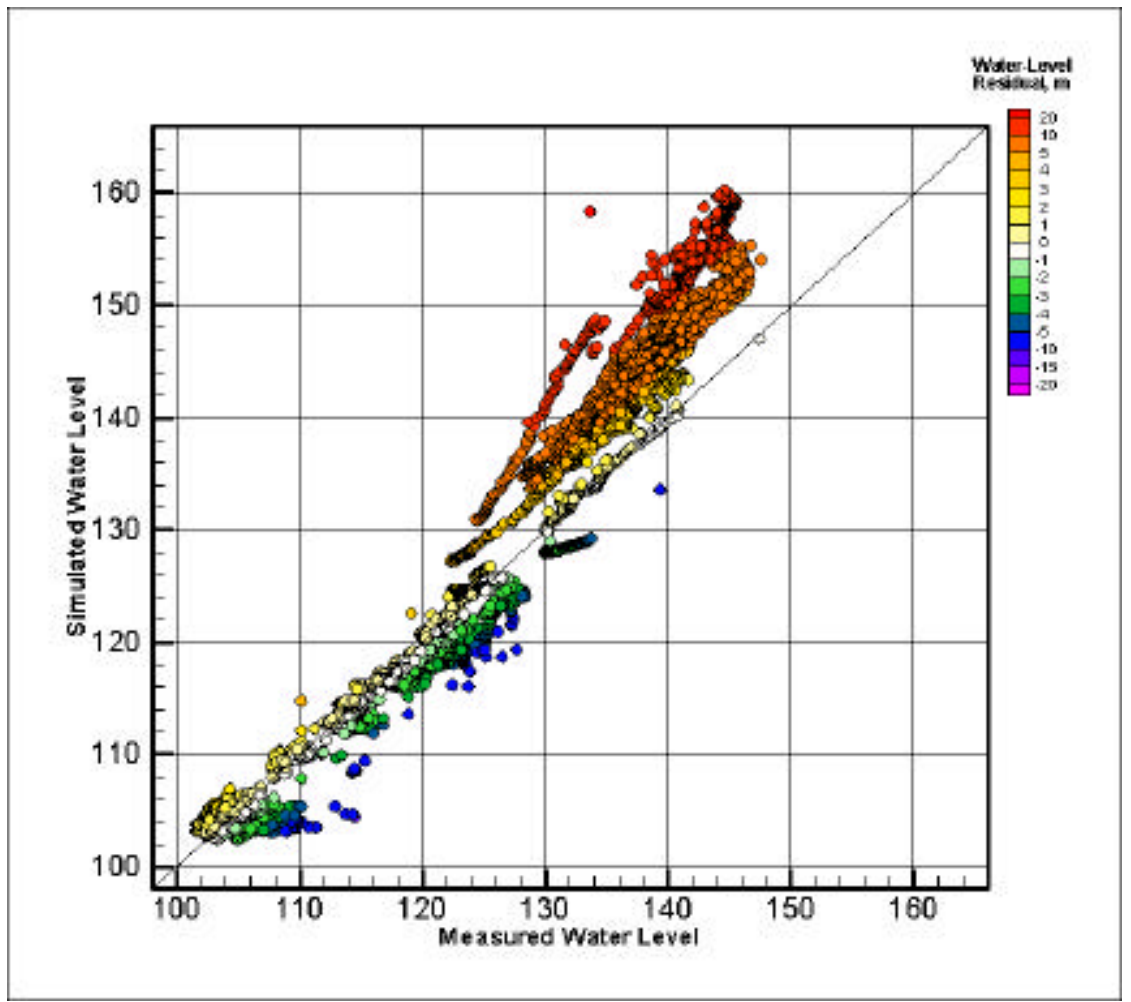

Figure 5.1. Simulated Versus Observed Heads for all Observations Through Time in a) the Current Model and b) the Prior Model (Cole et al. 2001) 
stage variations, and head observations from 1943 to 1996. The SGM discharges were also supplemented with the additional water source terms used in the 2002 System Assessment Capability (SAC) model (Bryce et al., 2000) ${ }^{1}$.

As a result of several important changes to the flow model, flow patterns differ in the two models near the B-BX-BY and S-SX WMAs. In the current model, flow near the B-BX-BY WMA moves north. By contrast, flow in this area traveled in an easterly direction in the prior model because model elements dried out under post-Hanford conditions. Although this difference in the two models makes it difficult to compare the numerical S-SX and B-BX-BY transport results directly, the detailed process model used in this analysis still provides an adequate check on the analytical groundwater modeling results presented in this report. Moreover, the use of the current model in this analysis maintains consistency with the flow and transport model presently being used for other Hanford Site assessments (e.g., SAC).

\subsection{Flow and Transport Parameters}

Despite differences in the description of flow between the prior model used in the S-SX FIR analysis and the current model used in this analysis, several important similarities still exist between the two models. For example, the nine major hydrogeologic units described in the prior model (Cole et al. 2001; White et al. 2001) are the same as those used in the current model and are illustrated in Figure 5.2. Recharge and aquifer boundaries were also similar in the two models. However, flow and transport properties differed in the two models because of differences in the calibration datasets.

To model groundwater flow, the distribution of hydraulic properties, including both horizontal and vertical hydraulic conductivity and porosity, were required for each hydrogeologic unit defined in the model. The procedure used to calibrate the current detailed process model is described in Cole et al. (2001). The resulting hydraulic conductivity distribution determined for the upper part of the aquifer is provided in Figure 5.3.

To simulate movement of contaminant plumes, the required transport properties include contaminantspecific distribution coefficients, bulk density, effective porosity, and the longitudinal and transverse dispersivities $\left(\alpha_{l}\right.$ and $\alpha_{t}$ ), which are the components of the dispersion tensor generally used to represent dispersion in a porous media that is isotropic with respect to dispersivity. As described in White et al. (2001), several difficulties are associated with determining appropriate values of dispersivity at the Sitewide scale. Although dispersivity is often determined by inverse modeling of onsite tracer test breakthrough curves, no field tests have been conducted at the Hanford Site to develop an estimate for this parameter at the scale of transport appropriate for the SGM.

Dispersivity is likely to vary across the Site depending on the degree of heterogeneity and the temporal variability of flow gradients. In this analysis, however, as in the Composite Analysis (Kincaid

${ }^{1}$ Bryce, RW, CT Kincaid, PW Eslinger and LF Morasch. 2002. An Initial Assessment of Hanford Impact Performed with the System Assessment Capability. PNNL-Draft Report, Pacific Northwest National Laboratory, Richland, WA. 
et al. 1998), constant dispersivity values (e.g., longitudinal dispersivity, $\alpha_{l}=95 \mathrm{~m}$ ) were used. Although this value is not based on any Hanford Site data, it does satisfy the grid Peclet number constraint as well as heterogeneity constraints determined in the Composite Analysis. It was assumed that the transverse dispersivity, $\alpha_{t}$, was approximately $20 \%$ of the longitudinal dispersivity (19 m). 


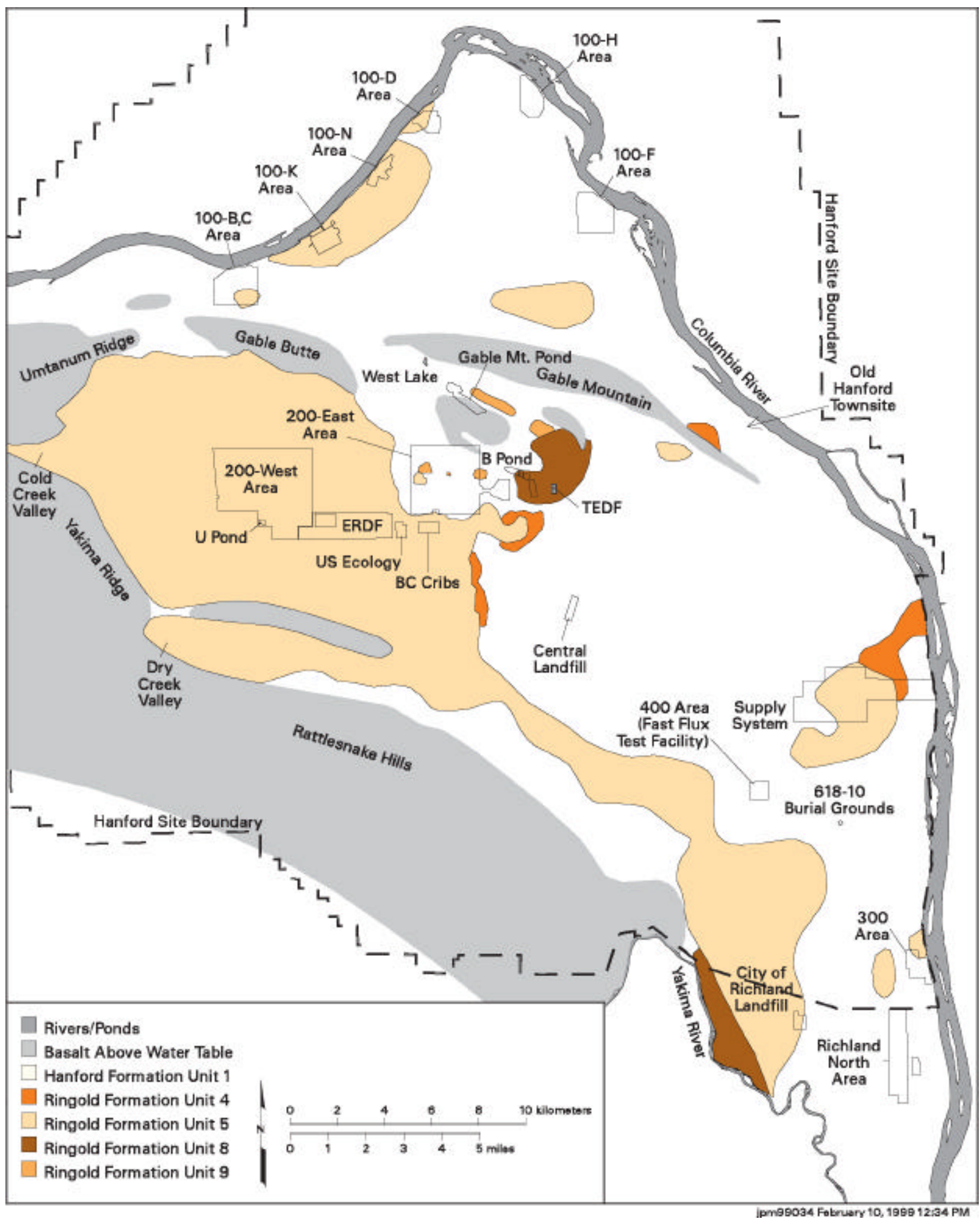

Figure 5.2. Map of SGM Hydrogeologic Units Containing the Water Table in March 1999 


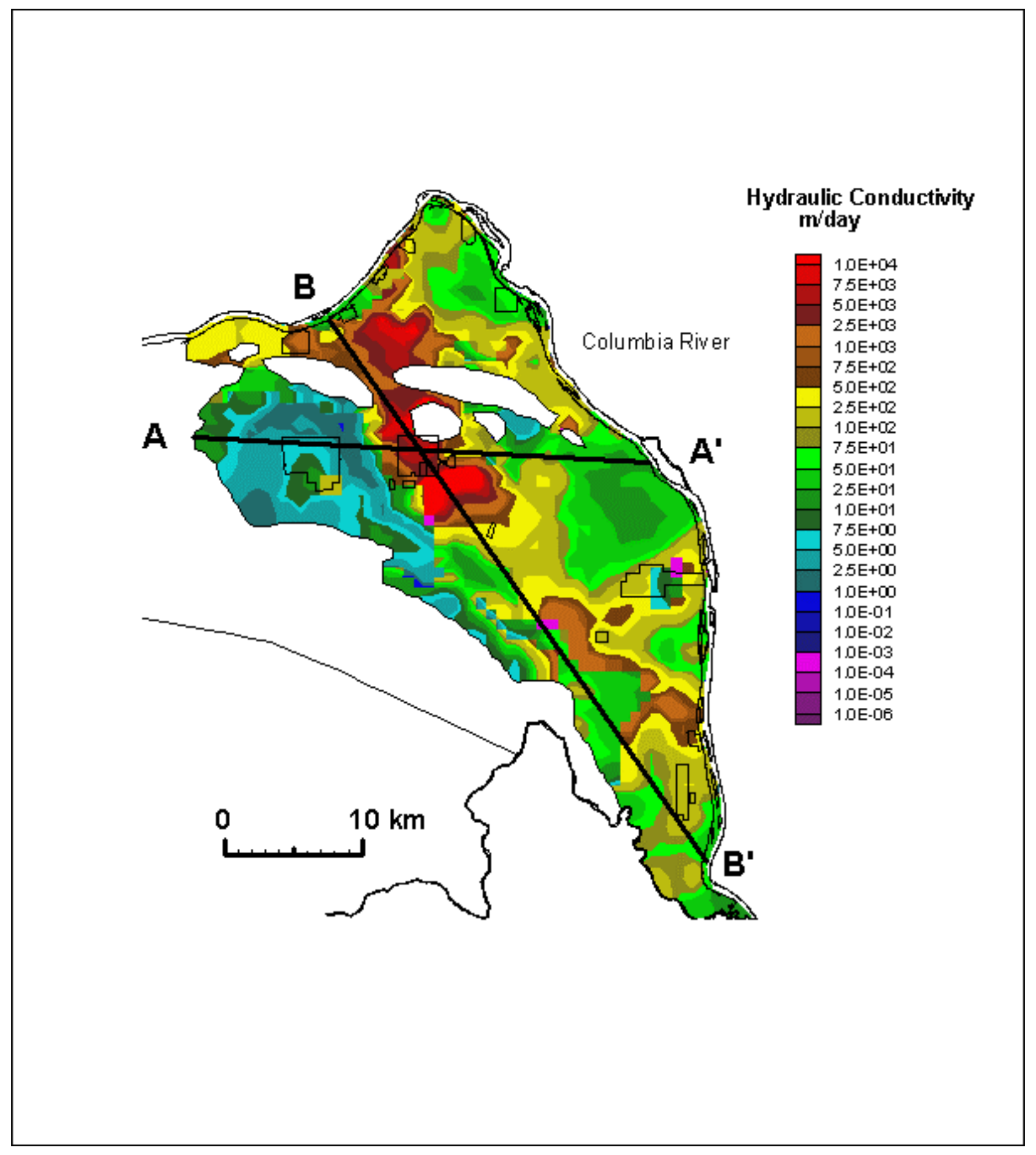

Figure 5.3. Hydraulic Conductivity Distribution (Cole et al. 2001) 


\subsection{Grid Refinement}

The grid refinement procedure used in White et al. (2001) was also used in this analysis. As in the S-SX FIR transport modeling, the first step involved running the SGM using the 750-m Composite Analysis (Kincaid et al. 1998) model grid with a central area of refinement that resulted in 375-m spacing. The Composite Analysis dispersivities were used $\left(\alpha_{l}=95 \mathrm{~m}\right.$ and $\left.\alpha_{t}=19 \mathrm{~m}\right)$ and the source terms determined from the vadose zone modeling with STOMP. The source was input at the SGM Composite Analysis model node closest to the BX and trench fence lines for Cases 1 and 12, respectively. Mass flux versus time inputs to this Composite Analysis model grid simulation were equivalent to those used as input to the analytical model except for the temporal discretizations (i.e., time steps). Transport results (Figure 5.4) from this analysis with the Composite Analysis transport model grid identified the critical areas for refinement between the source area and the arrival location to the north along the river.

A factor of three refinement was performed in the plume area on a grid with 750-m spacing throughout and is outlined with the red polygon shown in Figure 5.4(a). The grid after refinement is illustrated in Figure 5.4(b) with a 250-m node spacing in the refined area. Because the contaminant traveled north between Gable Mountain and Gable Butte toward the Columbia River and then east, the selected area of refinement included the area north and east of Gable Butte and Gable Mountain. This yielded a grid spacing of $250 \mathrm{~m}$ in the refined area and $750 \mathrm{~m}$ in the region outside the red polygon. The grid was not refined vertically with depth because the aquifer thickness in the source and nearby area is relatively thin.

\subsection{Modeling Results-Transport from BX Tank Farm and B-38 Trench}

The same three-dimensional transient groundwater flow system was used for Tc-99 transport model ing for both Cases 1 and 12. The only differences between these two cases were due to the source terms. For Case 1, the input sources corresponded to the Tc-99 mass flux in the aquifer at the BX fence line, whereas in Case 12 trench sources were used for trench B-38 at the trench fence line.

Figure 5.5 is a composite figure that illustrates the SGM results predicted for Case 1. Case 12 results are shown in Figure 5.6. Both figures illustrate plan view concentration contours at the water table at times when the maximum concentration occurs at the exclusion boundary and the Columbia River. As shown in Tables 5.1 and 5.2, peak concentrations at the source occur in the same year as the peak concentrations at the exclusion boundary. Also shown in Figures 5.5 and 5.6 are "maximum concentration versus time" arrival plots (i.e., breakthrough curves) for both the exclusion and the river boundaries. 


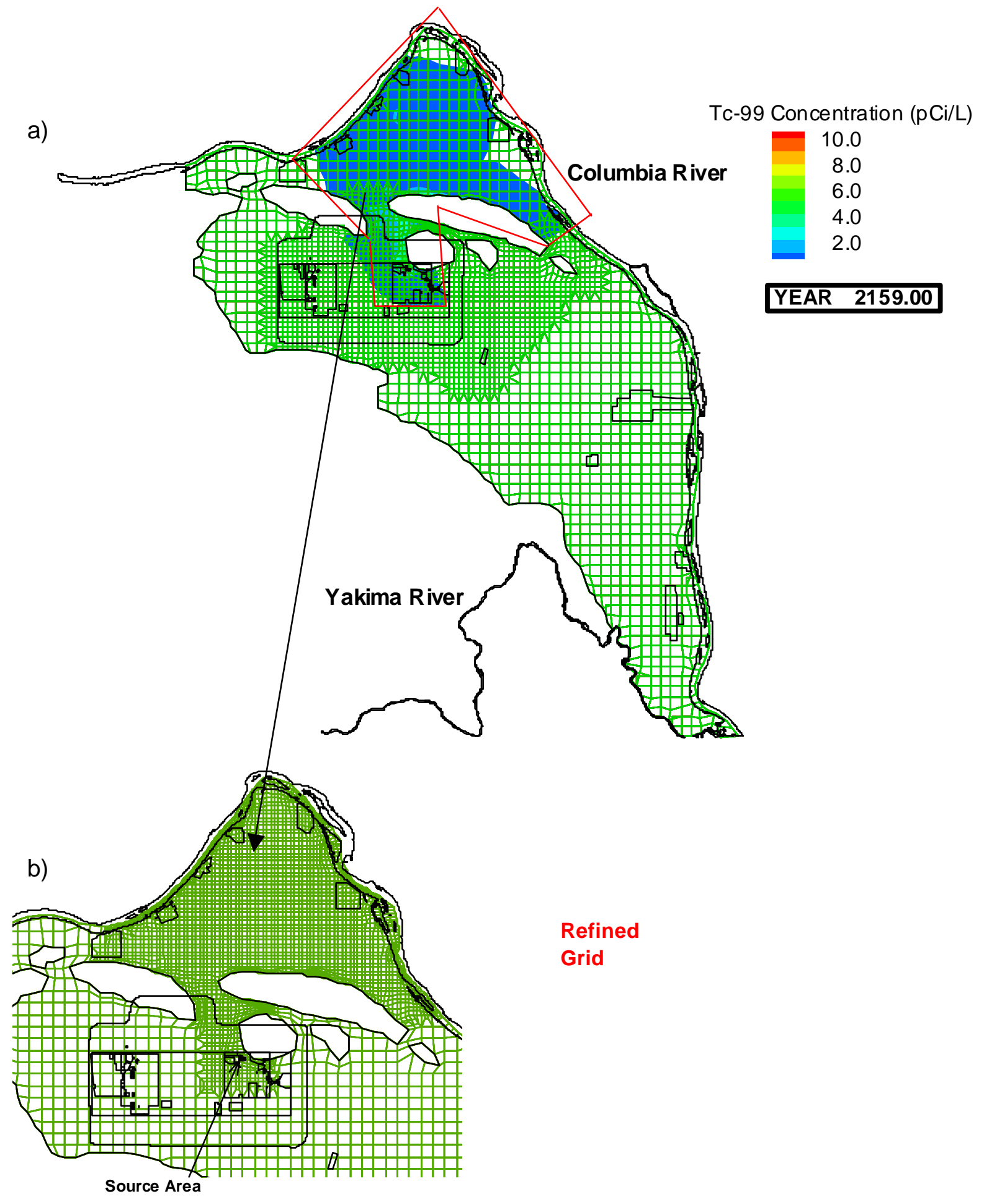

Figure 5.4. a) Coarse Composite Analysis Grid with Plume in 2340 (red polygon denotes area of grid refinement) and b) Grid after Refinement 


\subsection{Result Comparisons-Analytical Versus Numerical Models}

In this section, predictions of peak concentrations and their arrival times are compared in the analytical and detailed process numerical models for both the BX tank (Case 1) and B-38 trench (Case 12). Although differences in prediction values do exist, the analytical model predictions of peak concentrations are close in value (within an order of magnitude) to those predicted by the numerical model. Significant differences exist for the prediction in peak arrival times, but in general these differences can be attributed to the difference in representing flow fields used in the analytic model derived from the VAM3D model results (Lu 1996) and the current SGM numerical model.

\subsubsection{BX Tank Farm}

Table 5.1 compares the final results of the analytical and numerical models for each case investigated. Results show that concentrations for the analytical model are slightly higher (less than one order of magnitude) than those for the numerical simulation at each respective compliance point for Case 1. For all three boundaries, the peak concentrations in the analytical model are approximately 3.5 times that predicted by the numerical model. This is an expected result because more dilution occurs in the numerical than in the analytical model.

Several differences in the models can account for the difference in prediction values. For example, dispersion in the detailed numerical model is isotropic with two parameters $\left(\alpha_{1}=95 \mathrm{~m}, \alpha_{\mathrm{t}}=19.0 \mathrm{~m}\right)$, whereas in the analytical model, dispersion is treated as anisotropic in a simplified way using three parameters $\left(\alpha_{x}=30.5 \mathrm{~m}, \alpha_{y}=3.05 \mathrm{~m}\right.$, and $\left.\alpha_{z}=0.01 \mathrm{~m}\right)$. Moreover, path-line distances are different. In the analytical model, it was assumed that a contaminant would be transported from its source in an easterly direction toward the Columbia River. In the numerical model, flow traveled predominantly north, passing between Gable Butte and Gable Mountain before discharging into the river. As a result, the distance to the Exclusion Boundary in the numerical model $(2.2 \mathrm{~km})$ was less than half the distance in the analytical model $(4.6 \mathrm{~km})$. Distance to the Columbia River in the analytical model was one-third greater than in the numerical model (16 versus $12 \mathrm{~km}$ ). No distances are recorded in Table 5.1 for the fence line because in the numerical model the BX fence line concentration occurred at the source.

Despite the difference in travel distance, the peak concentration arrival times for the numerical model occurred at later times for both the fence line (2048 versus 2099) and exclusion boundary (2053 versus 2099), whereas for the Columbia River boundary the peak concentration arrival time occurred earlier (2169 versus 2279). Although this result implies inconsistent trends, it is important to consider several important factors, including the transient nature of the flow system in the numerical model and the differences in treatment of flow and transport. For example, the travel distance to the river is shorter in the numerical model; therefore, an earlier breakthrough in the peak concentration is a reasonable result. The earlier breakthrough, however, does not occur with the exclusion boundary. This difference in peakarrival time can be attributed to how flow is handle d. The analytical model assumed a constant flow velocity for each interval between the B-BX-BY WMA and compliance points, whereas the numerical simulation flow was transient and accounted for several water source terms that caused the water table to rise near the BX tank farm. Although the peak arrival times differ due to different descriptions of the flow field, the peak concentrations predicted by the numerical model compare well with those predicted by the analytical model. 
Table 5.1. Maximum Tc-99 Concentration (pCi/L) at Compliance Points for Base Case (Case 1)

\begin{tabular}{|c|c|c|c|c|c|c|c|c|}
\hline $\begin{array}{c}\text { Tc-99 } \\
\text { Conc. }\end{array}$ & \multicolumn{2}{|c|}{ Fence Line } & \multicolumn{4}{c|}{ Exclusion Boundary } & \multicolumn{3}{c|}{ Columbia River } \\
\hline & $\begin{array}{r}\text { Time } \\
(\mathrm{yr})\end{array}$ & $\begin{array}{c}\text { Conc } \\
(\mathrm{pCi} / \mathrm{L})\end{array}$ & $\begin{array}{c}\text { Time } \\
(\mathrm{yr})\end{array}$ & $\begin{array}{c}\text { Conc. } \\
(\mathrm{pCi} / \mathrm{L})\end{array}$ & $\begin{array}{c}\text { Distance } \\
(\mathrm{km})\end{array}$ & $\begin{array}{c}\text { Time } \\
(\mathrm{yr})\end{array}$ & $\begin{array}{c}\text { Conc. } \\
(\mathrm{pCi} / \mathrm{L})\end{array}$ & $\begin{array}{c}\text { Distance } \\
(\mathrm{km})\end{array}$ \\
\hline Analytical & 2048 & $8.05 \mathrm{E}+02$ & 2053 & $2.54 \mathrm{E}+02$ & 4.6 & 2279 & $7.14 \mathrm{E}+01$ & 16 \\
Numerical & 2099 & $2.08 \mathrm{E}+02$ & 2099 & $7.39 \mathrm{E}+01$ & 2.2 & 2164 & $1.99 \mathrm{E}+01$ & 12 \\
\hline
\end{tabular}

\subsubsection{B-38 Trench}

For the B-38 trench case with a unit source release (Case 12), the effect of the water source terms in the numerical model are evident in the earlier peak arrival times predicted for all three boundaries (see Table 5.2). Although the peak concentration arrival time is only six years earlier at the fence line (2030 versus 2036), the arrival time at the exclusion boundary is nearly 50 years earlier (2030 versus 2077). At the Columbia River boundary, the peak arrival time is more than 150 years earlier in the numerical model (2144 versus 2301). The effect of the water source terms is also noted in the breakthrough curve shown in Figure 5.6. At early times, the fluctuation in concentration is pronounced, and the breakthrough curve is bimodal, with a second, lower peak occurring at year 2100 .

With the exception of the trench fence line concentration, peak concentrations predicted by the analytical model are two to three times smaller than those predicted by the numerical model. Although dilution is expected to occur with the addition of the water sources in the numerical model, the accelerated transport has a larger impact on the peak concentrations. Peak concentrations are higher relative to the analytical model because of the earlier breakthrough times. However, the concentration predictions of the numerical model are still within one order of magnitude of the predictions made by the analytic al model, which indicates that the numerical model serves as an adequate check on the analytical results.

Table 5.2. Maximum Tc- 99 Concentration (pCi/L) at Compliance Points for B-38 Trench with a Unit Source Release (Case 12)

\begin{tabular}{|c|c|c|c|c|c|c|c|c|}
\hline $\begin{array}{c}\text { Tc-99 } \\
\text { Conc. }\end{array}$ & \multicolumn{2}{|c|}{ Fence Line } & \multicolumn{4}{c|}{ Exclusion Boundary } & \multicolumn{3}{c|}{ Columbia River } \\
\hline & $\begin{array}{c}\text { Time } \\
(\mathrm{yr})\end{array}$ & $\begin{array}{c}\text { Conc } \\
(\mathrm{pCi} / \mathrm{L})\end{array}$ & $\begin{array}{c}\text { Time } \\
(\mathrm{yr})\end{array}$ & $\begin{array}{c}\text { Conc. } \\
(\mathrm{pCi} / \mathrm{L})\end{array}$ & $\begin{array}{c}\text { Distance } \\
(\mathrm{km})\end{array}$ & $\begin{array}{c}\text { Time } \\
(\mathrm{yr})\end{array}$ & $\begin{array}{c}\text { Conc. } \\
(\mathrm{pCi} / \mathrm{L})\end{array}$ & $\begin{array}{c}\text { Distance } \\
(\mathrm{km})\end{array}$ \\
\hline Analytical & 2036 & $2.02 \mathrm{E}+01$ & 2077 & $1.46 \mathrm{E}+00$ & 4.6 & 2301 & $6.74 \mathrm{E}-01$ & 16 \\
Numerical & 2030 & $1.03 \mathrm{E}+01$ & 2030 & $4.01 \mathrm{E}+00$ & 2.2 & 2144 & $1.33 \mathrm{E}+00$ & 12 \\
\hline
\end{tabular}



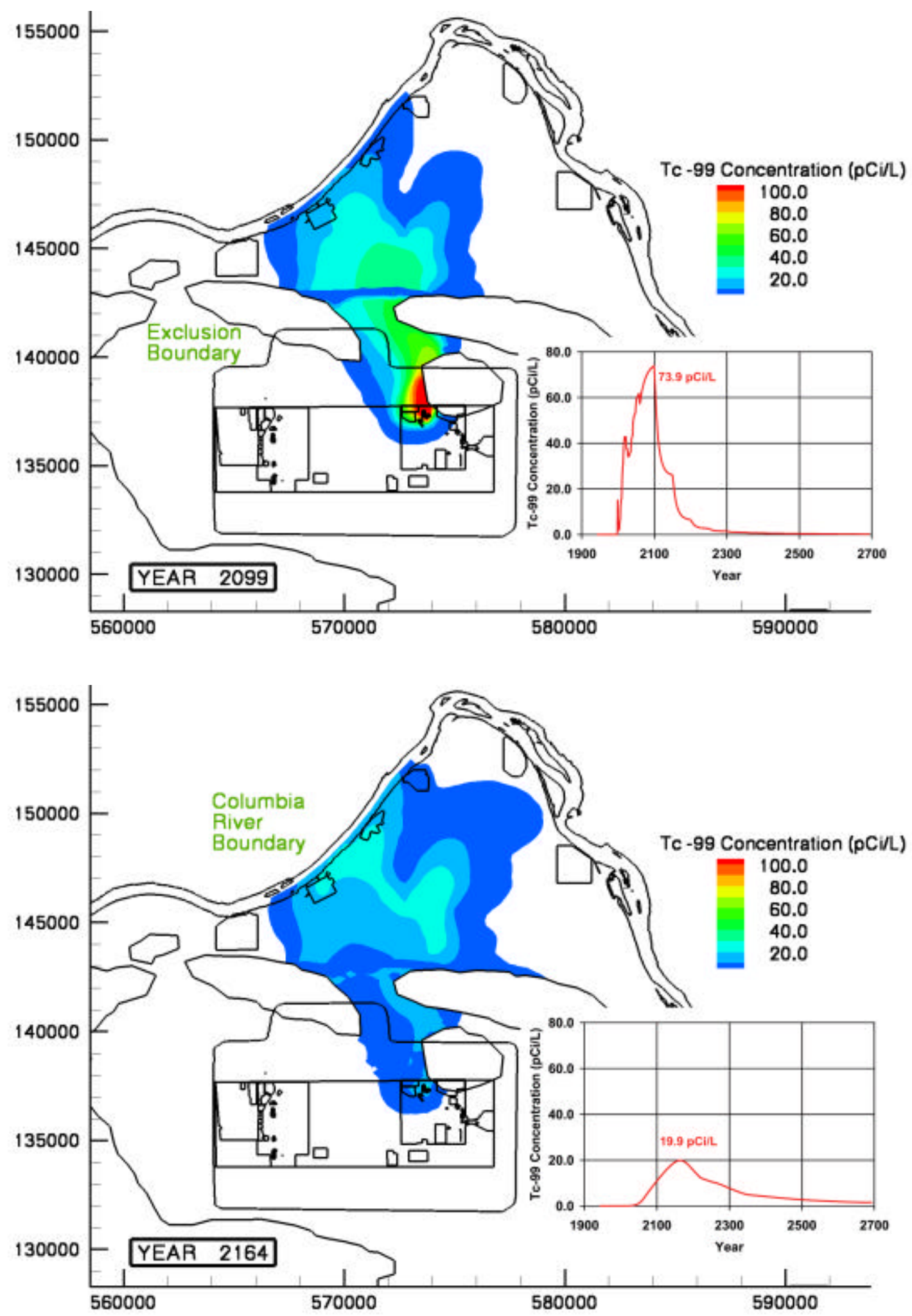

Figure 5.5. Composite SGM Results for Case 1, Illustrating Plan-View Concentration Contours at Peak Arrival Times for the Exclusion Boundary (top) and the Columbia River (bottom) 

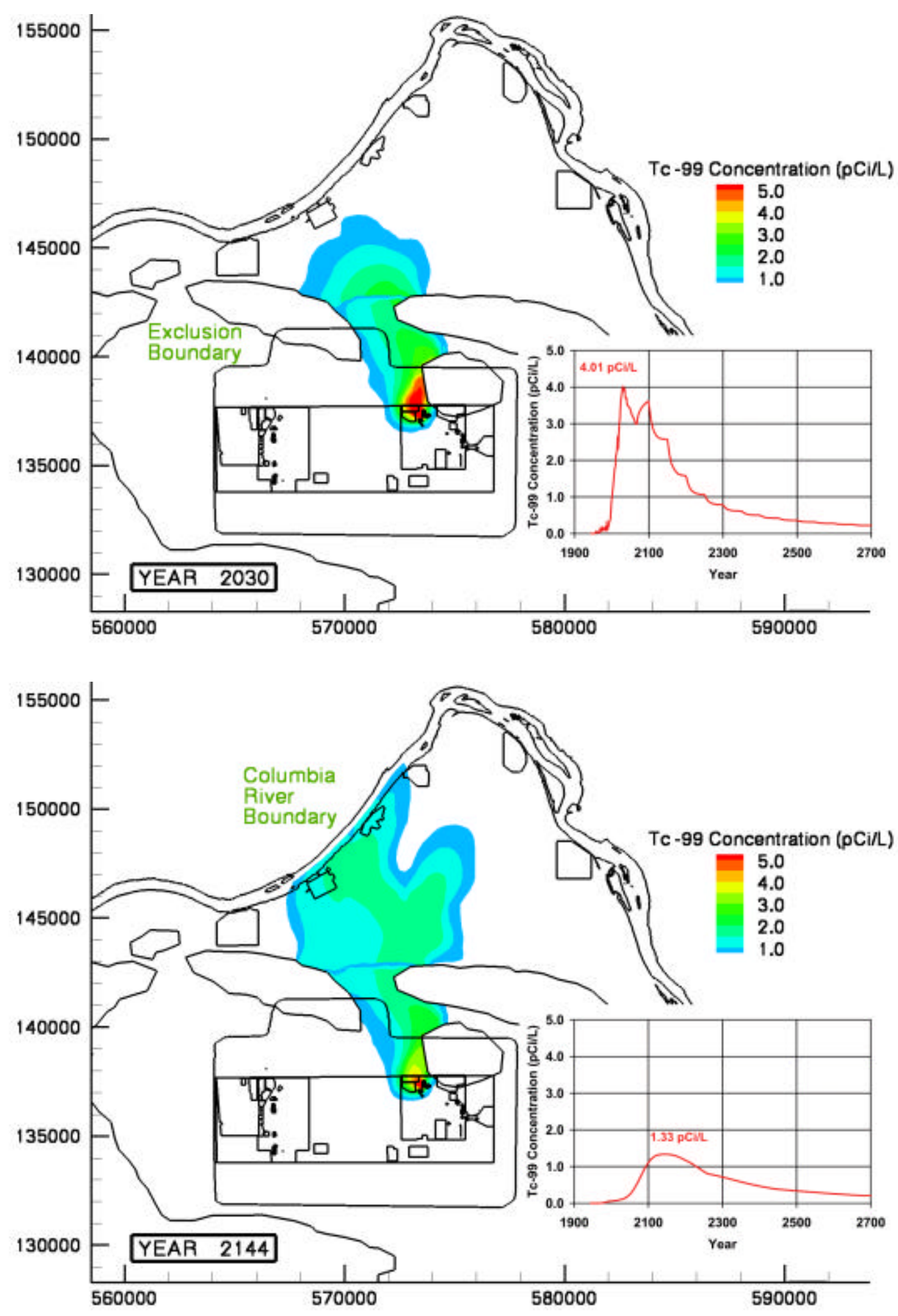

Figure 5.6. Composite SGM Results for Case 12, Illustrating Plan-View Concentration Contours at Peak Arrival Times for the Exclusion Boundary (top) and the Columbia River (bottom) 


\subsection{Electronic Files}

The principal objectives of this investigation were to conduct the simulations and analyses using an open scientific approach and to provide modeling results that could be verified and repeated. In partial fulfillment of these objectives, the source coding for the STOMP simulator, ancillary utilities coding, input files, simulation output files, and converted result files are provided in electronic form, with sufficient detail to enable the reported calculations to be repeated. This section describes the directory structure and contents of the files stored in electronic format. Files for different cross sections and inventory locations are saved with the same file name but are stored in different directories.

\subsection{Source Coding}

Source codes for the STOMP simulator and ancillary utilities are stored in the "source" directory. The STOMP source code is in the file "stomp1_sp.f" and comprises a main calling routine and subroutines listed in alphabetical order. The STOMP source code can be compiled with a Fortran 77 compiler, which include files "parameters" and "commons." The "parameters" file was dimensioned for all of the simulations. Once compiled, the STOMP simulator must be linked with the "splib.a" library configured for a particular computer. Files and instructions needed to create the "splib.a" library are included in the file "splib.tar.gz." The location of source coding for the various conversion and translations utilities used during these investigations is shown in Table 6.1.

Table 6.1. Source Code Directory

\begin{tabular}{|l|l|l|}
\hline Program Name & Source Code File & Auxiliary Files \\
\hline GeoSTOMP & geo_stomp.f & \\
InvSTOMP & inv_stomp.f & \\
PlotTec & plot_tec.f & \multirow{2}{*}{ commons, parameters } \\
STOMP & stomp1_sp.f & \\
TankSTOMP & tank_stomp.f & \\
Surfcalc & surfcalc.c & \\
Combobtcs & combobtcs.c & \\
Disp & point3d_disp.f & \\
\hline
\end{tabular}

\subsection{Geology}

Zonation files to define the rock/soil-type and inactive-node distributions were generated using the GeoSTOMP and TankSTOMP utilities from input files that contained geometric information obtained by digitizing cross sections from the geology reported in Kahleel et al. (2001). These lithologic descriptions were based on inferences drawn from groundwater monitoring wells near the B-BX-BY tank farms and from grain size data and supplemented by information from tank farm drywells and excavation (e.g., Price and Fecht 1976a,b). Developing zonation files was a two-step procedure, where the rock/soil 
distributions and above-ground inactive nodes were first defined from the site geology as defined in Khaleel et al. (2001). The distribution of tank inactive nodes was then incorporated into the zonation file from the tank locations and geometry as defined by Khaleel et al. (2001). The utility GeoSTOMP was executed to create the geology and above-ground zonation file, and the utility TankSTOMP was then executed to embed the tank geometries into the zonation file. Zonation files are stored in the "xsect" subdirectories of the"bx" and "B-38" directories. A catalogue of the input files for the GeoSTOMP and TankSTOMP utilities and zonation files for the investigated simulations given in Table 6.2. Rock/soil zonation files can be visualized as two-dimensional color-scaled images with Tecplot by opening the layout file for the cross section of interest.

Table 6.2. Rock/Soil and Inactive-Node Distribution Files

\begin{tabular}{|l|l|l|}
\hline File Name & Description & File Type \\
\hline bxtanks_zonation.plt & Converted zonation file with embedded tanks & Tecplot Ascii \\
B-38_zonation.plt & Converted zonation file & Tecplot Ascii \\
*_output.geo & GeoSTOMP reference output & Text \\
*.geos & GeoSTOMP input file & Text \\
bx.tanks & TankSTOMP input file & Text \\
*_geology.lay & Tecplot layout file for rock/soil zonation & Tecplot Layout \\
bxtanks_zonation.asc & STOMP rock/soil zonation file with embedded tanks & Text \\
\hline * indicates the cross-section indicator (e.g., bx or B-38). \\
\hline
\end{tabular}

\subsection{Initial Inventory}

Inventory files to define the initial inventory distribution of the three solute species (U-238, Tc-99, and $\mathrm{NO}_{3}$ ) were generated from tabular input (MDP, Appendix D) with the utility InvSTOMP for the BX-108 to BX-102 cross section. Inventory files are stored in two directories "conc" and "conc-shifted," which respectively correspond to the Base Case inventory that has a starting location east of Tank BX-102 and extends to the east fence line, and the shifted inventory scenario that centers the inventories between tanks BX-105 and -102 (MDP, Appendix D). A catalogue of the input files for the InvSTOMP utility and initial inventory distribution files for the investigated simulations is given in Table 6.3, where the solute species indicators, $\mathrm{u}$, tc, and no3, refer to the solute species U-238, Tc-99, and $\mathrm{NO}_{3}$, respectively. Initial inventory distribution files can be visualized as two-dimensional color-scaled images with Tecplot by opening the layout file for the cross section of interest.

Table 6.3. Initial Inventory Distribution Files

\begin{tabular}{|l|l|l|}
\hline \multicolumn{1}{|c|}{ File Name } & \multicolumn{1}{|c|}{ Description } & \multicolumn{1}{c|}{ File Type } \\
\hline inv_*_bx & InvSTOMP input file & Text \\
bx_*_inv.asc & STOMP initialinventory-distribution input file & Text \\
bx_*inv.asc.plt & Tecplot formatted file of initial inventory distribution & Text \\
bx_*_inv.lay & Tecplot layout file for initial inventory distribution & Tecplot Layout \\
\hline * represents the solute species (e.g., u, tc, or no3). \\
\hline
\end{tabular}




\subsection{Steady Flow Simulations}

Steady flow simulations were executed to generate initialcondition flow fields for each of the transient solute transport simulations. These simulations were executed with the STOMP simulator, which produced a "restart" file that described the steady flow field. The input, output, and restart files are catalogued in Table 6.4, where the cross section indicators bx and B-38 refer to two different domains developed from BX-HH'. Steady-flow files are stored in the "ssflow" subdirectories of the individual numbered case directories. Restart files generated by the flow simulation and used in the transport simulation are stored in the ssflow subdirectories.

Table 6.4. Steady Flow Initial Condition Files

\begin{tabular}{|l|l|l|}
\hline File Name & Description & File Type \\
\hline input & STOMP input file & Text \\
output & STOMP reference-node output file & Text \\
plot & STOMP plot-file output file & Text \\
restart & STOMP restart file & Text \\
\hline
\end{tabular}

\subsection{Coupled Vadose Zone and Unconfined Aquifer Modeling}

Coupled vadose zone and unconfined aquifer modeling files are stored in directories named according to case number (e.g., directory "case1" holds files associated with the Base Case (Case 1) simulations). Within these directories are subdirectories for the steady-state flow and transport simulations. These hold input files, zonation files, reference-node output files, plot-file output files, surface-flux output files, converted plot-file output, Tecplot layout files, solute concentration and mass flux data files, and images. In addition to cross-section subdirectories, the case directory holds shell-script files, Latex text files, and averaged solute concentration and mass flux data files. Table 6.5 summarizes the naming conventions for the files stored under each case directory.

For each transient flow and solute transport simulation, the STOMP simulator reads an input file, restart file, zonation file, and solute inventory file and generates one reference-node output file, one or more plot-file output files, and one surface-flux output file. The STOMP-generated plot-file output files were converted to Tecplot ASCII format using the PlotTec utility. These ascii files, when visualized through Tecplot, were used to generate color-scaled images of saturation, and solute concentration for selected points in time.

The STOMP generated surface-flux output files were translated to ascii mass flux and concentration text format using prefpsurf.c and combobtc.c utilities. These files contain aqueous volumetric flux and solute mass flux at the WMA boundary with the groundwater for every simulation year. These data files were translated to area-weighted average data files for use in plotting breakthrough curves.

Plot-file output can be viewed as color-scaled two-dimensional images by opening the layout file for the cross section of interest. Surface-flux output and breakthrough curves can be viewed as plots using standard graphing software (e.g., gnuplot, Excel) for the cross section of interest. Reference-node data can be viewed by editing the reference-node output file. 
Table 6.5. Coupled Vadose Zone and Unconfined Aquifer Modeling Files

\begin{tabular}{|l|l|l|}
\hline File Name & Description & File Type \\
\hline input & STOMP simulator input & Text \\
output & STOMP simulator reference-node output \\
surface & STOMP simulator surface-flux output \\
cn_*_yr_\#.lay & Tecplot layout file for color-scale images of plot-file output \\
p\#.plt & Tecplot data file for color-scale images of plot-file output \\
all_*.dat & Solute-concentration breakthrough data at all compliance points \\
mf_*.dat & Mass-flux breakthrough data at WMA Boundary & Text \\
\hline average.csh & $\begin{array}{l}\text { C Shell script for computing average solute concentration and } \\
\text { mass flux } \\
\text { C Shell script for computing average solute concentration and } \\
\text { mass flux } \\
\text { Area-weighted average solute-concentration breakthrough data } \\
\text { at first compliance point } \\
\text { Area-weighted average mass-flux breakthrough data at first } \\
\text { compliance point } \\
\text { Solute breakthrough curve data at the four compliance points }\end{array}$ & Text \\
c_c\#_ave.dat & Text \\
mf_c\#_ave.dat & Text \\
sp*.btc & $\begin{array}{l}\text { Text } \\
\text { Notes: is the plot file number indicator (e.g., plot.175, plot.3462, etc) } \\
\text { cn is the case number (e.g., case1, case2,...case13) } \\
\text { yr represents time [e.g., ini (initial), fin (final), or 2020 (year)]. } \\
* \text { represents the plot variable [e.g., sat (saturation), u (aqueous), uvol (total), tc, or no3]. }\end{array}$ \\
\hline
\end{tabular}

\subsection{Analytical Groundwater Transport Modeling}

Data files (input, output, and csh script files) for the analytical groundwater transport model were archived in the case figure directories (bxfigs and trenchfigs) (Table 6.6). C-Shell scripts for running the analytical model (disp) and generating plots are included in these directories. These scripts (runpoint.csh) also contain the flow-path length, velocities, and hydraulic parameters. The analytical model script creates output files for each species that contains the time and calculated concentrations at each compliance point in columns. Additional scripts were developed and archived in the case directories for generating plots from the analytical results (runcombo.csh and rungnu.csh). These scripts were executed for each case directory to generate the encapsulated postscript files for the plots of the results used in this report. 
Table 6.6. Analytic al Groundwater Transport Modeling Files

\begin{tabular}{|l|l|l|}
\hline File Name & Description & File Type \\
\hline Runpoint.csh & $\begin{array}{l}\text { C-Shell script for executing the analytical model } \\
\text { (includes model parameters) }\end{array}$ & Text \\
mf_*.dat & $\begin{array}{l}\text { Solute mass flux input to analytical model (area- } \\
\text { weighted averages @ fence line boundary ) }\end{array}$ & Text \\
$\begin{array}{l}\text { ptriv_*.btc \& } \\
\text { etexc_*.btc }\end{array}$ & $\begin{array}{l}\text { Solute breakthrough curves at the two compliance } \\
\text { points (river and exclusion boundary) }\end{array}$ & Text \\
\hline * indicates the solute specie (e.g., u (aqueous), uvol (total), tc, or no3). \\
\hline
\end{tabular}




\subsection{References}

Baetslé LH. 1969. "Migration of radionuclides in porous media." Progress in Nuclear Energy Series XII, Health Physics, AMF Duhamel, ed. Pergamon Press, Elmsford, NY, pp. 707-730.

Bear J. 1985. "Conceptual and Mathematical Modeling of Groundwater Flow and Pollution: An Overview." American Society of Civil Engineers Hydraulics Specialty Conference, August 12-17, 1985, Lake Buena Vista, FL.

Bergeron MP and SK Wurstner. 2000. Groundwater Calculations Supporting the 2001 Immobilized Low-Activity Waste Disposal Facility Performance Assessment at the Hanford Site in Southeastern Washington. PNNL-13400, Pacific Northwest National Laboratory, Richland, WA.

Bergeron MP, E Freeman, S Wurstner, CT Kincaid, FM Coony, D Strenge, R Aaberg, and P Eslinger. 2001. Addendum to Composite Analysis for Low-Level Waste Disposal in the 200 Area Plateau of the Hanford Site. PNNL-11800-Addendum 1, Pacific Northwest National Laboratory, Richland, WA.

Bramley R and X Wang. 1995. SPLIB: A Library of Iterative Methods for Sparse Linear Systems. Indiana University, Bloomington.

Cole CR, SK Wurstner, MP Bergeron, MD Williams, and PD Thorne. 1997. Three-Dimensional Analysis of Future Groundwater Flow Conditions and Contaminant Plume Transport in the Hanford Site Unconfined Aquifer System: FY 1996 and 1997 Status Report. PNNL-11801, Pacific Northwest National Laboratory, Richland, WA.

Cole CR, MP Bergeron, SK Wurstner, PD Thorne, S. Orr, and MI McKinley. 2001. Transient Inverse Calibration of Hanford Site-Wide Groundwater Model to Hanford Operational Impacts-1943 to 1996. PNNL-13447, Pacific Northwest National Laboratory, Richland, WA.

Dormuth KW and RB Lyon. 1985. "The Link Between Process Models and Simplified Models." Proceedings of the Nuclear Energy Agency Workshop, Paris, pp. 81-87.

Domenico PA and FW Schwartz. 1990. Physical and Chemical Hydrogeology. John Wiley \& Sons, New York, pp. 824.

Gardner WR. 1958. "Some Steady-State Solutions of the Unsaturated Moisture Flow Equation with Applications to Evaporation From a Water Table.” Soil Science, 85:228-232.

Gelhar LW. 1993. Stochastic Subsurface Hydrology. Prentice Hall, Englewood Cliffs, NJ.

Gupta SK, CR Cole, CT Kincaid, and AM Monti. 1987. Coupled Fluid, Energy, and Solute Transport (CFEST) Model: Formulation and User's Manual, BMI/ONWI-660, Battelle Memorial Institute, Columbus, $\mathrm{OH}$.

Gupta SK. 1996. Draft User's Manual, CFEST-96 Flow and Solute Transport, Constant/Variable Density, Computationally Efficient, and Low Disk PC/Unix Version. Environmental System Technologies, Irvine, CA.

Haass CC. 1999. Engineering Report: Single-Shell Tank Farms Interim Measures to Limit Infiltration Through the Vadose Zone. RPP-5002 Rev. 0, Lockheed Martin Hanford Corp., Richland, WA.

Kaplan DL and RJ Serne. 1999. Geochemical Data Package for the Immobilized Low-Activity Waste Performance Assessment. PNNL-13037, Pacific Northwest National Laboratory, Richland, WA. 
Khaleel R, TE Jones, AJ Knepp, FM Mann, DA Myers, PM Rogers, RJ Serne, and MI Wood. 2001. Modeling Data Package for S-SX Field Investigation Report (FIR). RPP-6296 Rev. 0, CH2MHILL Hanford Group, Inc., Richland, WA.

Kincaid CT, MP Bergeron, CR Cole, MD Freshley, NL Hassig, VG Johnson, DI Kaplan, RJ Serne, GP Streile, DL Strenge, PD Thorne, LW Vail, GA Whyatt, and SK Wurstner. 1998. Composite Analysis for Low-Level Waste Disposal in the 200-Area Plateau of the Hanford Site. PNNL-11800, Pacific Northwest National Laboratory, Richland, WA.

Kincaid CT, JW Shade, GA Whyatt, MG Piepho, K Rhoads, JA Voogd, JH Westsik Jr, MD Freshley, KA Blanchard, and BG Lauzon. 1995. Performance Assessment of Grouted Double-Shell Tank Waste Disposal at Hanford. WHC-SD-WM-EE-004 Rev. 1, Westinghouse Hanford Company, Richland, WA.

Kincaid CT, MP Bergeron, CR Cole, MD Freshley, NL Hassig, VG Johnson, DI Kaplan, RJ Serne, GP Streile, DL Strenge, PD Thorne, LW Vail, GA Whyatt, and SK Wurstner. 1998. Composite Analysis for Low-Level Waste Disposal in the 200-Area Plateau of the Hanford Site. PNNL-11800, Pacific Northwest National Laboratory, Richland, WA.

Law A, S Panday, C Denslow, K Fecht, and A Knepp. 1996. Hanford Site-Wide Groundwater Flow and Transport Model Calibration Report. BHI-00608 Rev. 0, Bechtel Hanford, Inc., Richland, WA.

Lindsey KA and KD Reynolds. 2001. Vadose Zone Geology of Boreholes 299-E33-45 and 299-E33-46 B-BX-BY Waste Management Area, Hanford Site, South-Central Washington. RPP-8681 Rev. 0, CH2MHILL Hanford Group, Inc., Richland, WA.

Lu AH. 1996. Contaminant Transport in the Unconfined Aquifer; Input to the Low Level Tank Waste Interim Performance Assessment. WHC-SD-WM-RPT-214, Westinghouse Hanford Co., Richland, WA.

Mann FM, RJ Puigh II, SH Finfrock, EJ Freeman, R Khaleel, DH Bacon, MP Bergeron, BP McGrail, and SK Wurstner. 2001. Hanford Immobilized Low-Activity Tank Waste Performance Assessment, 2001 Version. DOE/ORP-2000-24, U.S. Department of Energy Office of River Protection, Richland, WA. Millington RJ and JP Quirk. 1961. "Permeability of Porous Media.” Nature 183:387-388.

Mualem Y. 1976. "A New Model for Predicting the Hydraulic Conductivity of Unsaturated Porous Media." Water Resources Research 12:513-522.

National Research Council (NRC). 1990. Ground Water Models, Scientific and Regulatory Applications. National Academy Press, Washington, D.C.

Nichols WE, M Oostrom, and MD White. 2000. STOMP Subsurface Transport Over Multiple Phases, Version 2.0, Application Guide. PNNL-12028, Pacific Northwest National Laboratory, Richland, WA.

Polmann DJ. 1990. Application of Stochastic Methods to Transient Flow and Transport in Heterogeneous Unsaturated Soils. Ph.D. Thesis, Massachusetts Institute of Technology, Cambridge.

Price WH and KR Fecht. 1976a. Geology of the 241-S Tank Farm. ARH-LD-133, Atlantic Richfield Hanford Company, Richland, WA.

Price WH and KR Fecht. 1976b. Geology of the 241-SX Tank Farm. ARH-LD-134, Atlantic Richfield Hanford Company, Richland, WA.

Rittmann PD. 1999. Exposure Scenarios and Unit Dose Factors for the Hanford Immobilized LowActivity Tank Waste Performance Assessment. HNF-SD-WM-TI-707 Rev. 1., Fluor Daniel Northwest, Inc., Richland, WA. 
Talbott ME and LW Gelhar. 1994. Performance Assessment of a Hypothetical Low-Level Waste Facility: Groundwater Flow and Transport Simulation. NUREG/CR-6114 Vol. 3, U.S. Nuclear Regulatory Commission, Washington, D.C.

Theis CV. 1935. "The Relation Between the Lowering of the Piezometric Surface and the Rate and Duration of Discharge of a Well Using Groundwater Storage." Americal Union Transactions 16:519-524.

van Genuchten MT. 1980. "A Closed-Form Equation for Predicting the Hydraulic Conductivity of Unsaturated Soils.” Soil Science Society of America Journal 44:892-898.

Washington State Department of Ecology, United States Environmental Protection Agency, and United States Department of Energy. 1989 and as Amended Through December 31, 1998. Hanford Federal Facility Agreement and Consent Order. 89-10 Rev. 5, Ecology, EPA, and DOE, Olympia, Washington.

White MD and M Oostrom. 2000a. STOMP Subsurface Transport Over Multiple Phases, Version 2.0, Theory Guide. PNNL-12030, Pacific Northwest National Laboratory, Richland, WA.

White MD and M Oostrom. 2000b. STOMP Subsurface Transport Over Multiple Phases, Version 2.0, User's Guide. PNNL-12034, Pacific Northwest National Laboratory, Richland, WA.

White MD, M Oostrom, MD Williams, CR Cole and MP Bergeron. 2001. FY00 Initial Assessments for $S$-SX Field Investigation Report (FIR): Simulations of Contaminant Migration with Surface Barriers. PNWD-3111, Pacific Northwest National Laboratory, Richland, WA.

Wurstner SK, PD Thorne, MA Chamness, MD Freshley, and MD Williams. 1995. Development of a Three-Dimensional Groundwater Model of the Hanford Site Unconfined Aquifer System: FY 1995 Status Report. PNL-10886, Pacific Northwest Laboratory, Richland, WA.

Yeh AW-G. 1986. "Review of Parameter Identification Procedures in Groundwater Hydrology: The Inverse Problem.” Water Resour. Res. 22(2):95-108.

Yeh TCJ, LW Gelhar and AL Gutjahr. 1985. "Stochastic Analysis of Unsaturated Flow in Heterogeneous Soils, 2. Statistically Anisotropic Media with Variable $\alpha$. . Water Resources Research 21:457-464. 
Appendix A: BX Saturation and Concentration Distributions 

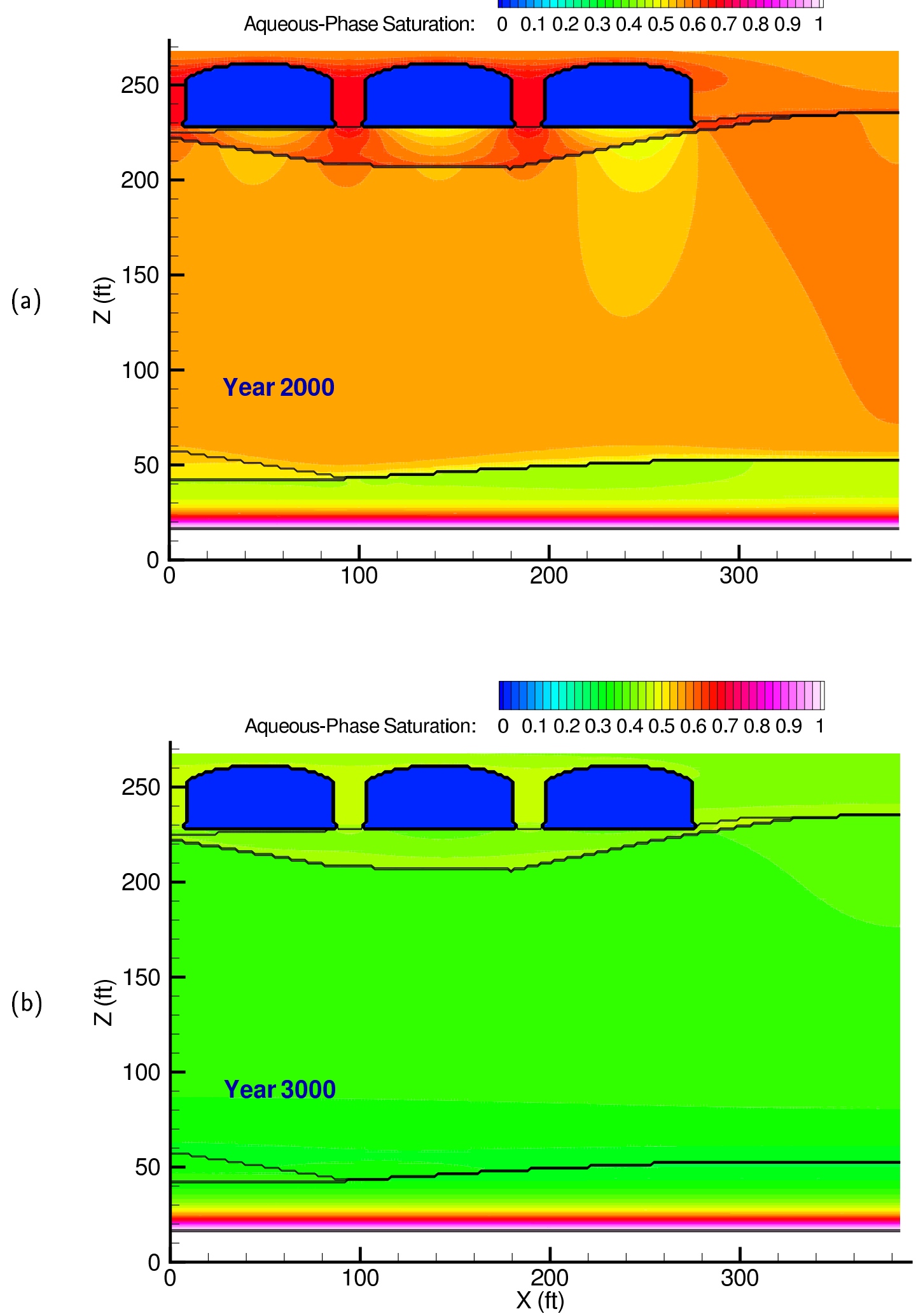

Figure A.1. Case 1 aqueous phase saturation distributions (100 mm/yr recharge) at (a) year 2000 and (b) year 3000 

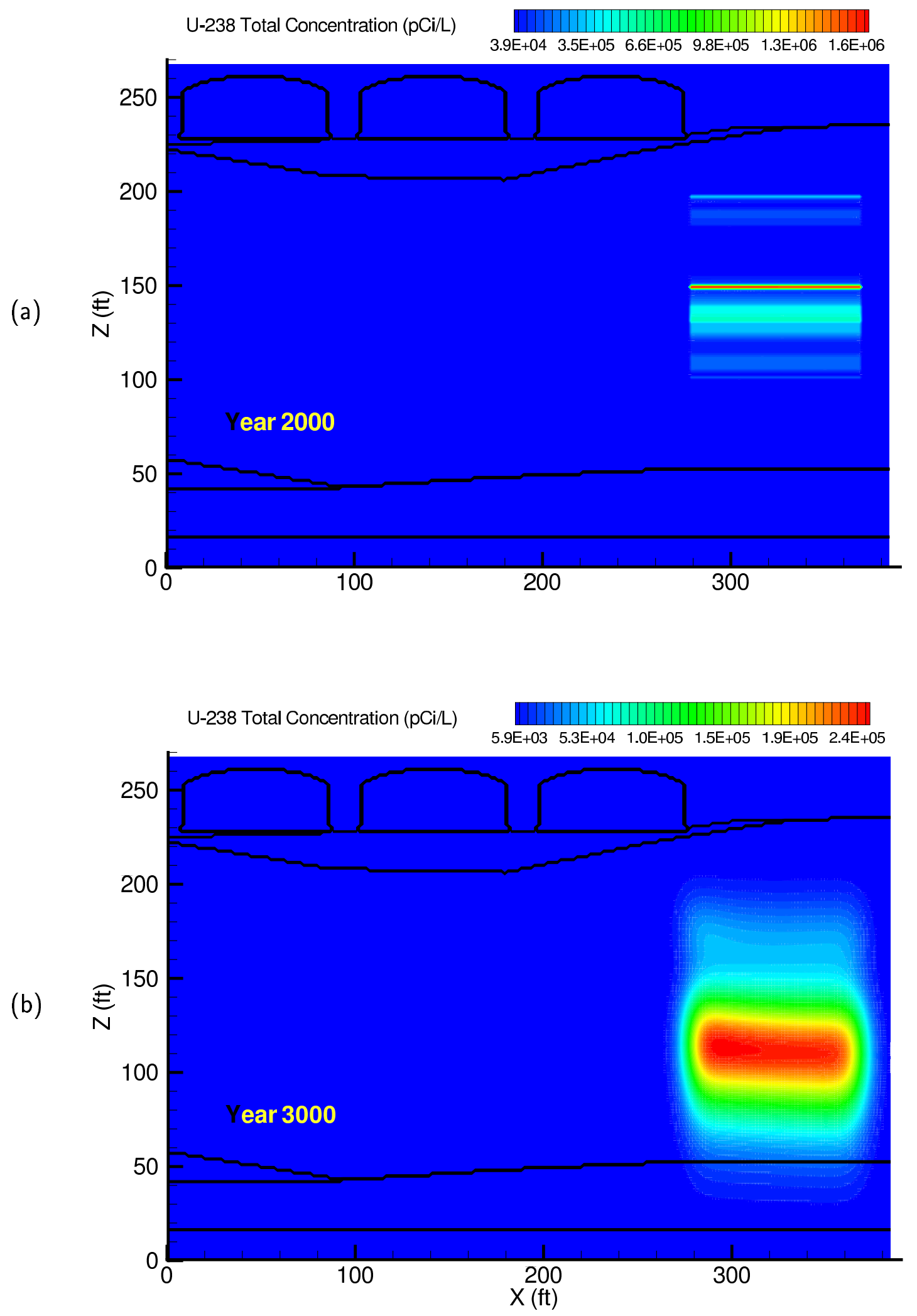

Figure A.2. Case 1 U-238 total concentration distributions at (a) year 2000 and (b) year 3000 (100 $\mathrm{mm} / \mathrm{yr}$ recharge) 

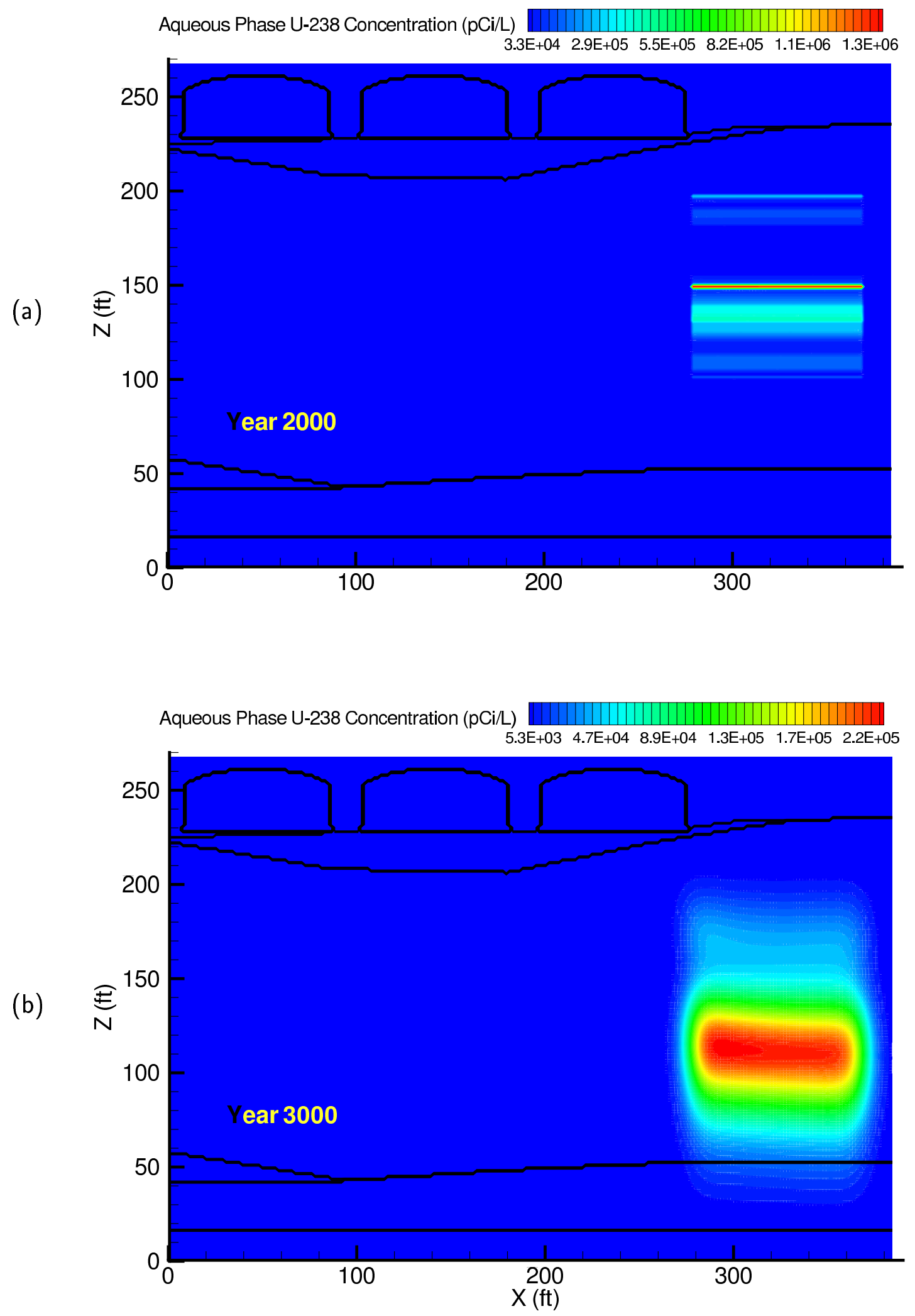

Figure A.3. Case 1 U-238 aqueous concentration distributions at (a) year 2000 and (b) year 3000 (100 mm/yr recharge) 

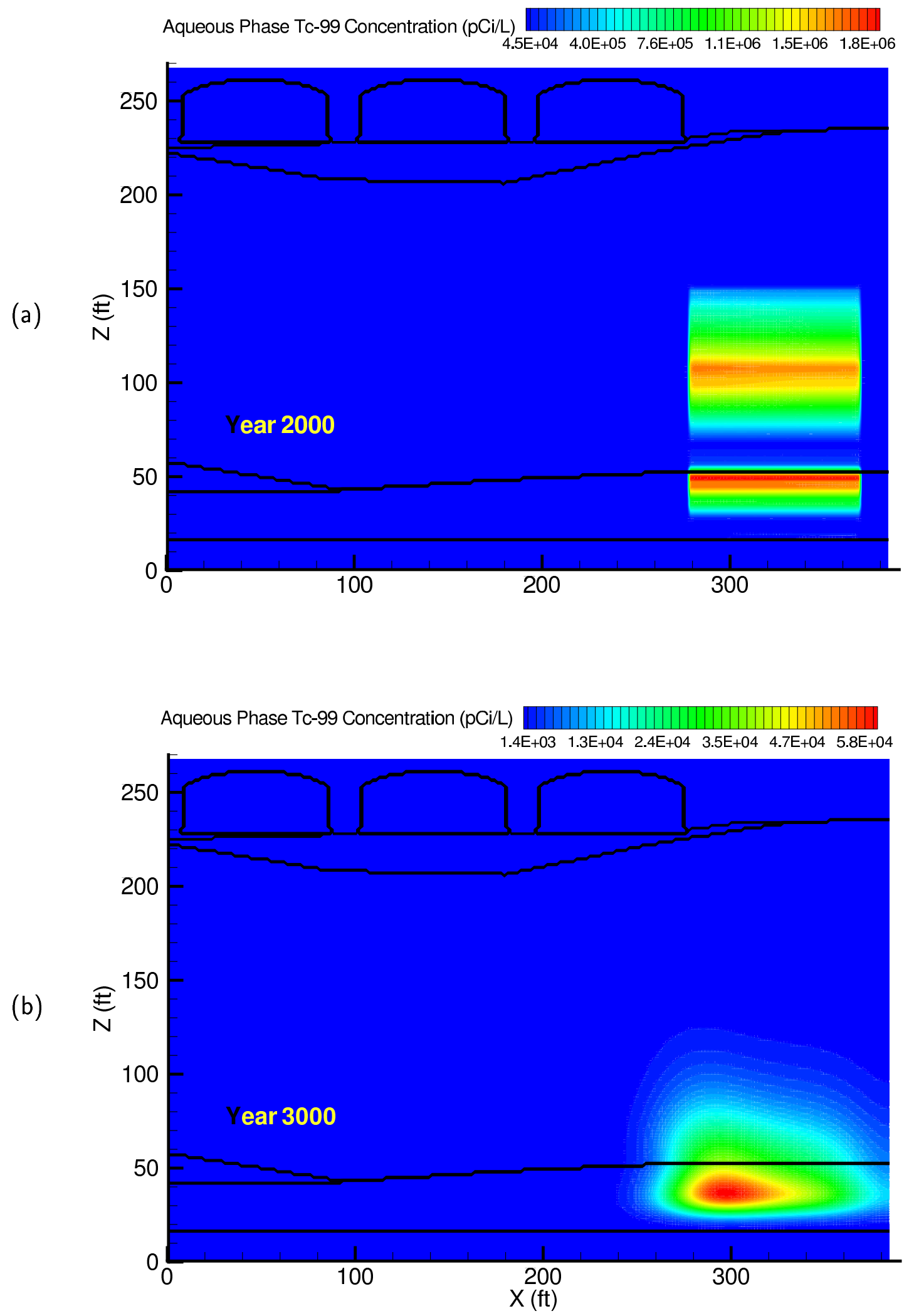

Figure A.4. Case 1 Tc-99 aqueous concentration distributions at (a) year 2000 and (b) year 3000 (100 mm/yr recharge) 

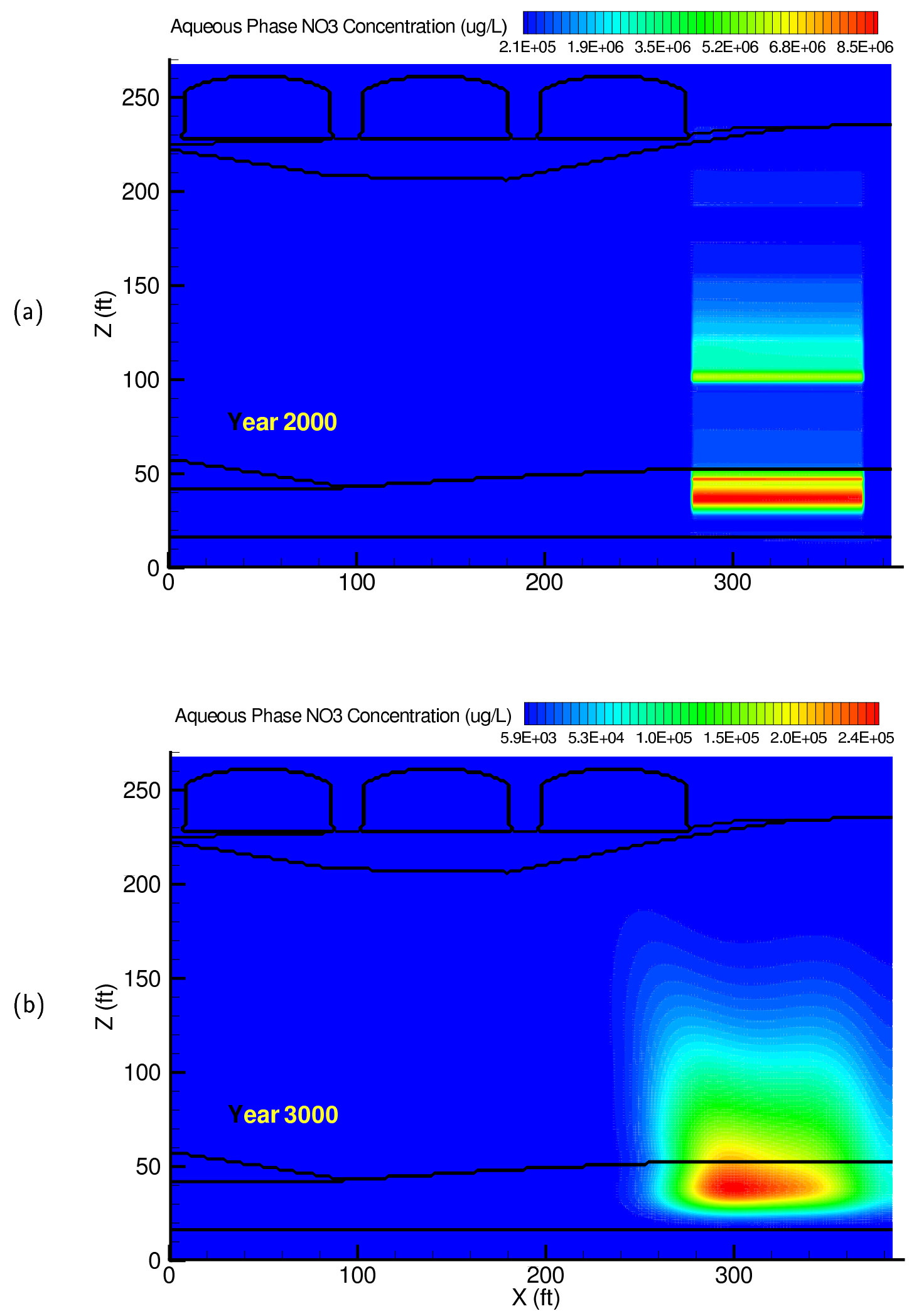

Figure A.5. Case $1 \mathrm{NO}_{3}$ aqueous concentration distributions at (a) year 2000 and (b) year 3000 (100 mm/yr recharge) 


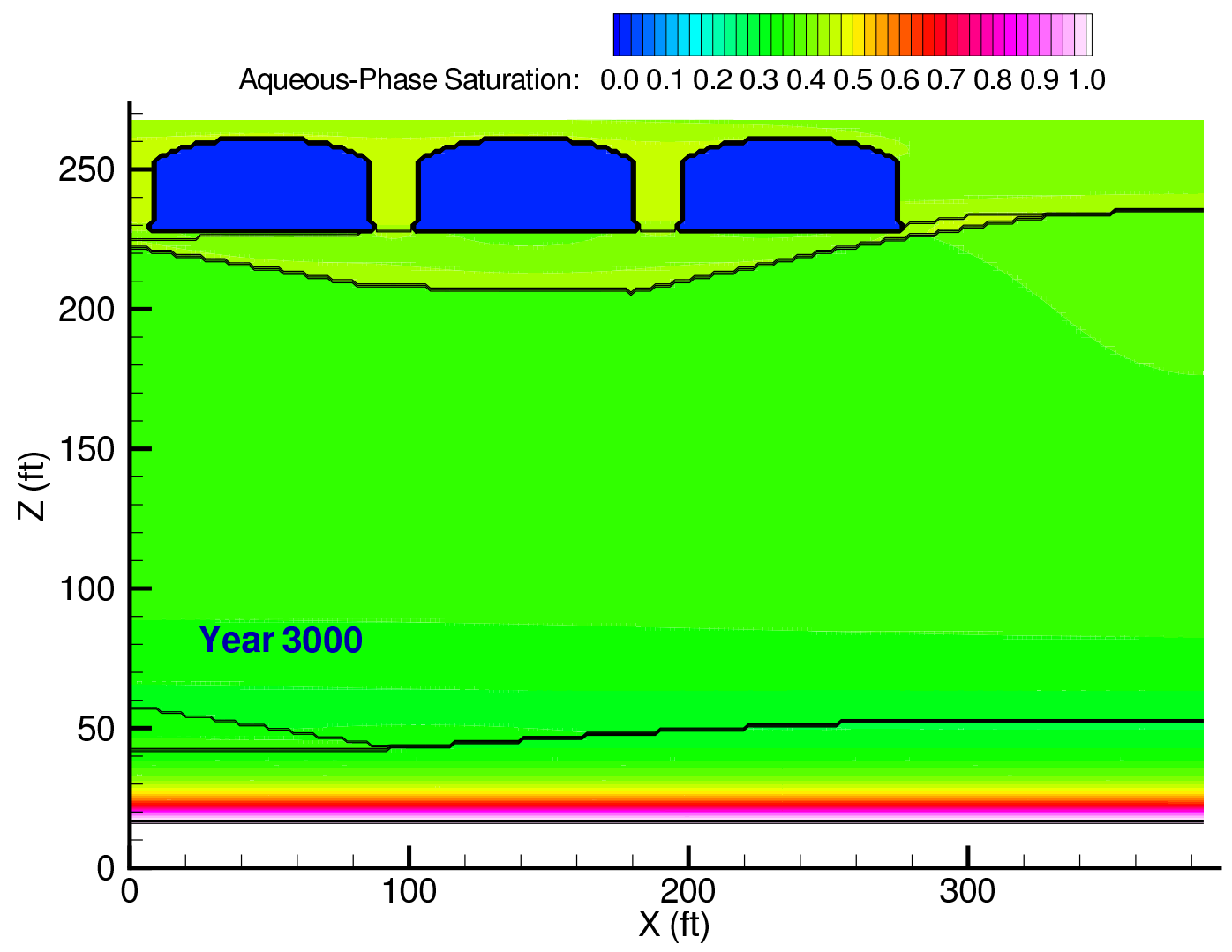

Figure A.6. Case 2 aqueous phase saturation distribution at year 3000 (with interim barrier) 

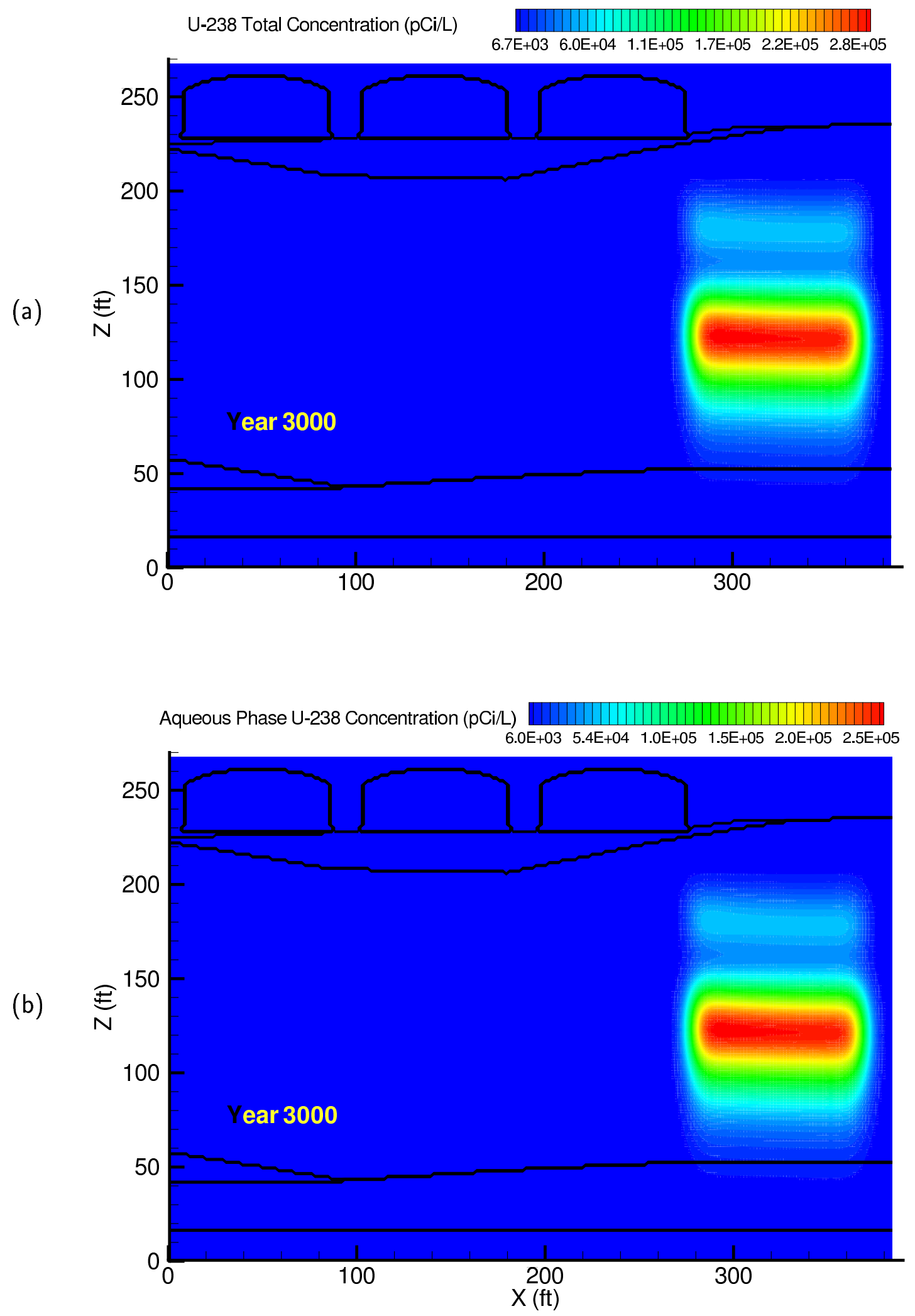

Figure A.7. Case 2 U-238 (a) total and (b) aqueous concentration distributions at year 3000 (with interim barrier) 

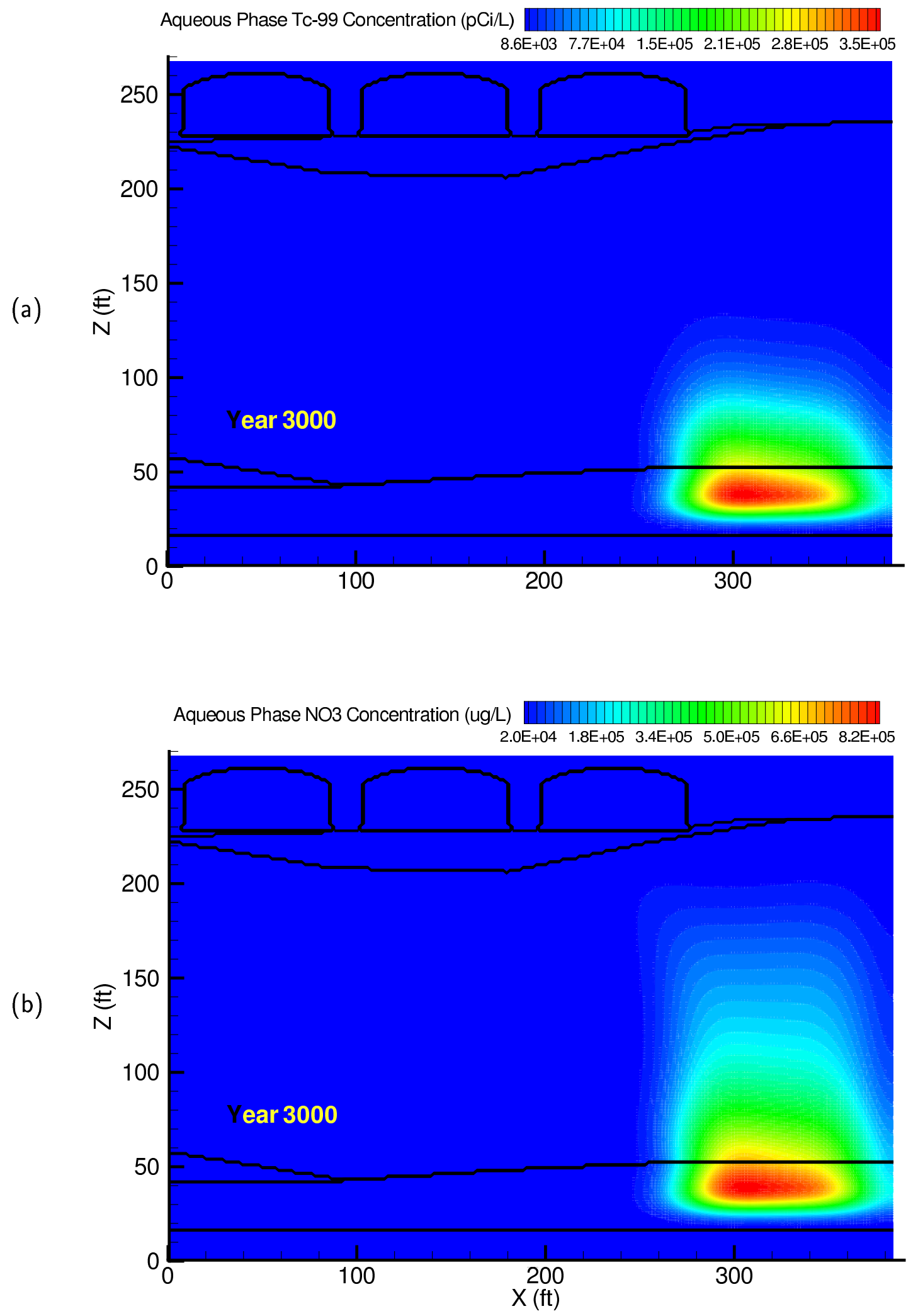

Figure A.8. Case 2 aqueous (a) Tc-99 and (b) $\mathrm{NO}_{3}$ concentration distributions at year 3000 (with interim barrier) 

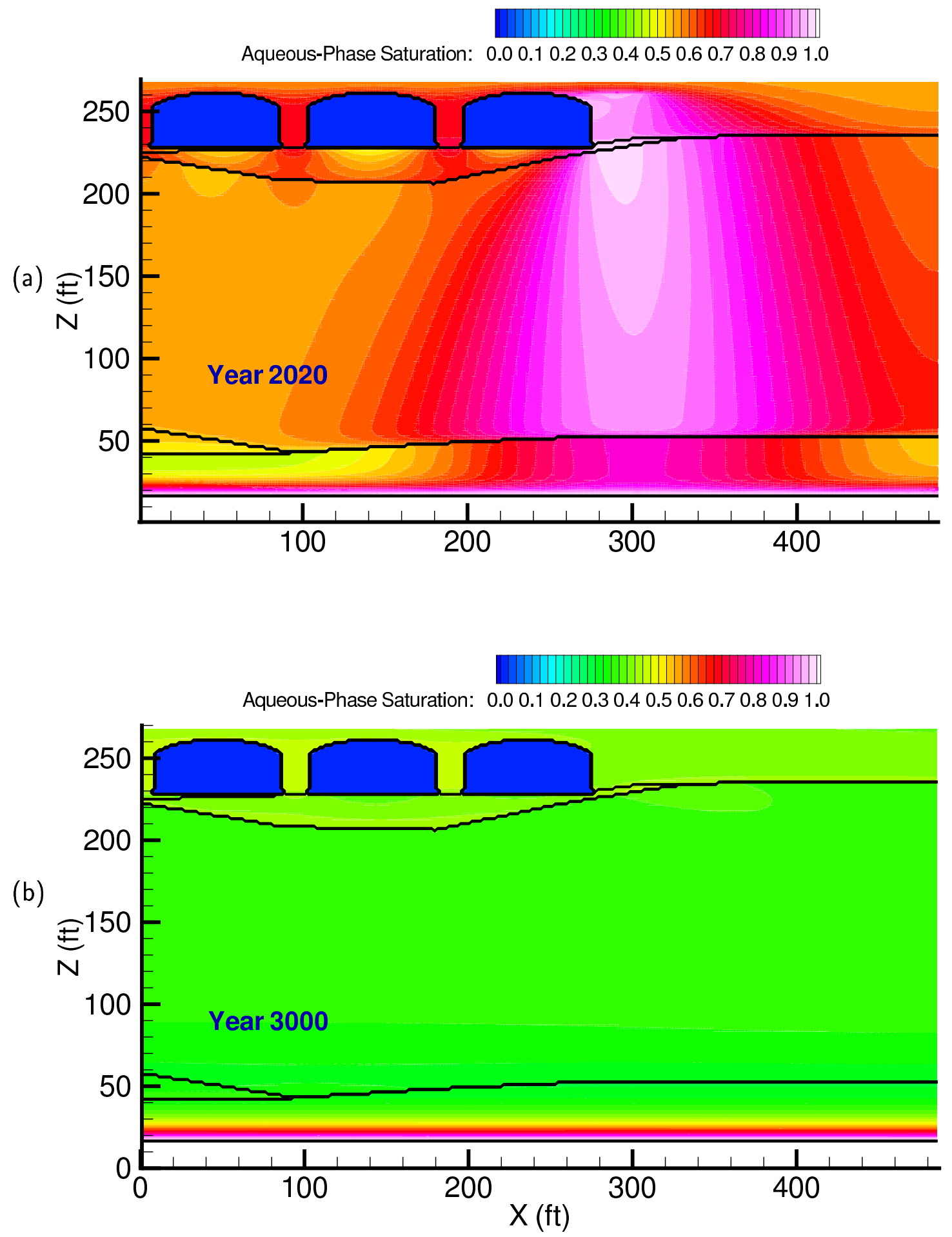

Figure A.9. Case 3 aqueous phase saturations for 20 year water leak at $1 \mathrm{gpm}$ at (a) year 2020 and (b) and year 3000 (100 mm/yr recharge) 

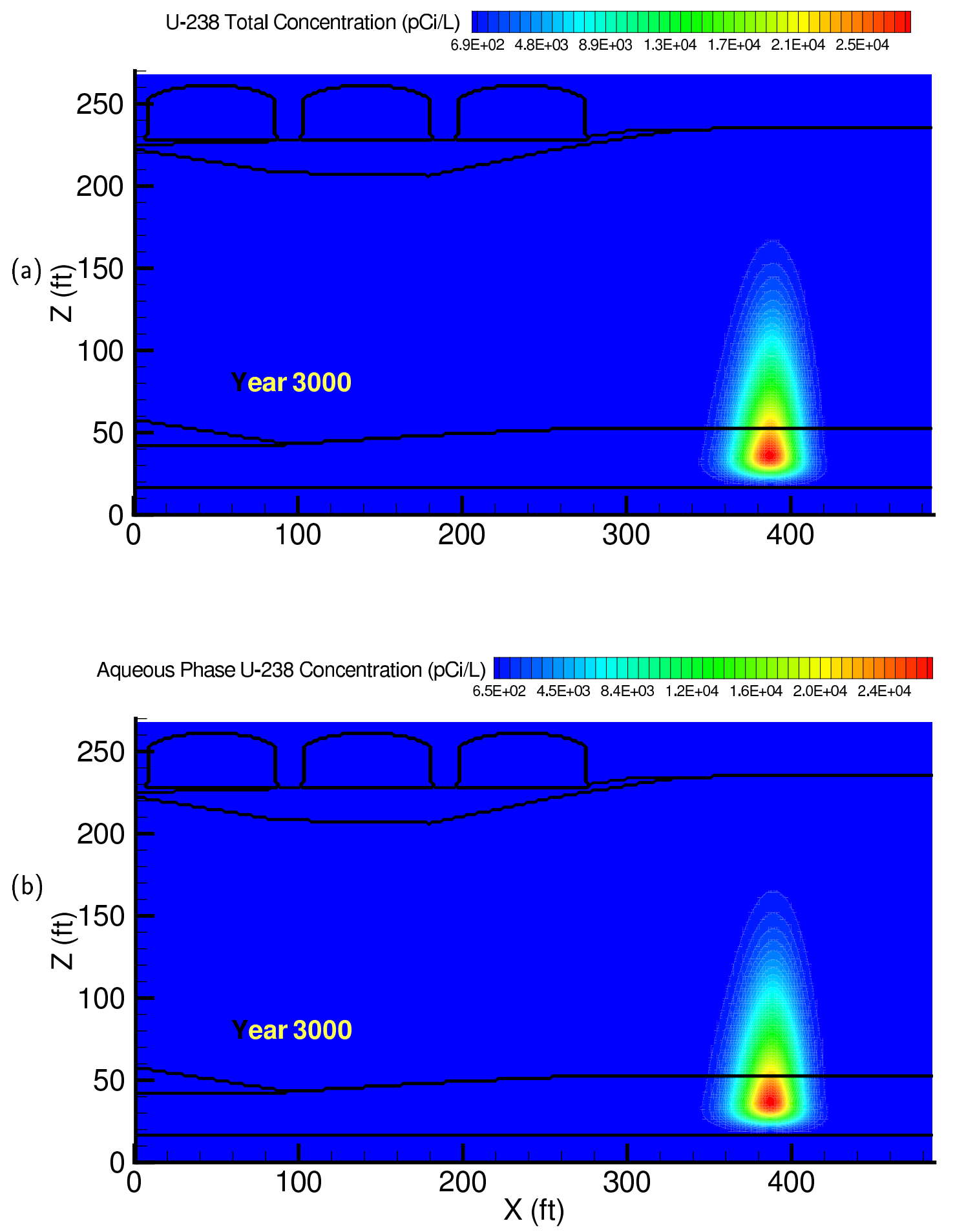

Figure A.10. Case 320 year water leak at 1 gpm for U-238 (a) total and (b) aqueous concentration distributions at year 3000 (100 mm/yr recharge) 

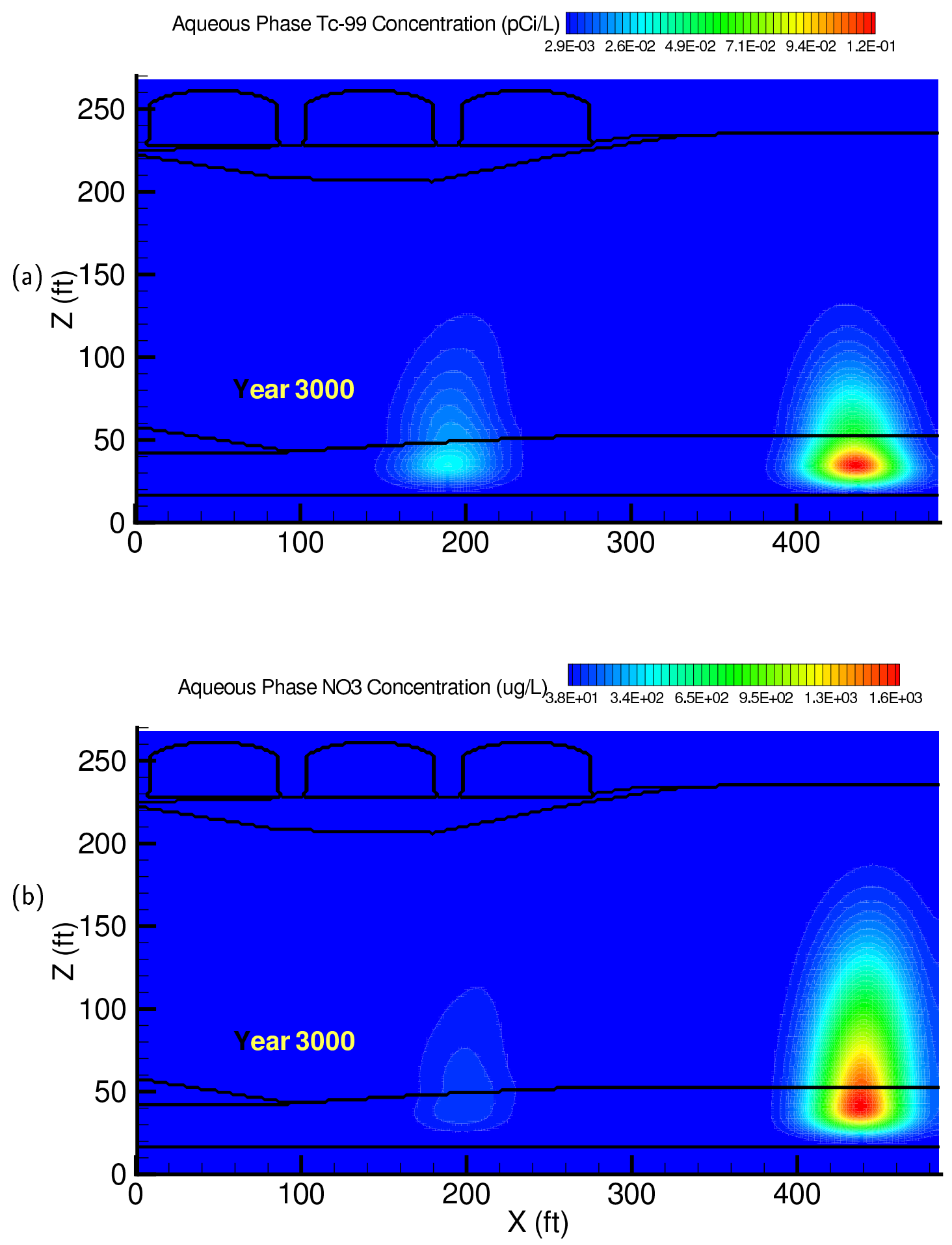

Figure A.11. Case 320 year water leak at 1 gpm for aqueous (a) Tc-99 and (b) $\mathrm{NO}_{3}$ concentration distributions at year $3000(100 \mathrm{~mm} / \mathrm{yr}$ recharge $)$ 

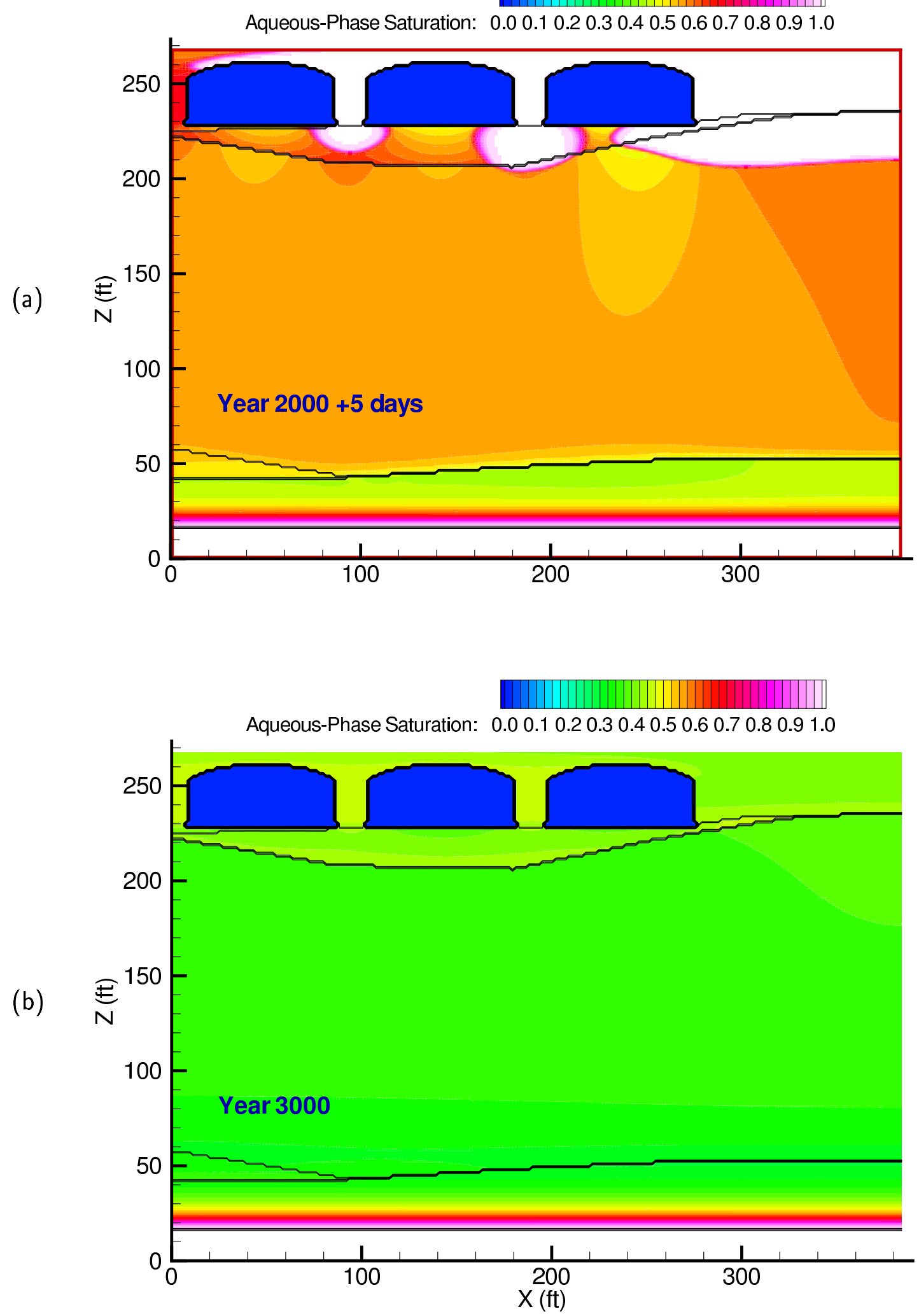

Figure A.12. Case 4 aqueous phase saturations for 200,000 gal over 5 days water leak at (a) year 2000 and 5 days; and (b) year 3000 (100 mm/yr recharge) 

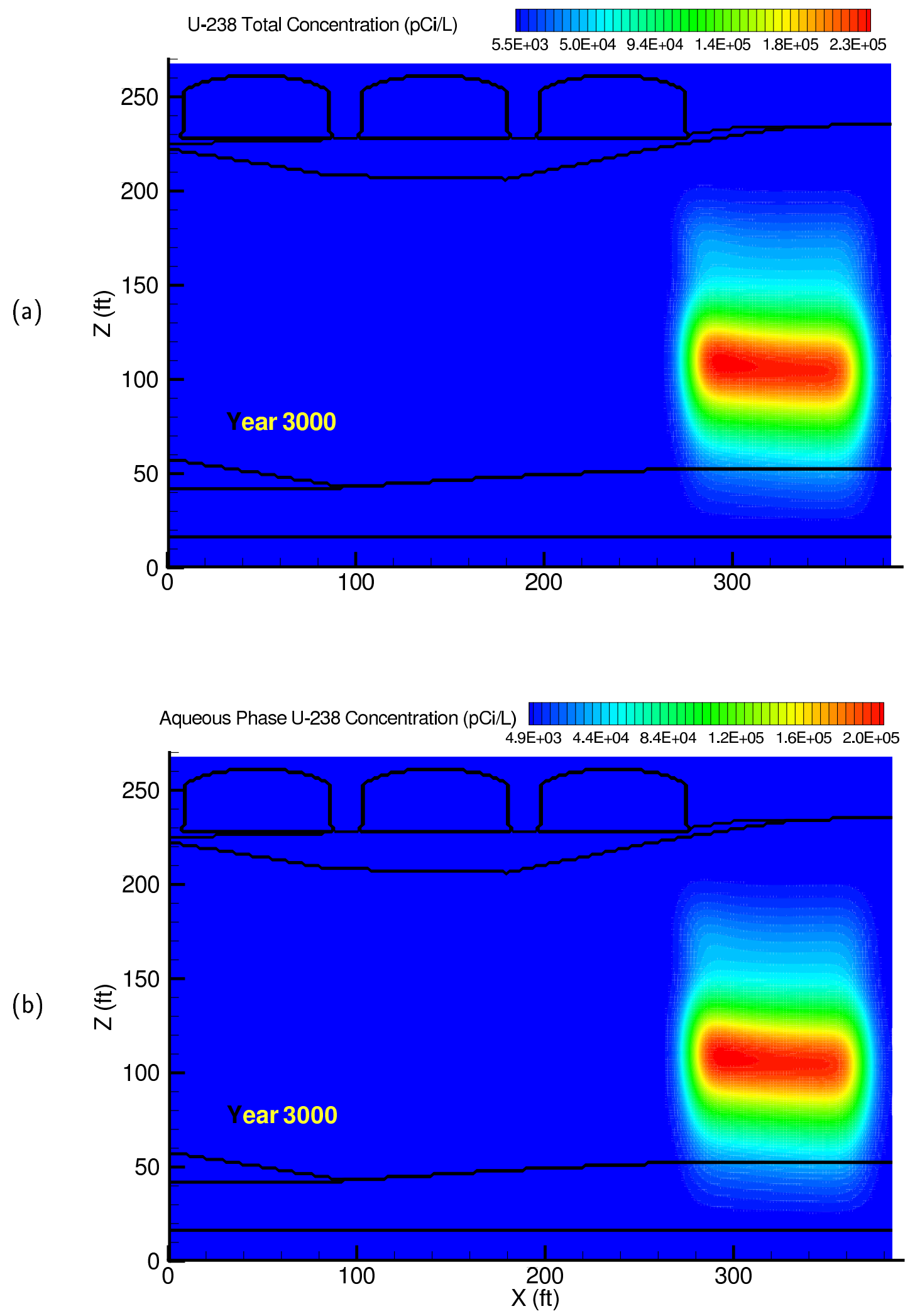

Figure A.13. Case 4 200,000 gal in 5 days water leak for U-238 (a) total and (b) aqueous concentration distributions at year $3000(100 \mathrm{~mm} / \mathrm{yr}$ recharge $)$ 

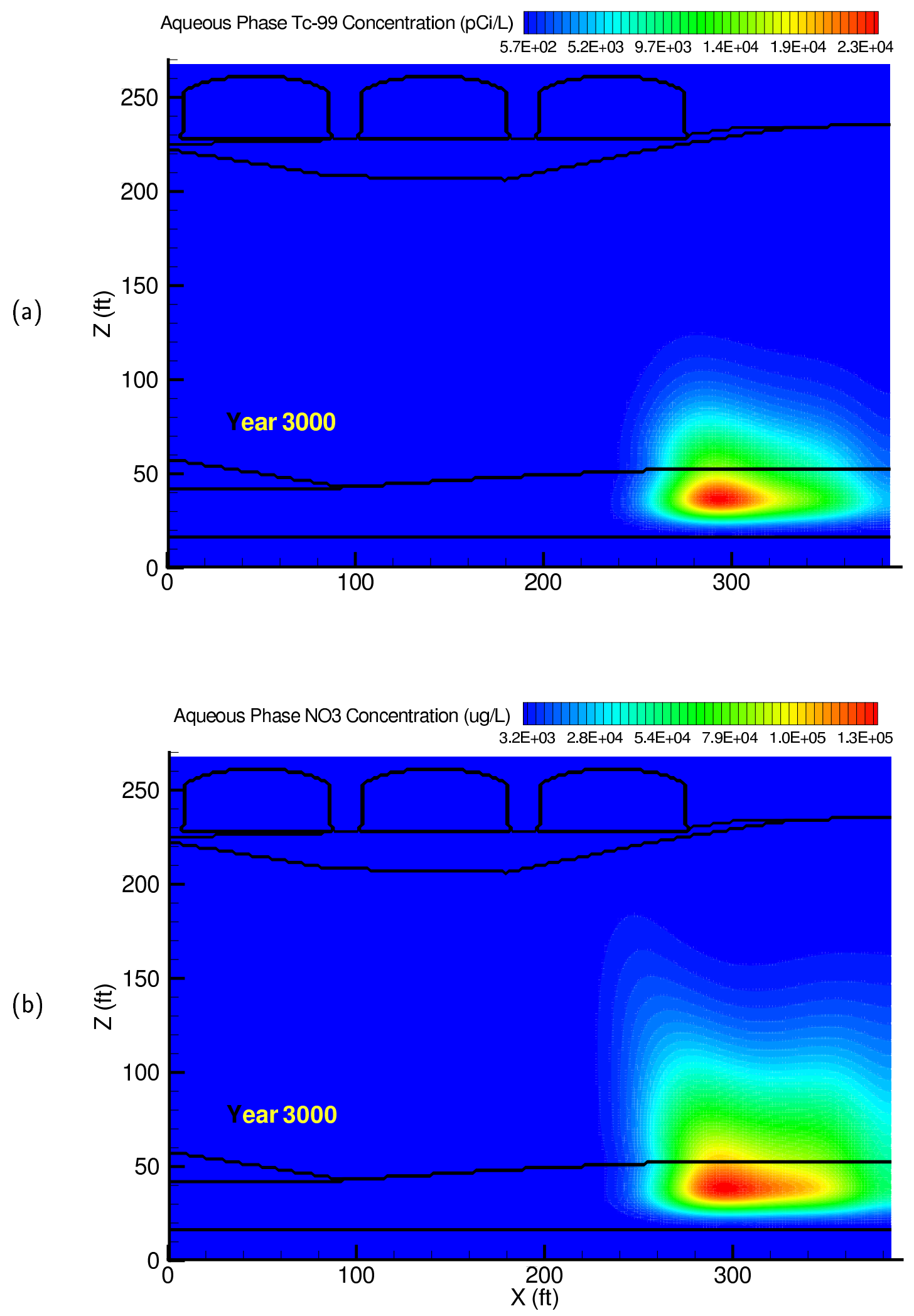

Figure A.14. Case 4 results for 200,000 gal in 5 days water leak for aqueous (a) Tc-99 and (b) $\mathrm{NO}_{3}$ concentration distributions at year $3000(100 \mathrm{~mm} / \mathrm{yr}$ recharge $)$ 

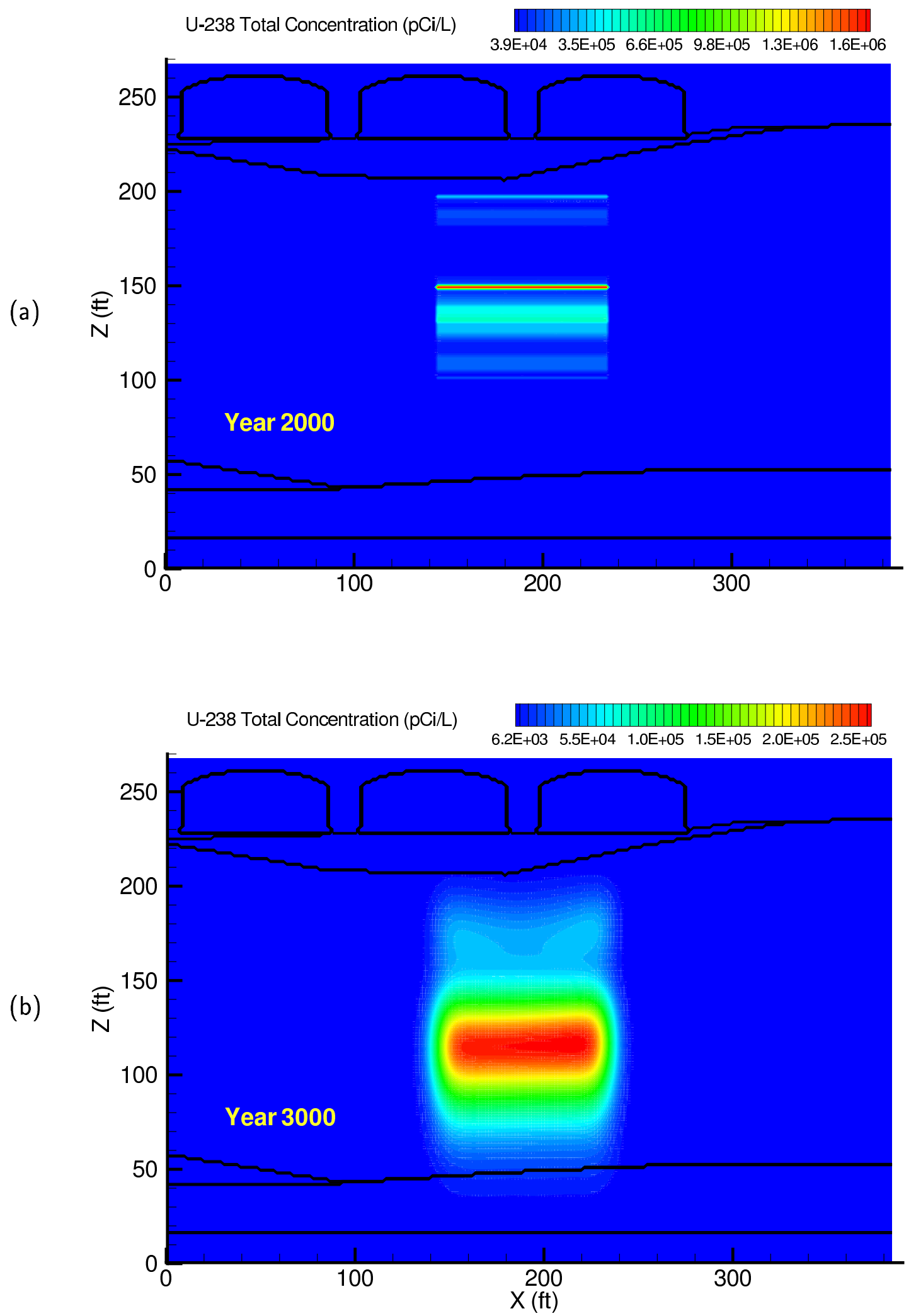

Figure A.15. Case 5 U-238 total concentration distributions at (a) year 2000 and (b) year 3000 (shifted inventory) 

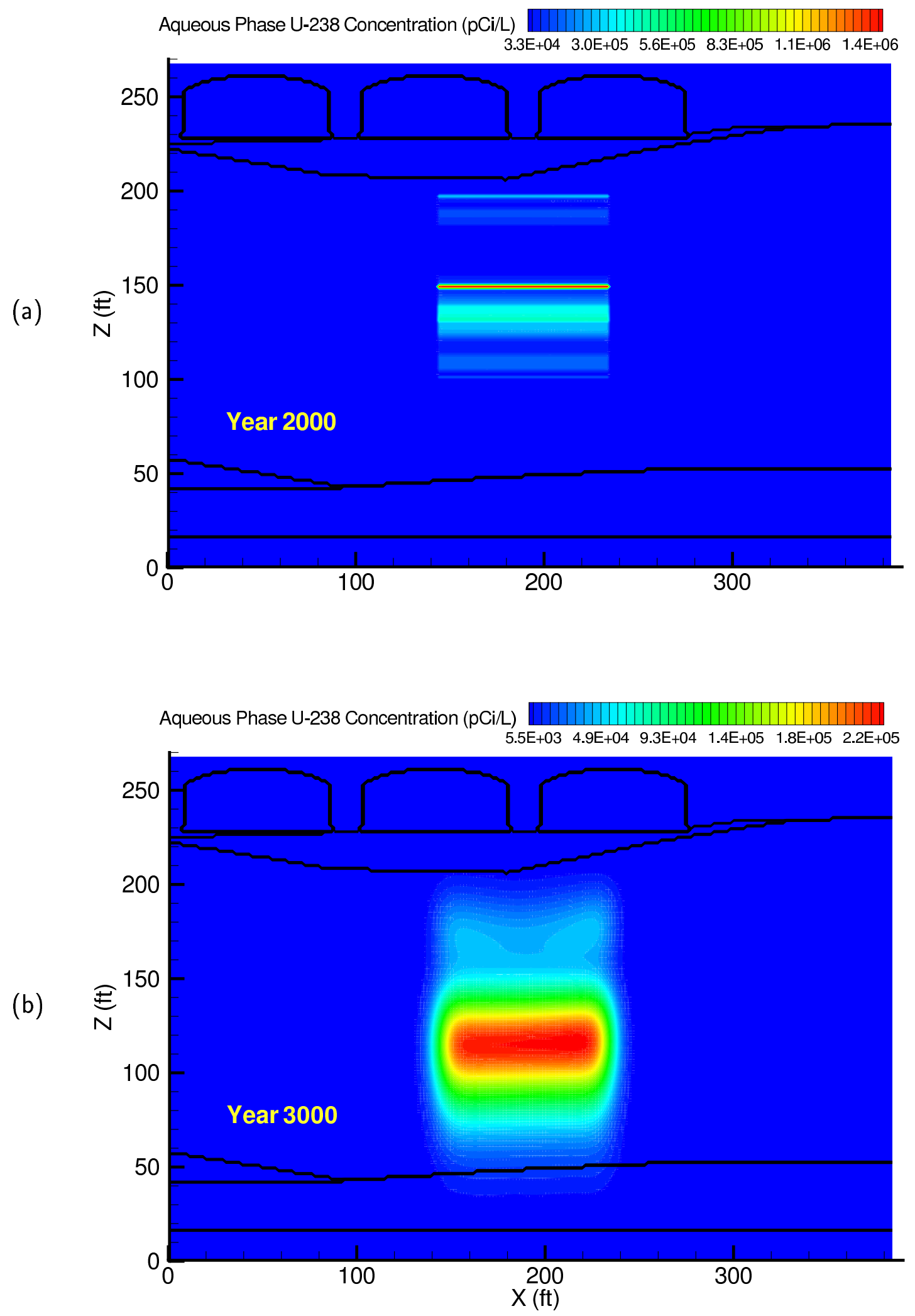

Figure A.16. Case 5 U-238 aqueous concentration distributions at (a) year 2000 and (b) year 3000 (shifted inventory) 

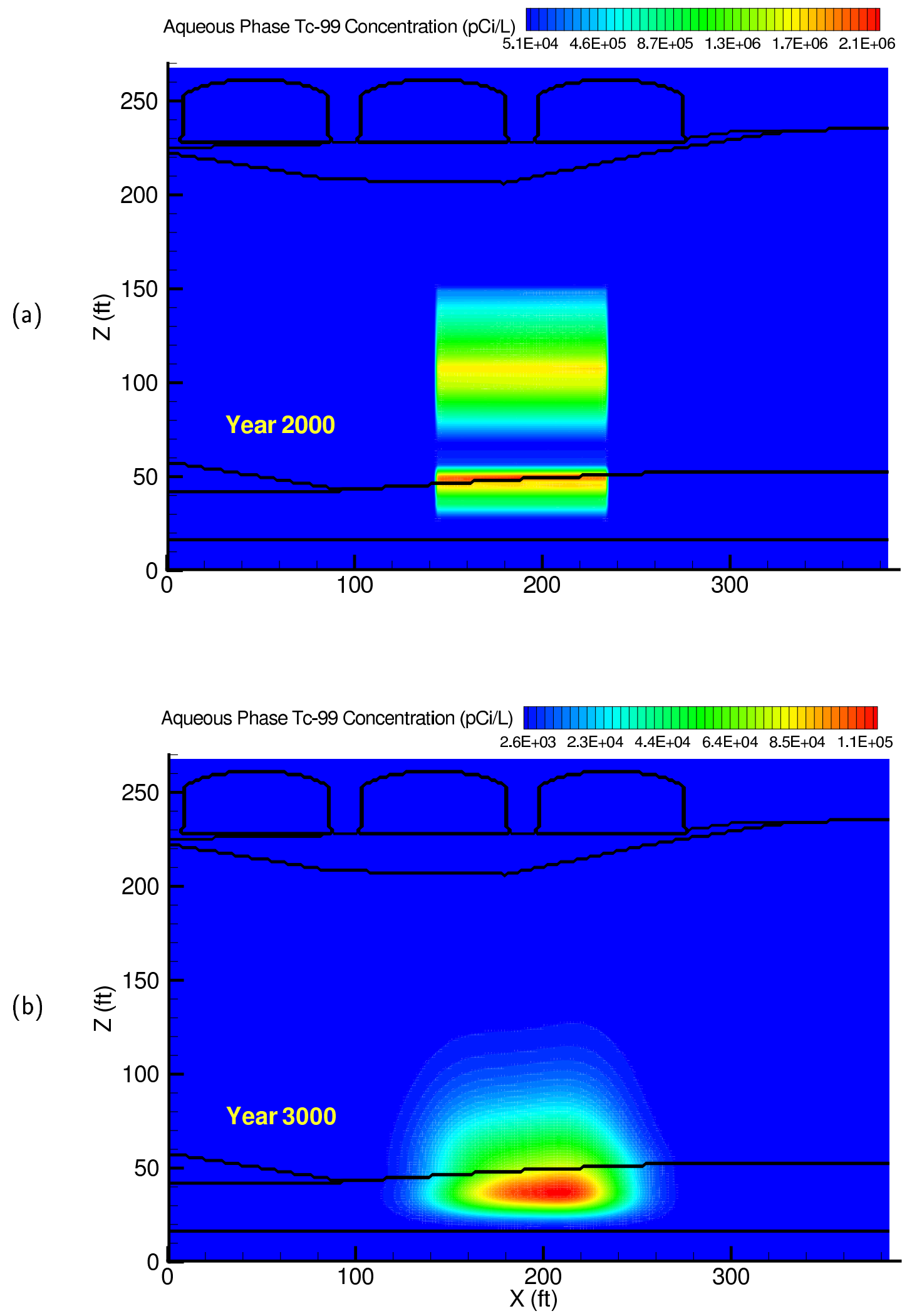

Figure A.17. Case 5 Tc-99 aqueous concentration distributions at (a) year 2000 and (b) year 3000 (shifted inventory) 

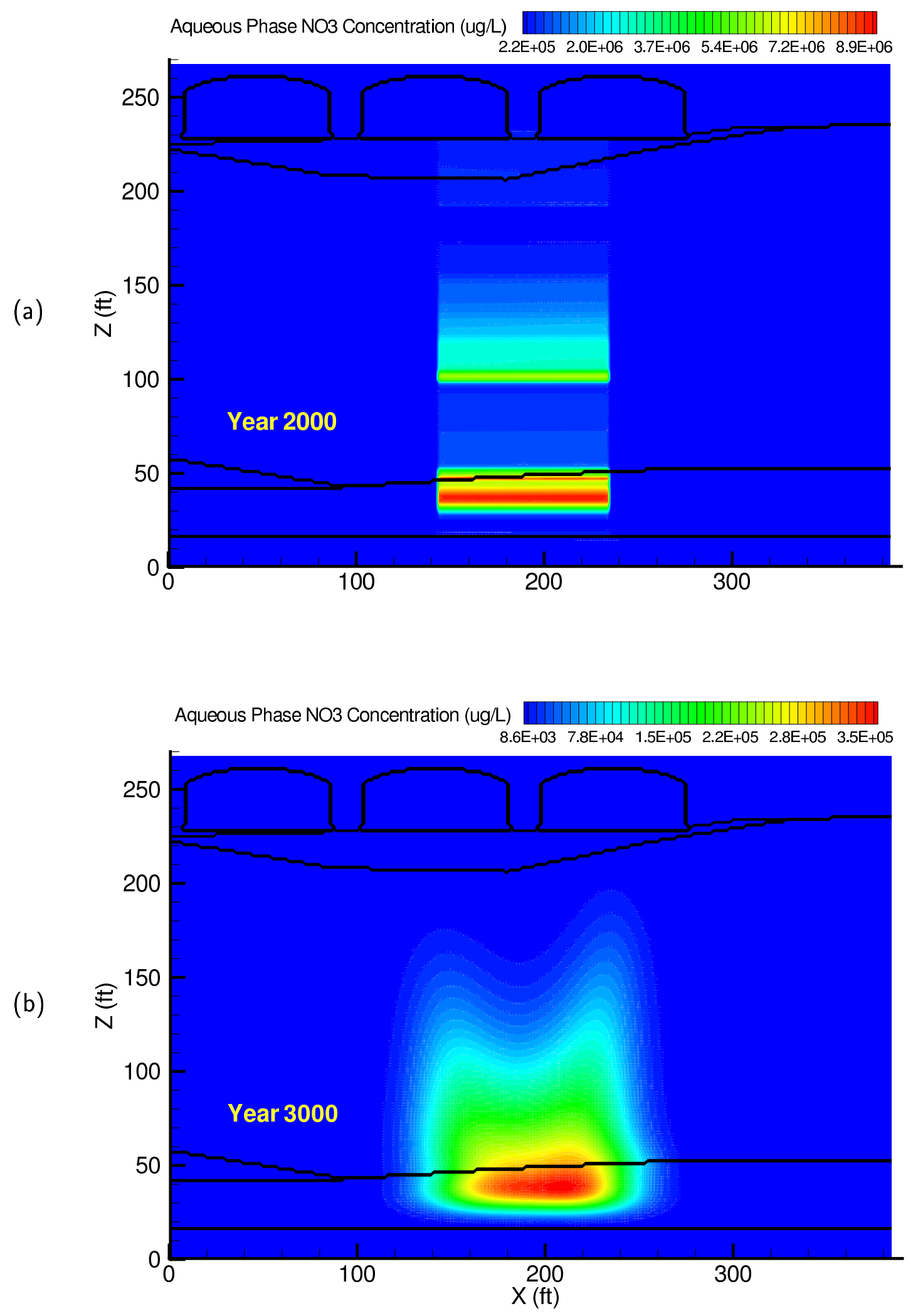

Figure A.18. Case $5 \mathrm{NO}_{3}$ aqueous concentration distributions at (a) year 2000 and (b) year 3000 (shifted inventory) 

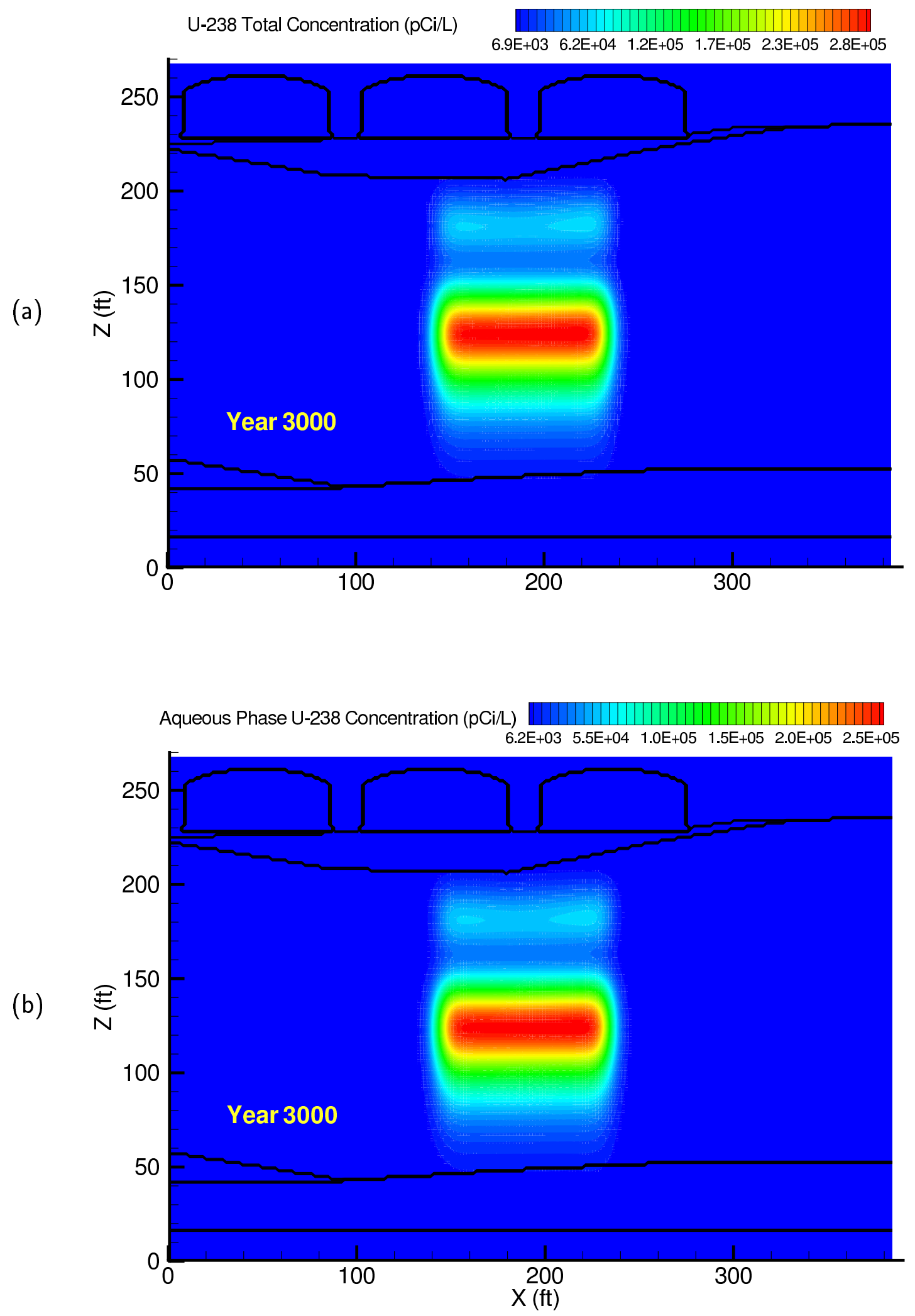

Figure A.19. Case 6 U-238 (a) total and (b) aqueous concentration distributions at year 3000 (shifted inventory with interim barrier) 

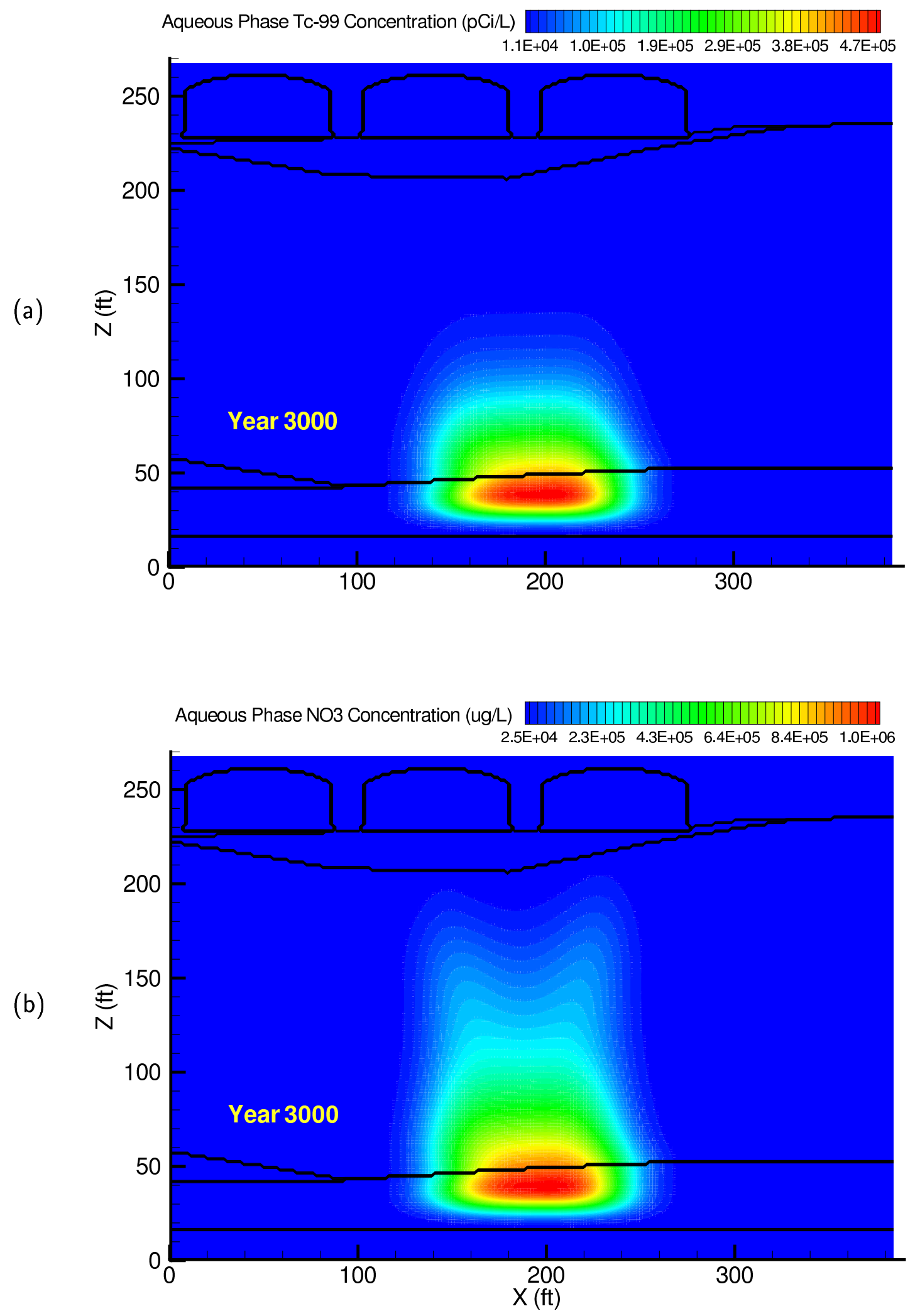

Figure A.20. Case 6 aqueous (a) Tc-99 and (b) $\mathrm{NO}_{3}$ concentration distributions at year 3000 (shifted inventory with interim barrier) 

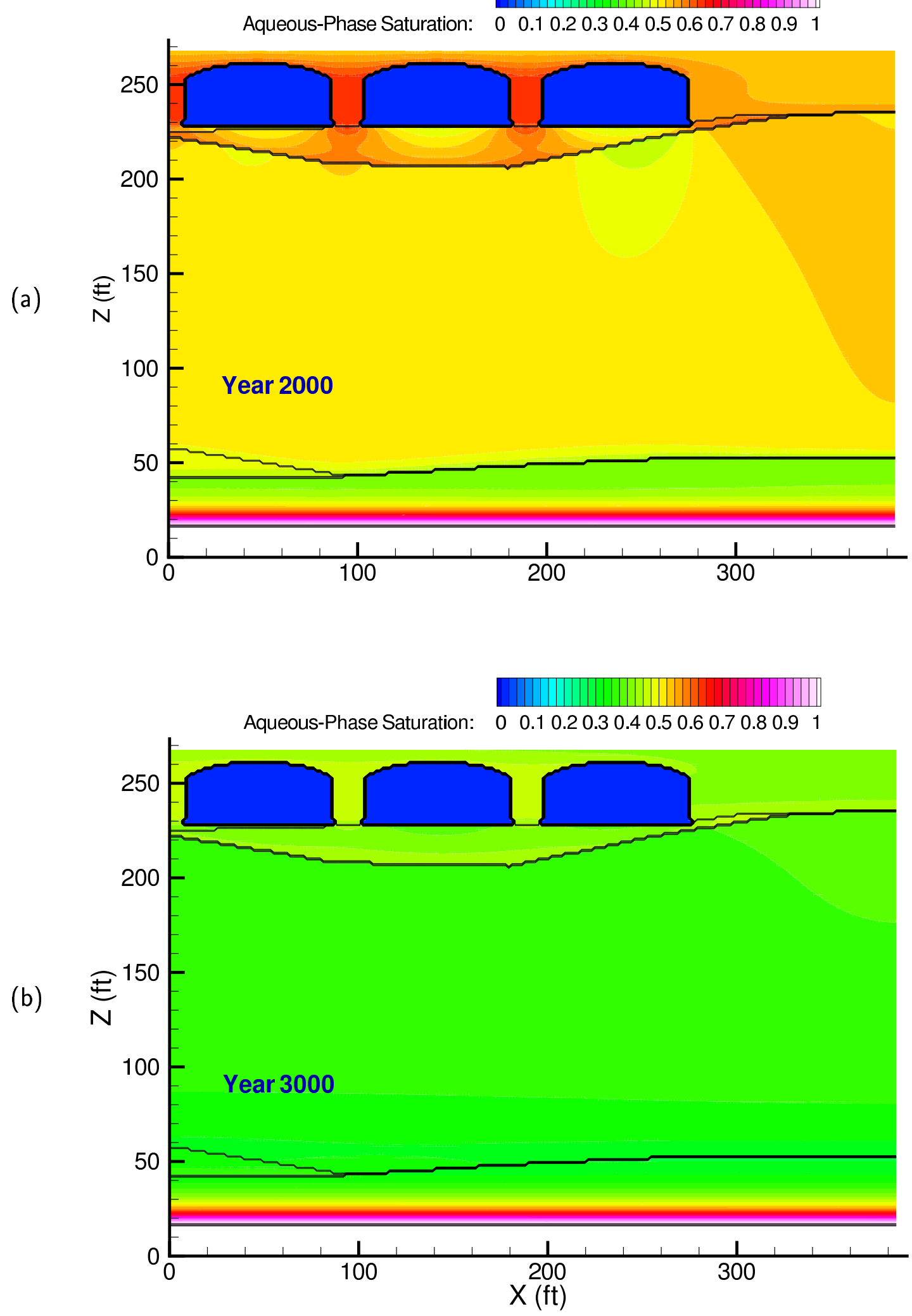

Figure A.21. Case 7 aqueous phase saturation distributions (50 mm/yr recharge) at (a) year 2000 and (b) year 3000 

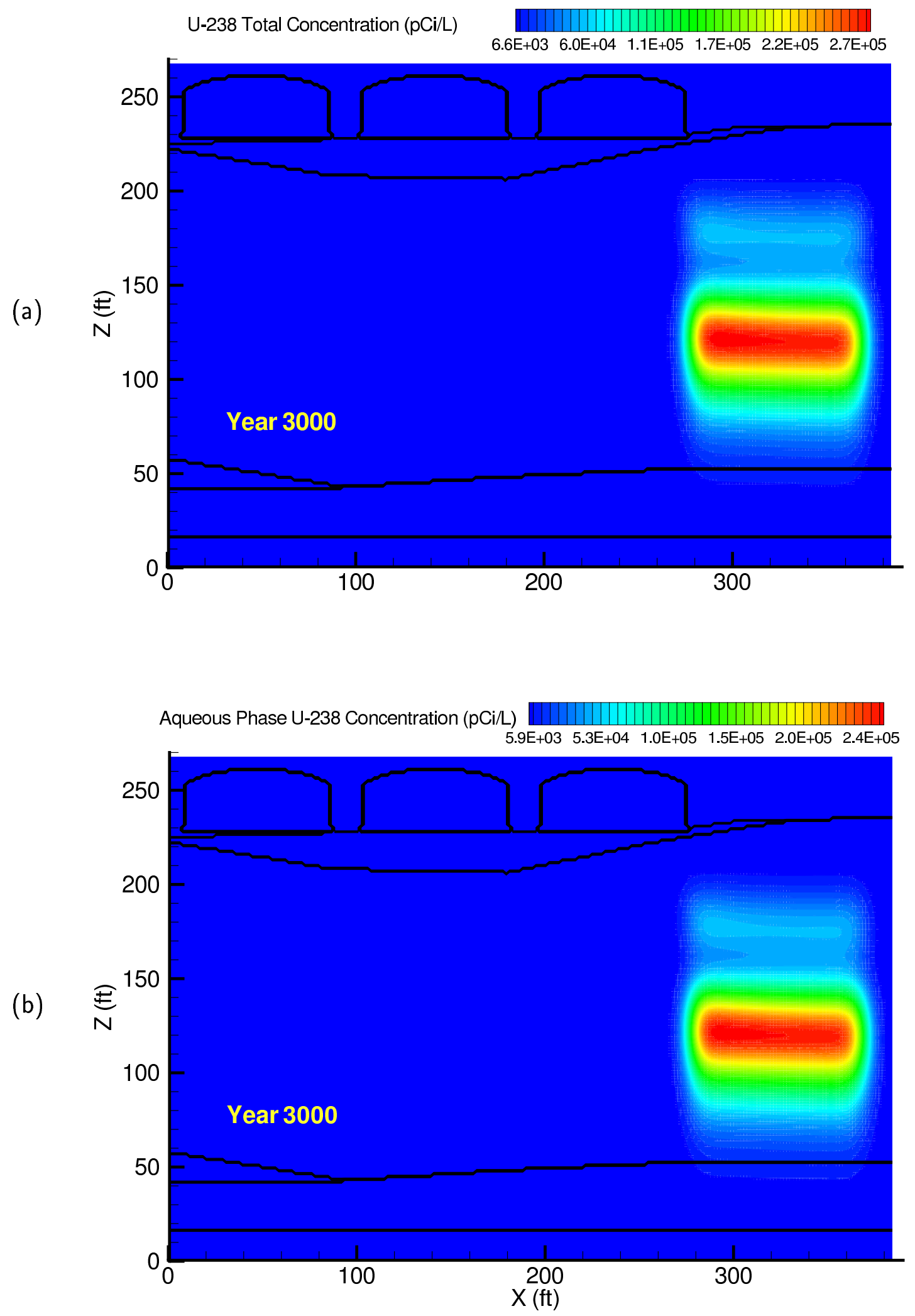

Figure A.22. Case 7 U-238 (a) total and (b) aqueous concentration distributions at year 3000 (50 $\mathrm{mm} / \mathrm{yr}$ recharge) 

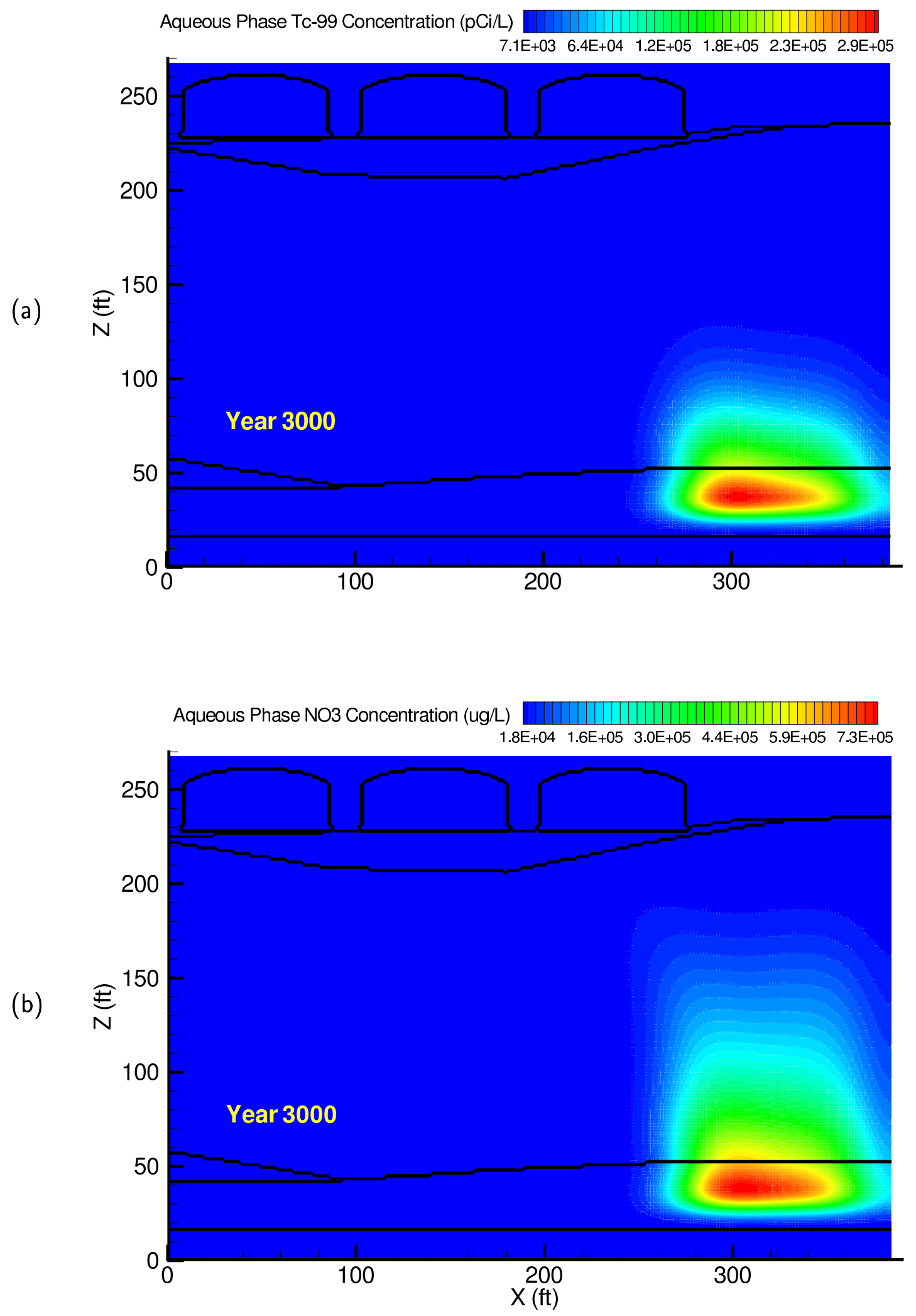

Figure A.23. Case 7 aqueous (a) Tc-99 and (b) $\mathrm{NO}_{3}$ concentration distributions at year 3000 (50 $\mathrm{mm} / \mathrm{yr}$ recharge) 

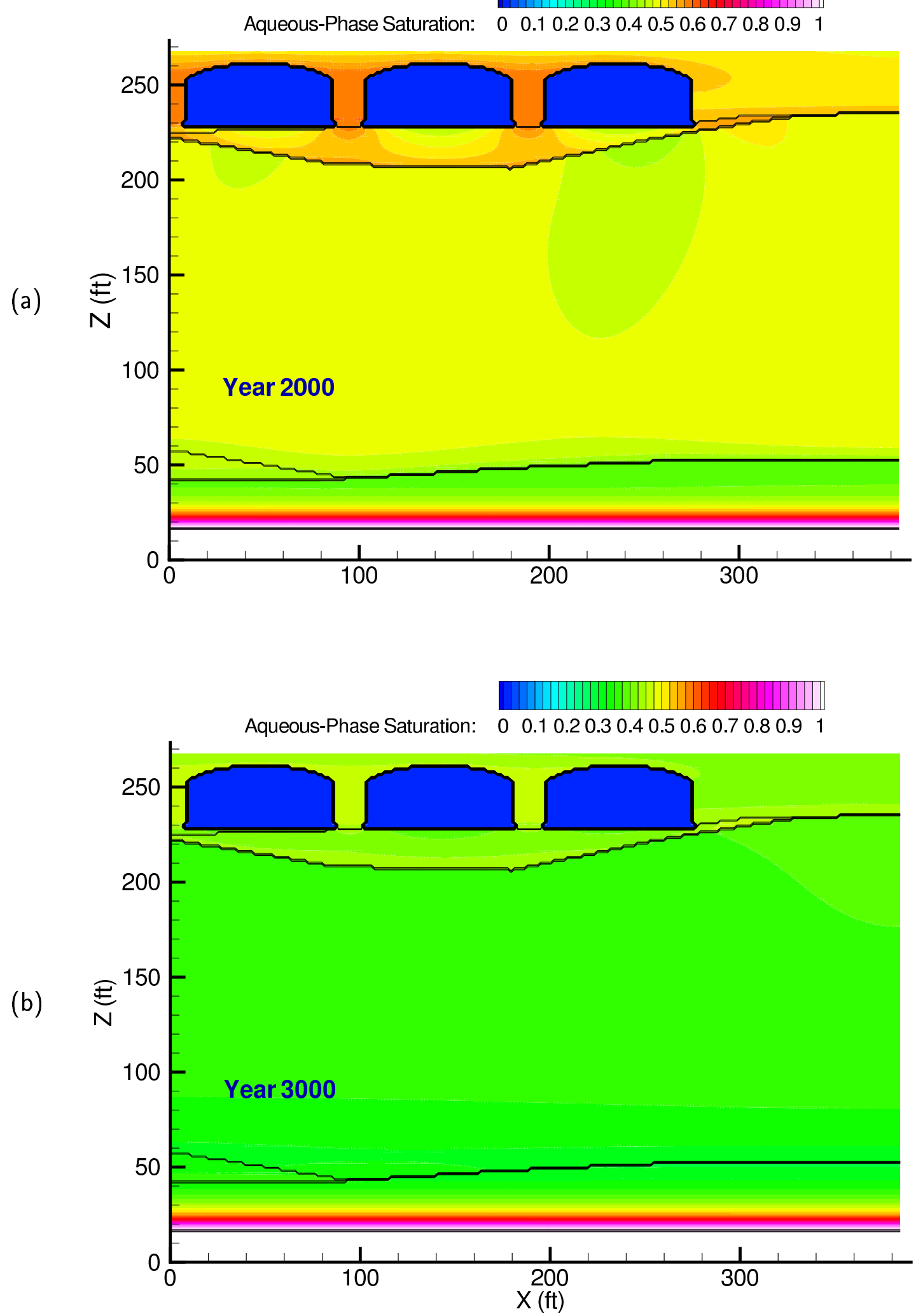

Figure A.24. Case 8 aqueous phase saturation distributions (30 mm/yr recharge) at (a) year 2000 and (b) year 3000 

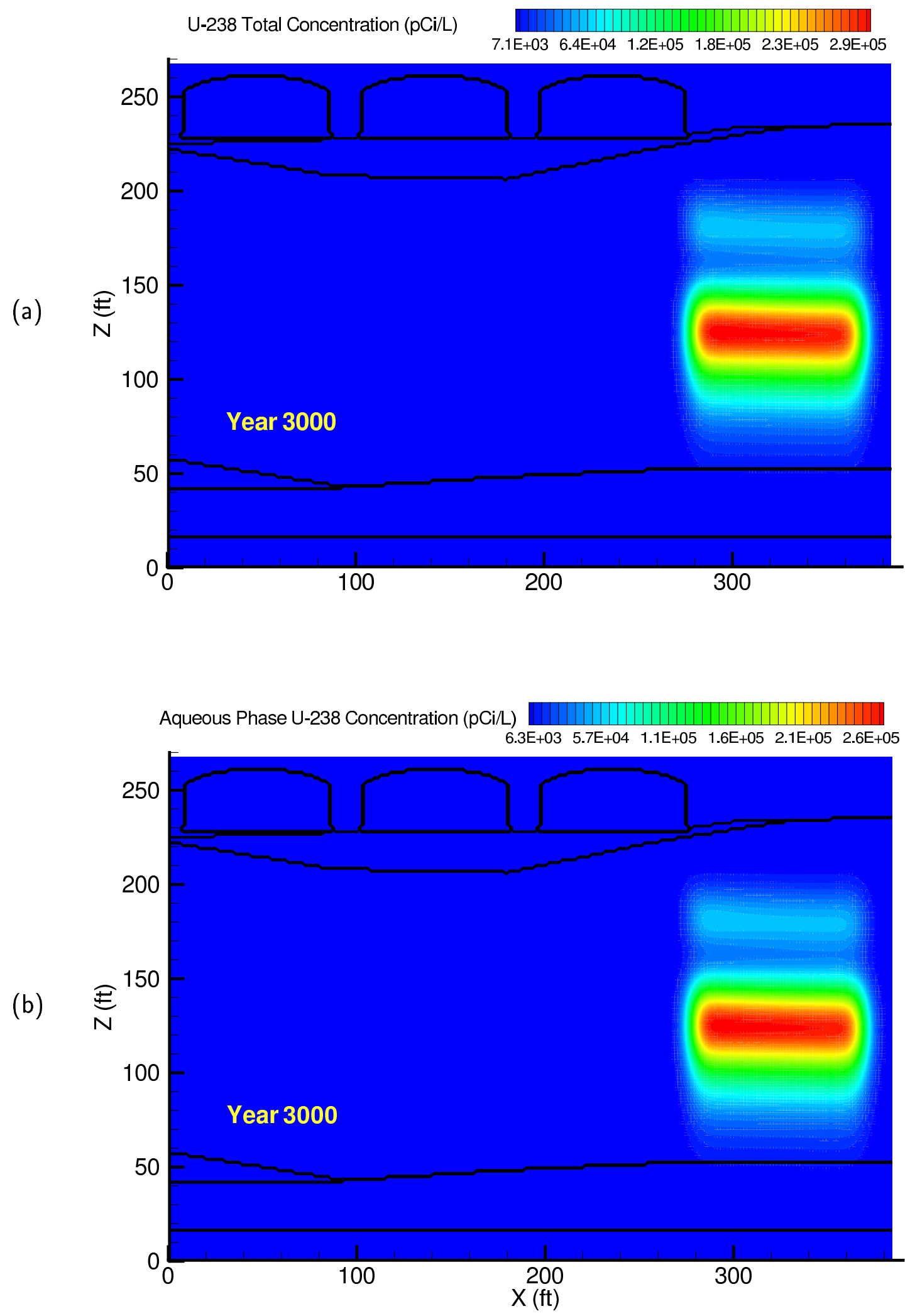

Figure A.25. Case 8 U-238 (a) total and (b) aqueous concentration distributions at year 3000 (30 $\mathrm{mm} / \mathrm{yr}$ recharge) 

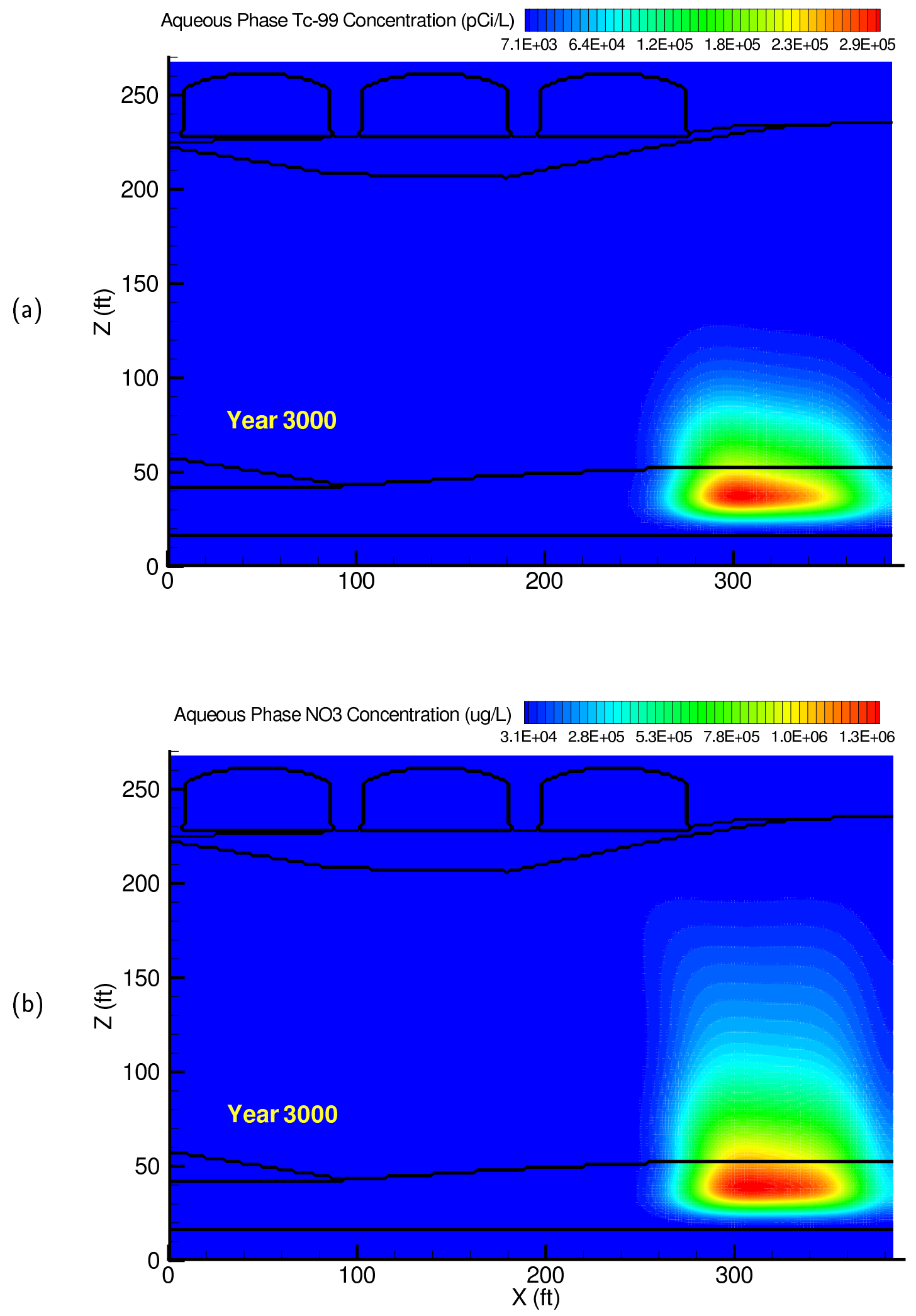

Figure A.26. Case 8 aqueous (a) Tc-99 and (b) $\mathrm{NO}_{3}$ concentration distributions at year 3000 (30 $\mathrm{mm} / \mathrm{yr}$ recharge) 

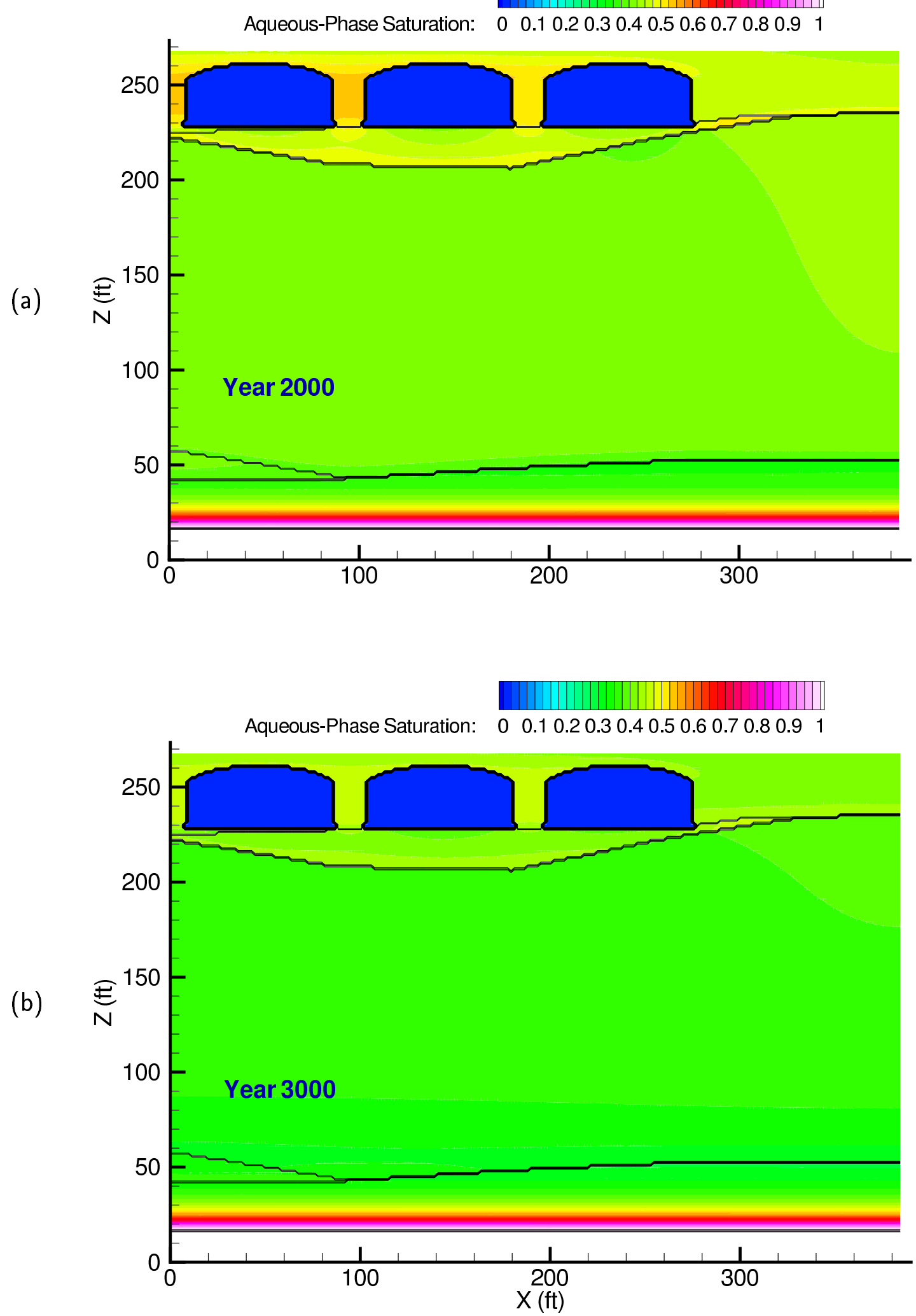

Figure A.27. Case 9 aqueous phase saturation distributions (10 mm/yr recharge) at (a) year 2000 and (b) year 3000 

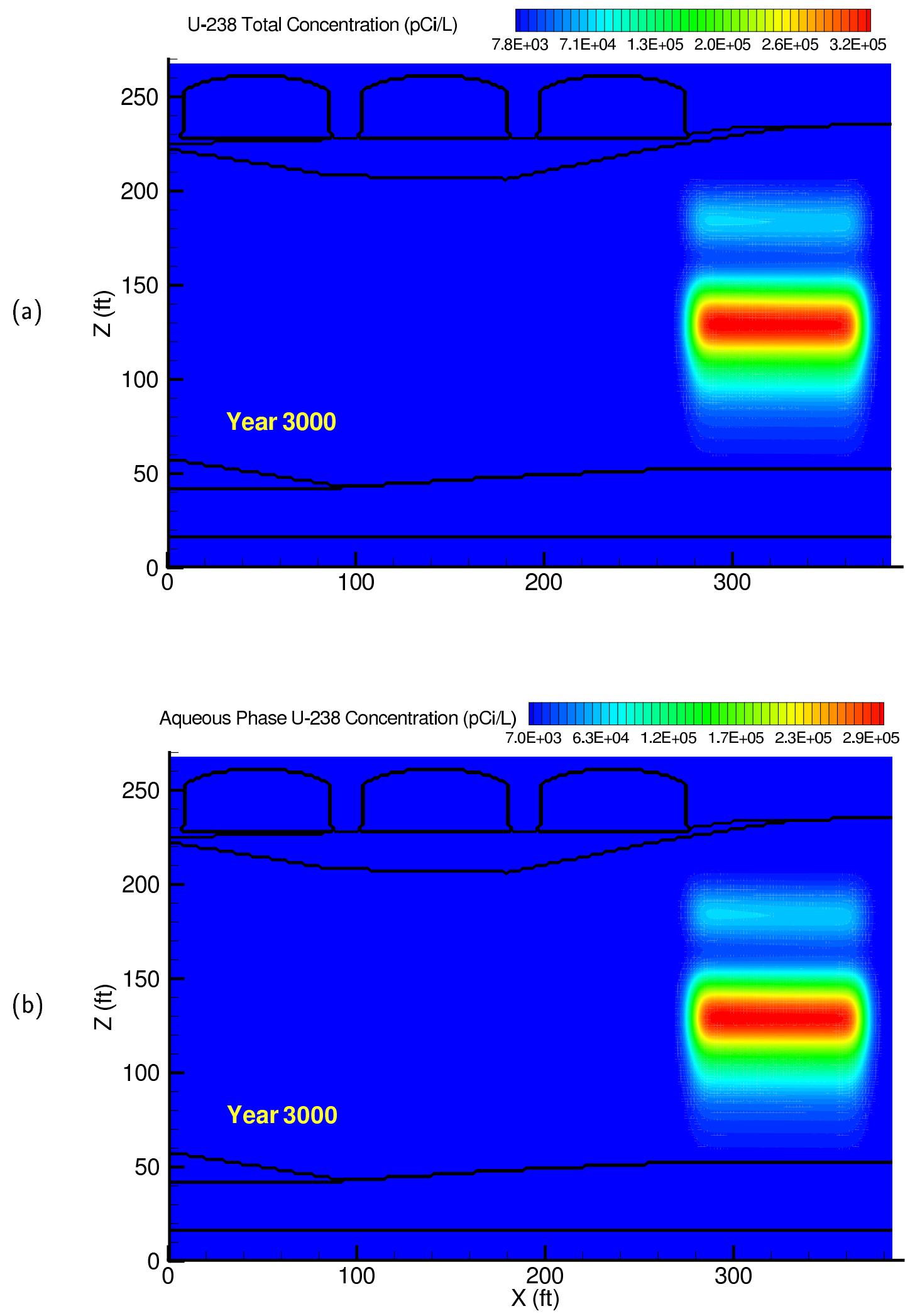

Figure A.28. Case 9 U-238 (a) total and (b) aqueous concentration distributions at year 3000 (10 $\mathrm{mm} / \mathrm{yr}$ recharge) 

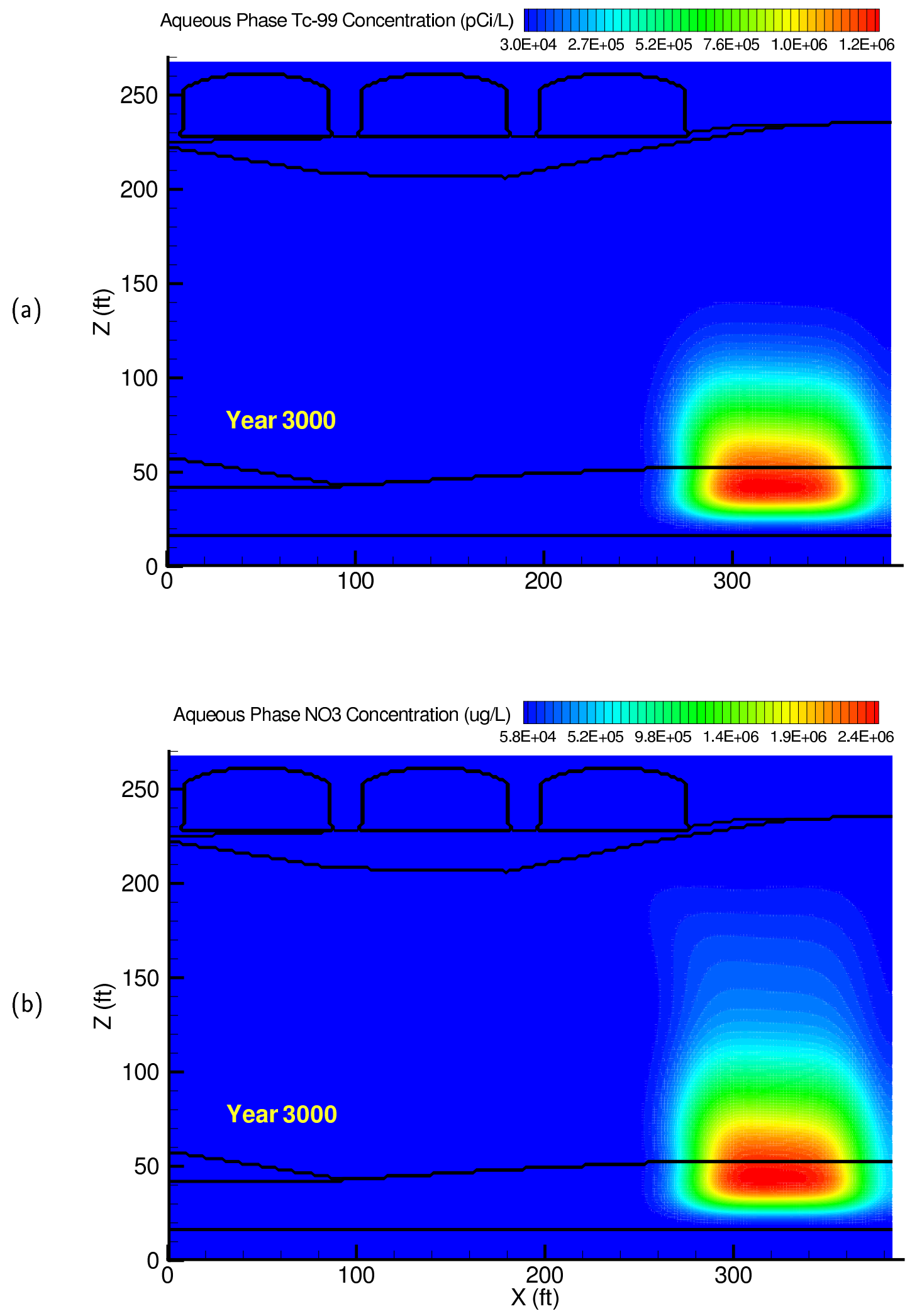

Figure A.29. Case 9 aqueous (a) Tc-99 and (b) $\mathrm{NO}_{3}$ concentration distributions at year 3000 (10 $\mathrm{mm} / \mathrm{yr}$ recharge) 

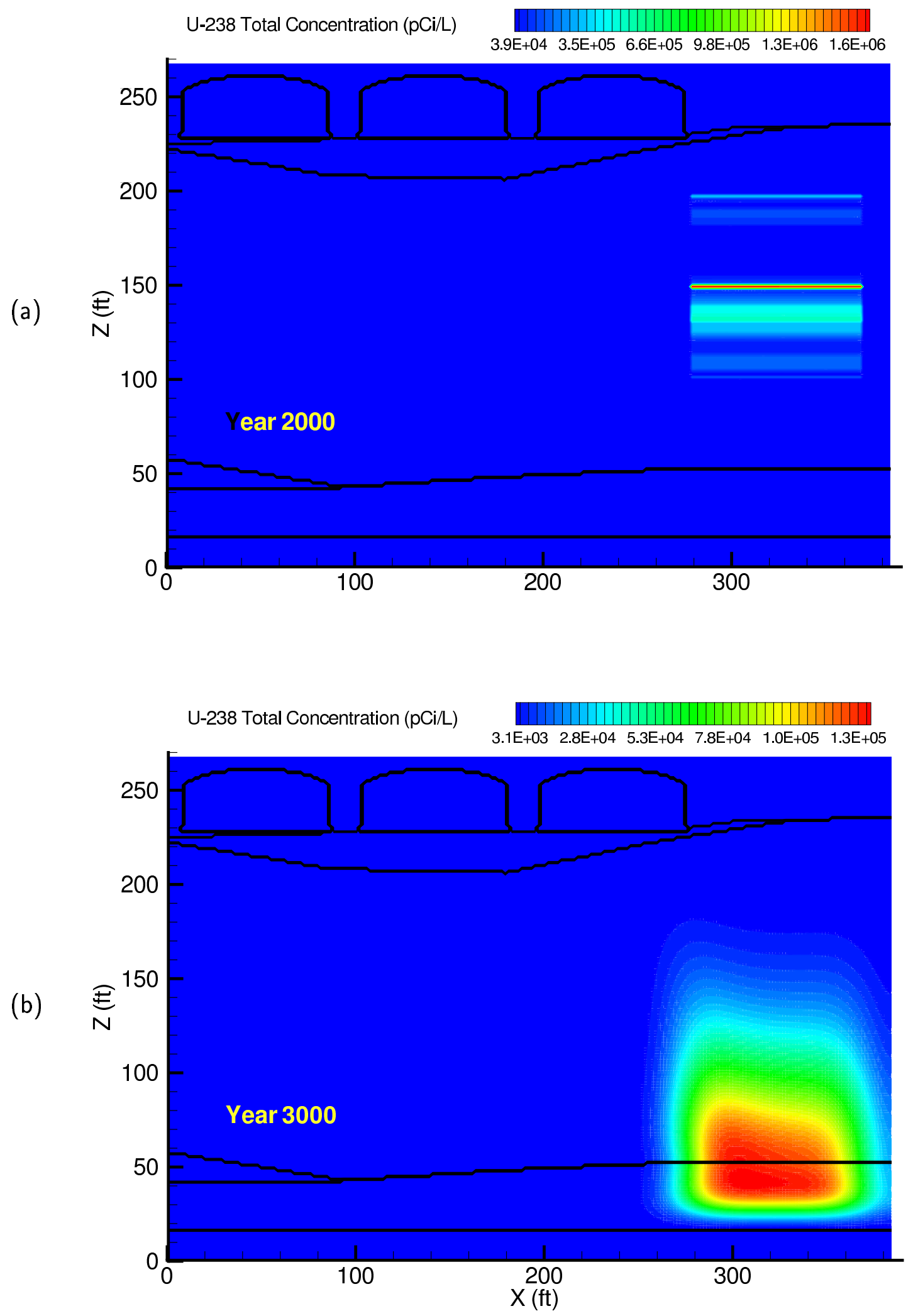

Figure A.30. Case 10 U-238 total concentration distributions at (a) year 2000 and (b) year 3000 $\left(\mathrm{K}_{d}=0.1\right)$ 

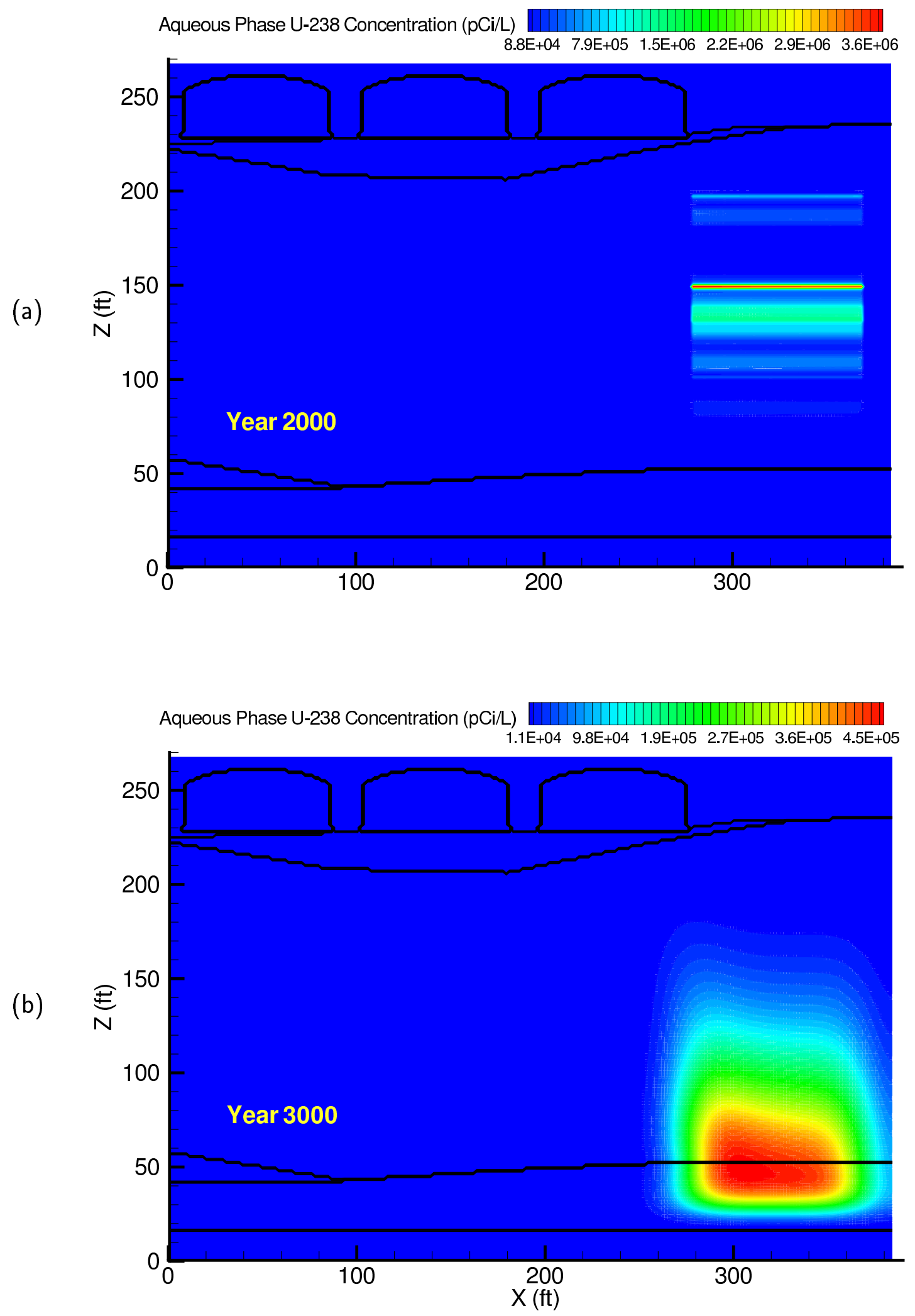

Figure A.31. Case 10 U-238 aqueous concentration distributions at (a) year 2000 and (b) year 3000 $\left(\mathrm{K}_{d}=0.1\right)$ 

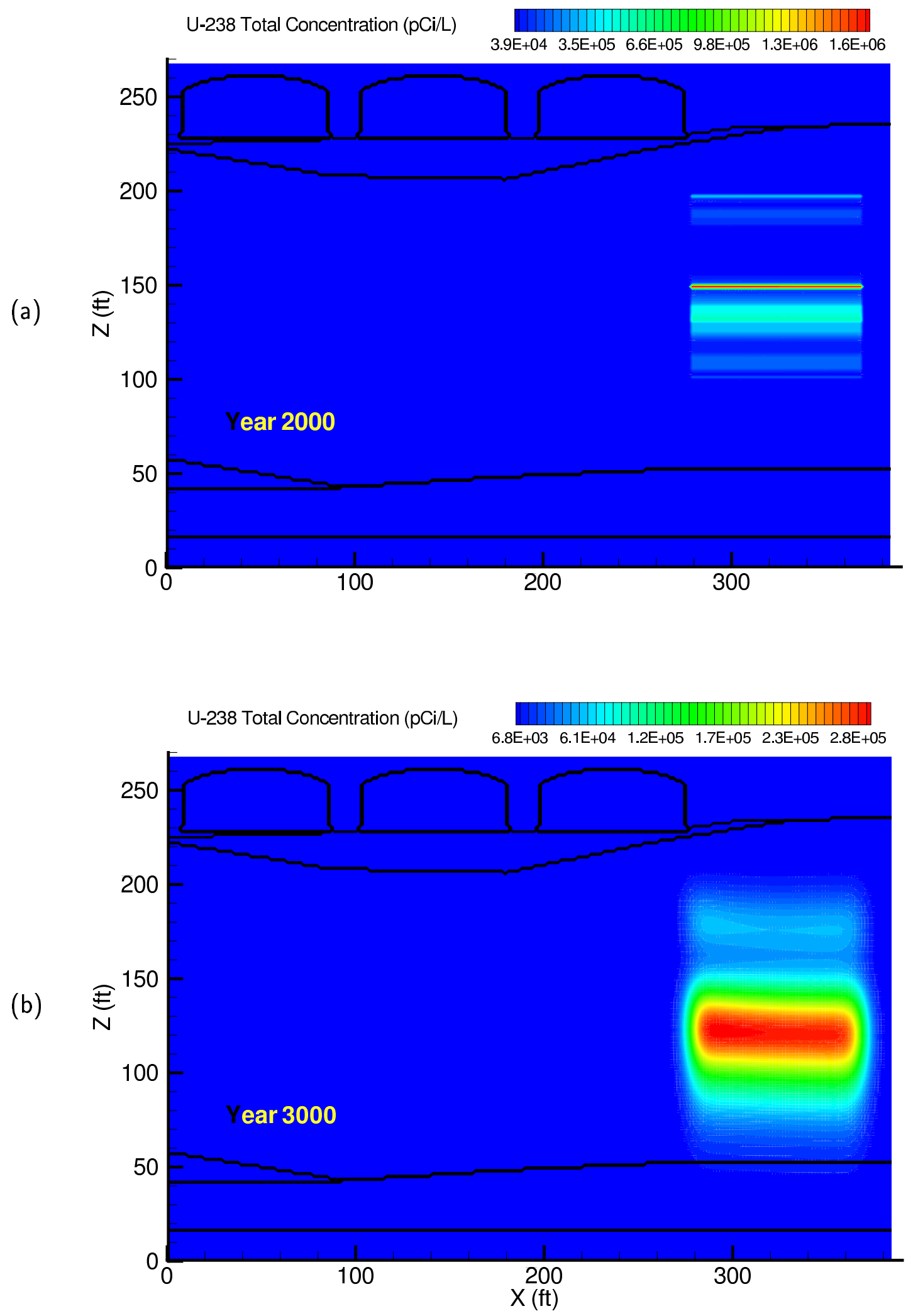

Figure A.32. Case 11 U-238 total concentration distributions at (a) year 2000 and (b) year 3000 $\left(\mathrm{K}_{d}=1.0\right)$ 

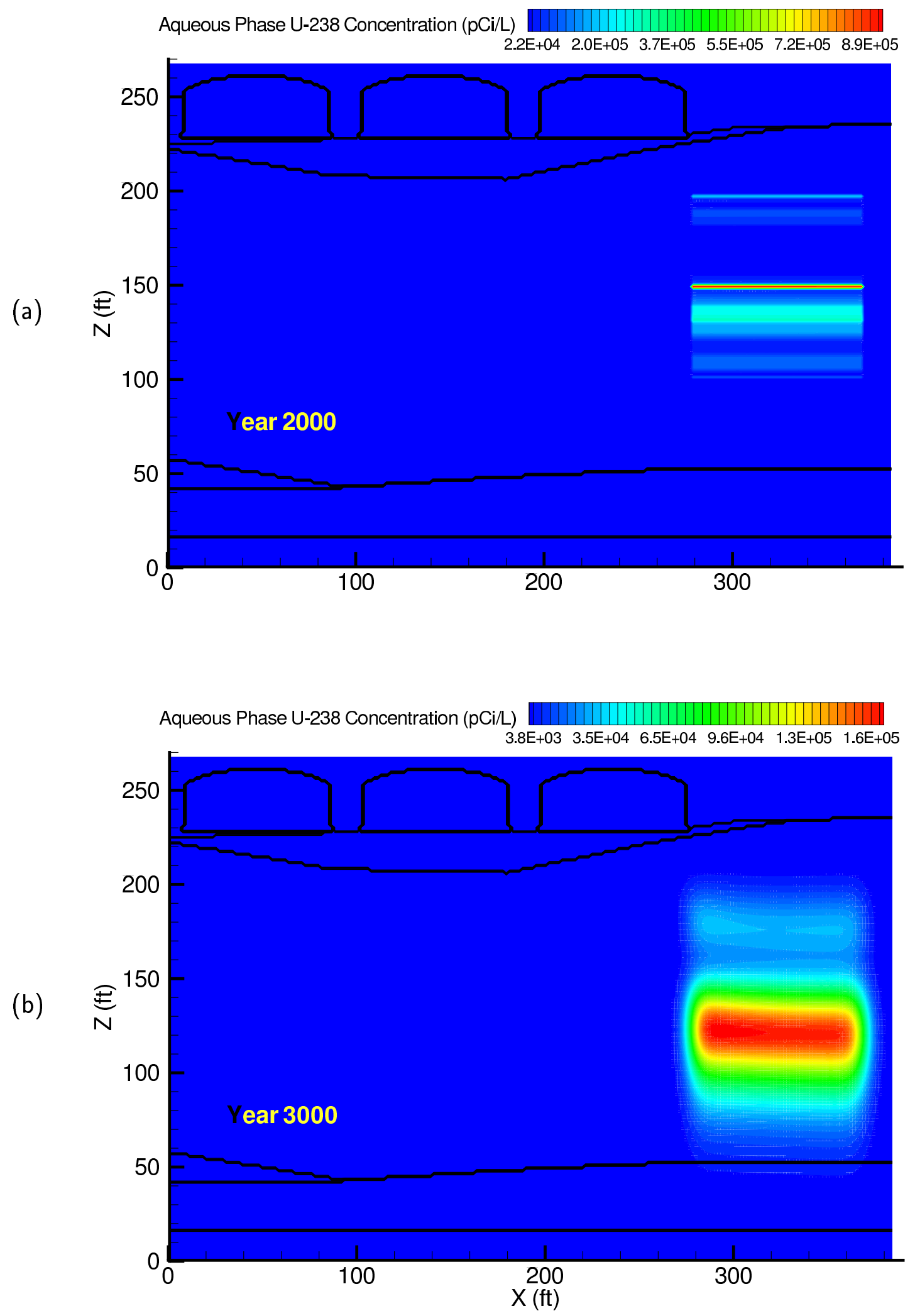

Figure A.33. Case 11 U-238 aqueous concentration distributions at (a) year 2000 and (b) year 3000 $\left(\mathrm{K}_{d}=1.0\right)$ 


\section{Appendix B: B Trench Saturation and Concentration Distributions}

B-1 


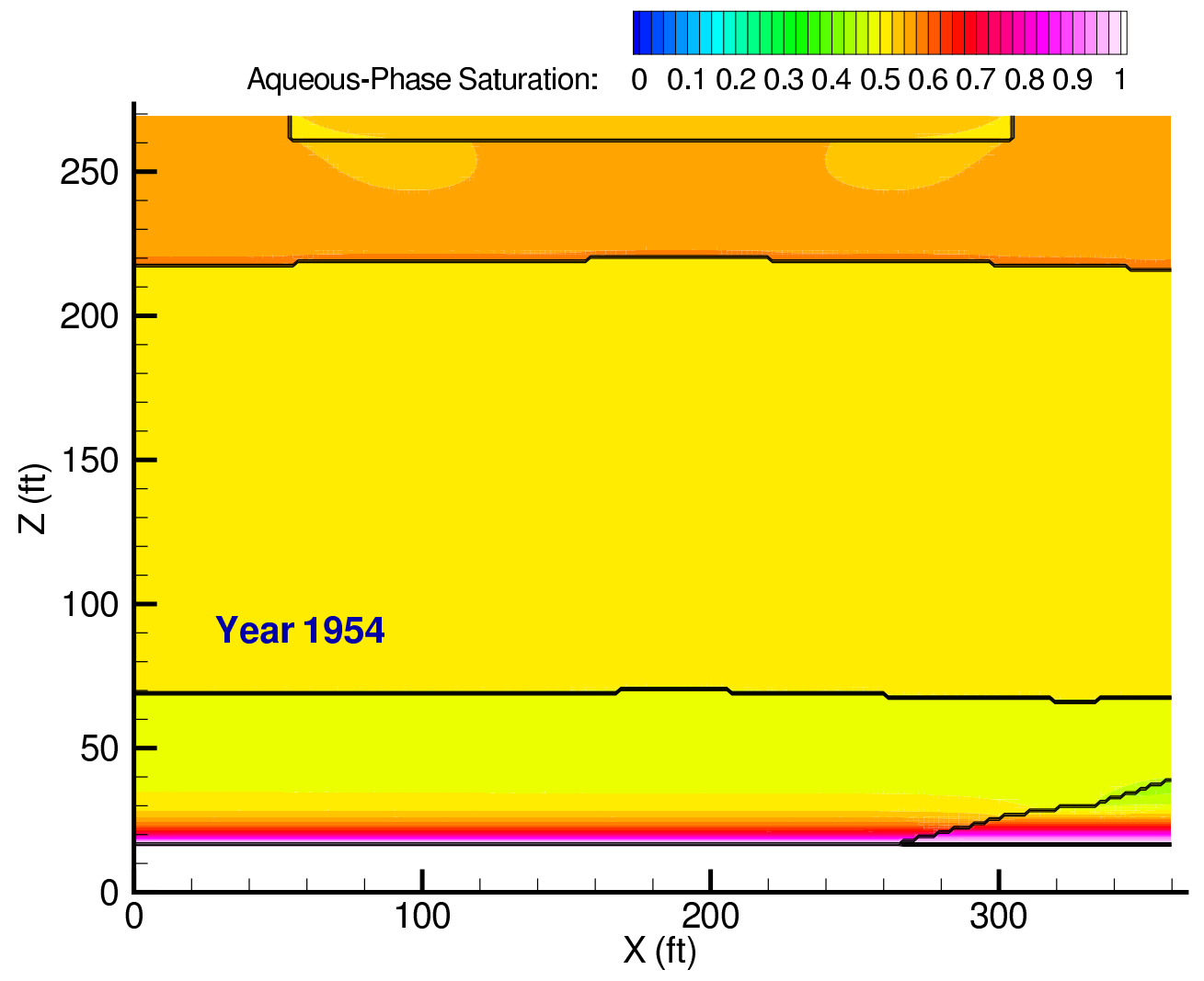

Figure B.1. Case 12 aqueous phase saturation at year 1954 (55.4 mm/yr recharge) 

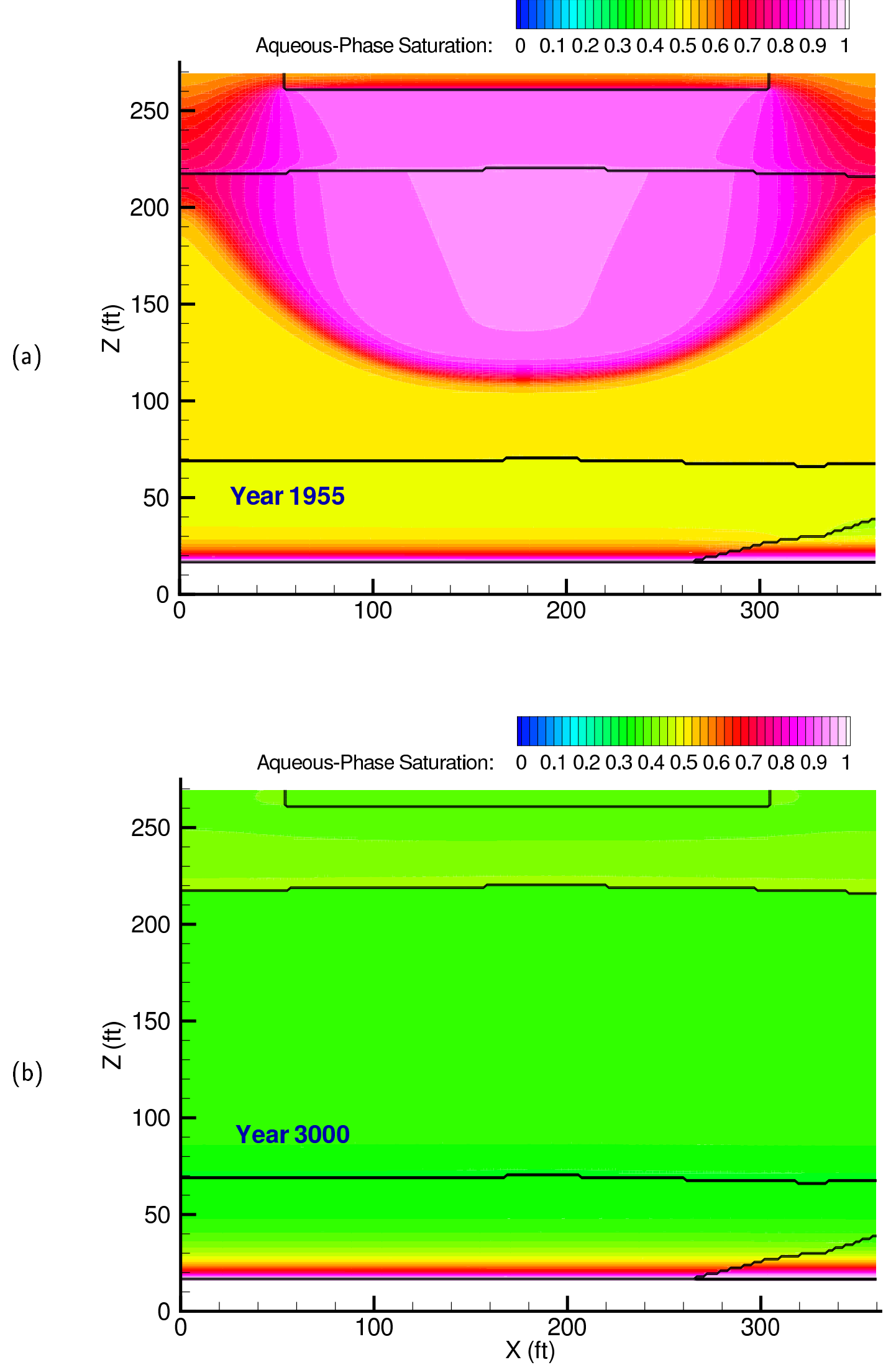

Figure B.2. Case 12 aqueous phase saturation distributions (55.4 mm/yr recharge) at (a) year 1954 and (b) year 3000 

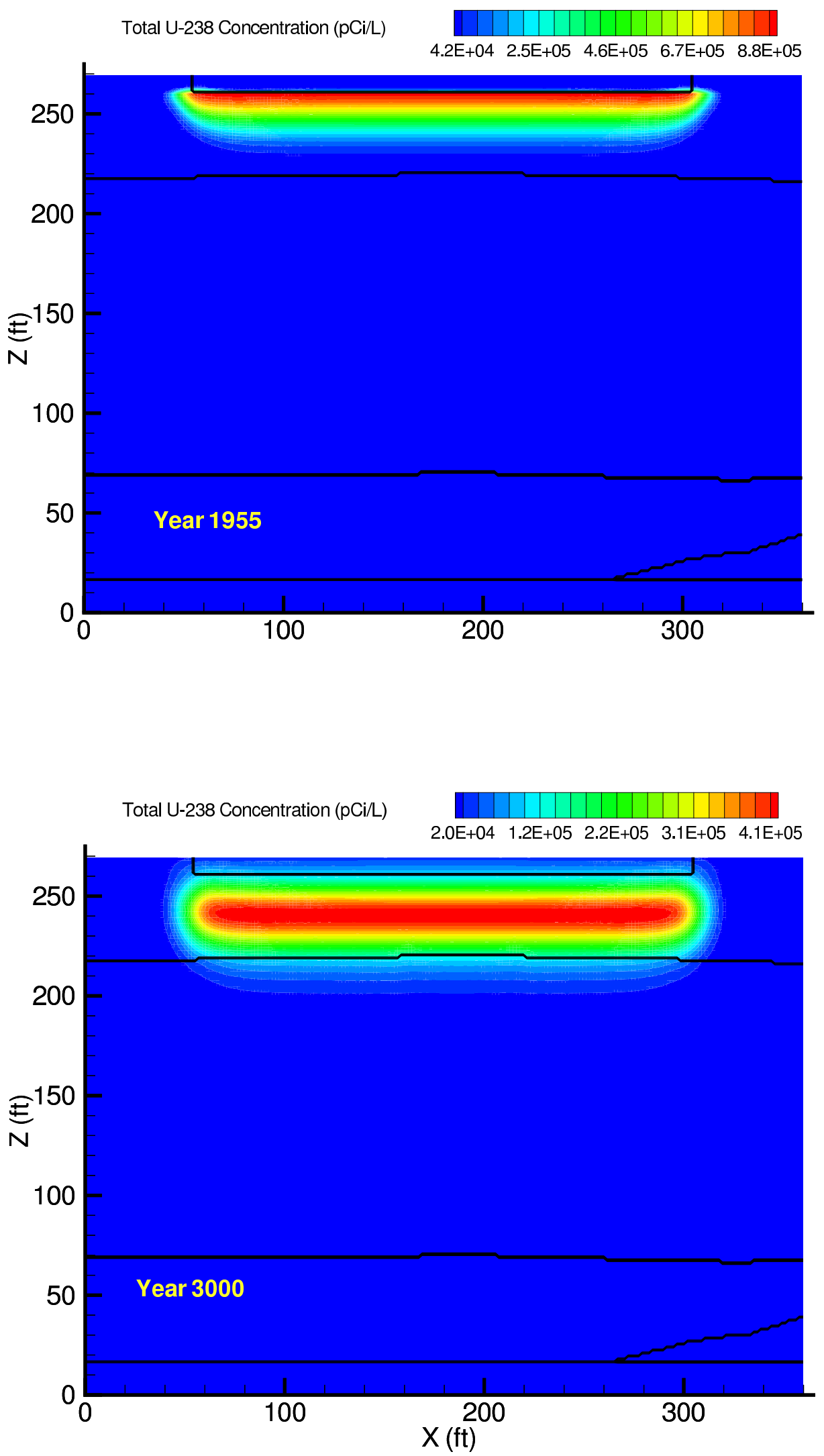

Figure B.3. Case 12 U-238 total concentration distributions at (a) year 1954 and (b) year 3000 (55.4 mm/yr recharge) 
Aqueous Phase U-238 Concentration (pCi/L)

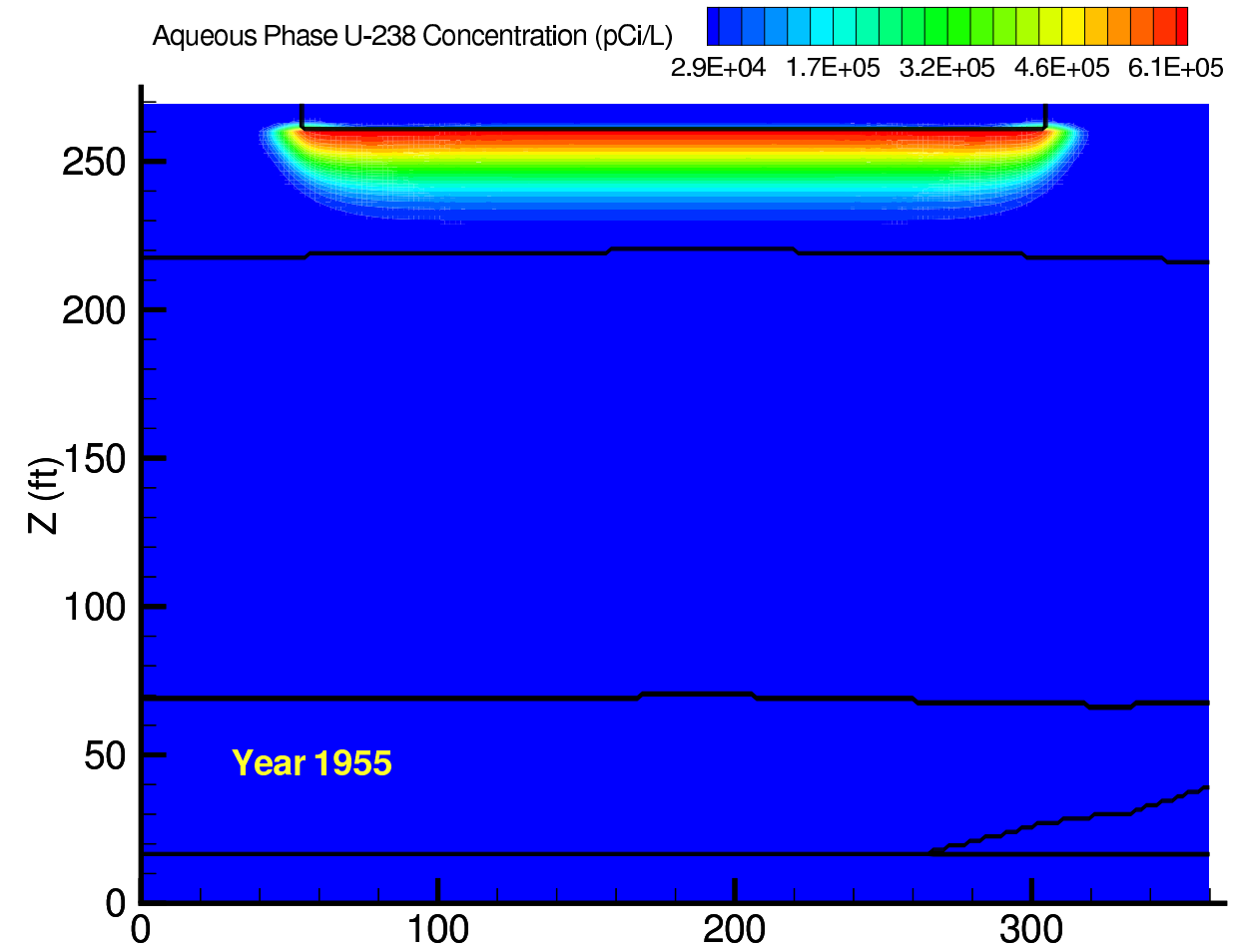

Aqueous Phase U-238 Concentration (pCi/L)

$\begin{array}{llll}1.5 \mathrm{E}+04 & 8.8 \mathrm{E}+04 & 1.6 \mathrm{E}+05 \quad 2.3 \mathrm{E}+05 \quad 3.1 \mathrm{E}+05\end{array}$

(b)

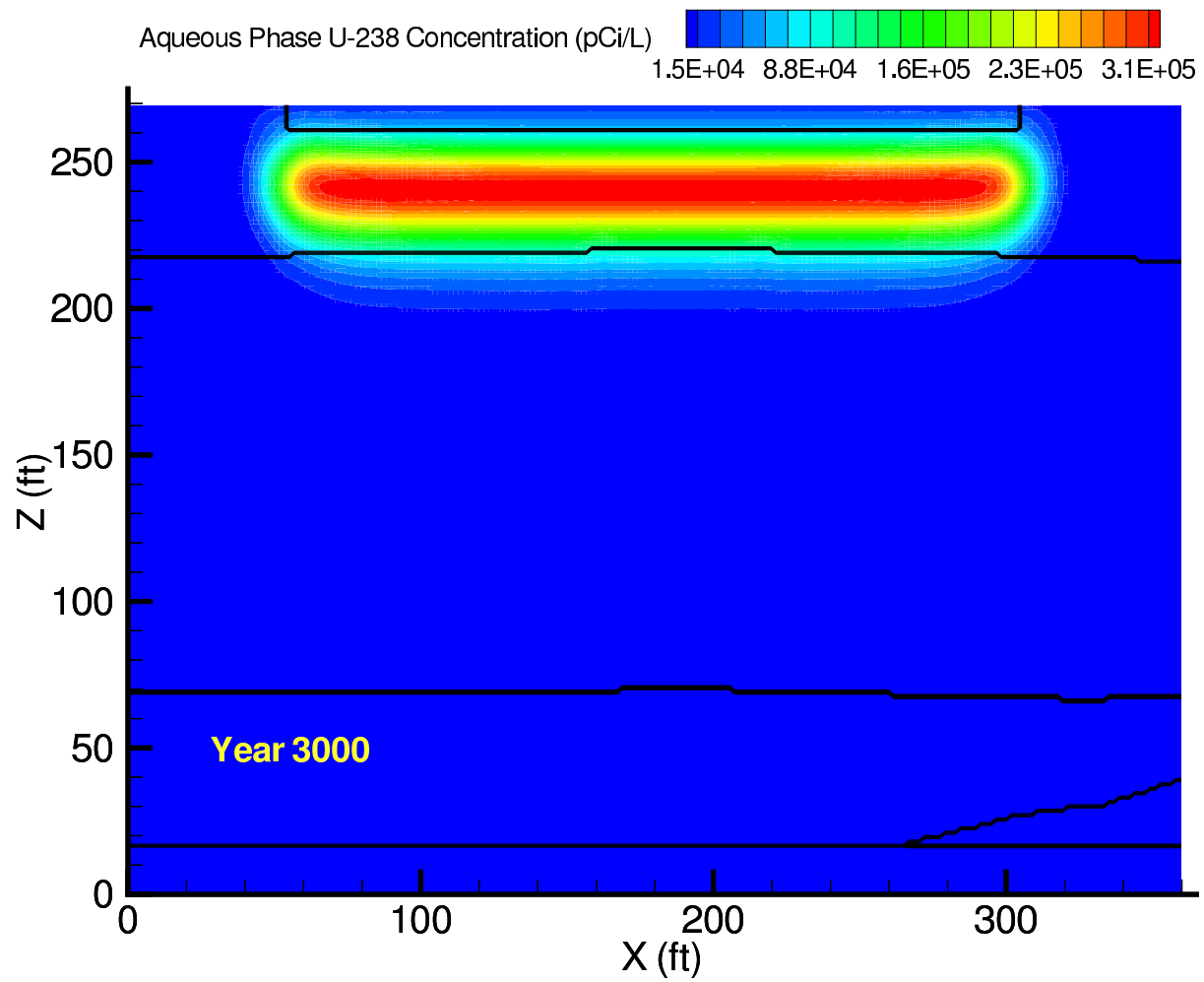

Figure B.4. Case 12 U-238 aqueous concentration distributions at (a) year 1955 and (b) year 3000 $(55.4 \mathrm{~mm} / \mathrm{yr}$ recharge) 
(a)

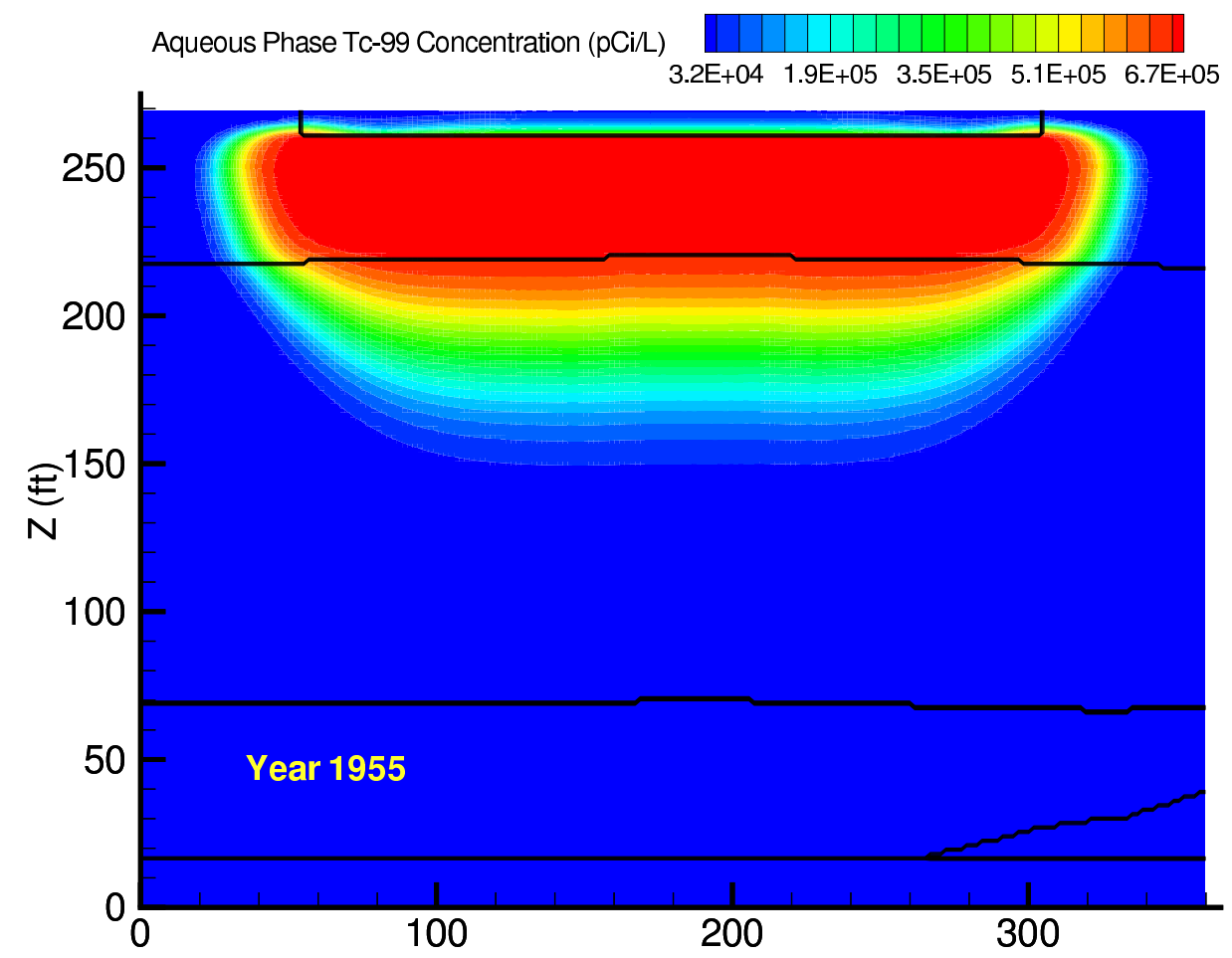

(b)

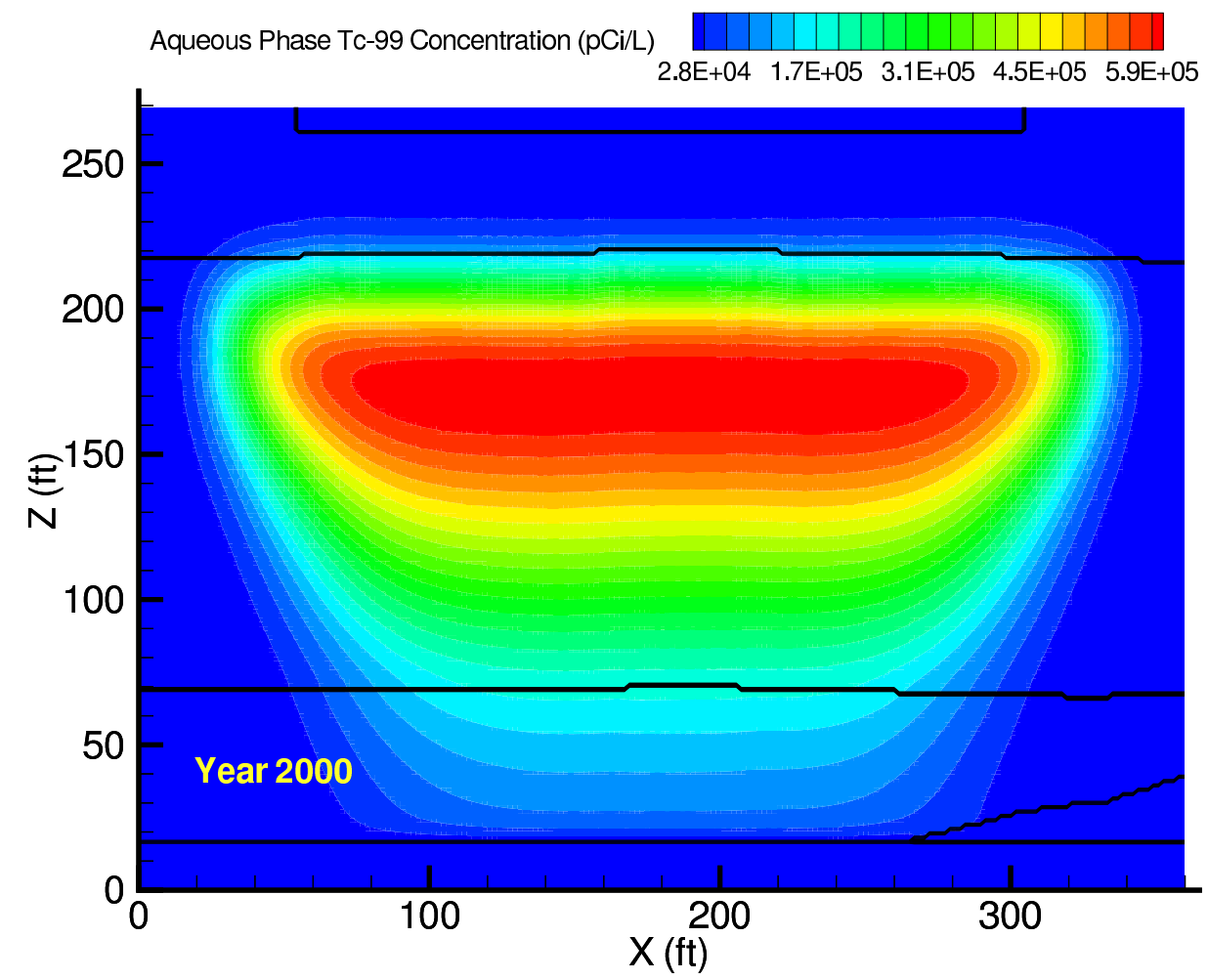

Figure B.5. Case 12 Tc-99 aqueous concentration distributions at (a) year 1955 and (b) year 2000 $(55.4 \mathrm{~mm} / \mathrm{yr}$ recharge $)$ 


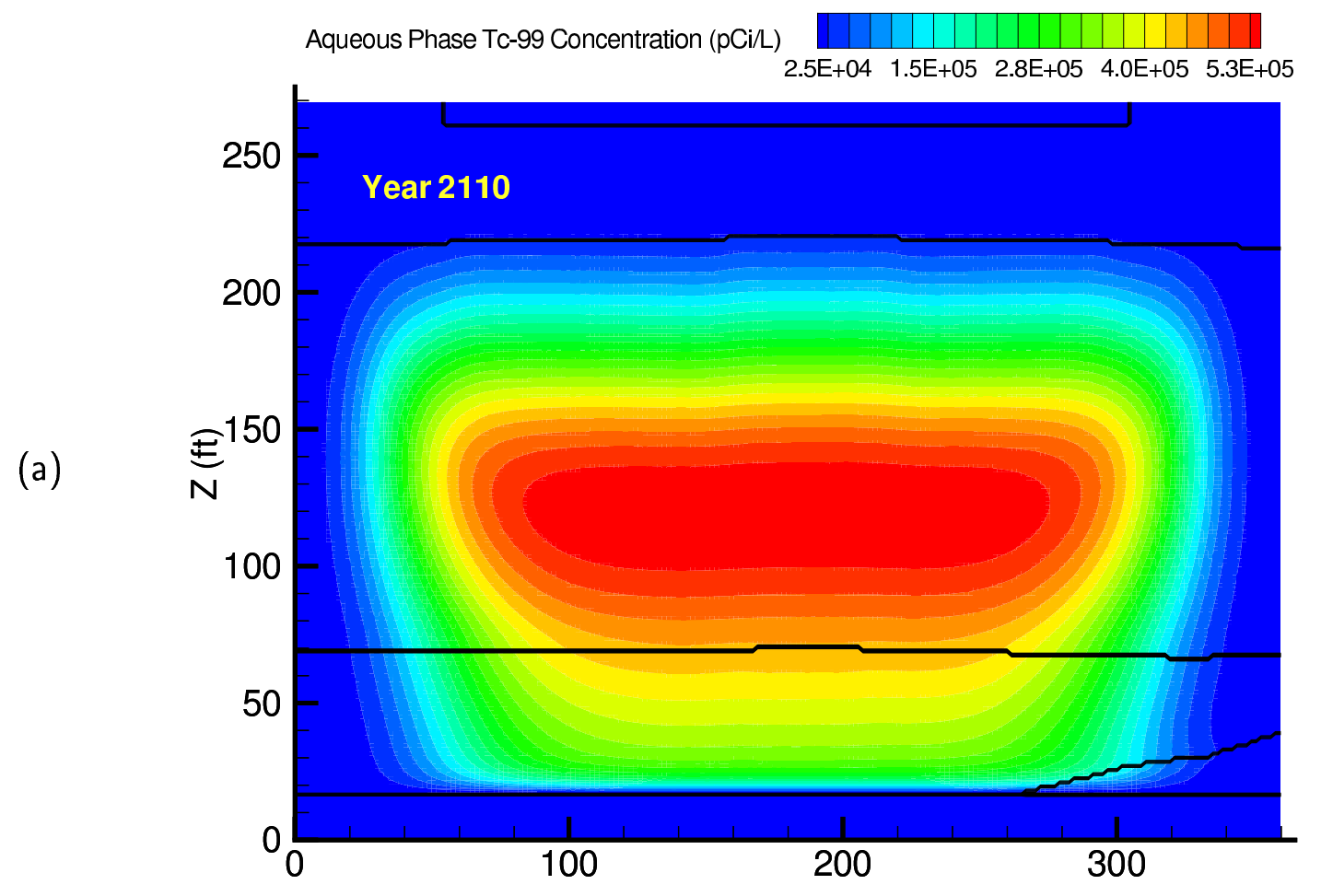

(b)

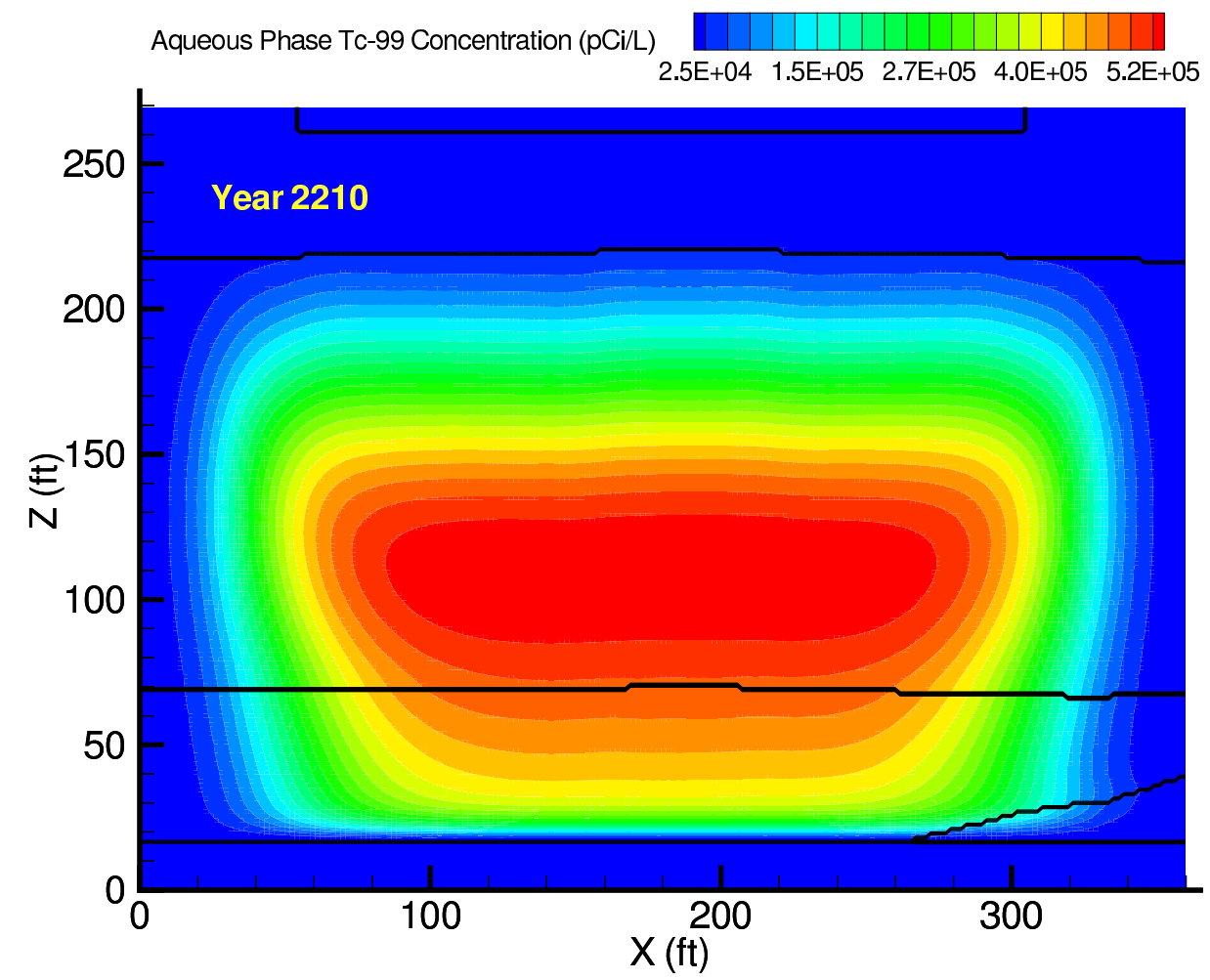

Figure B.6. Case 12 Tc-99 aqueous concentration distributions at (a) year 2110 and (b) year 2210 (55.4 mm/yr recharge) 


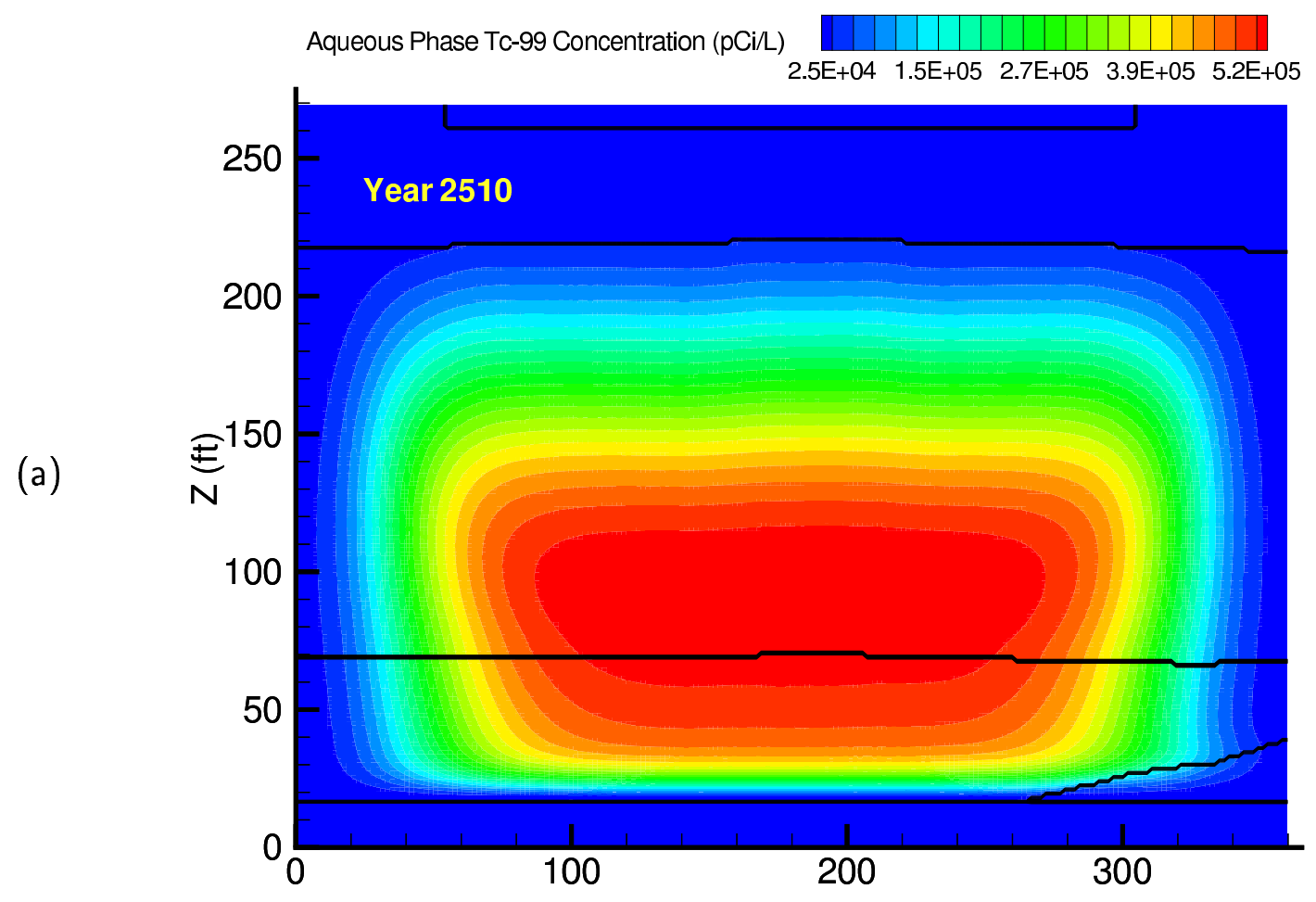

(b)

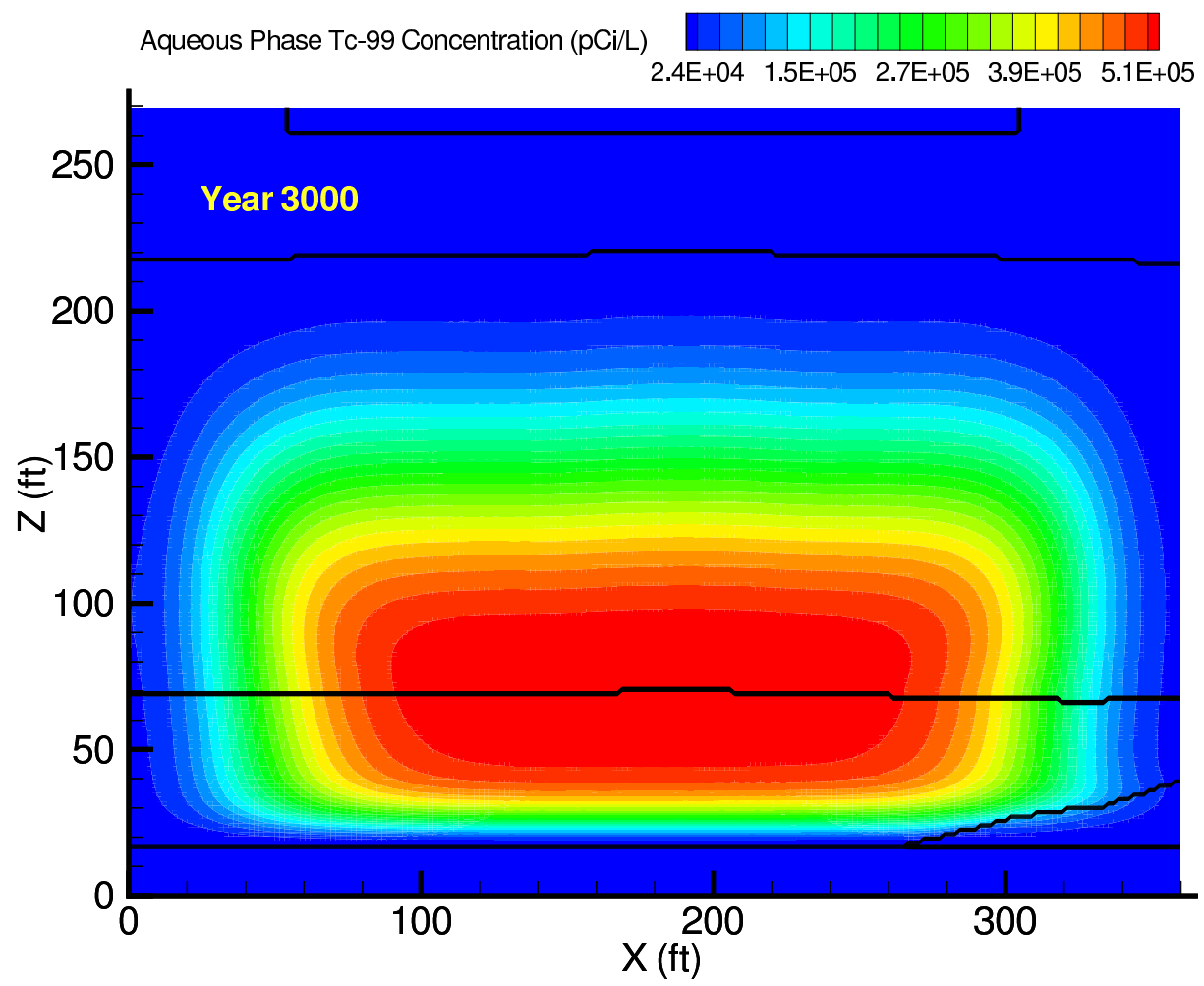

Figure B.7. Case 12 Tc-99 aqueous concentration distributions at (a) year 2510 and (b) year 3000 (55.4 mm/yr recharge) 


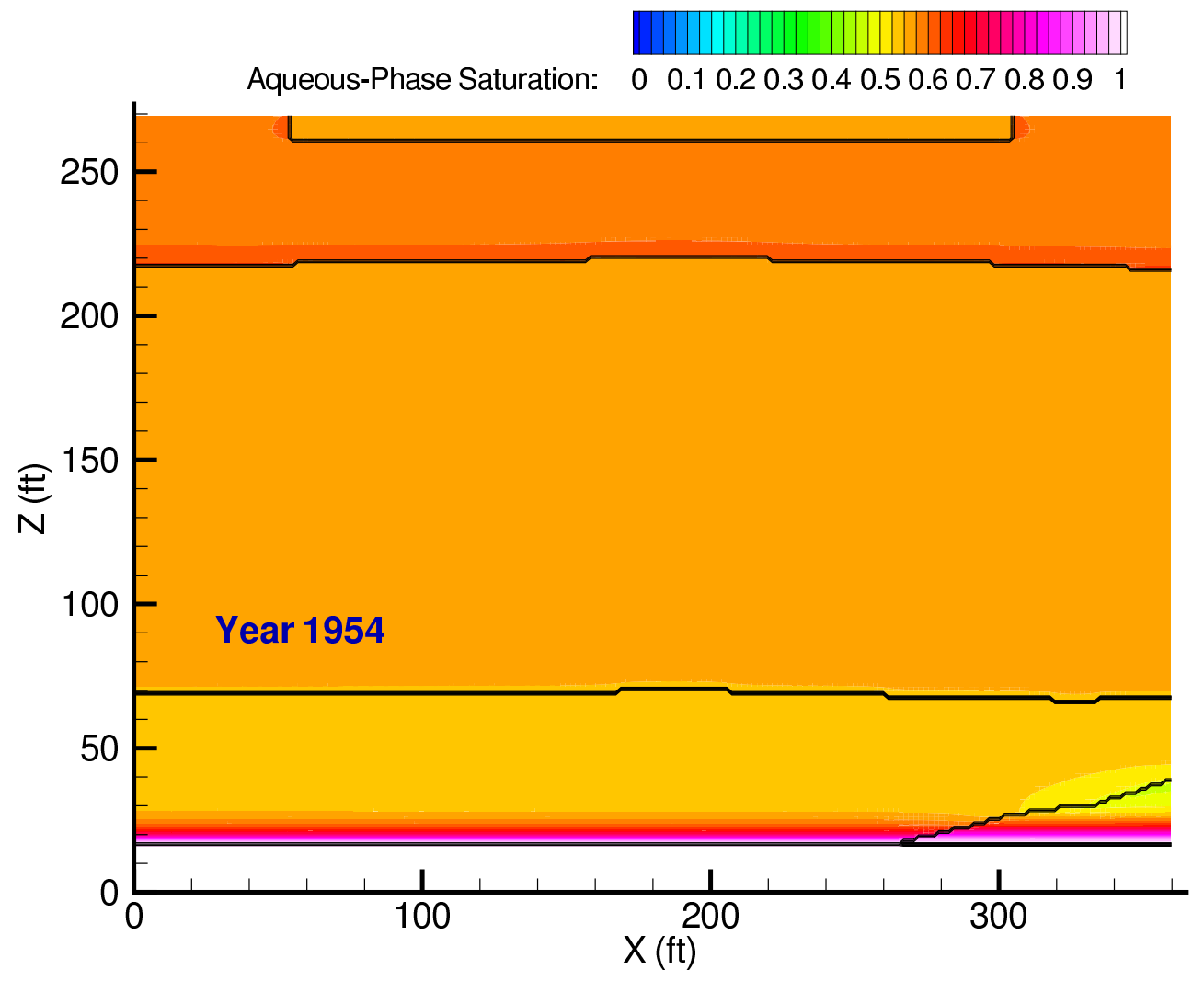

Figure B.8. Case 13 aqueous phase saturation at year 1954 (100 mm/yr recharge) 

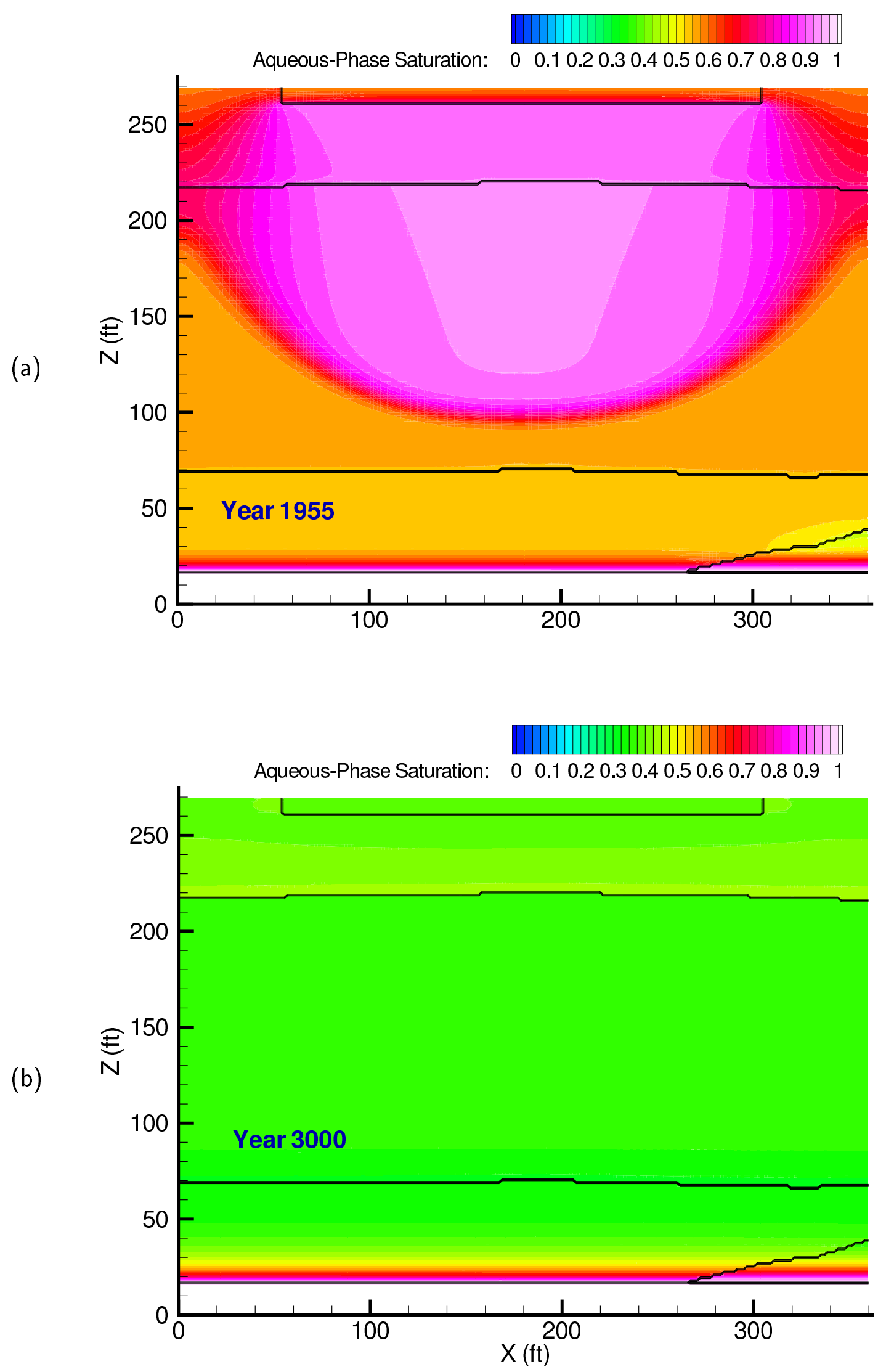

Figure B.9. Case 13 U-238 total concentration distributions at (a) year 1954 and (b) year 3000 (100 $\mathrm{mm} / \mathrm{yr}$ recharge) 

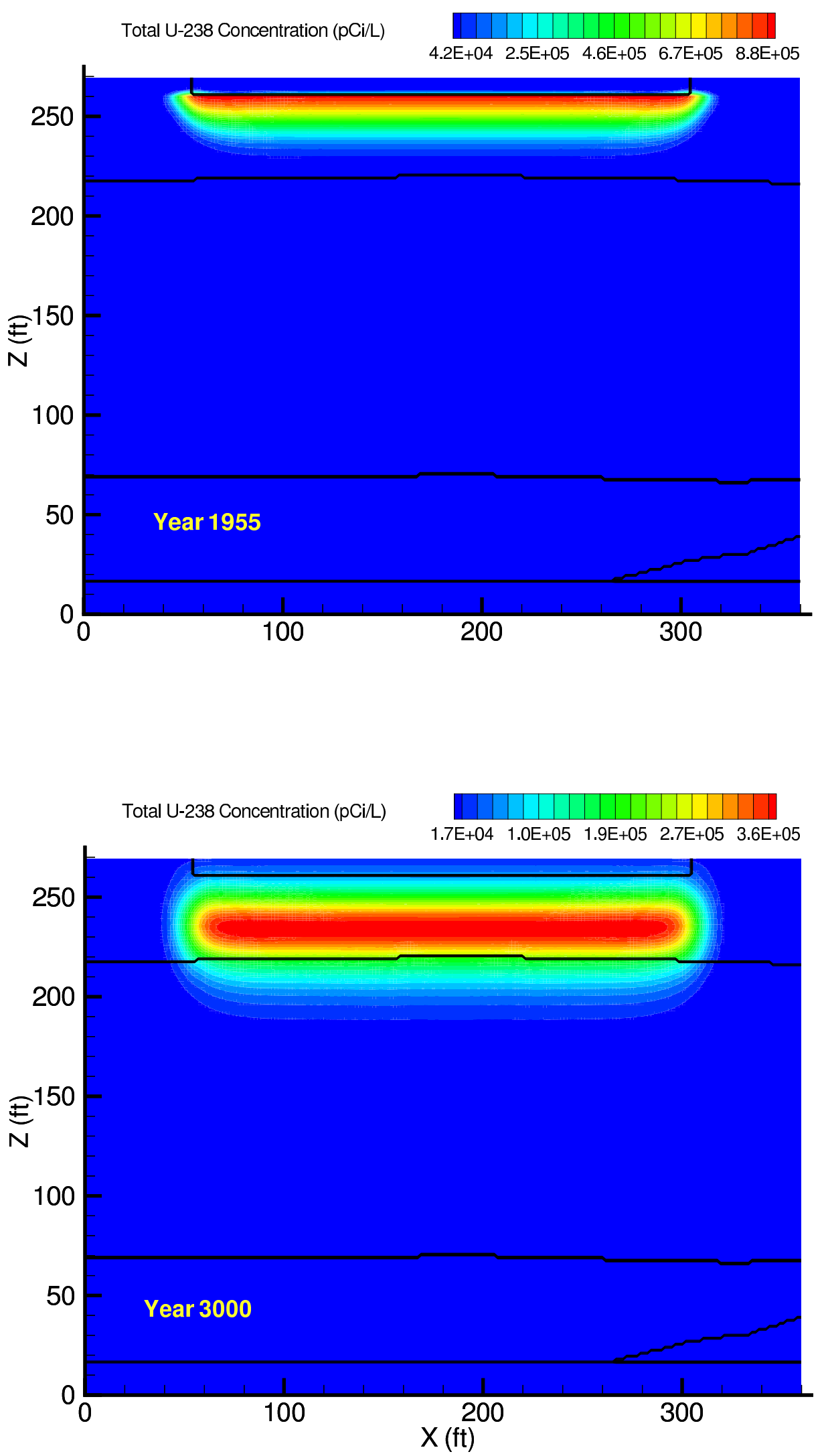

Figure B.10. Case 13 U-238 total concentration distributions at (a) year 1954 and (b) year 3000 (100 mm/yr recharge) 
Aqueous Phase U-238 Concentration (pCi/L)

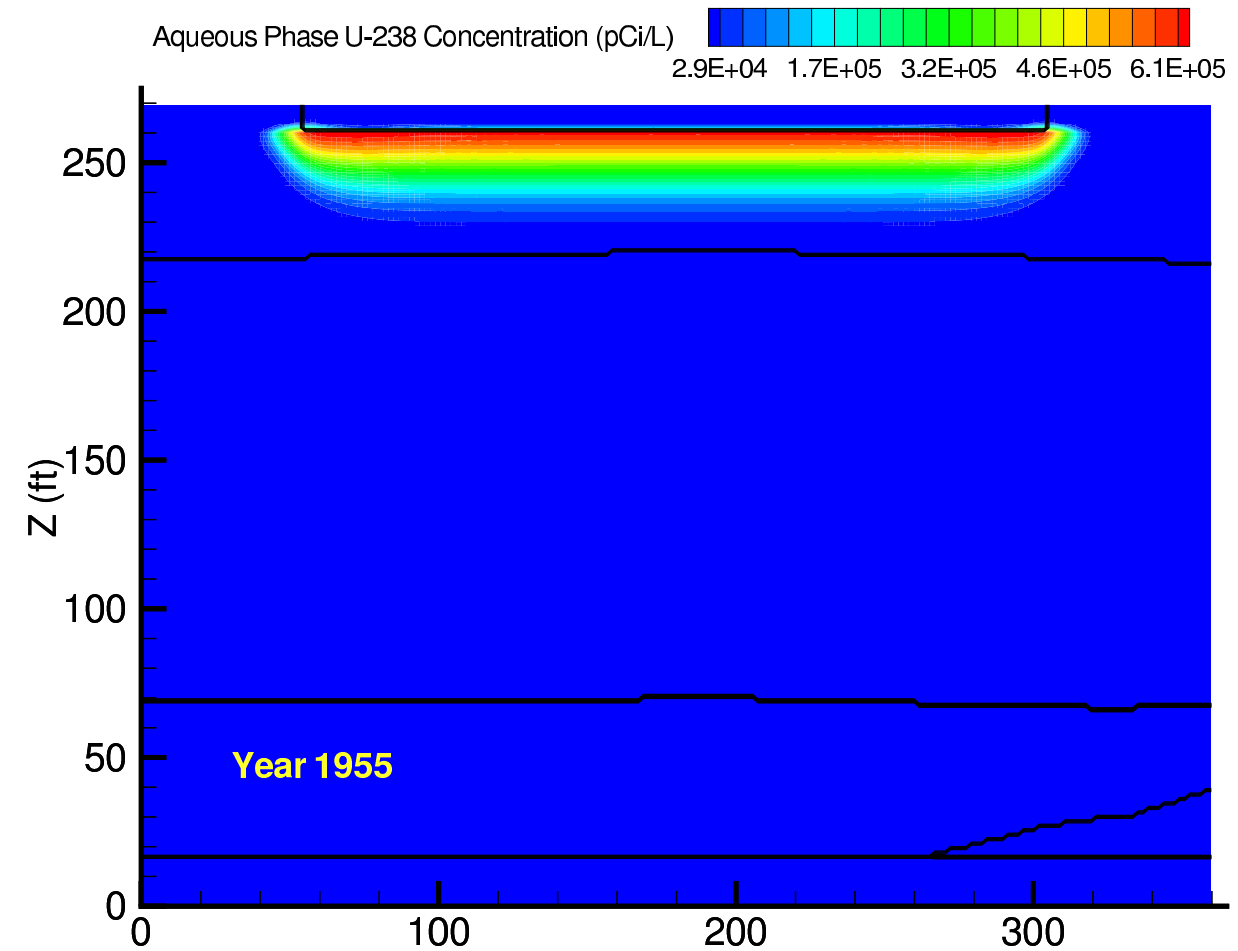

(b)

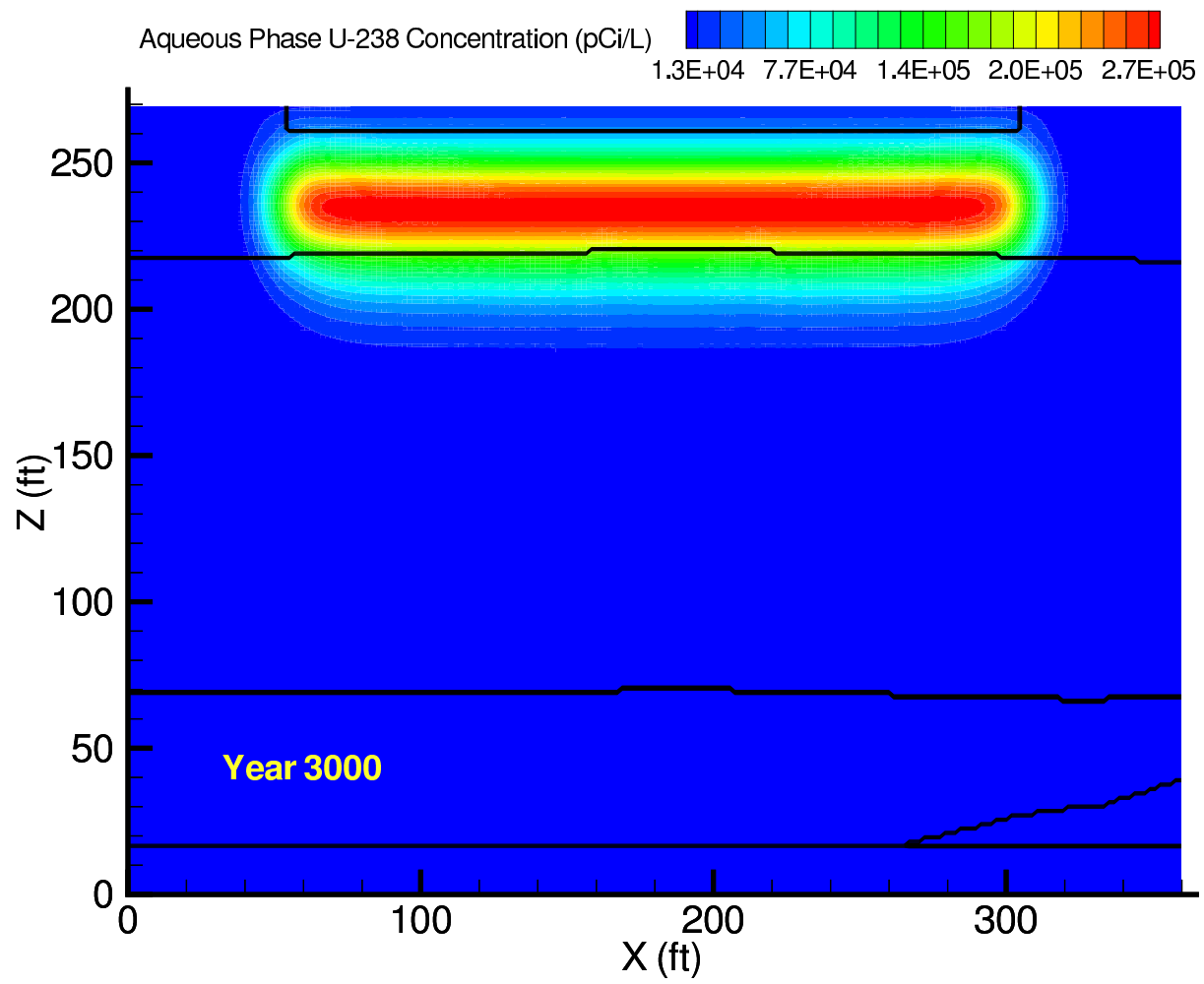

Figure B.11. Case 13 U-238 aqueous concentration distributions at (a) year 1955 and (b) year 3000 $(100 \mathrm{~mm} / \mathrm{yr}$ recharge) 
(a)

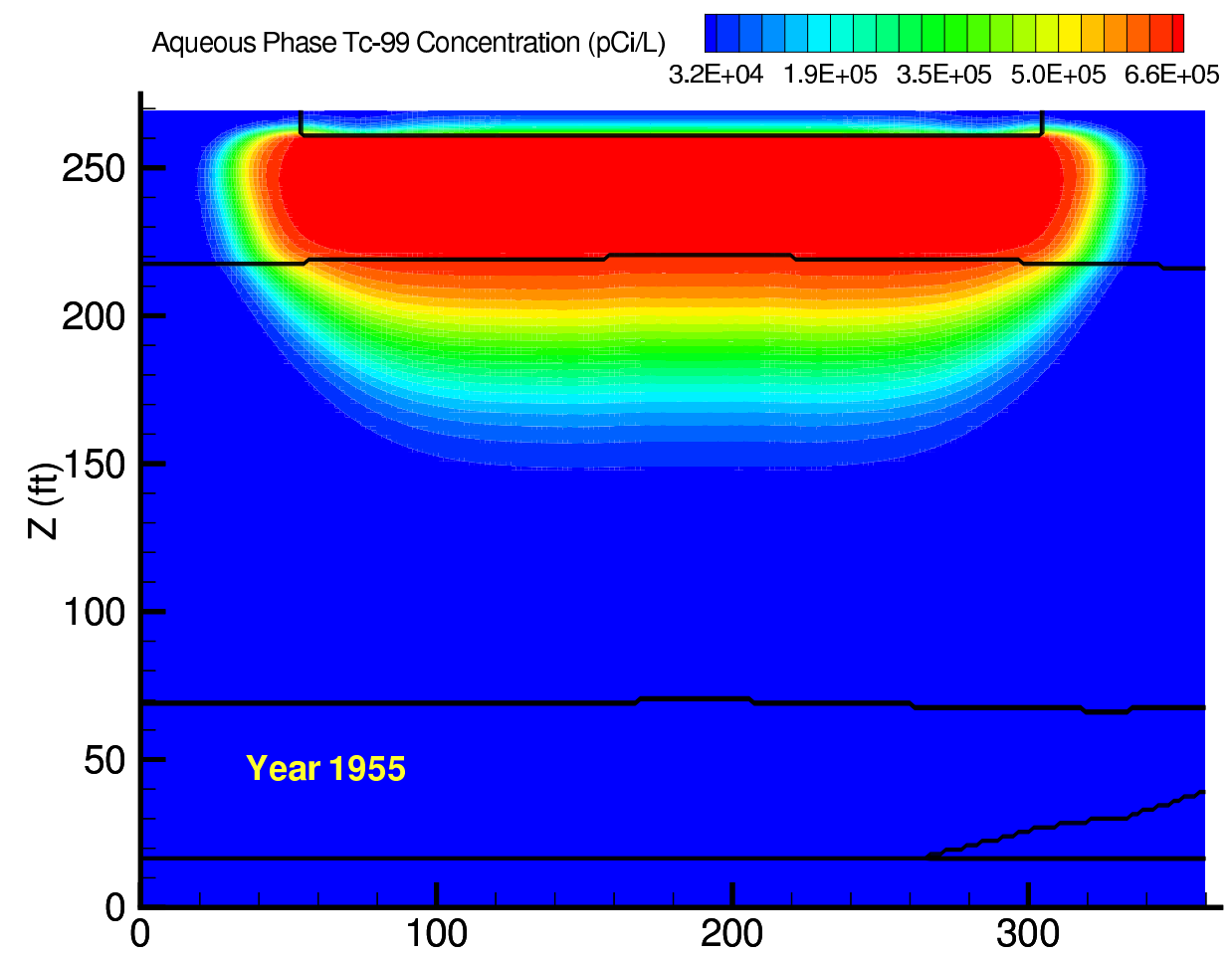

(b)

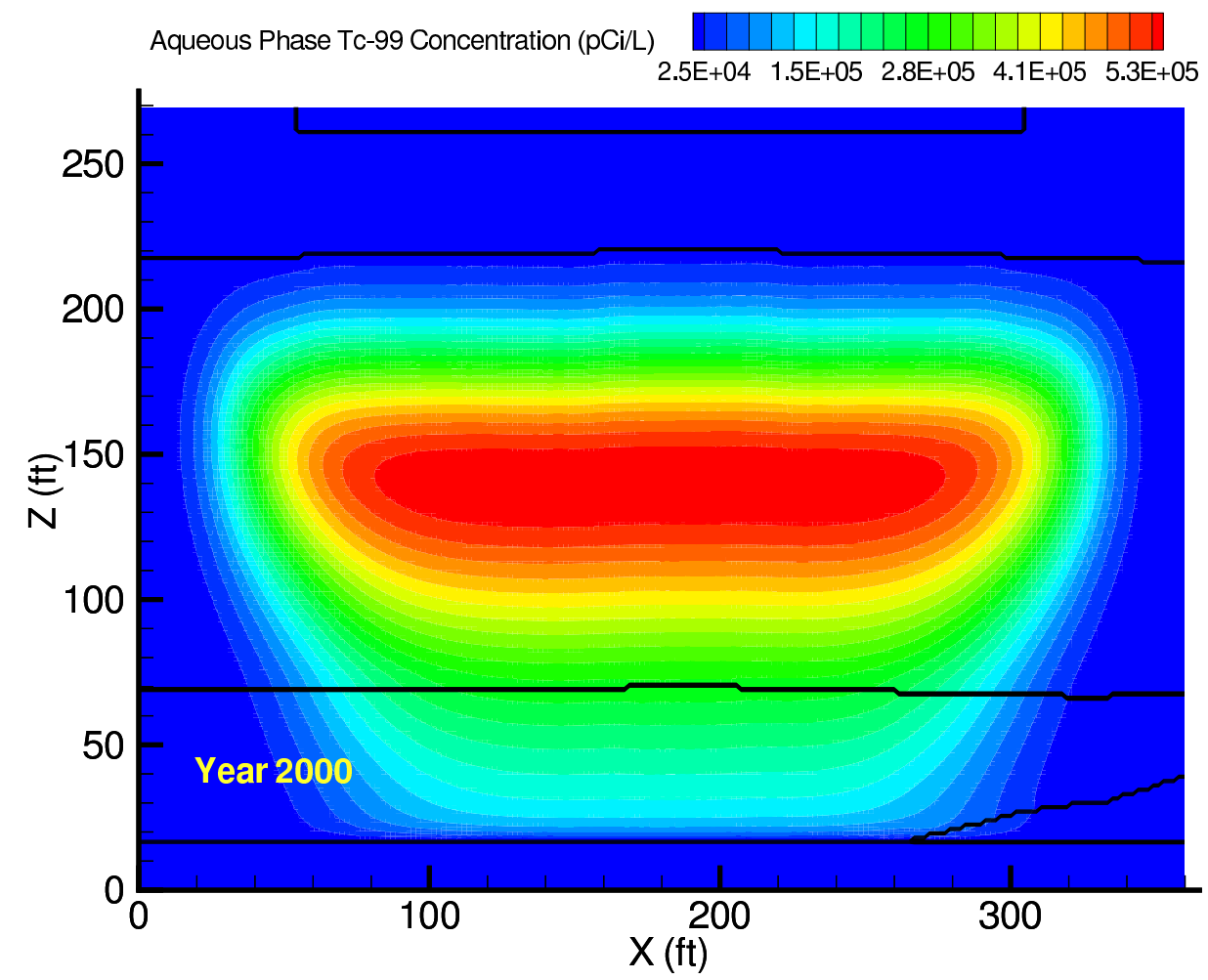

Figure B.12. Case 13 Tc-99 aqueous concentration distributions at (a) year 1955 and (b) year 2000 $(100 \mathrm{~mm} / \mathrm{yr}$ recharge) 


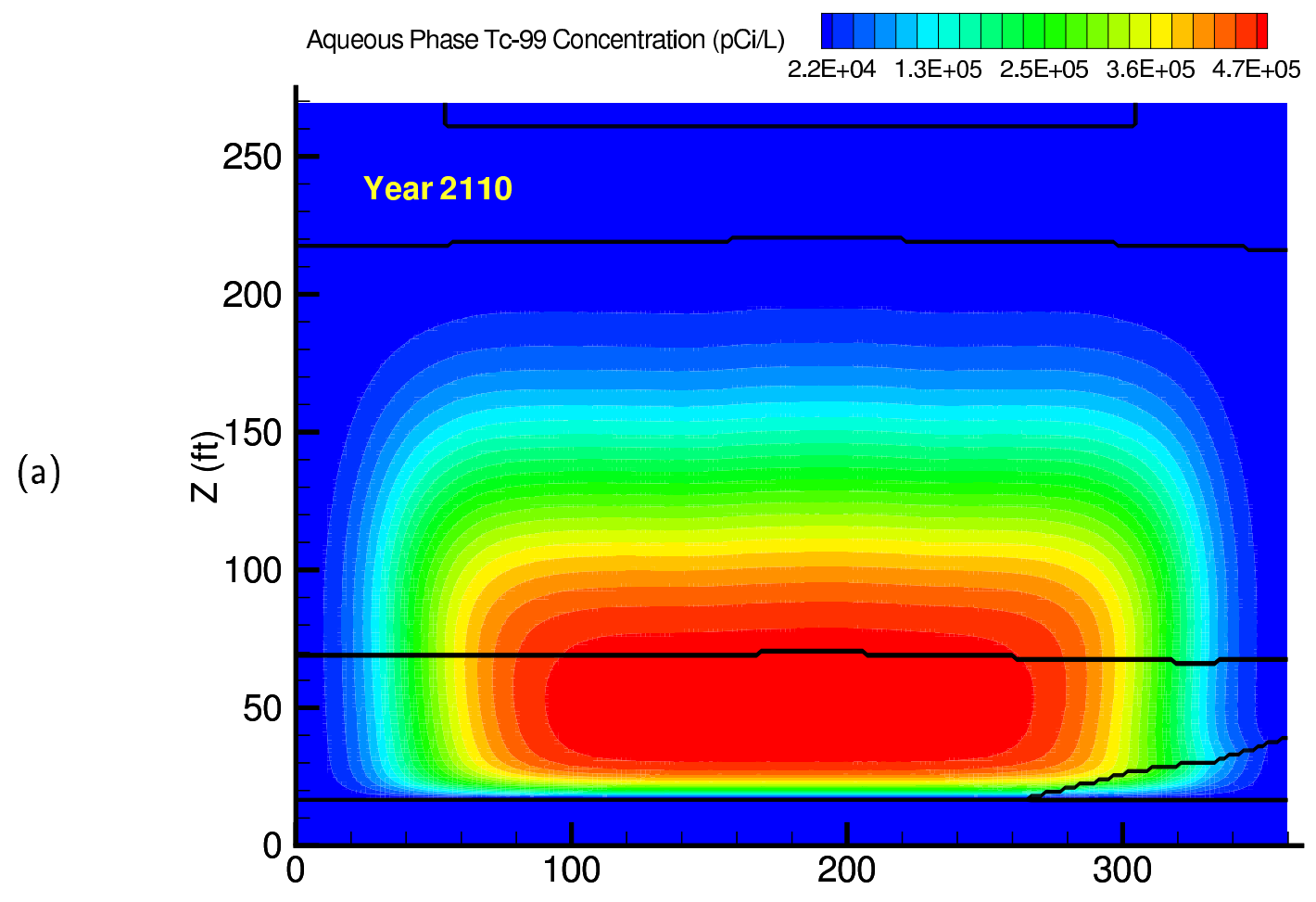

(b)

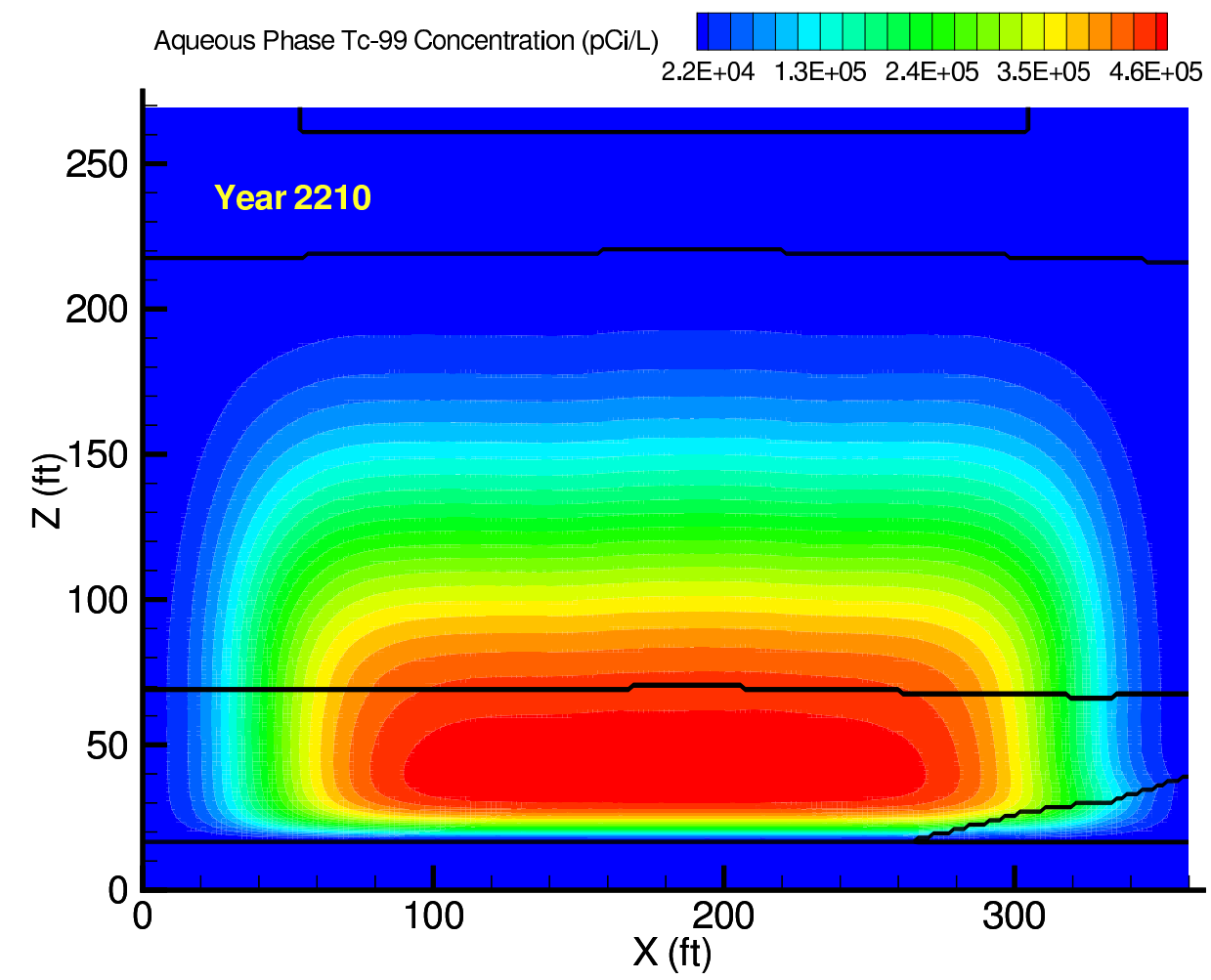

Figure B.13. Case 13 Tc-99 aqueous concentration distributions at (a) year 2110 and (b) year 2210 (100 $\mathrm{mm} / \mathrm{yr}$ recharge) 


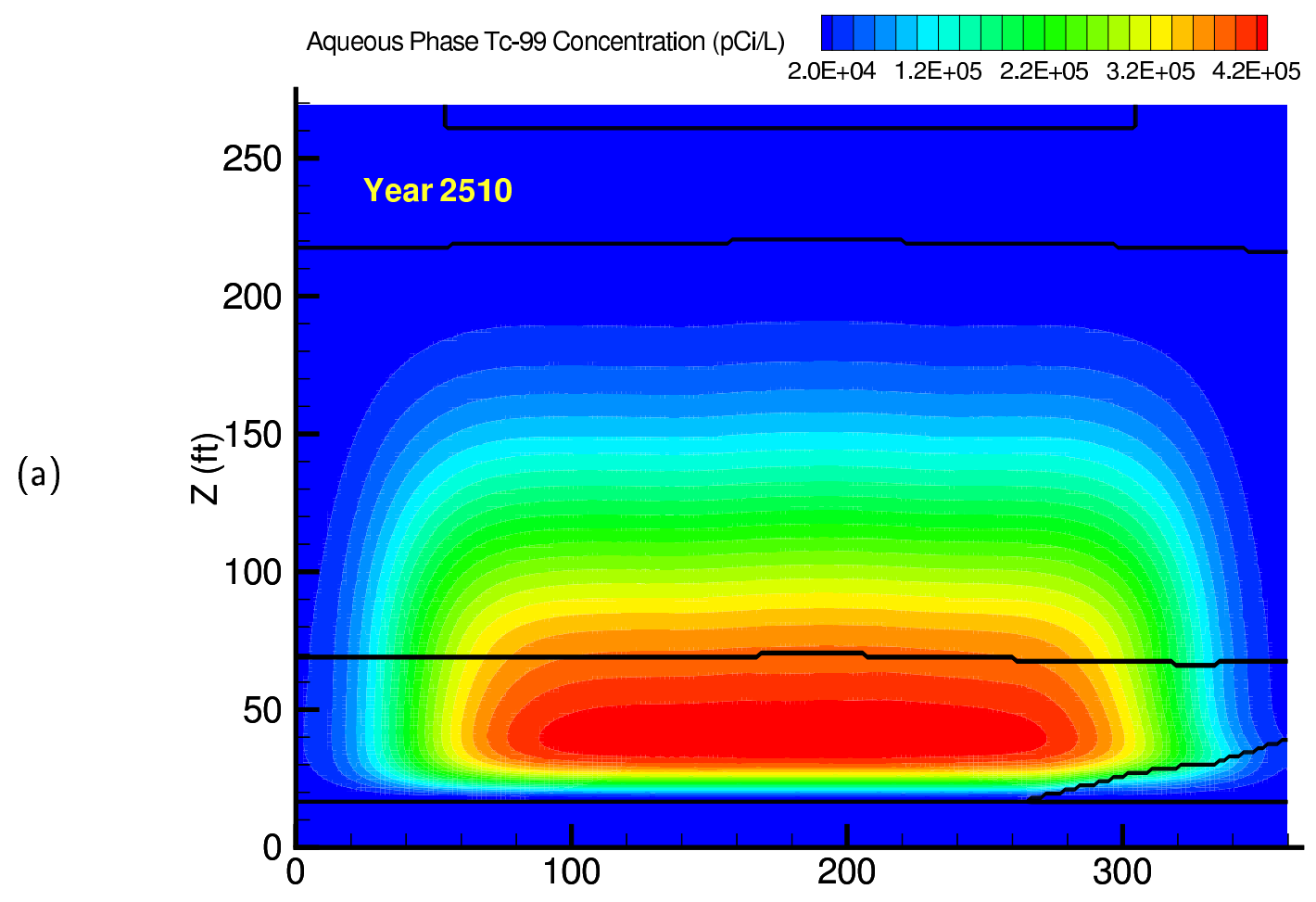

(b)

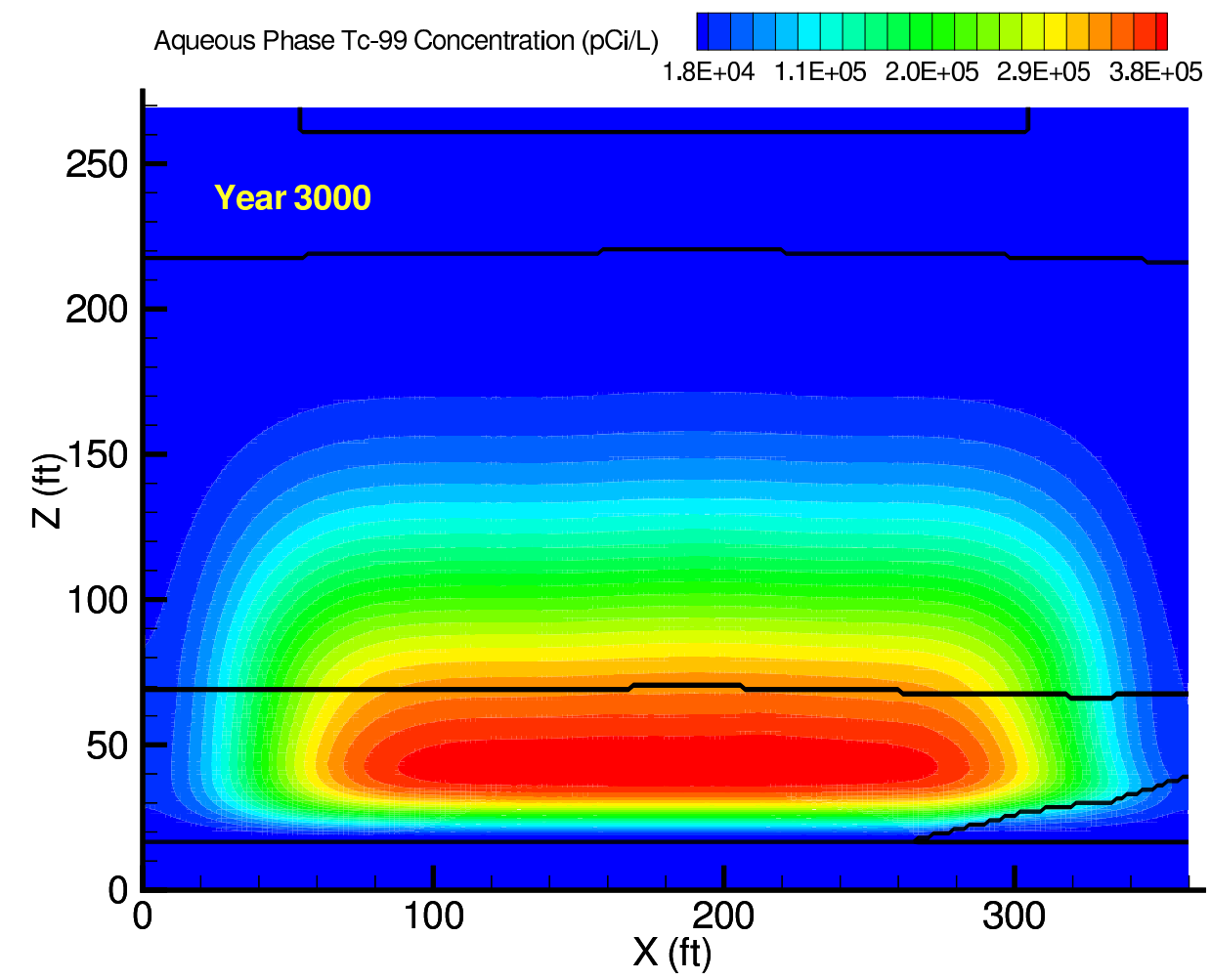

Figure B.14. Case 13 Tc-99 aqueous concentration distributions at (a) year 2510 and (b) year 3000 (100 $\mathrm{mm} / \mathrm{yr}$ recharge) 


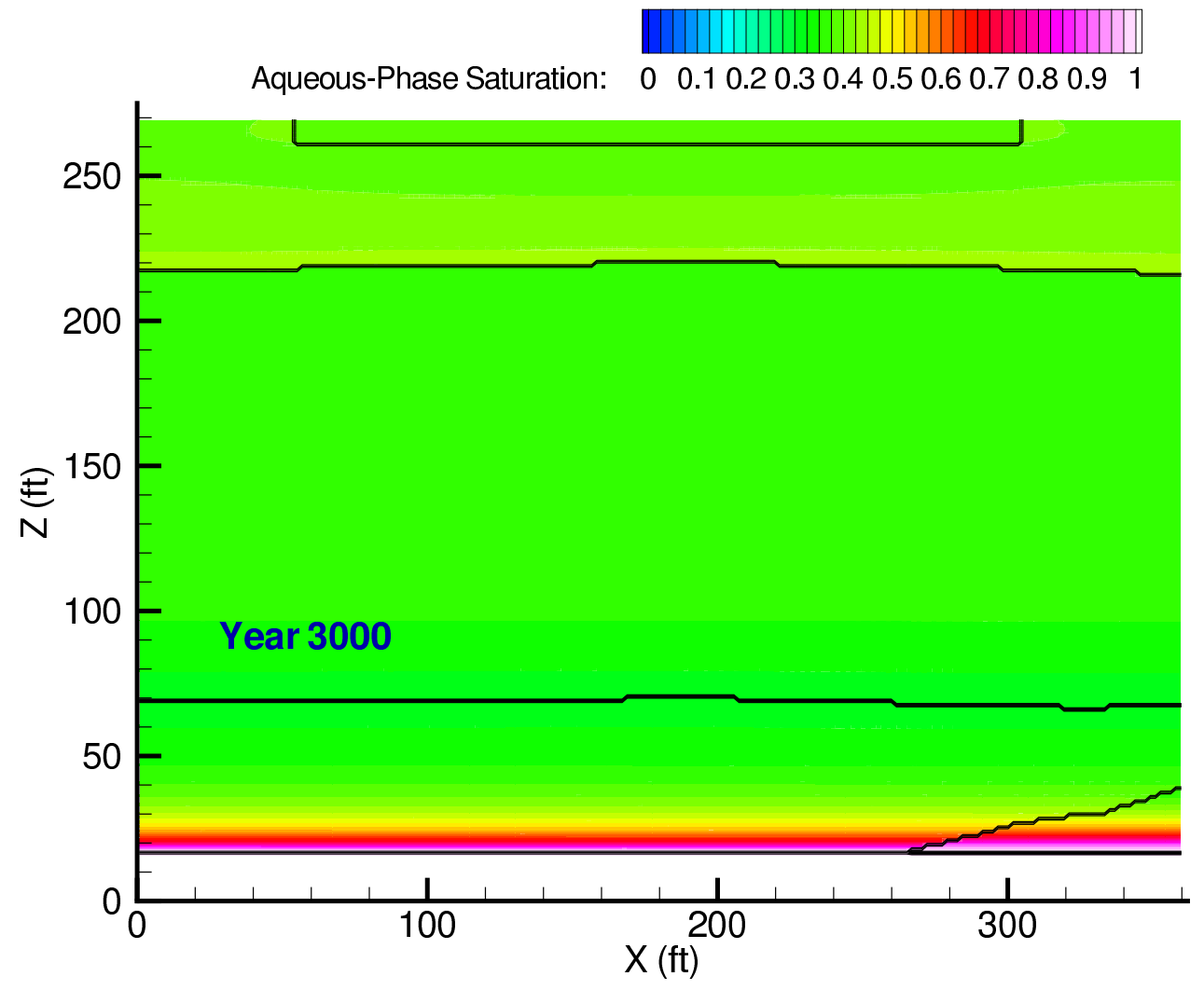

Figure B.15. Case 14 aqueous phase saturation with delayed closure barrier at year 3000 (100 $\mathrm{mm} / \mathrm{yr}$ recharge) 
(a)

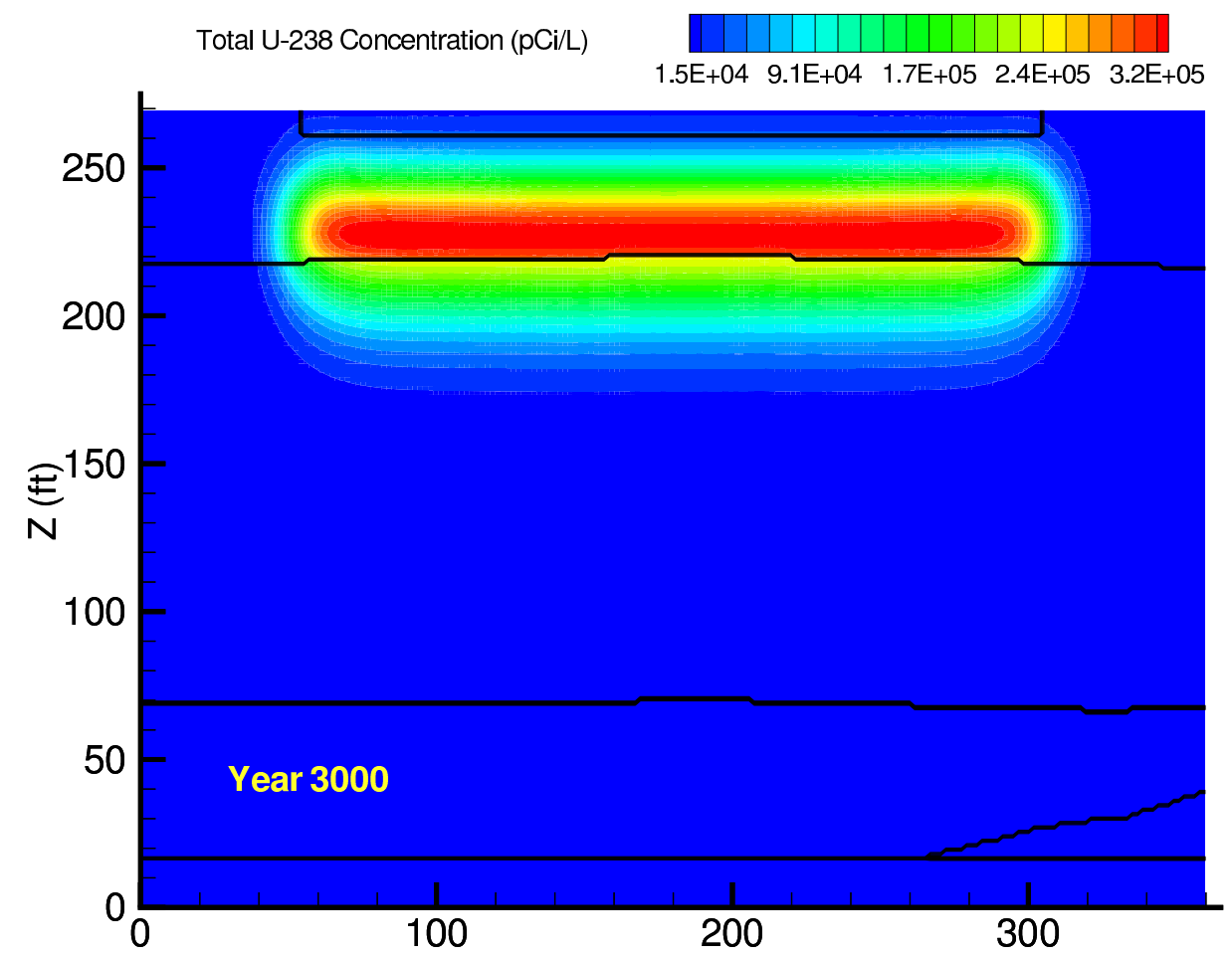

(b)

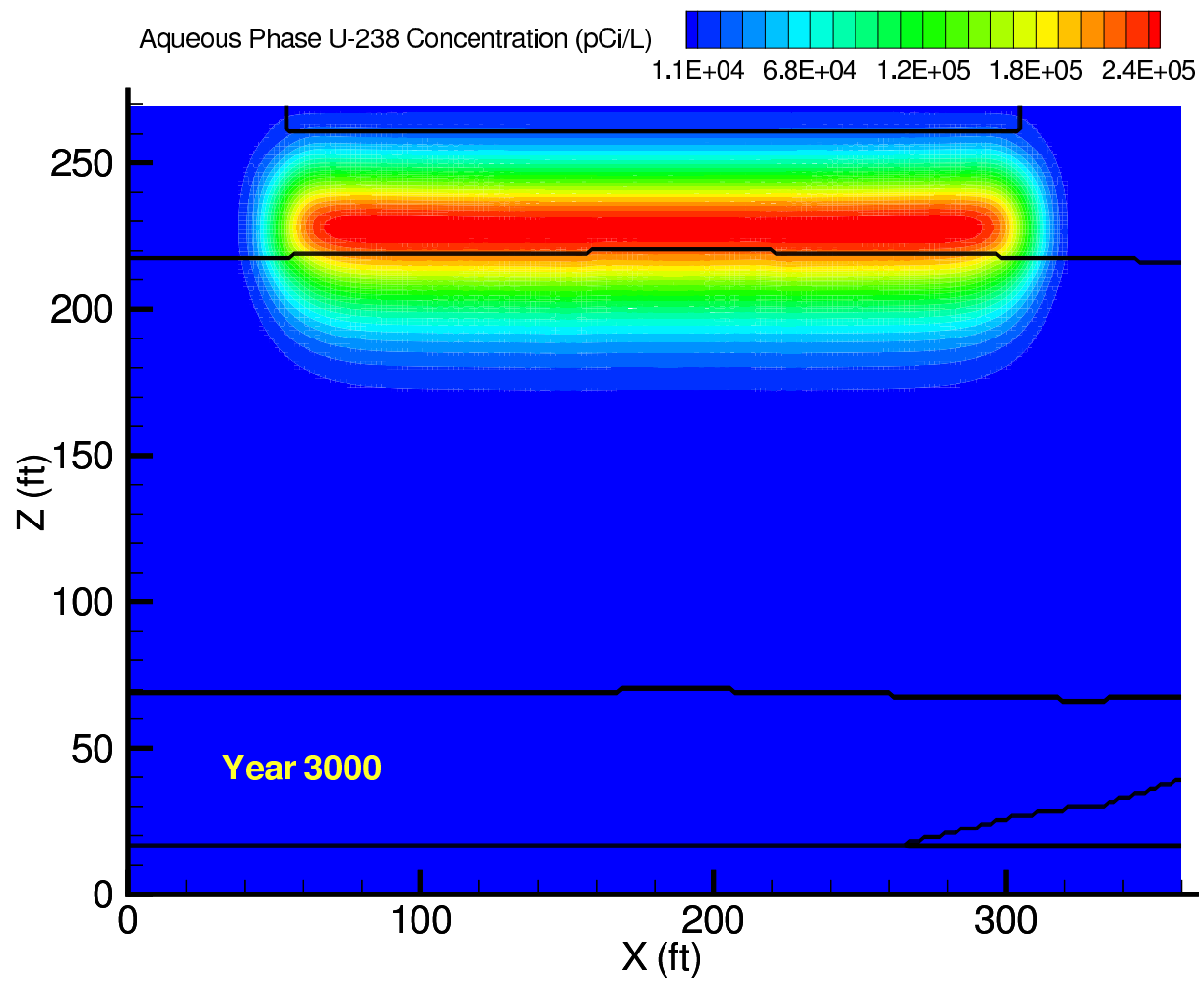

Figure B.16. Case 14 U-238 (a) total and (b) aqueous concentration distributions with delayed closure barrier at year $3000(100 \mathrm{~mm} / \mathrm{yr}$ recharge $)$ 


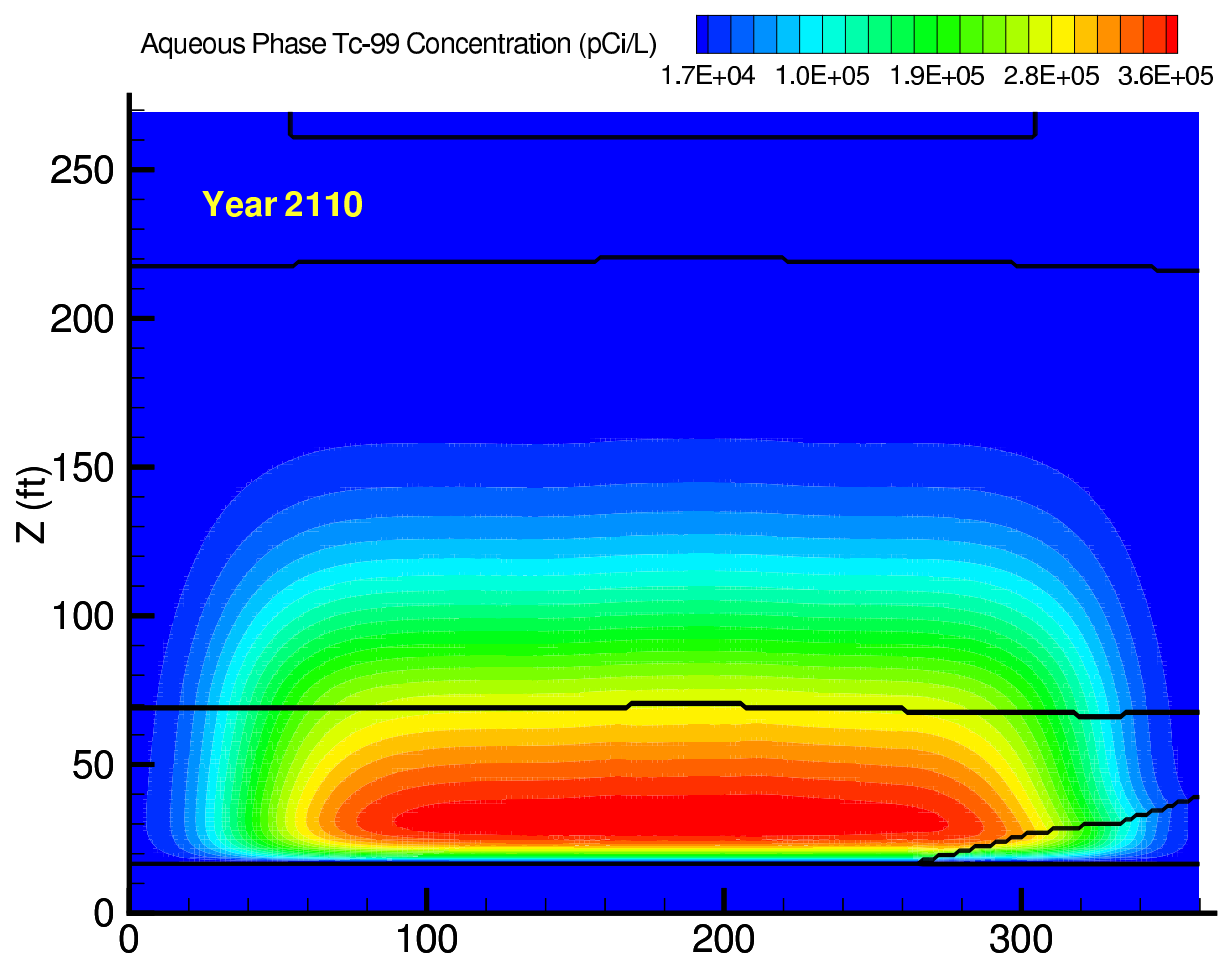

(b)

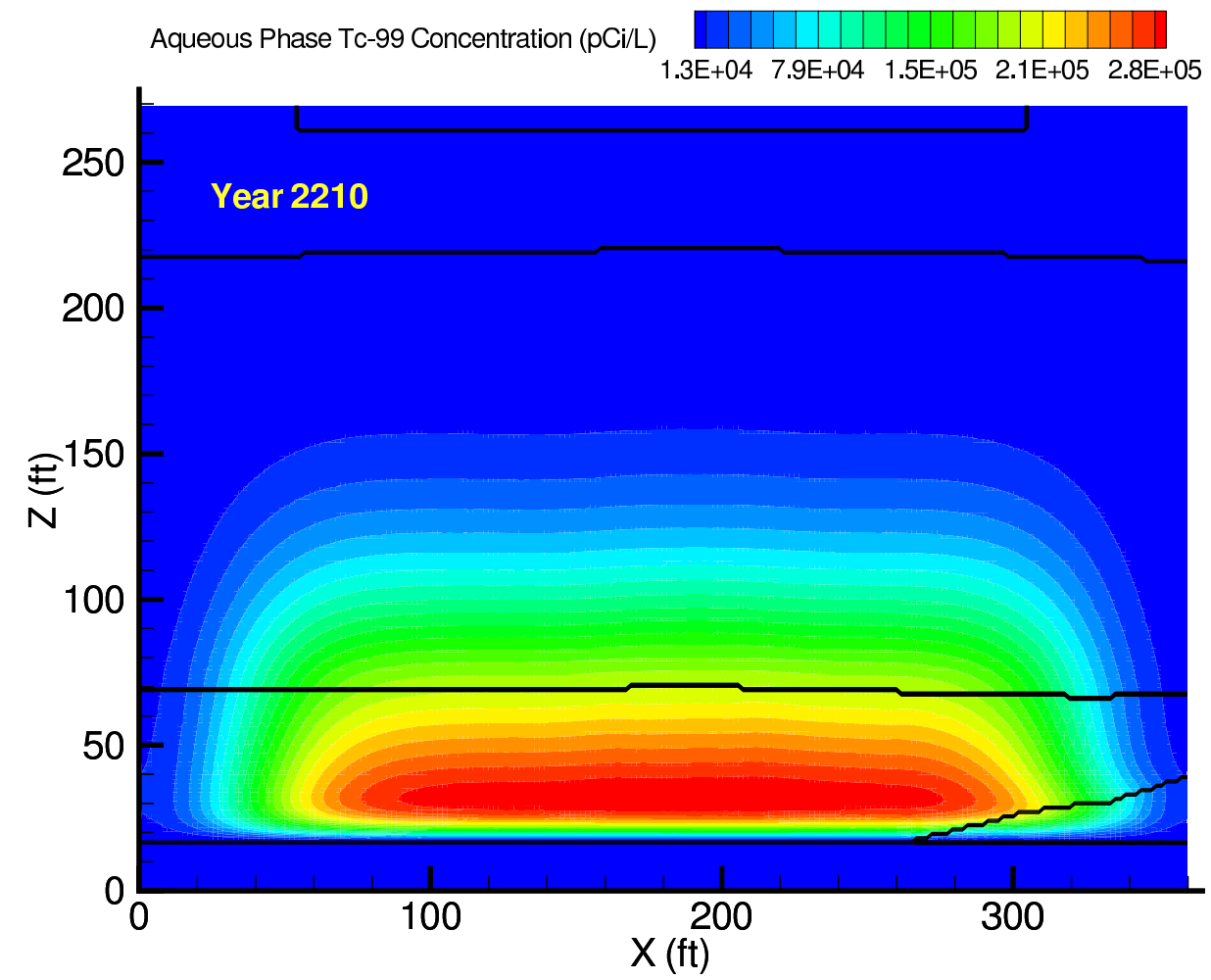

Figure B.17. Case 14 Tc-99 aqueous concentration distributions with delayed closure barrier at (a) year 2110 and (b) year $2210(100 \mathrm{~mm} / \mathrm{yr}$ recharge $)$ 


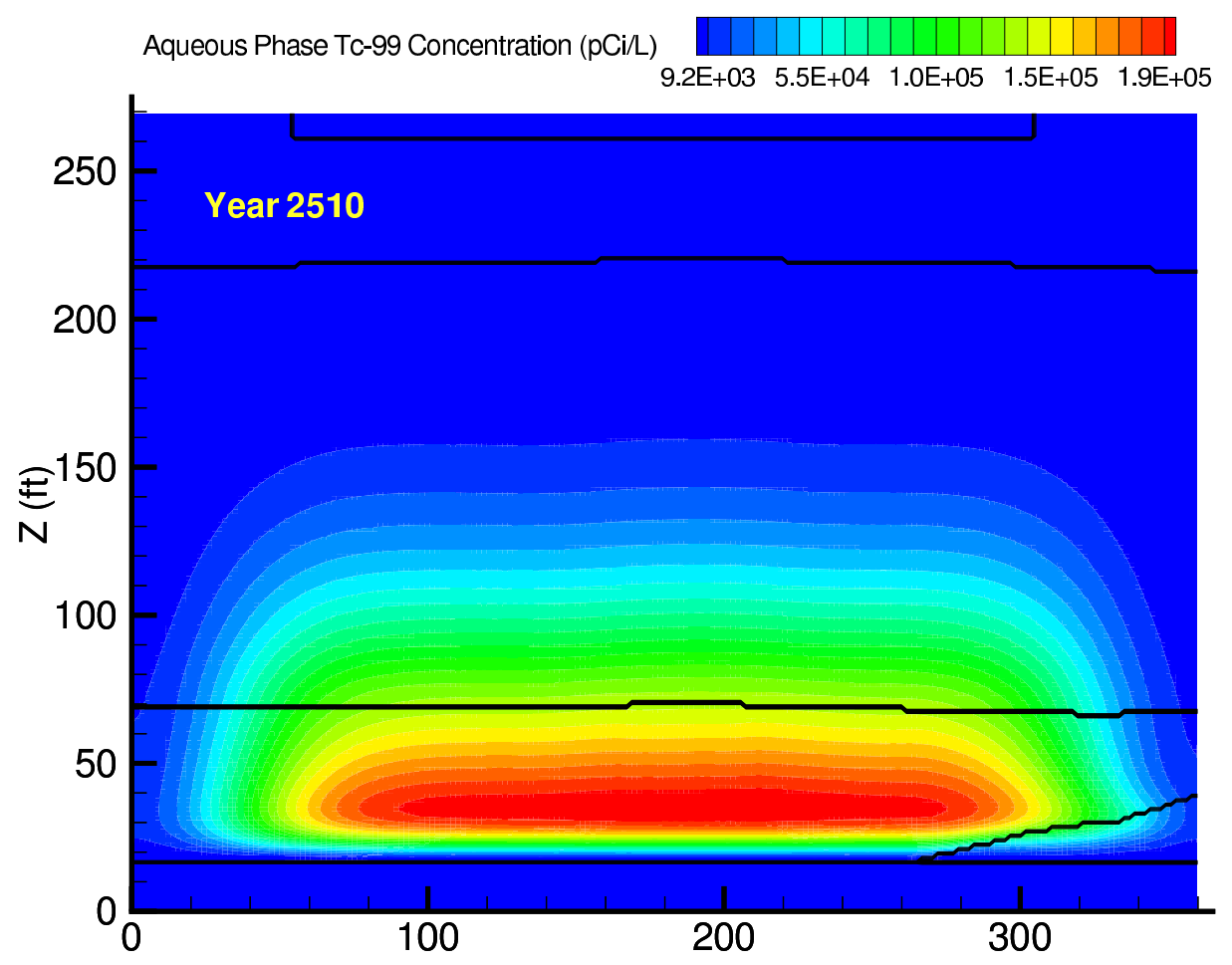

(b)

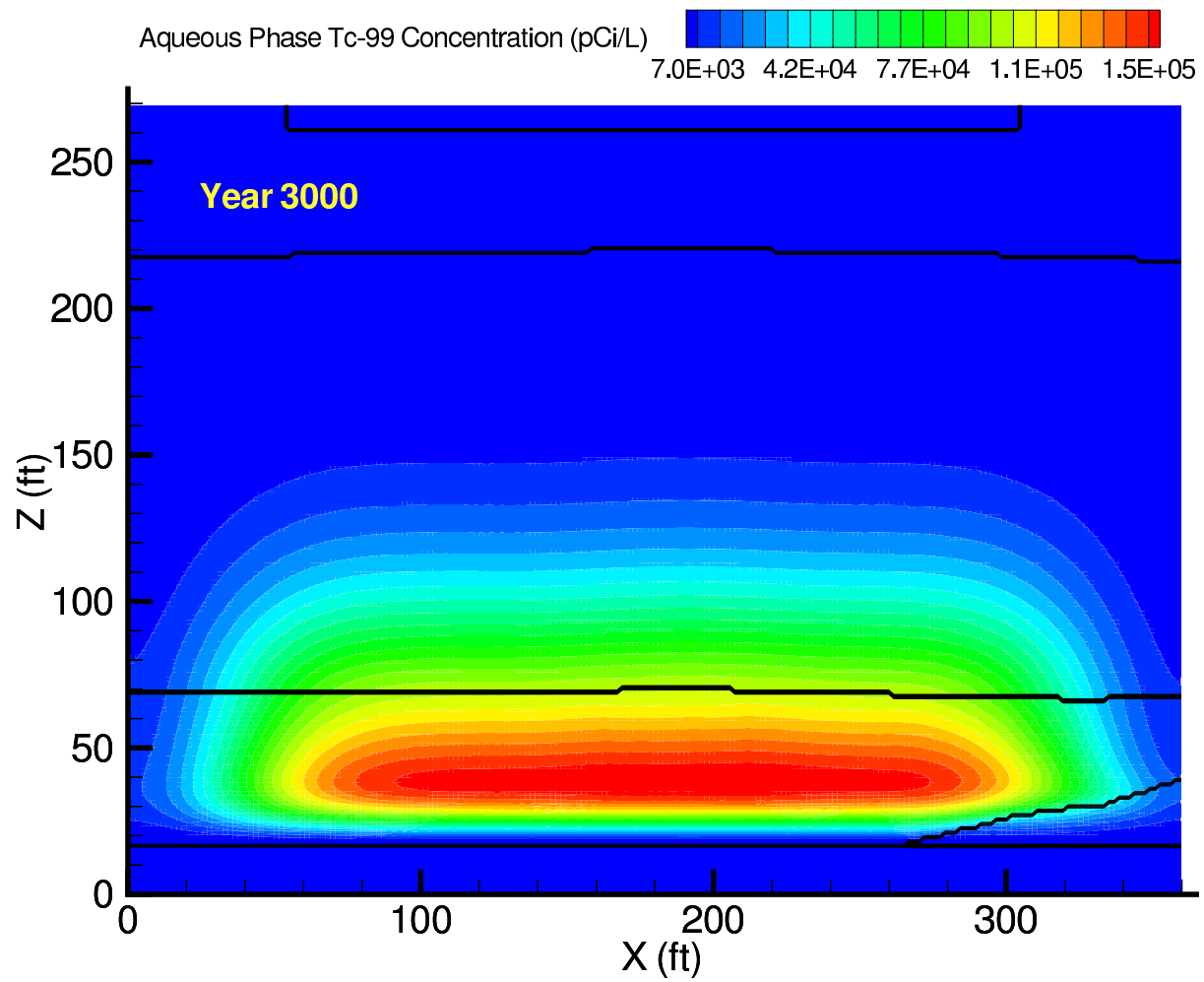

Figure B.18. Case 14 Tc-99 aqueous concentration distributions with delayed closure barrier at (a) year 2510 and (b) year 3000 (100 mm/yr recharge) 
Appendix C: BX Breathrough Curves

C-1 

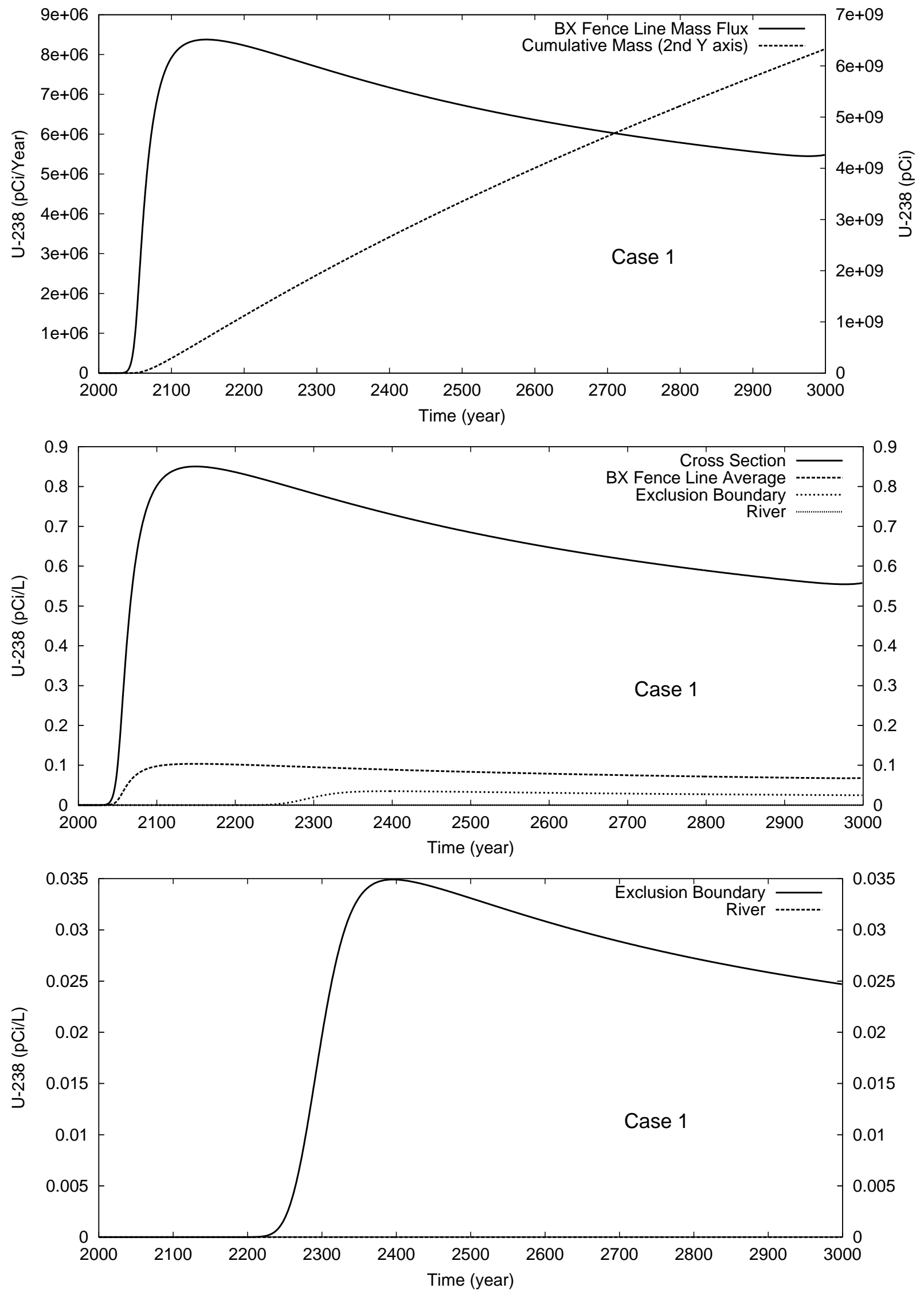

Figure C.1. Case 1 Results for U-238: Mass Flux and Breakthrough Curves

$$
\text { C-2 }
$$



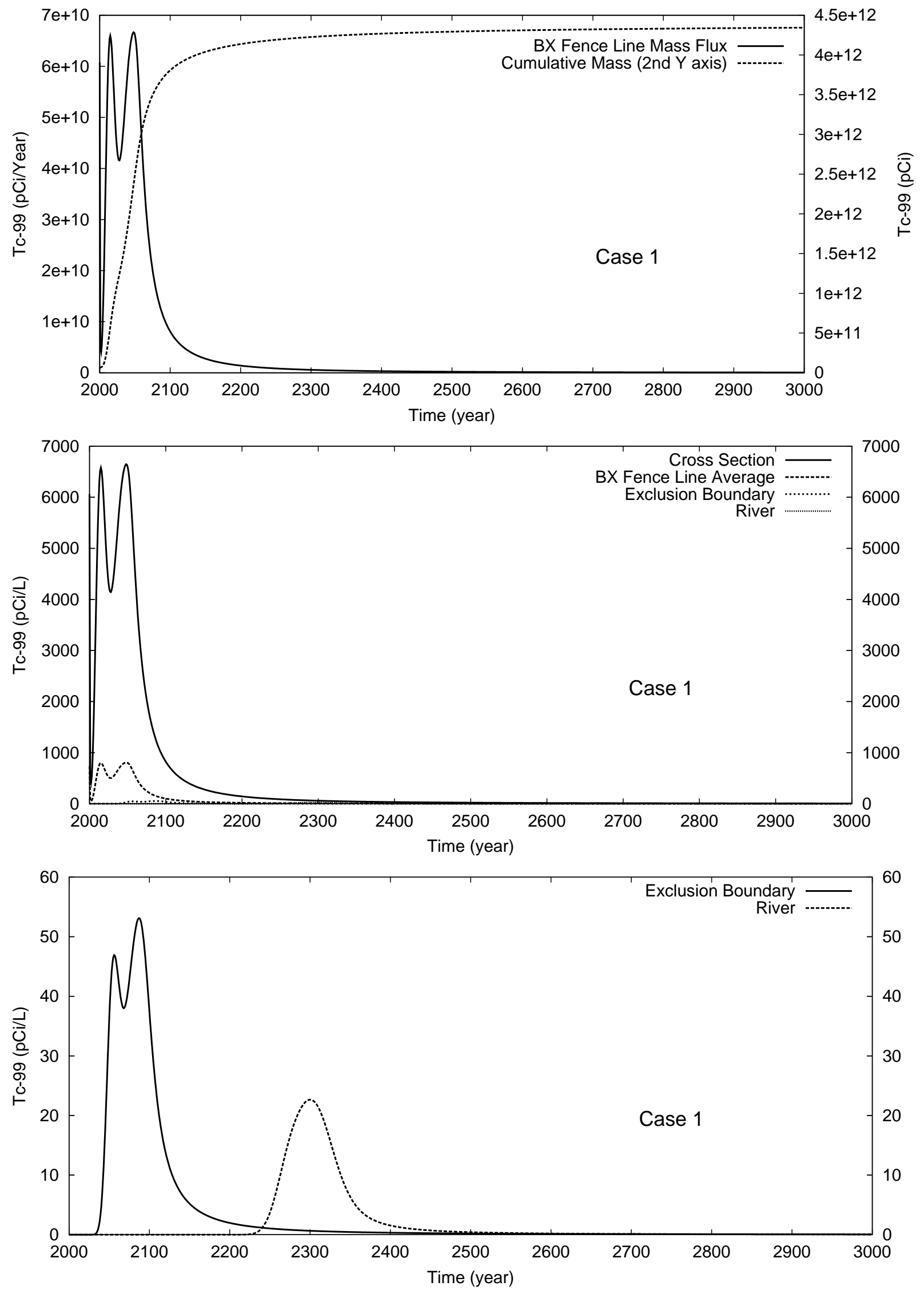

Figure C.2. Case 1 Results for Tc-99: Mass Flux and Breakthrough Curves

C-3 

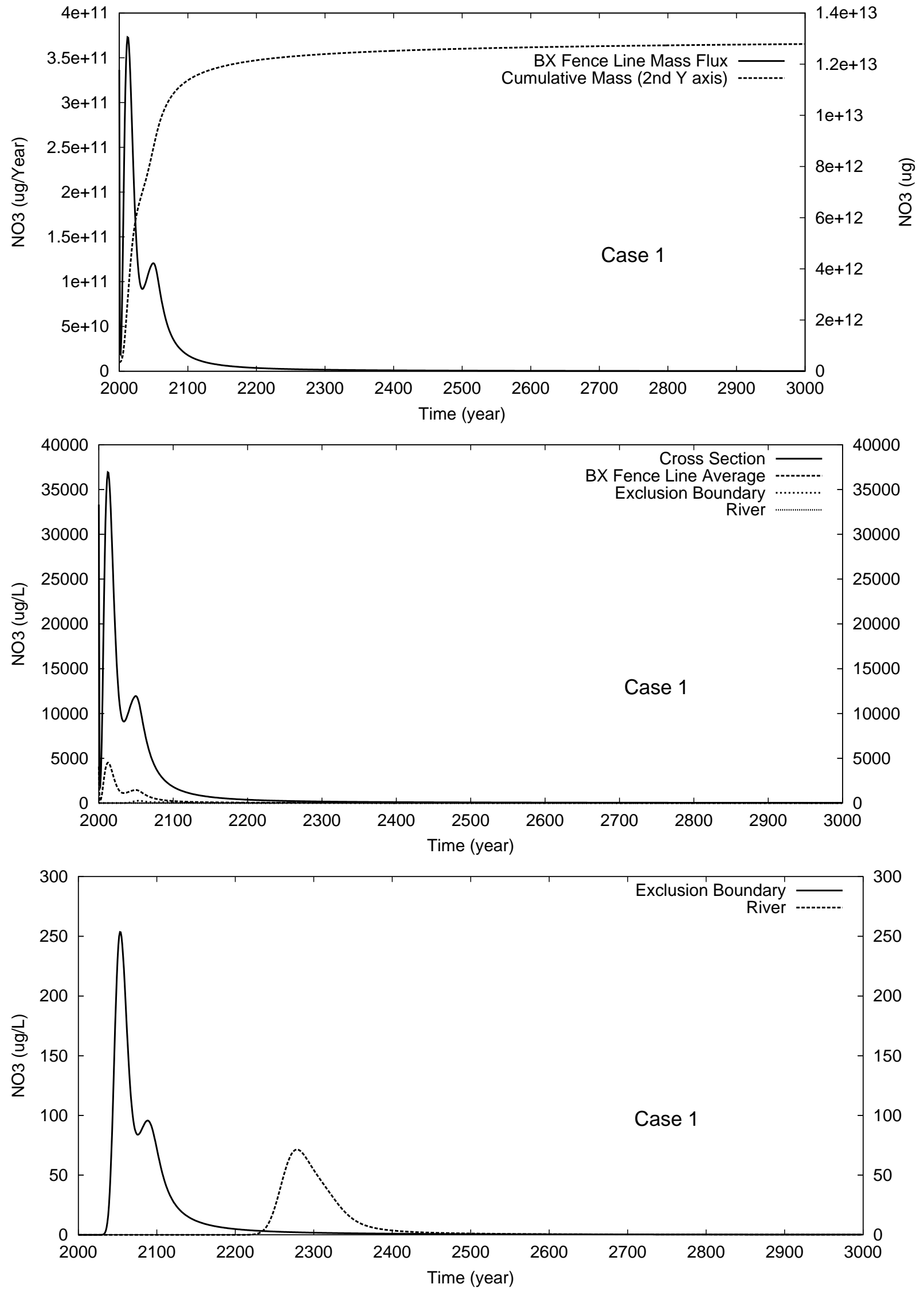

Figure C.3. Case 1 Results for NO3: Mass Flux and Breakthrough Curves C-4 

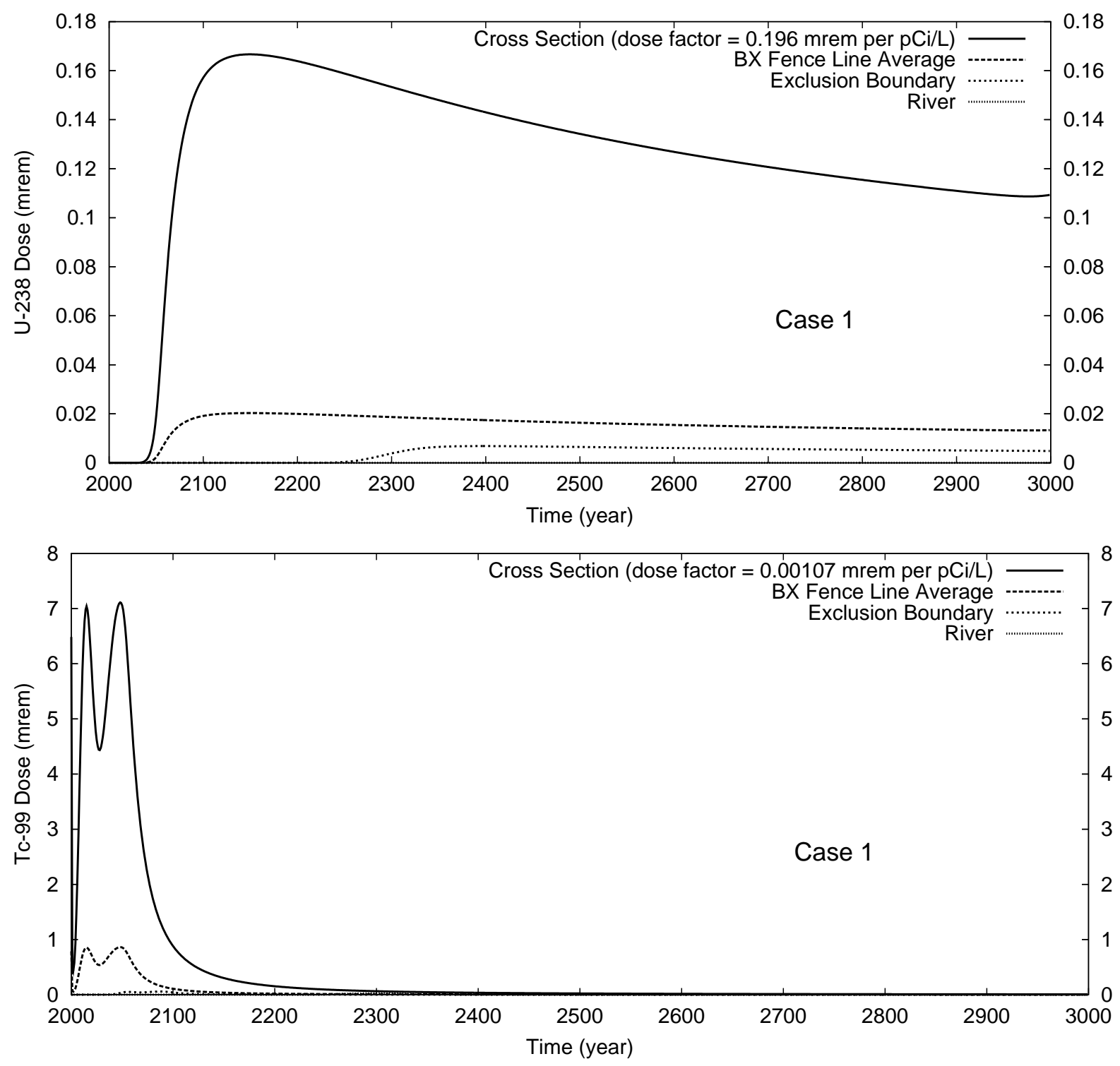

Figure C.4. Case 1 Results for U-238 and Tc-99 Dose at Compliance Points 

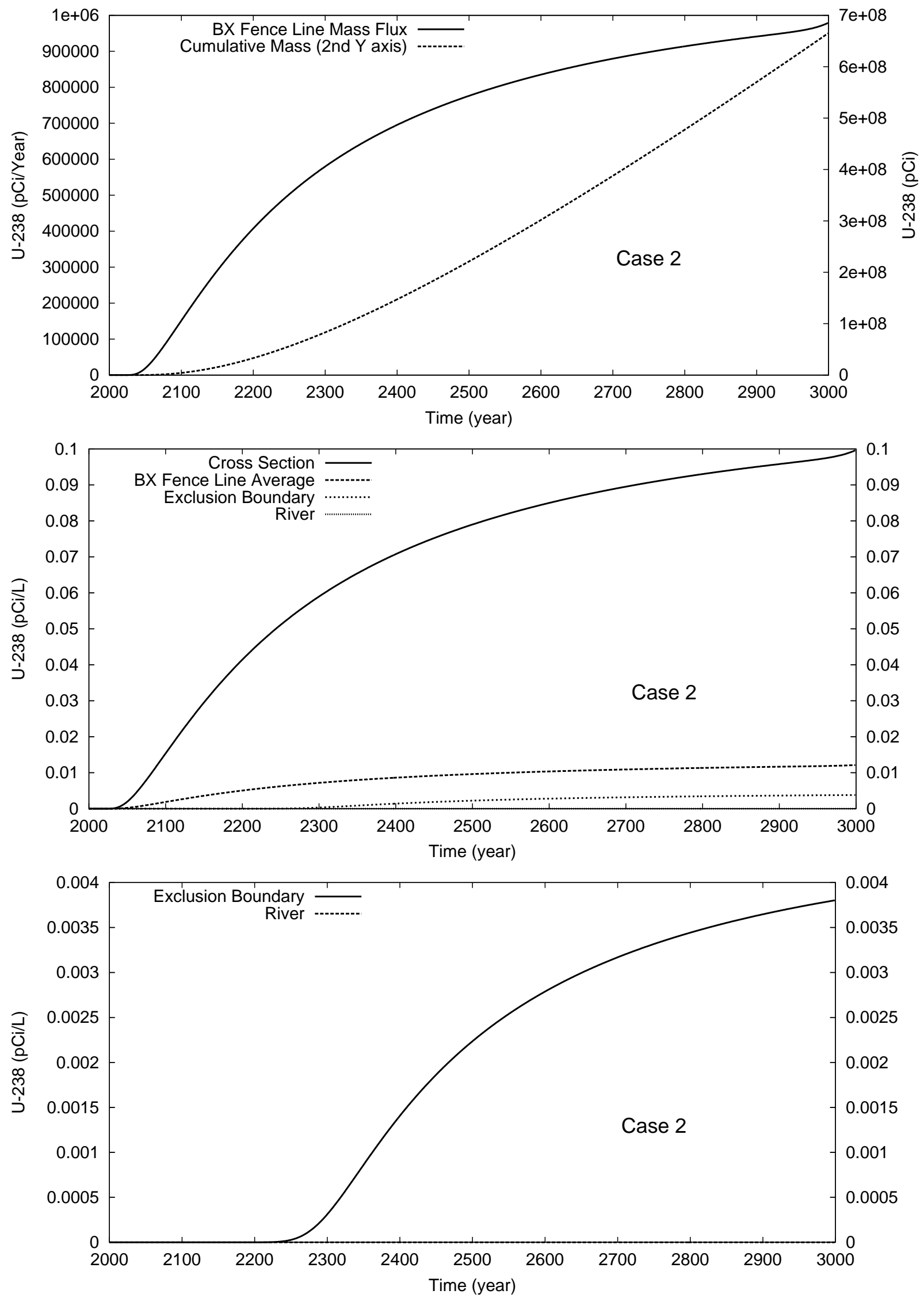

Figure C.5. Case 2 Results for U-238: Mass Flux and Breakthrough Curves

$$
\text { C-6 }
$$



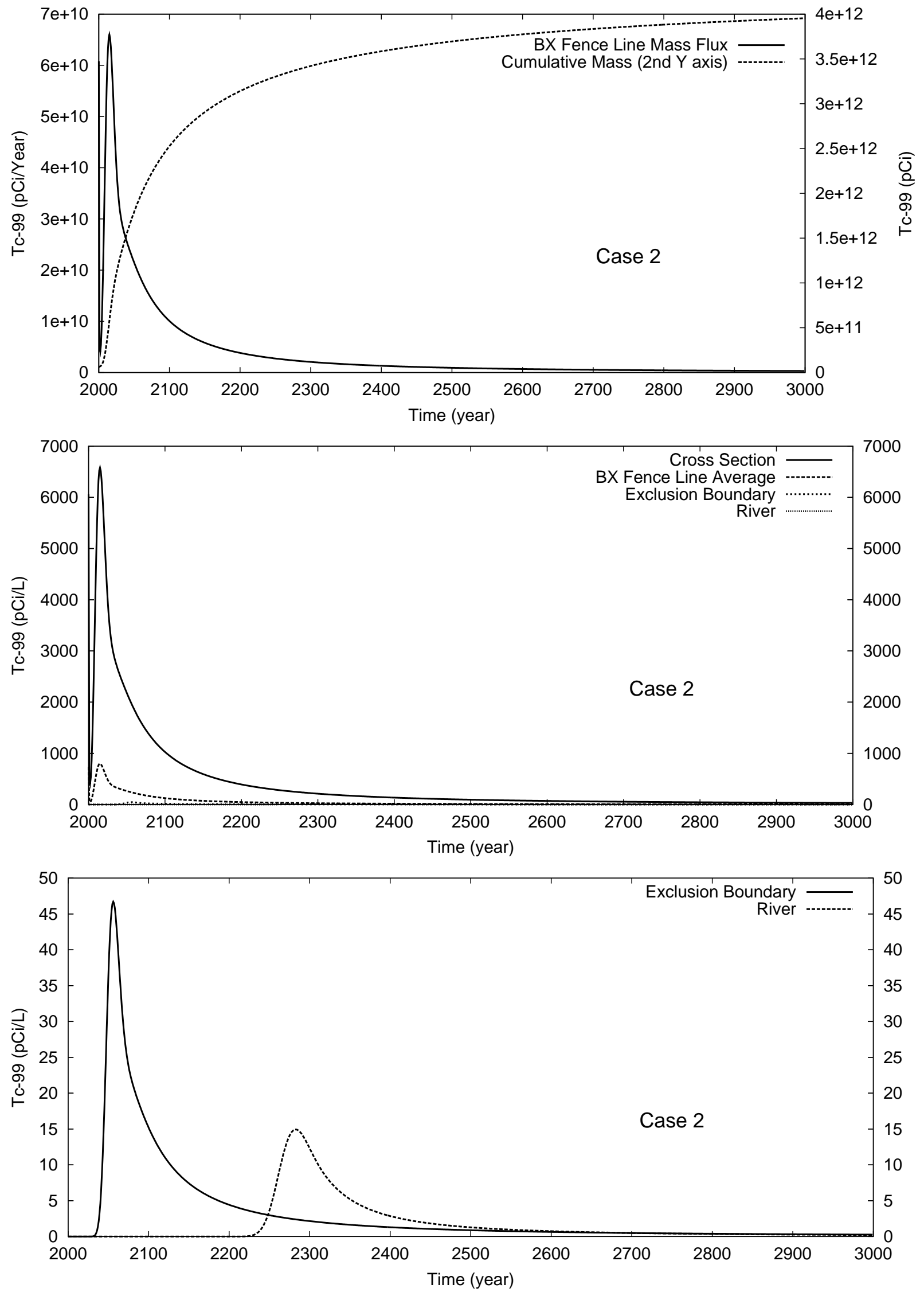

Figure C.6. Case 2 Results for Tc-99: Mass Flux and Breakthrough Curves

C-7 

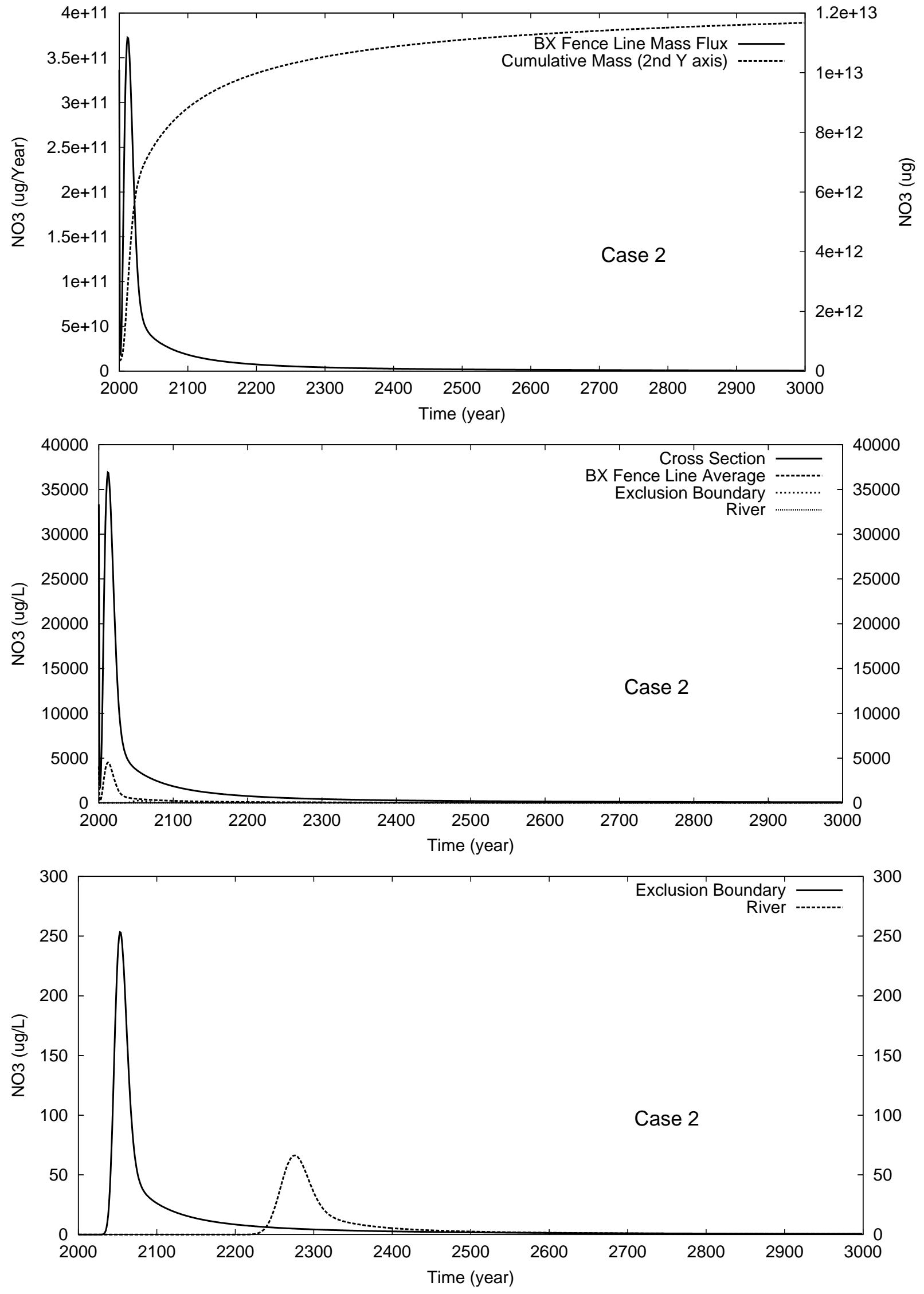

Figure C.7. Case 2 Results for NO3: Mass Flux and Breakthrough Curves C-8 

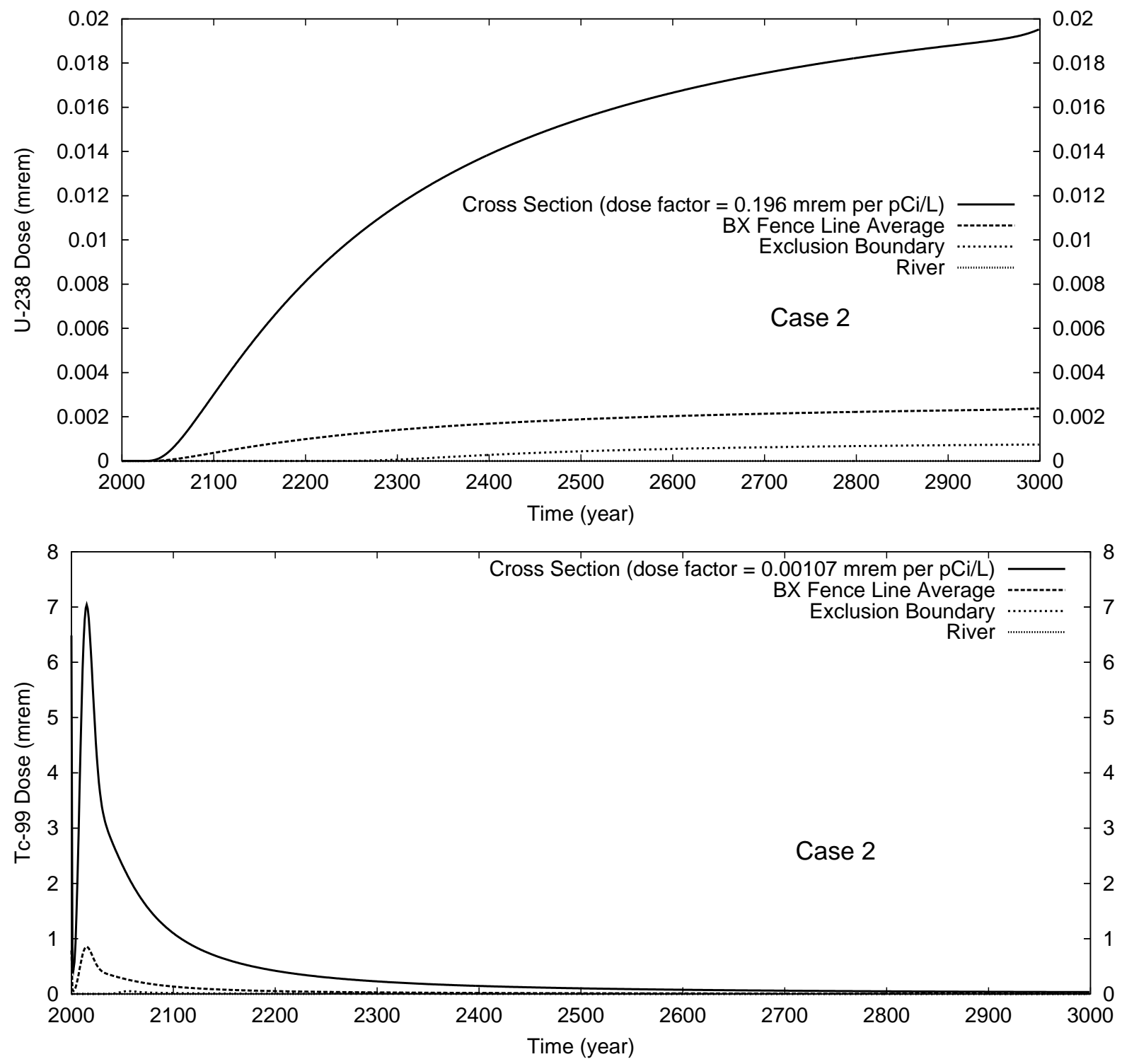

Figure C.8. Case 2 Results for U-238 and Tc-99 Dose at Compliance Points 

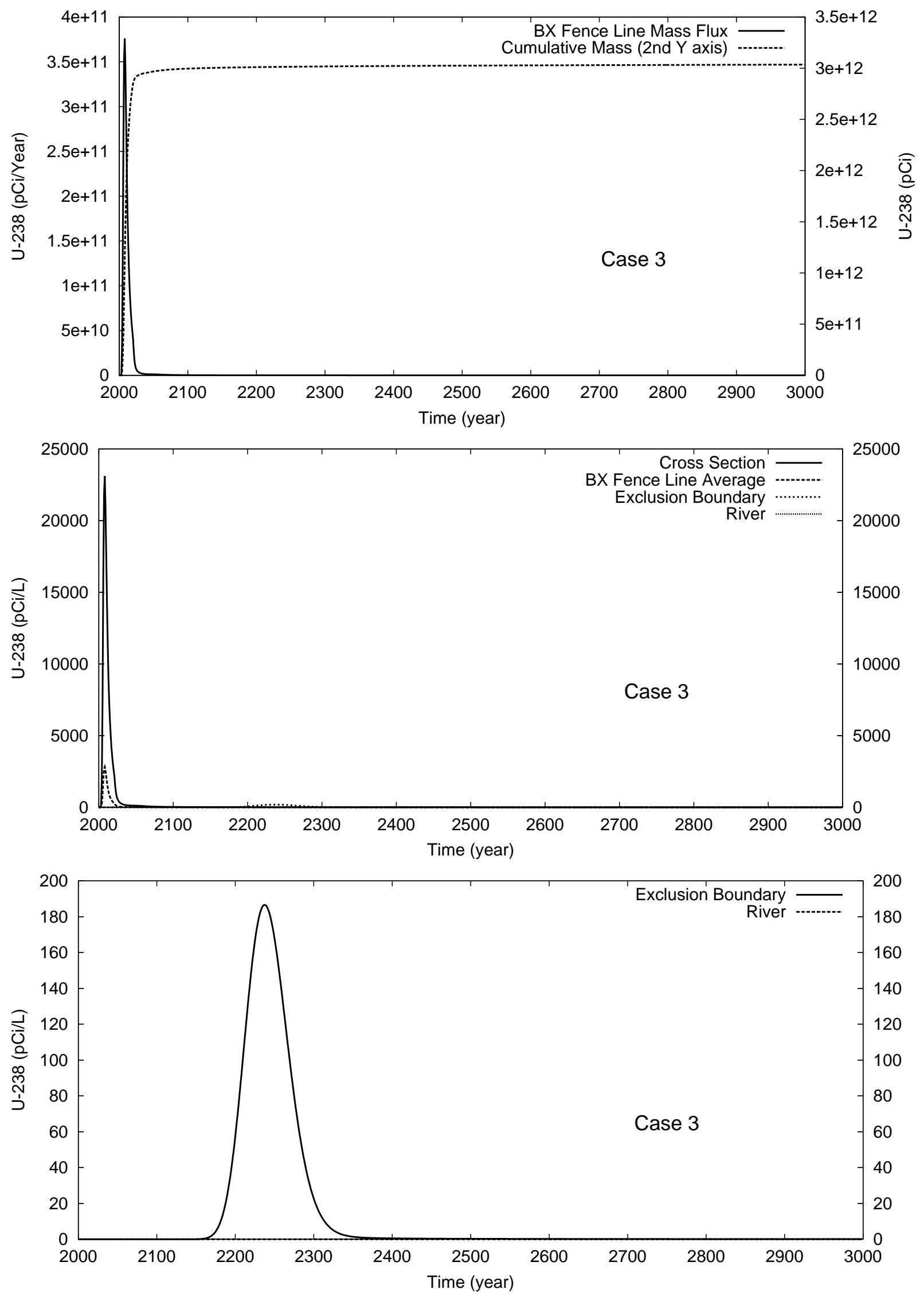

Figure C.9. Case 3 Results for U-238: Mass Flux and Breakthrough Curves C-10 

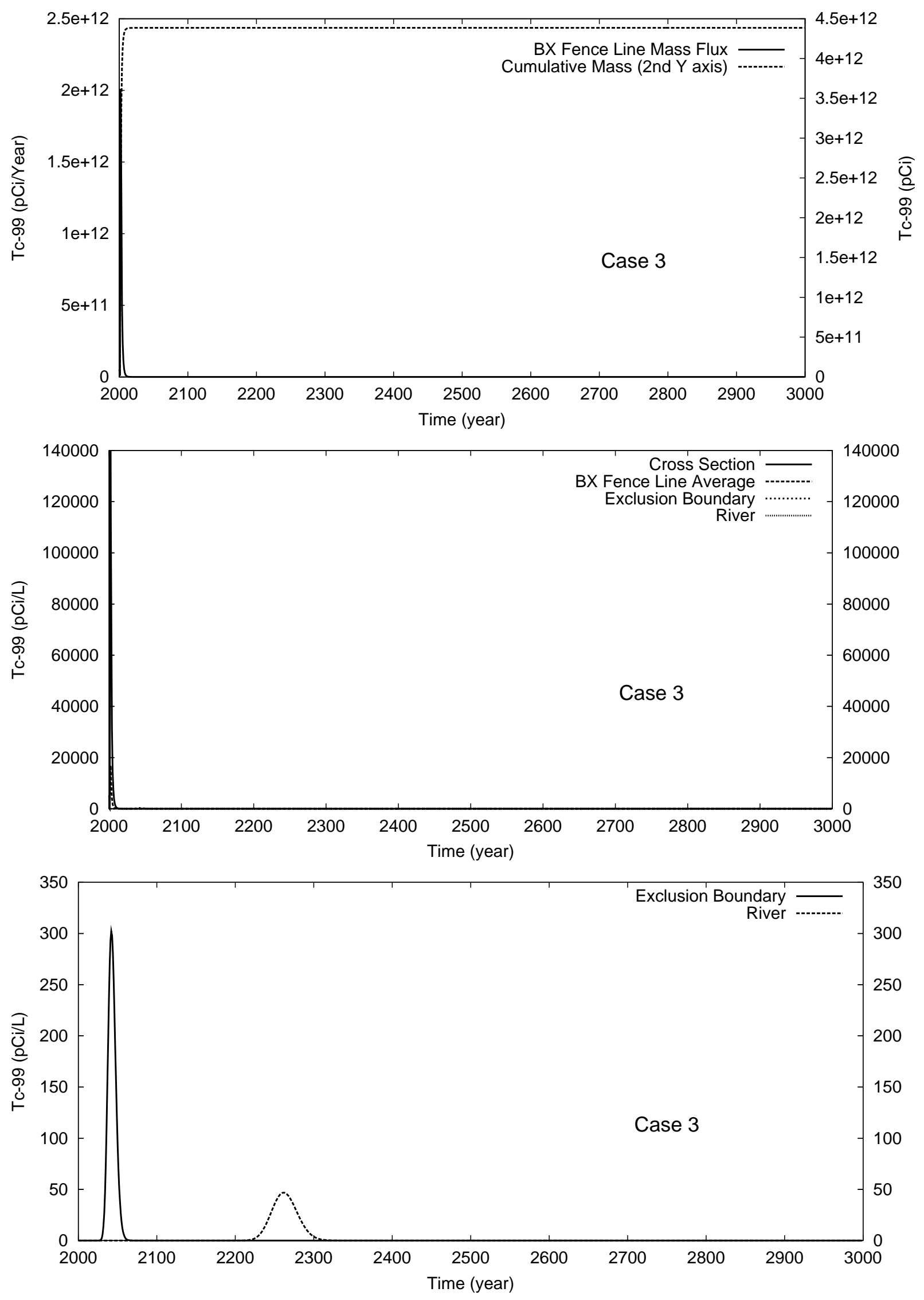

Figure C.10. Case 3 Results for Tc-99: Mass Flux and Breakthrough Curves C-11 

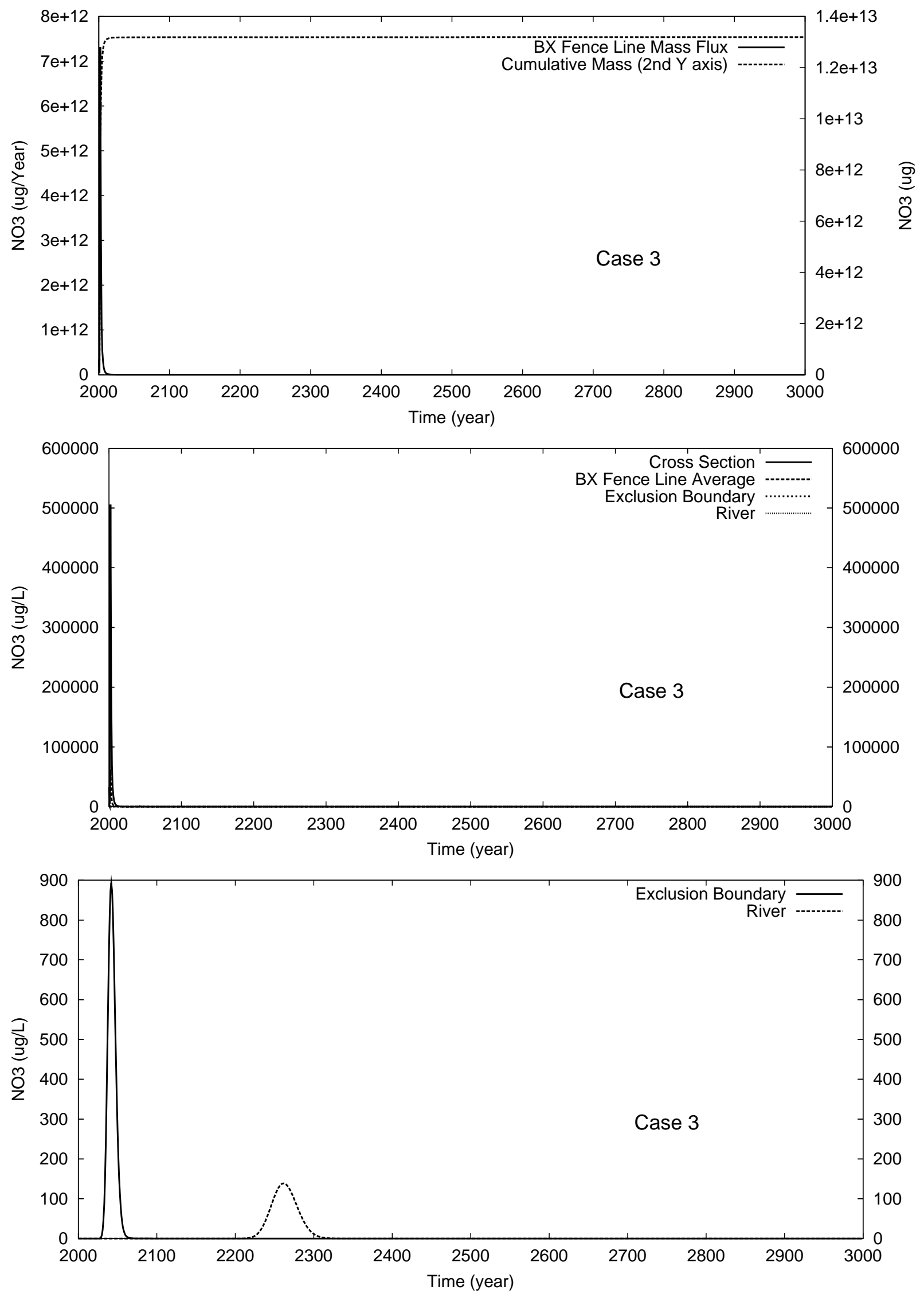

Figure C.11. Case 3 Results for NO3: Mass Flux and Breakthrough Curves C-12 

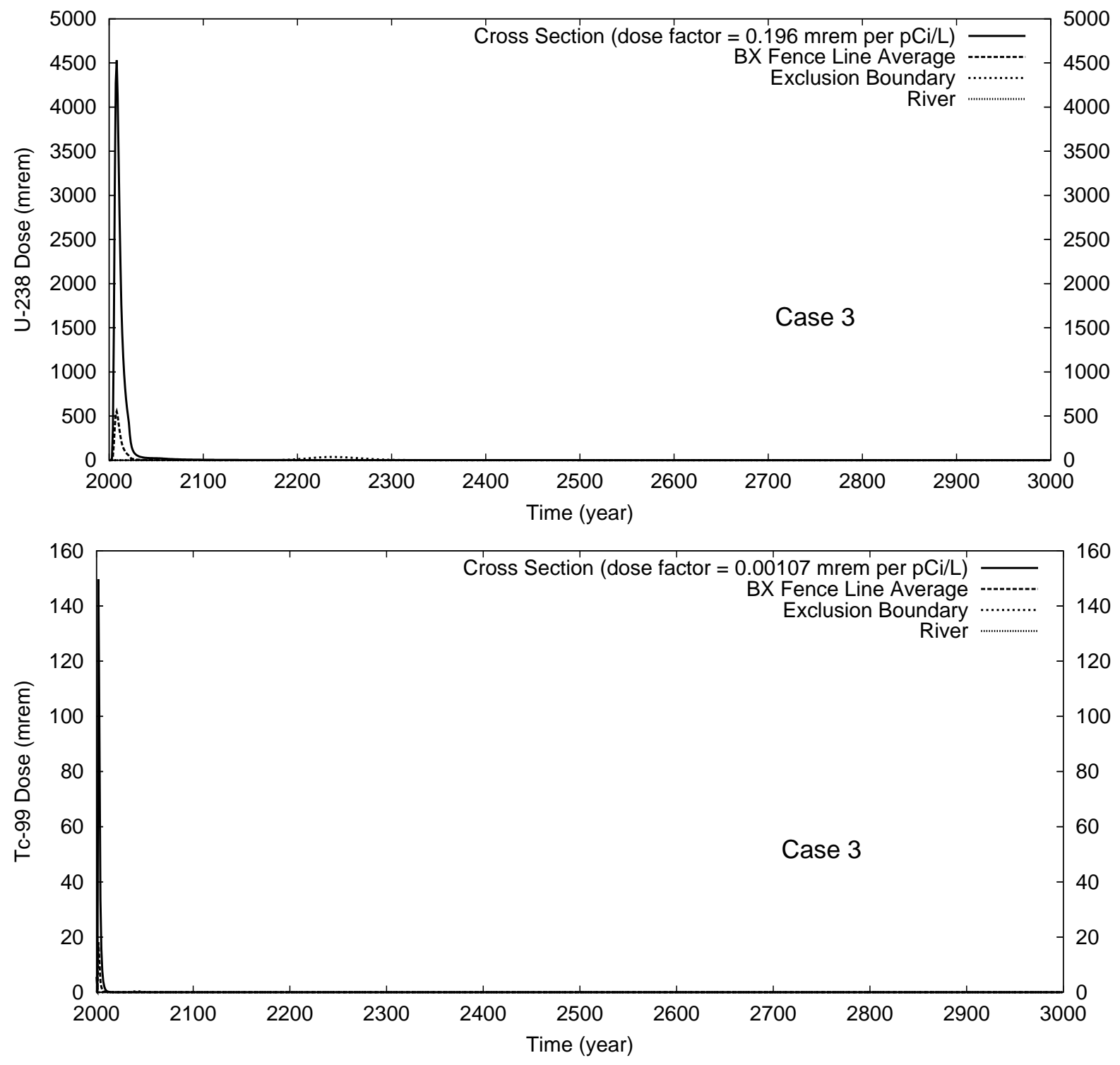

Figure C.12. Case 3 Results for U-238 and Tc-99 Dose at Compliance Points 

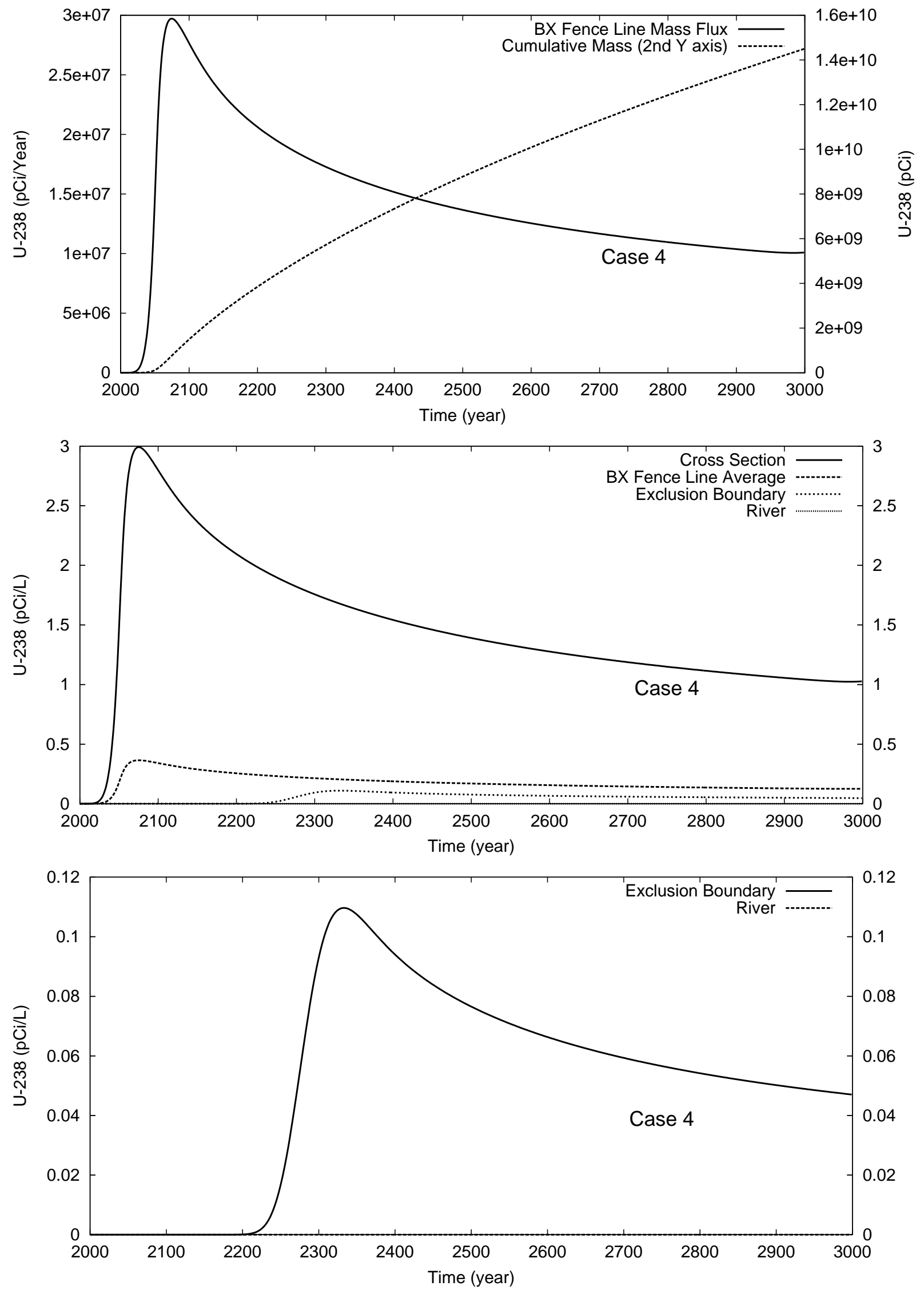

Figure C.13. Case 4 Results for U-238: Mass Flux and Breakthrough Curves C-14 

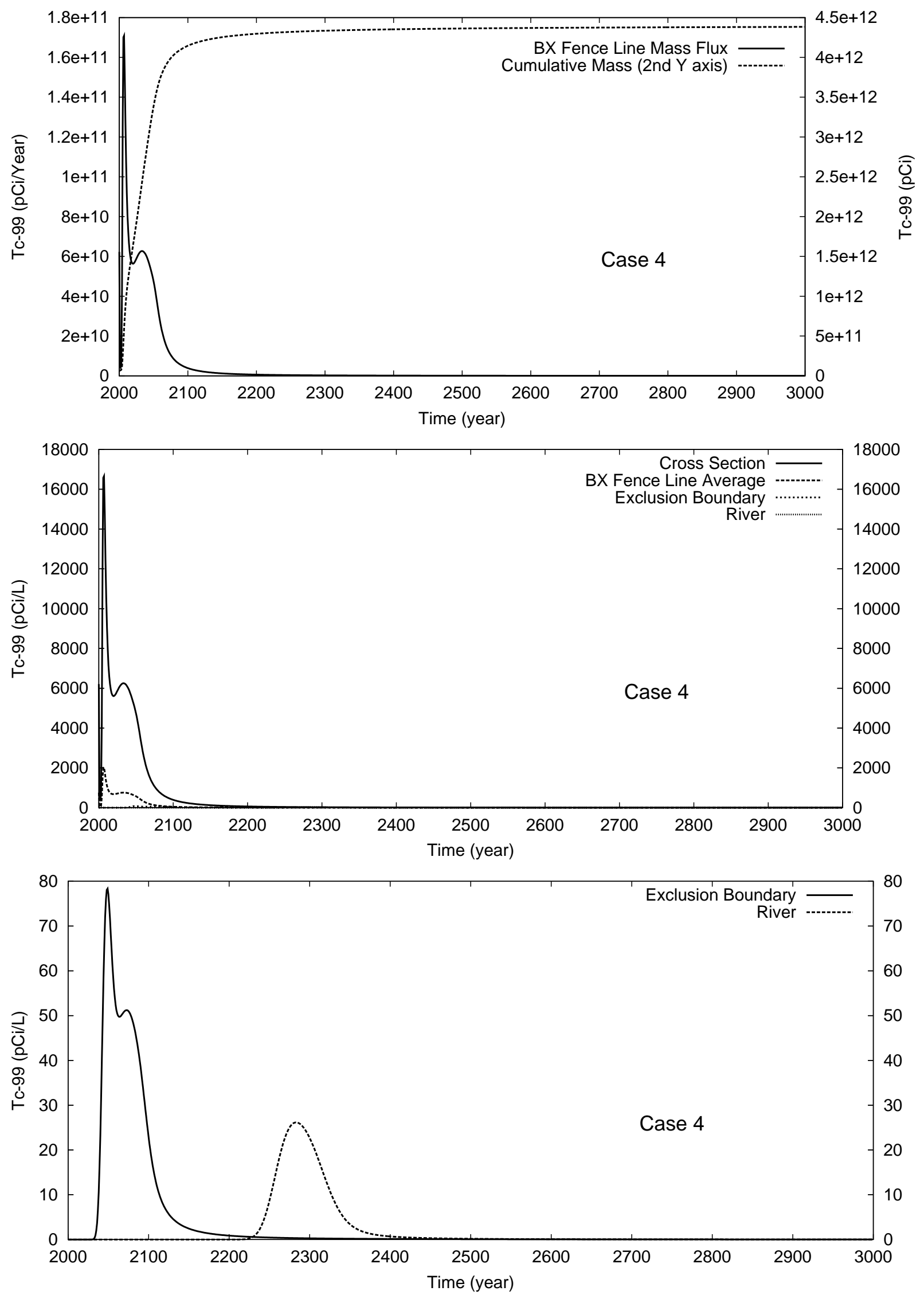

Figure C.14. Case 4 Results for Tc-99: Mass Flux and Breakthrough Curves

C-15 

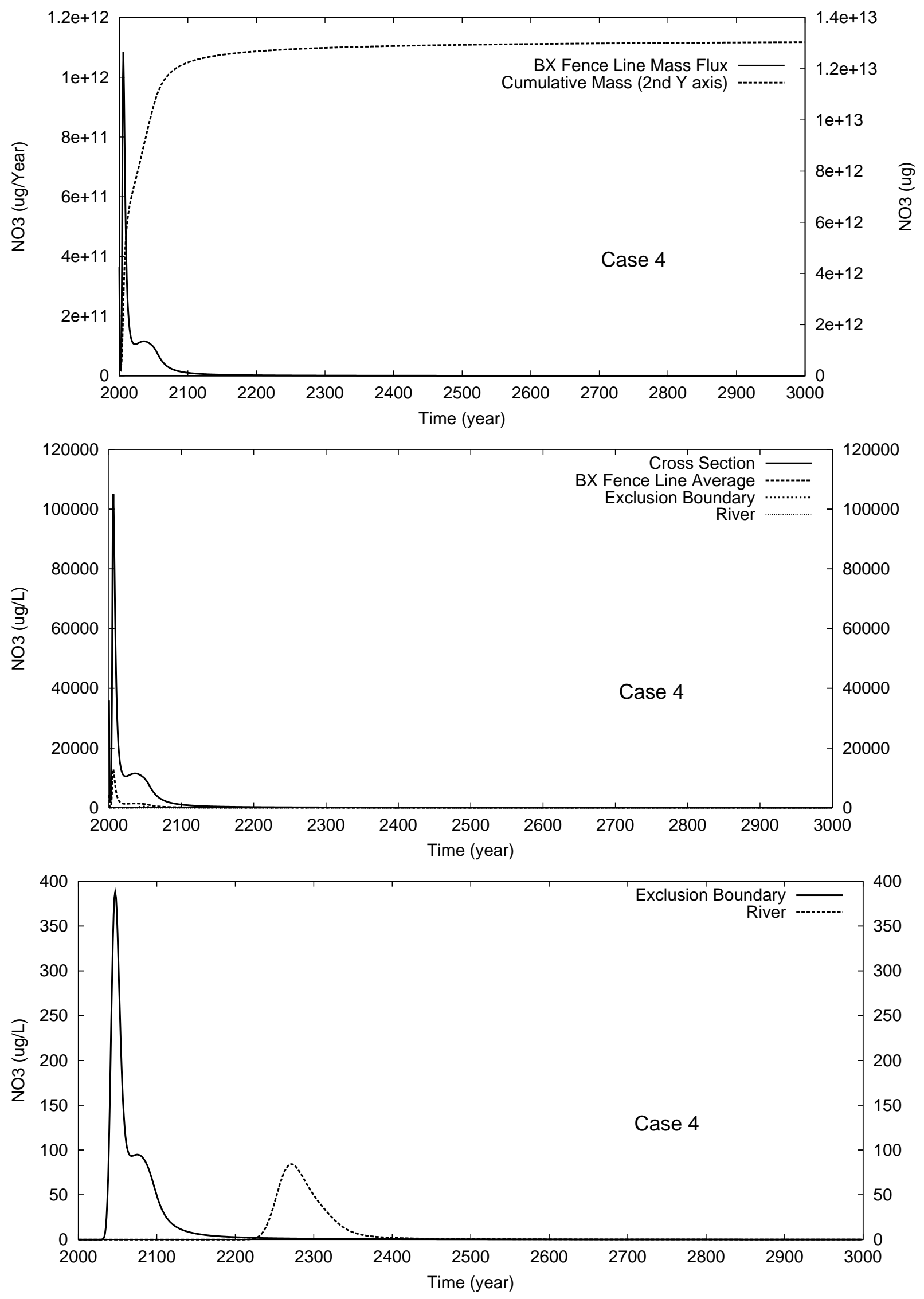

Figure C.15. Case 4 Results for NO3: Mass Flux and Breakthrough Curves

$$
\text { C-16 }
$$



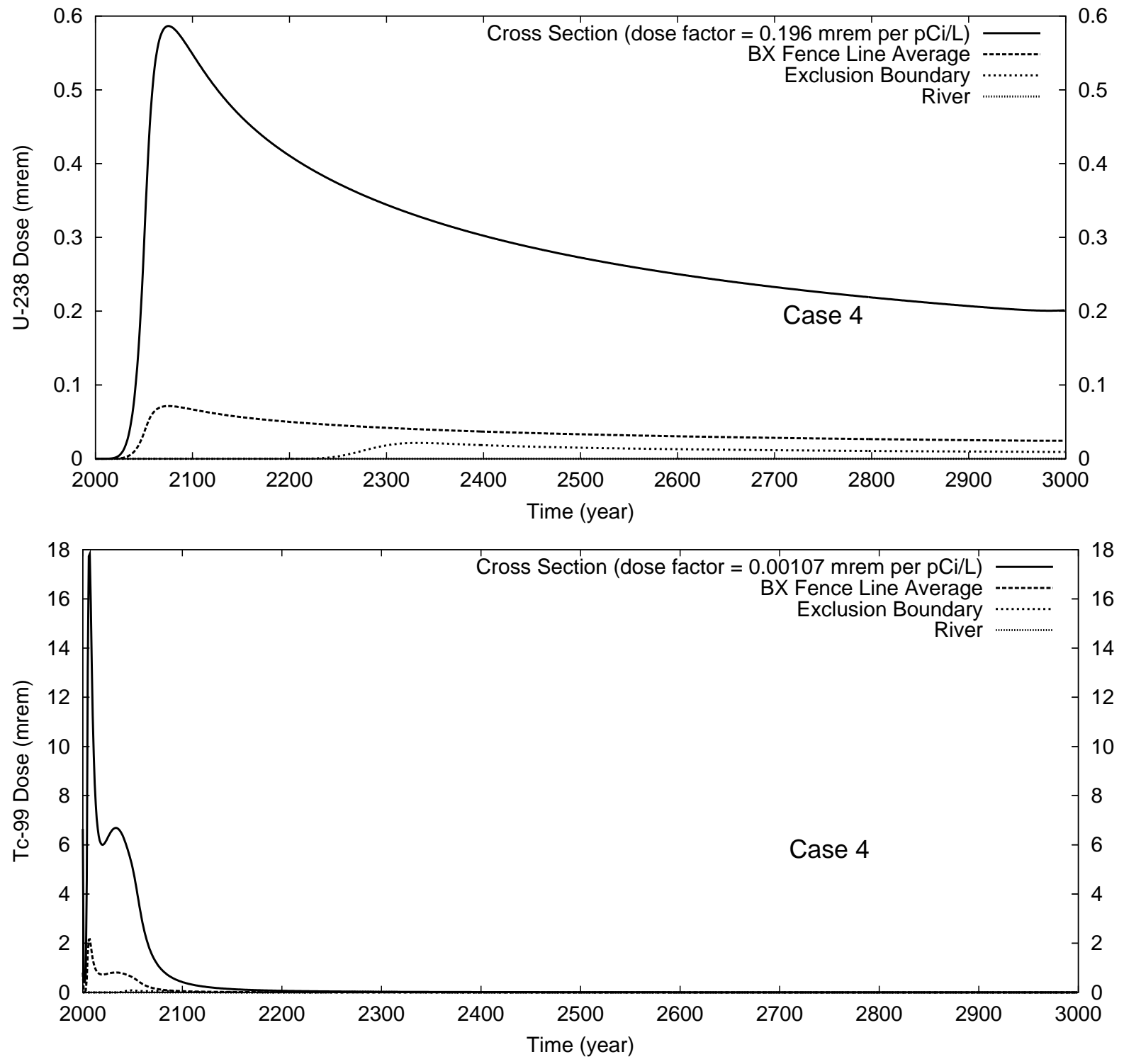

Figure C.16. Case 4 Results for U-238 and Tc-99 Dose at Compliance Points 

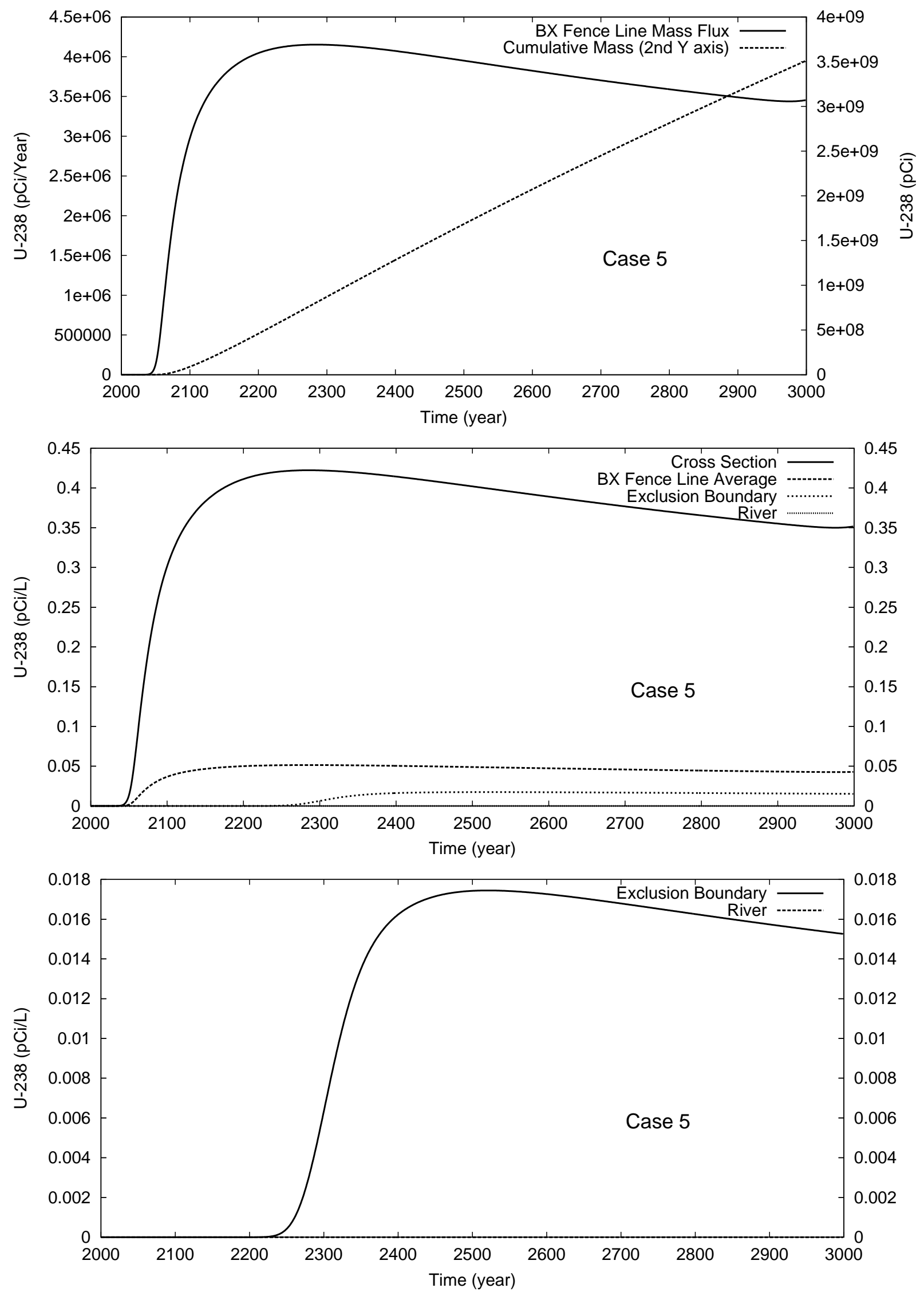

Figure C.17. Case 5 Results for U-238: Mass Flux and Breakthrough Curves C-18 

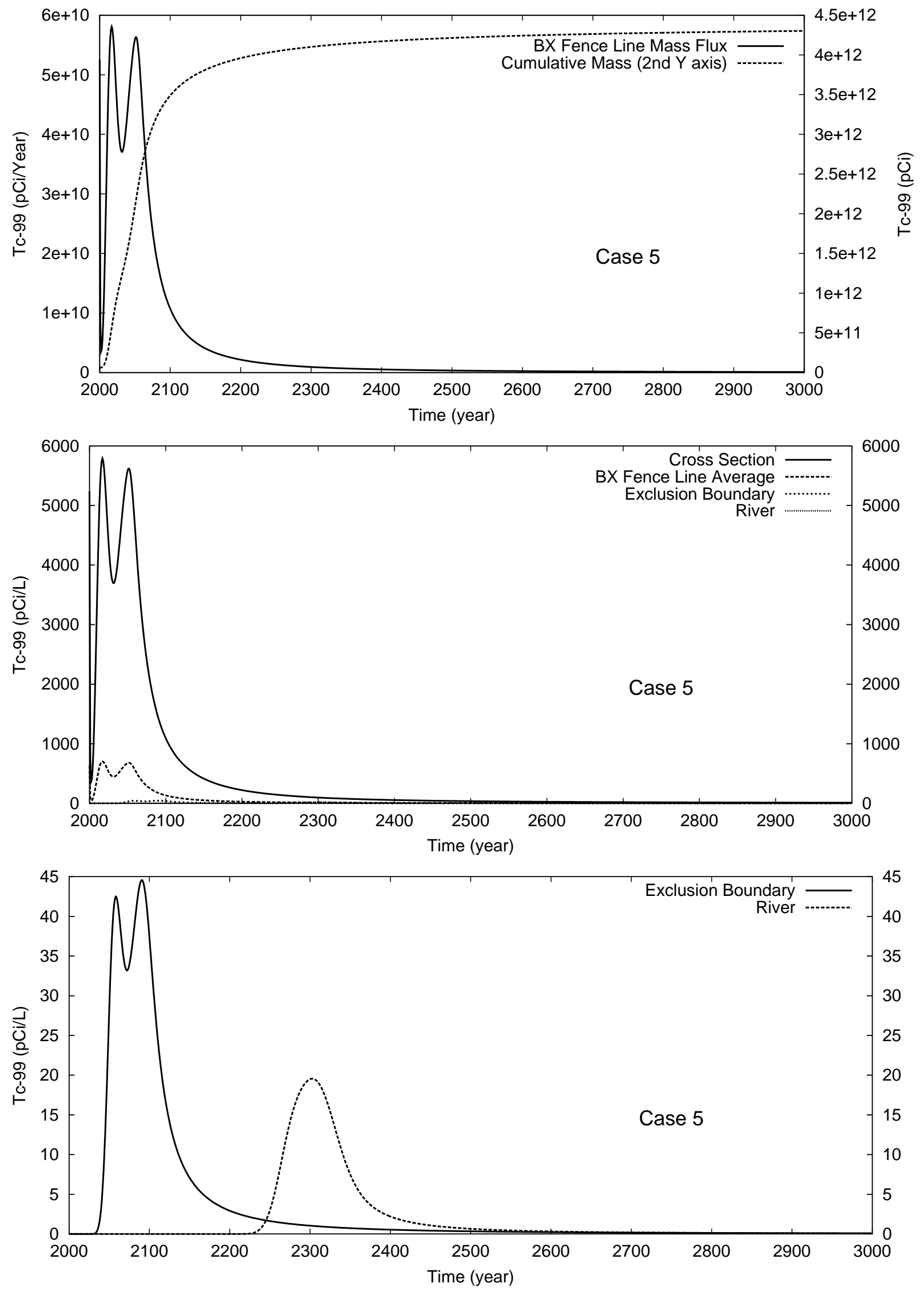

Figure C.18. Case 5 Results for Tc-99: Mass Flux and Breakthrough Curves C-19 

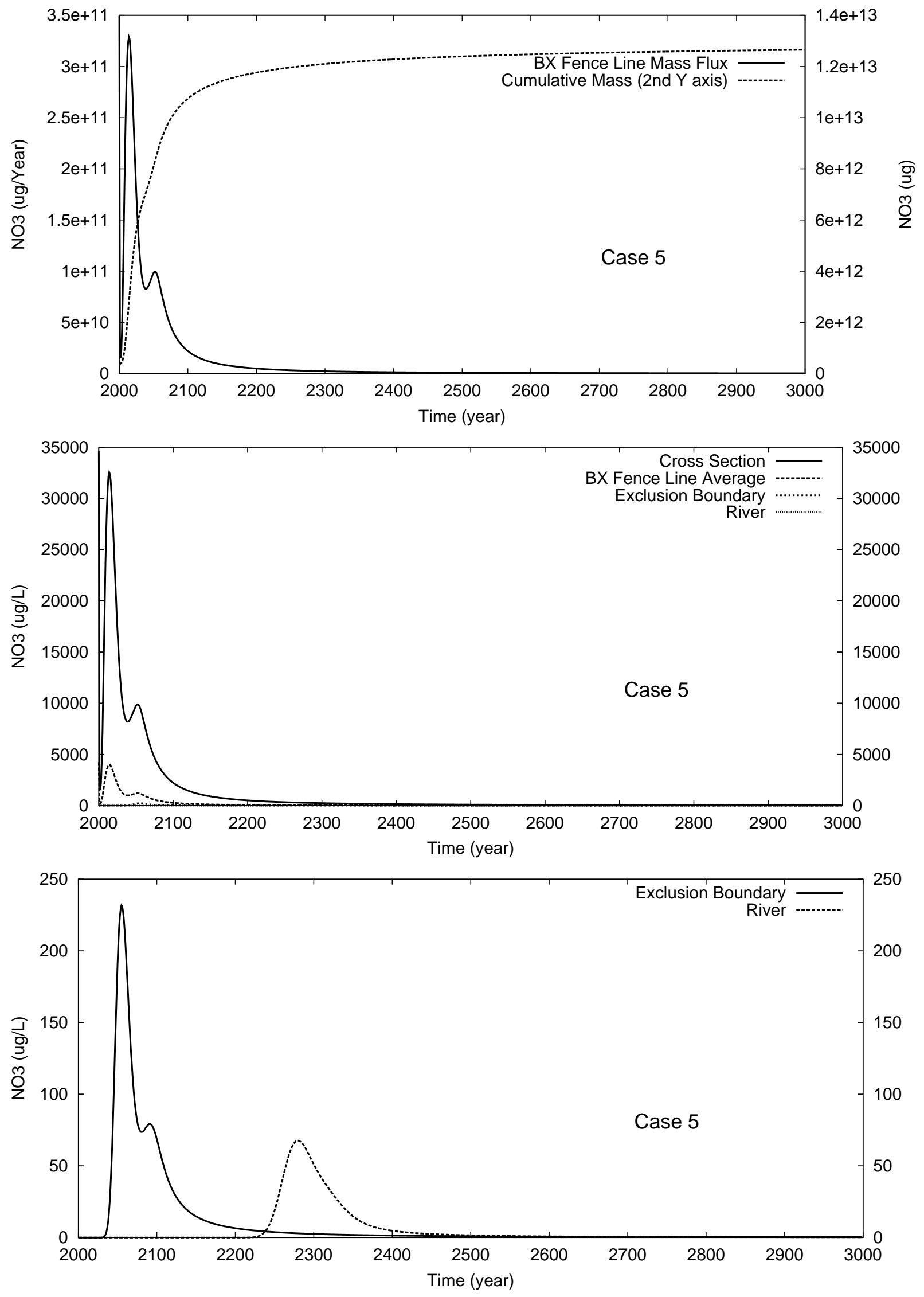

Figure C.19. Case 5 Results for NO3: Mass Flux and Breakthrough Curves C-20 

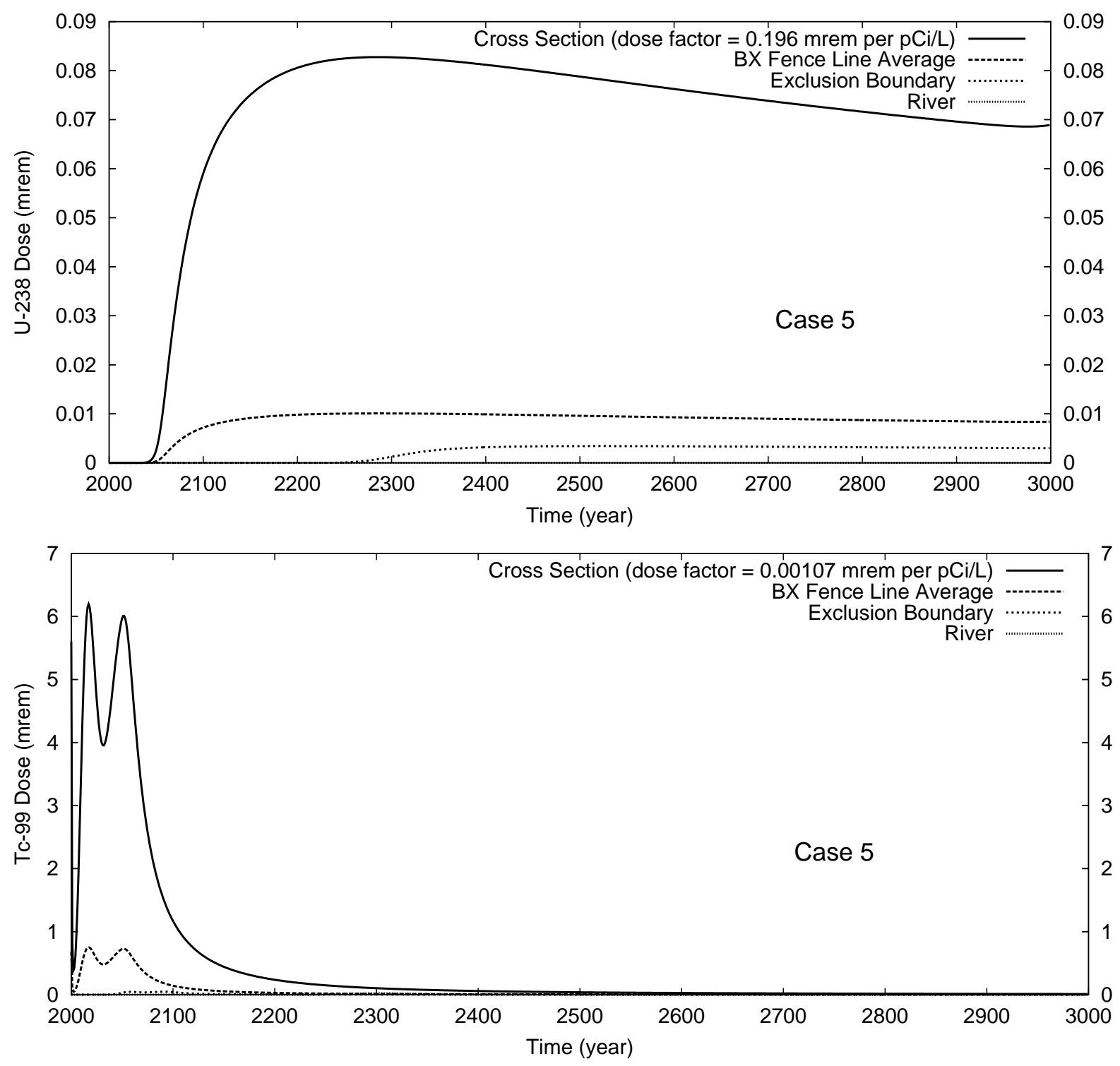

Figure C.20. Case 5 Results for U-238 and Tc-99 Dose at Compliance Points 

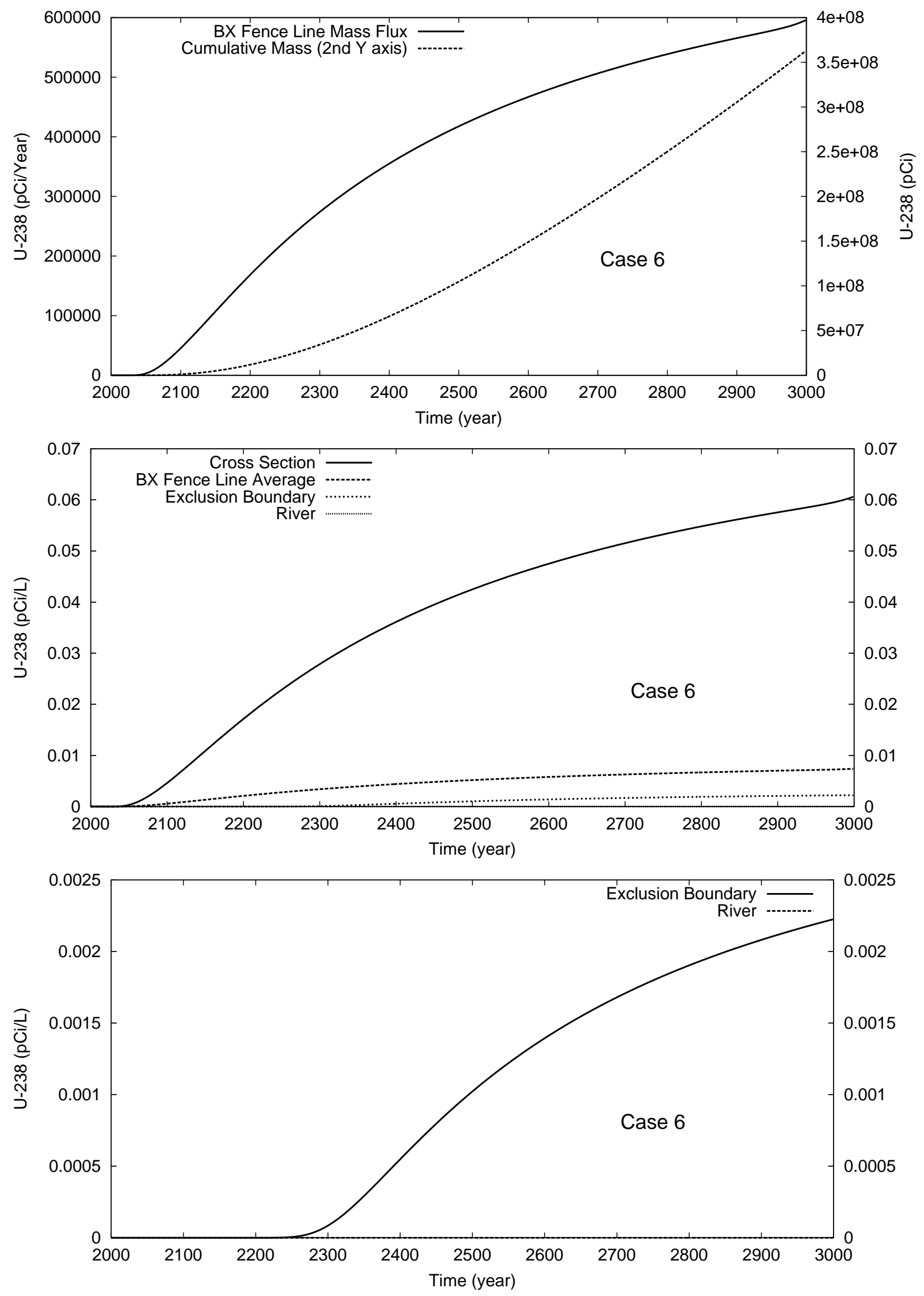

Figure C.21. Case 6 Results for U-238: Mass Flux and Breakthrough Curves $\mathrm{C}-22$ 

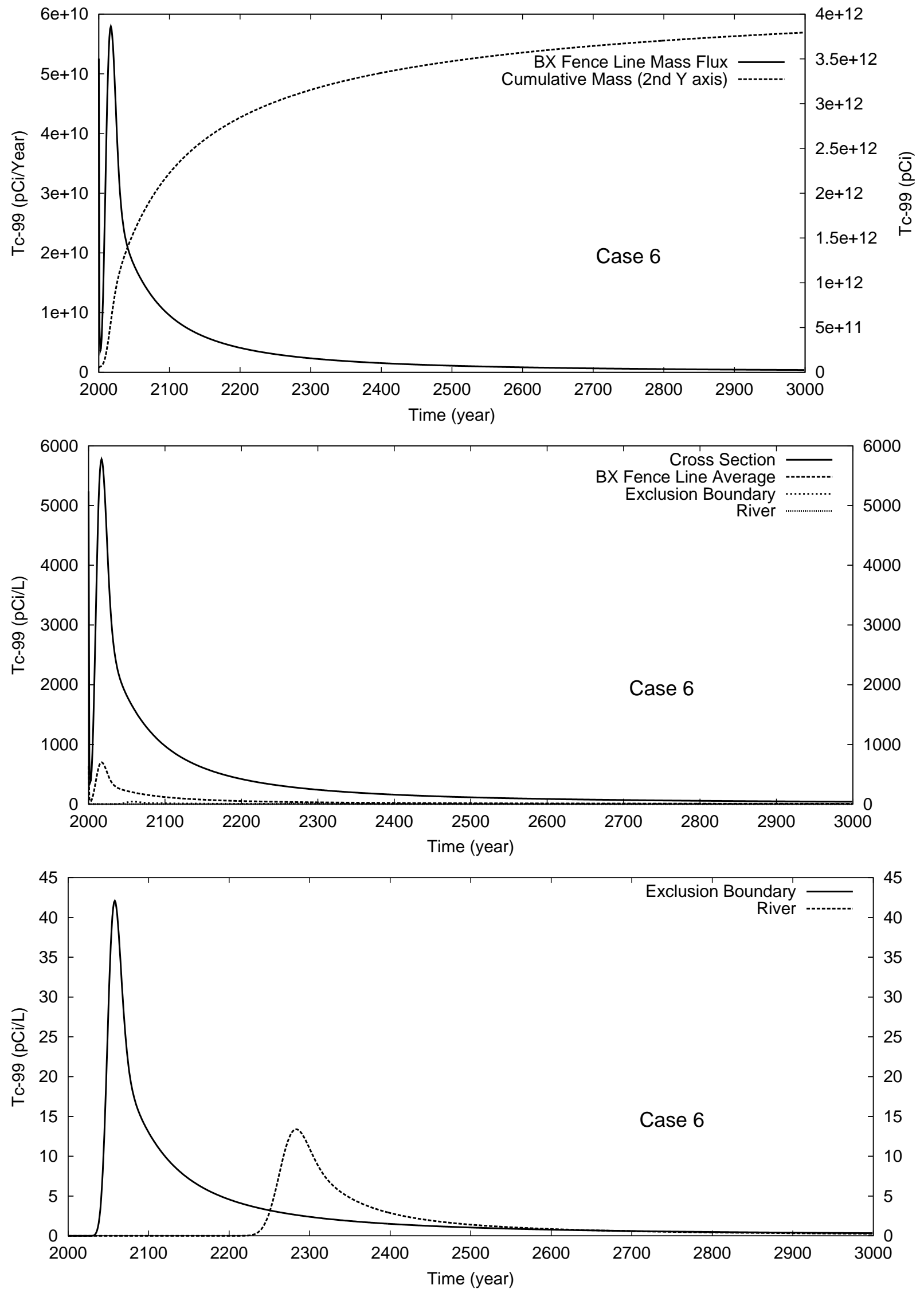

Figure C.22. Case 6 Results for Tc-99: Mass Flux and Breakthrough Curves

$$
\text { C-23 }
$$



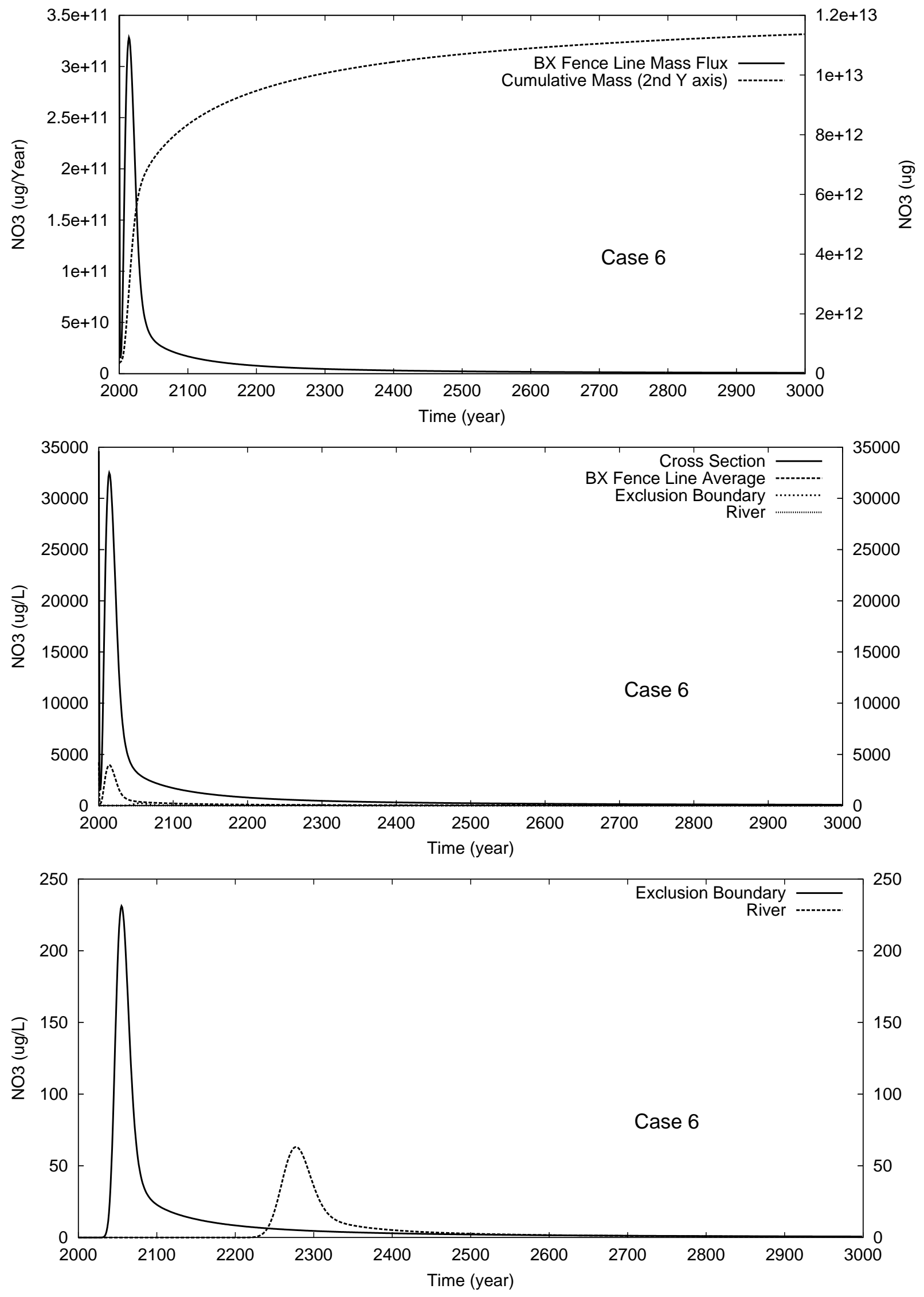

Figure C.23. Case 6 Results for NO3: Mass Flux and Breakthrough Curves C-24 

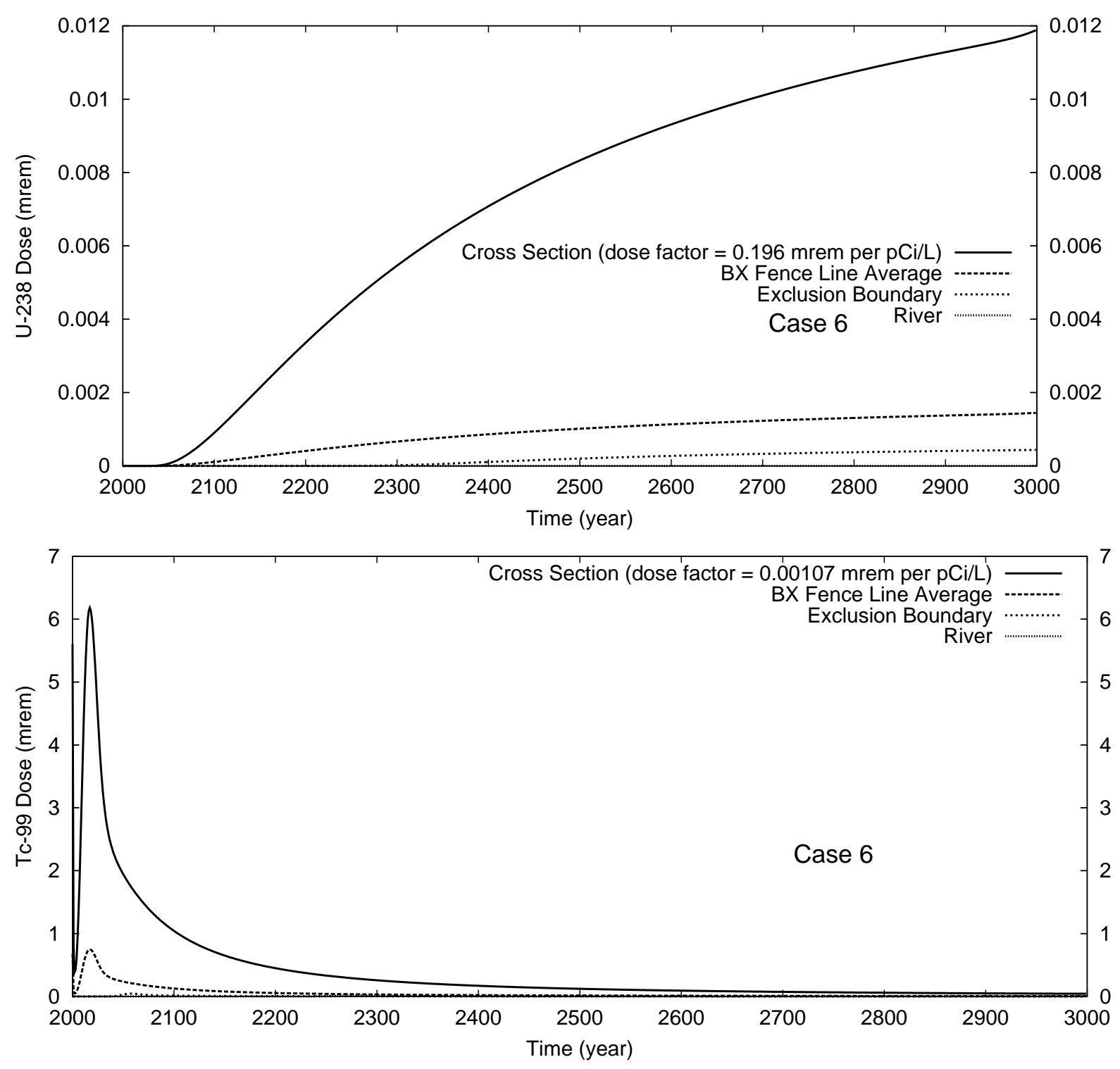

Figure C.24. Case 6 Results for U-238 and Tc-99 Dose at Compliance Points 

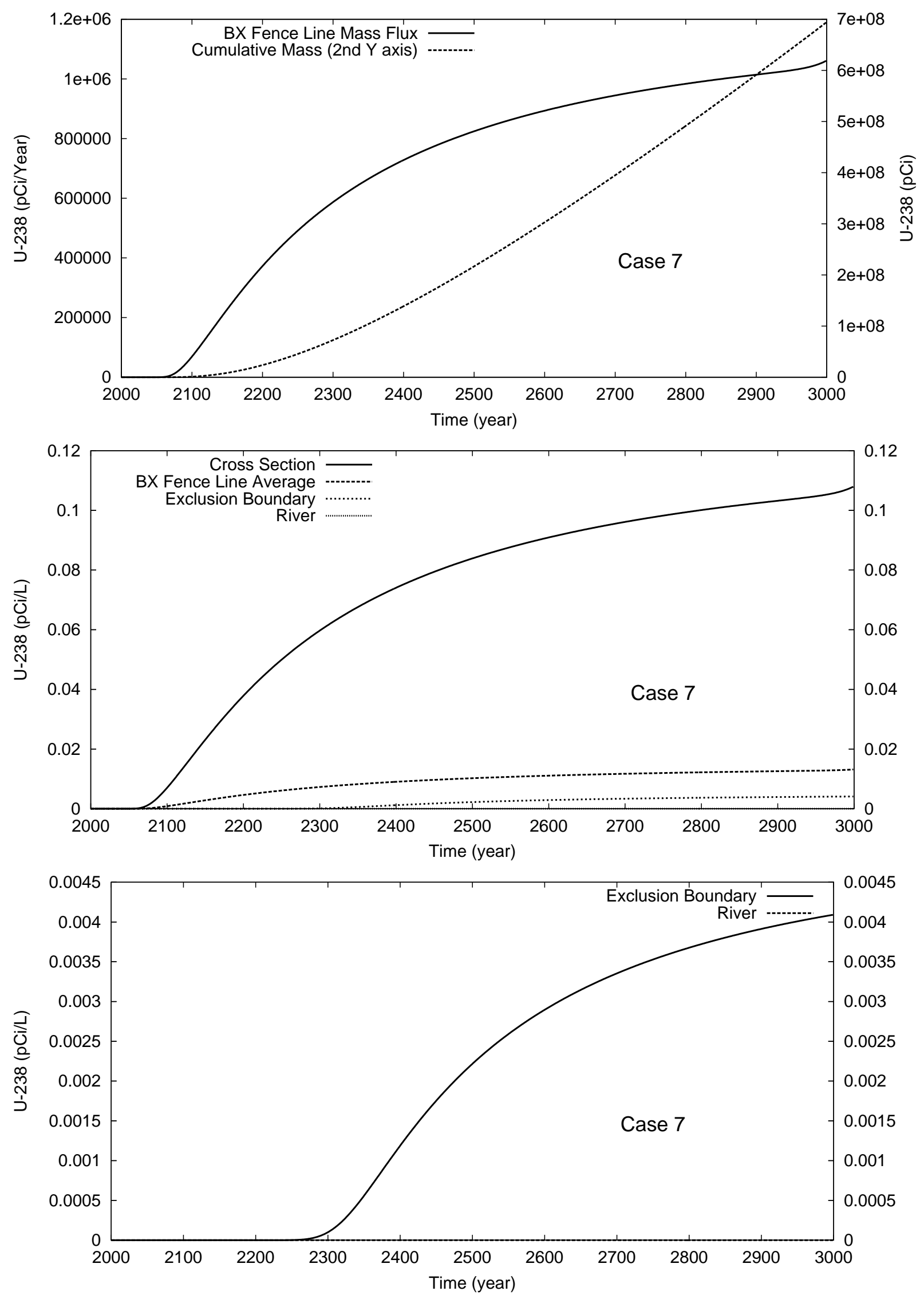

Figure C.25. Case 7 Results for U-238: Mass Flux and Breakthrough Curves C-26 

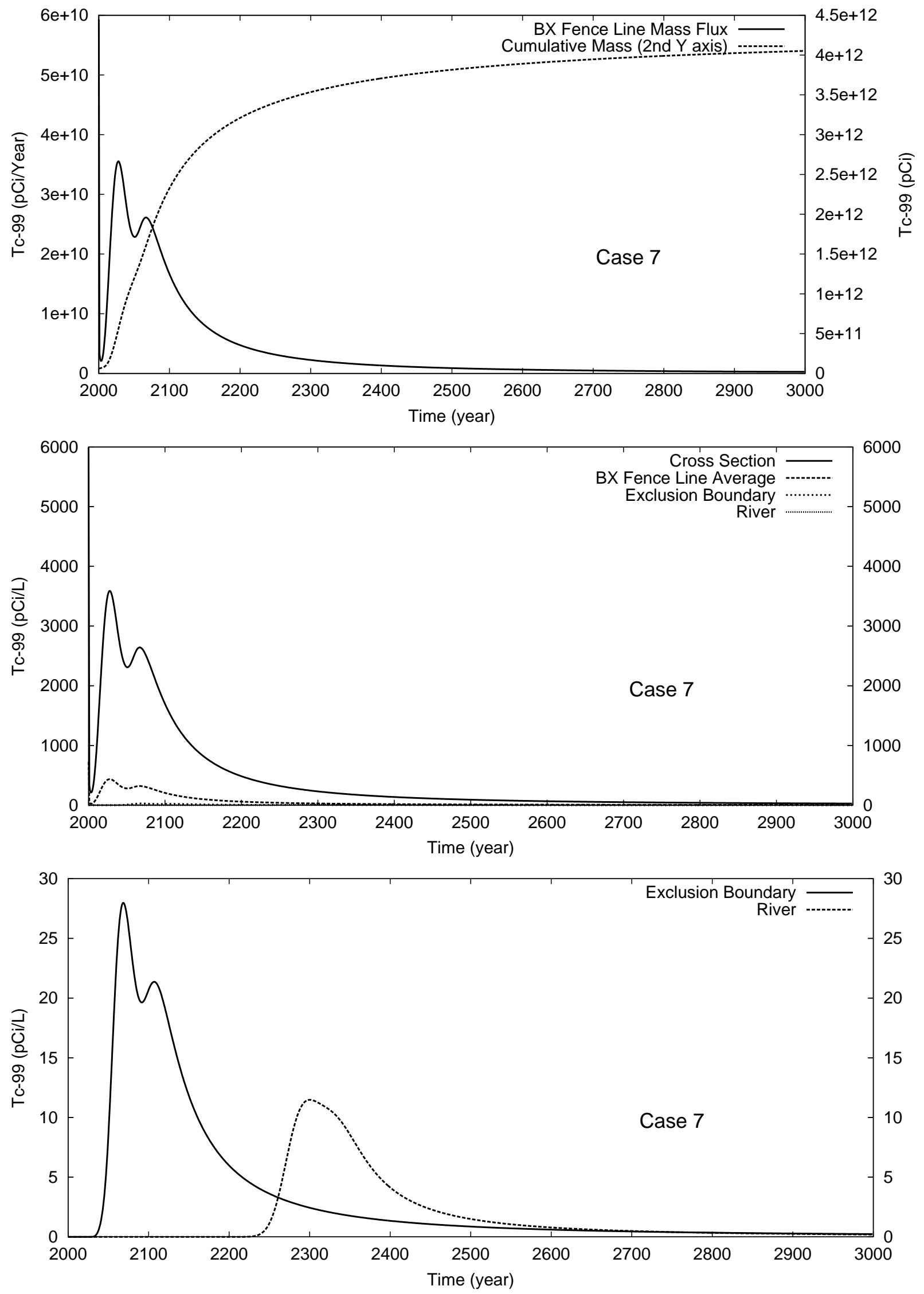

Figure C.26. Case 7 Results for Tc-99: Mass Flux and Breakthrough Curves

C-27 

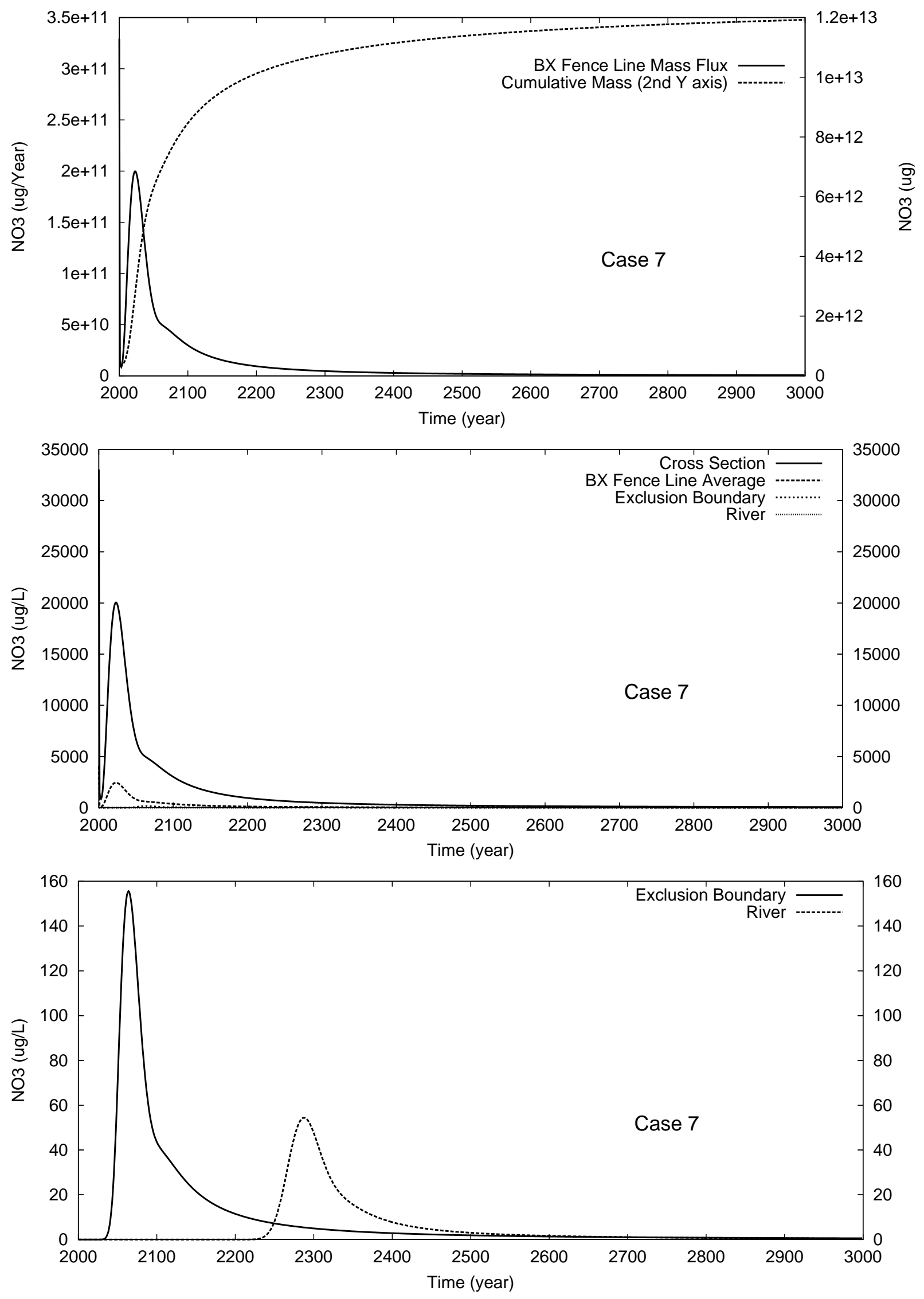

Figure C.27. Case 7 Results for NO3: Mass Flux and Breakthrough Curves C-28 

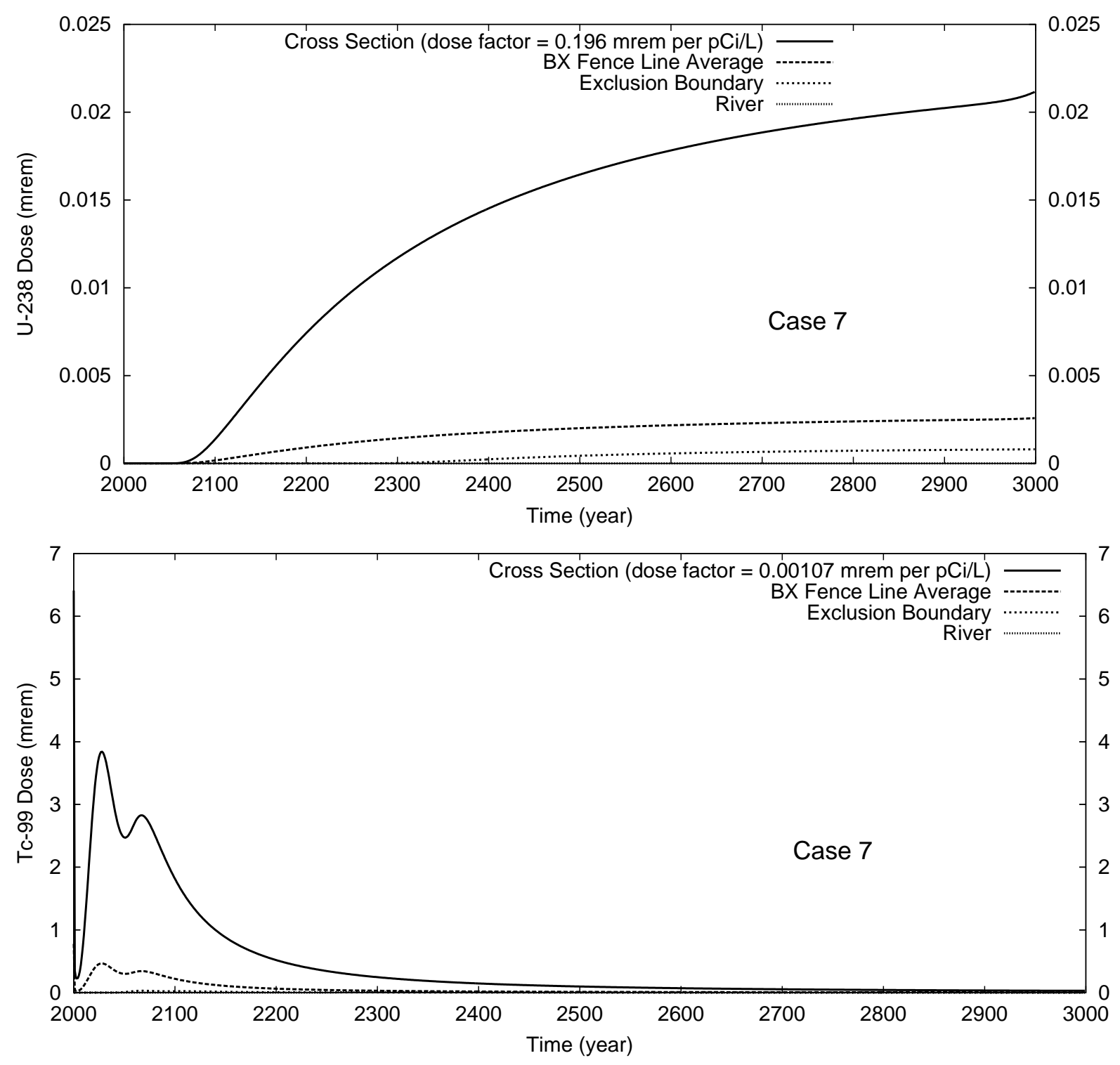

Figure C.28. Case 7 Results for U-238 and Tc-99 Dose at Compliance Points 

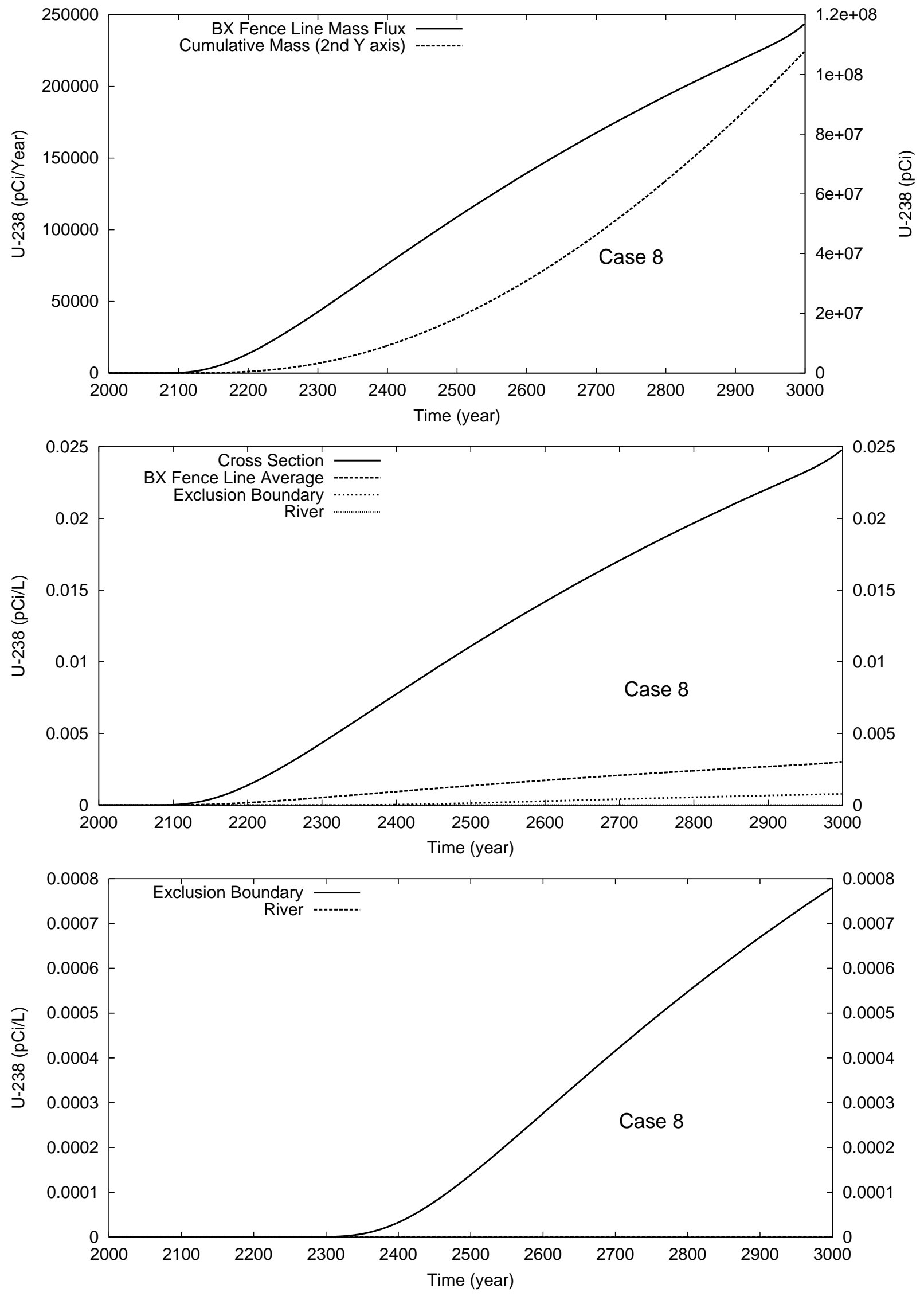

Figure C.29. Case 8 Results for U-238: Mass Flux and Breakthrough Curves C-30 

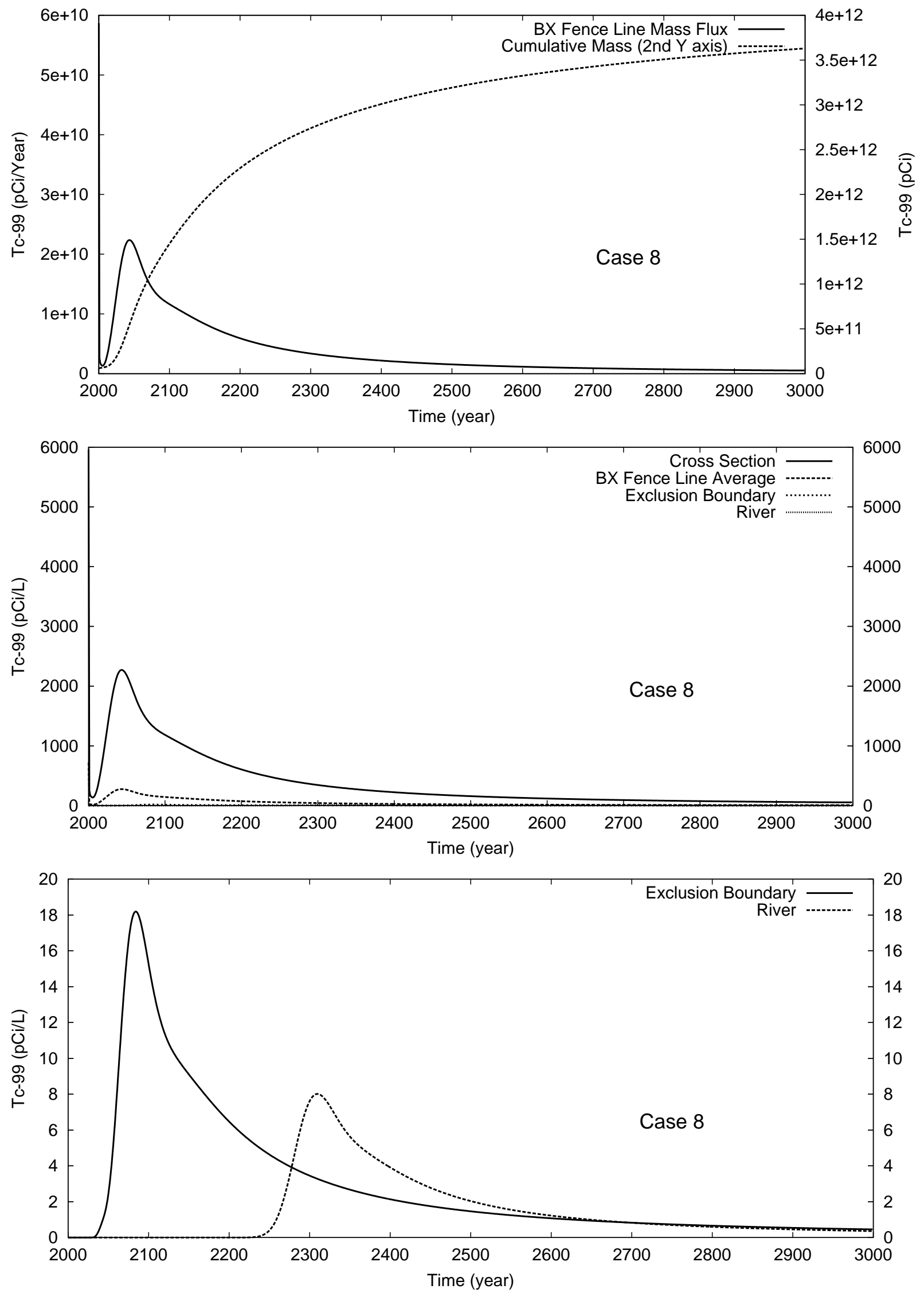

Figure C.30. Case 8 Results for Tc-99: Mass Flux and Breakthrough Curves C-31 

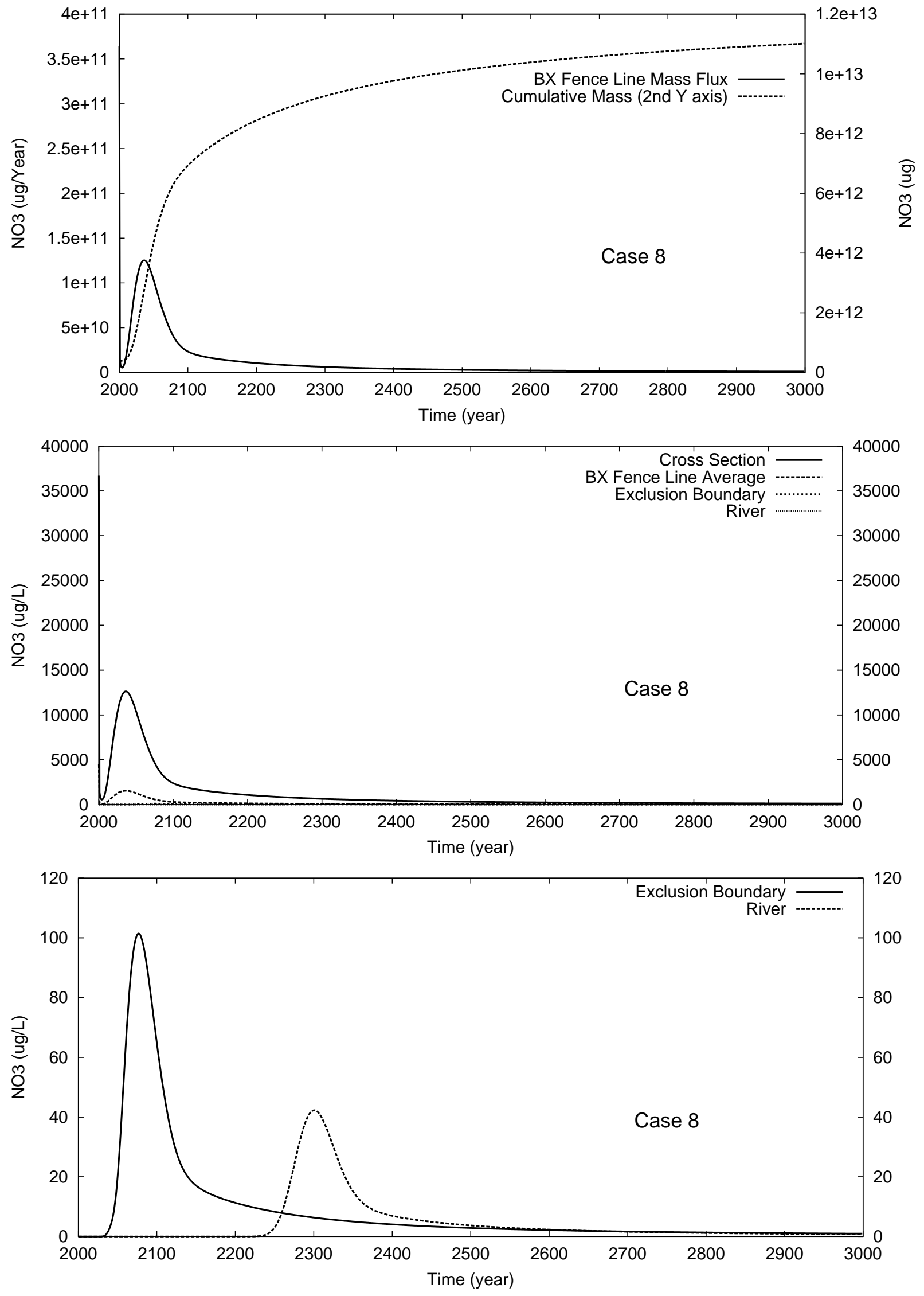

Figure C.31. Case 8 Results for NO3: Mass Flux and Breakthrough Curves

$$
\text { C-32 }
$$



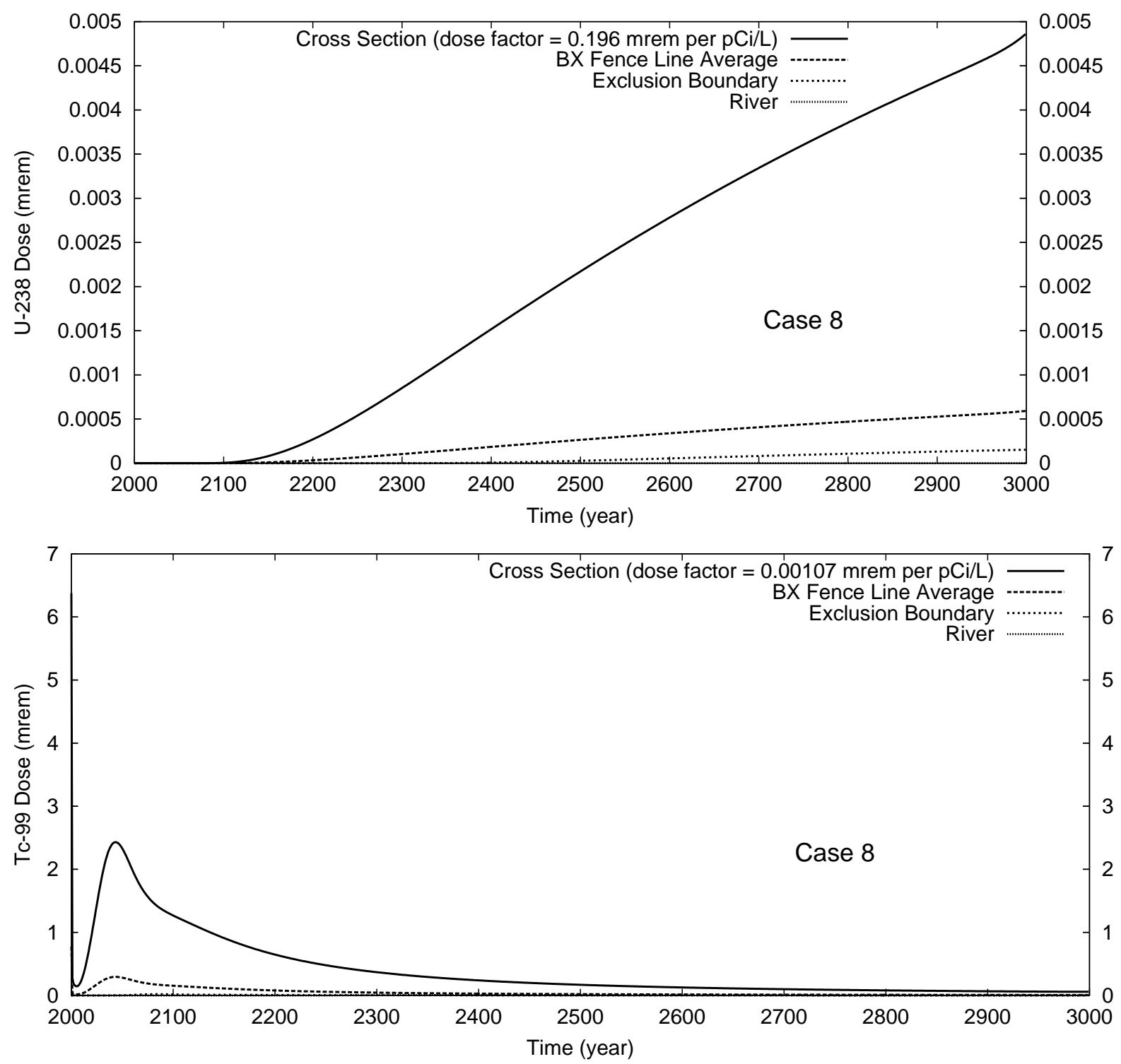

Figure C.32. Case 8 Results for U-238 and Tc-99 Dose at Compliance Points 

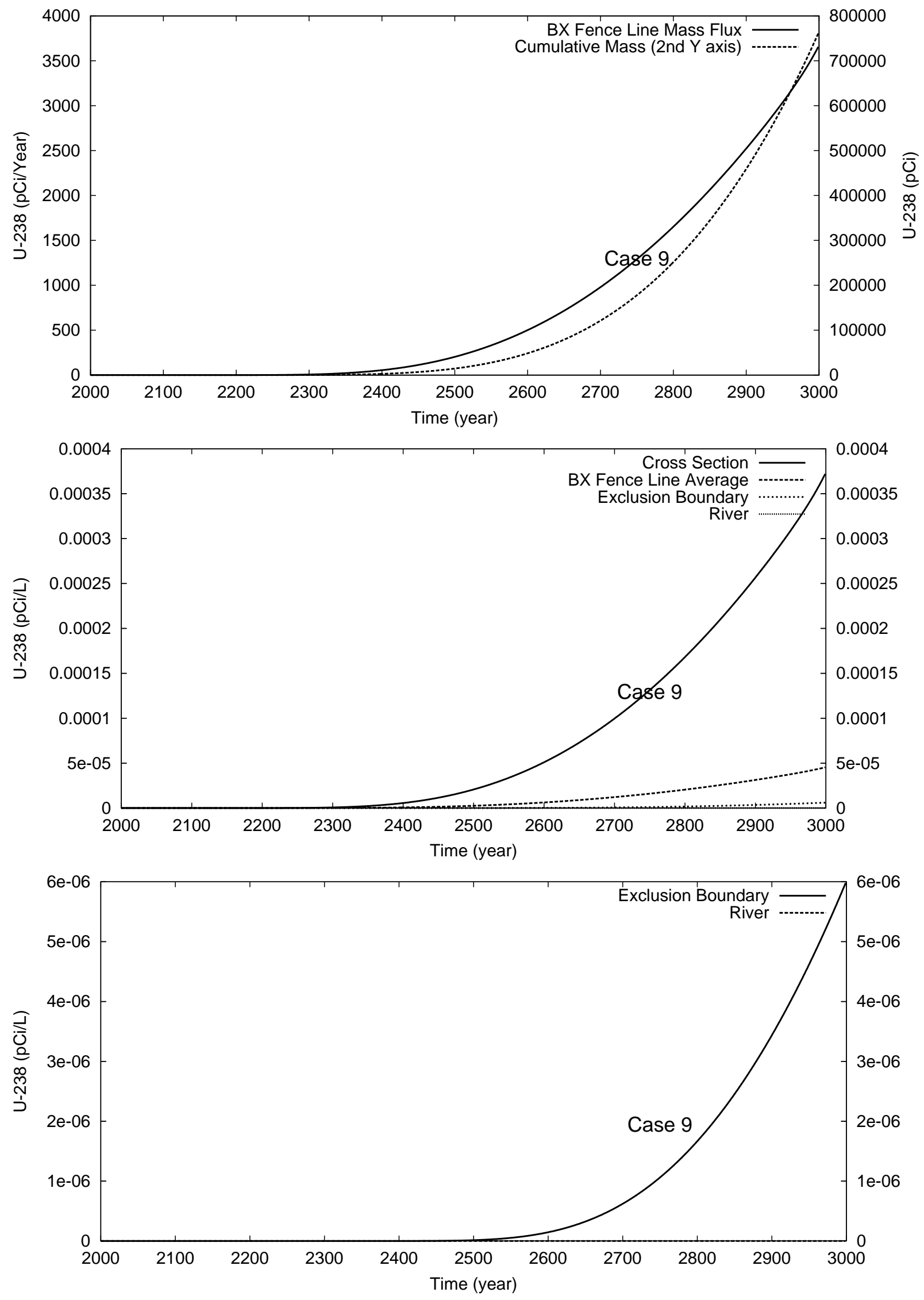

Figure C.33. Case 9 Results for U-238: Mass Flux and Breakthrough Curves C-34 

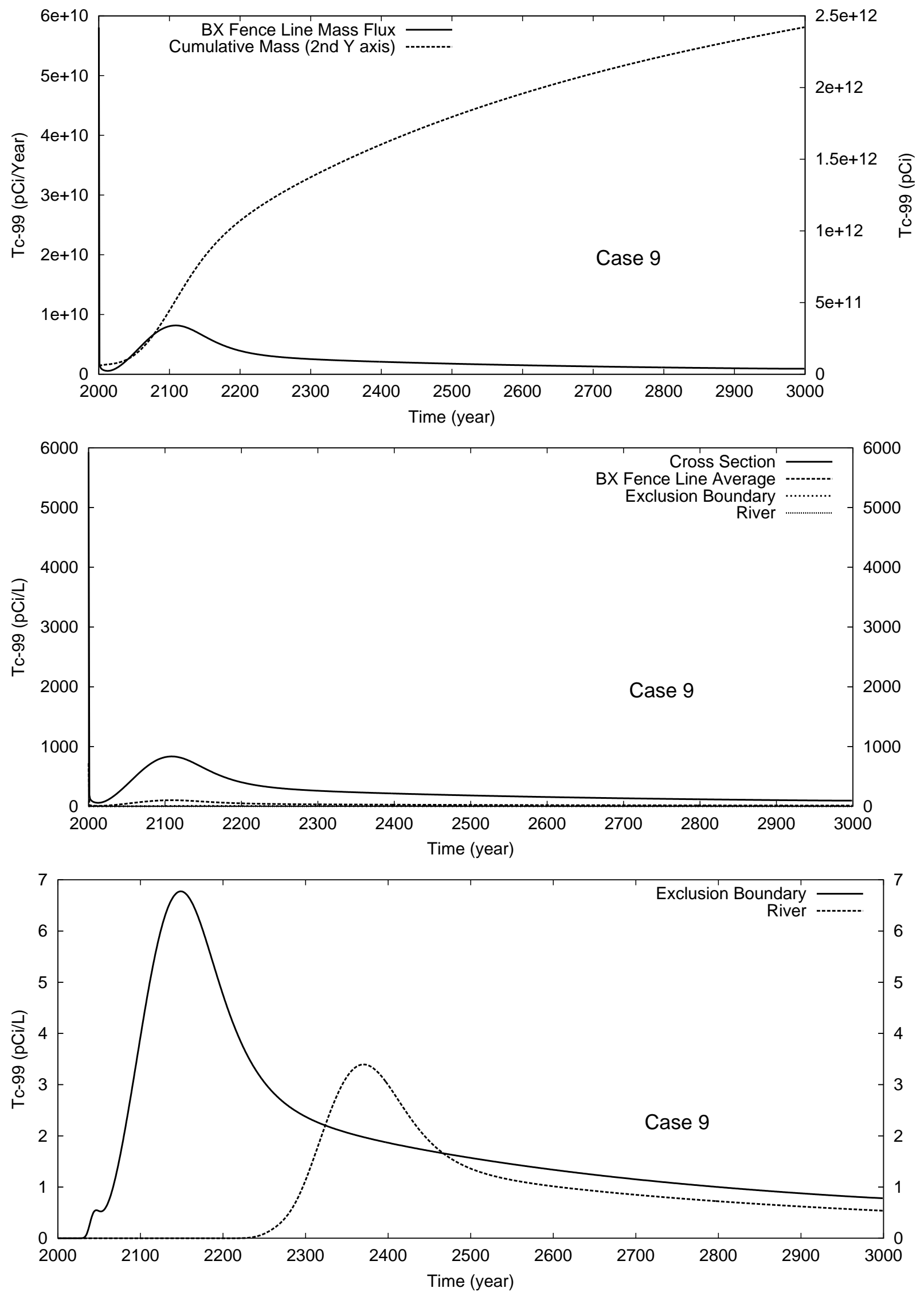

Figure C.34. Case 9 Results for Tc-99: Mass Flux and Breakthrough Curves C-35 

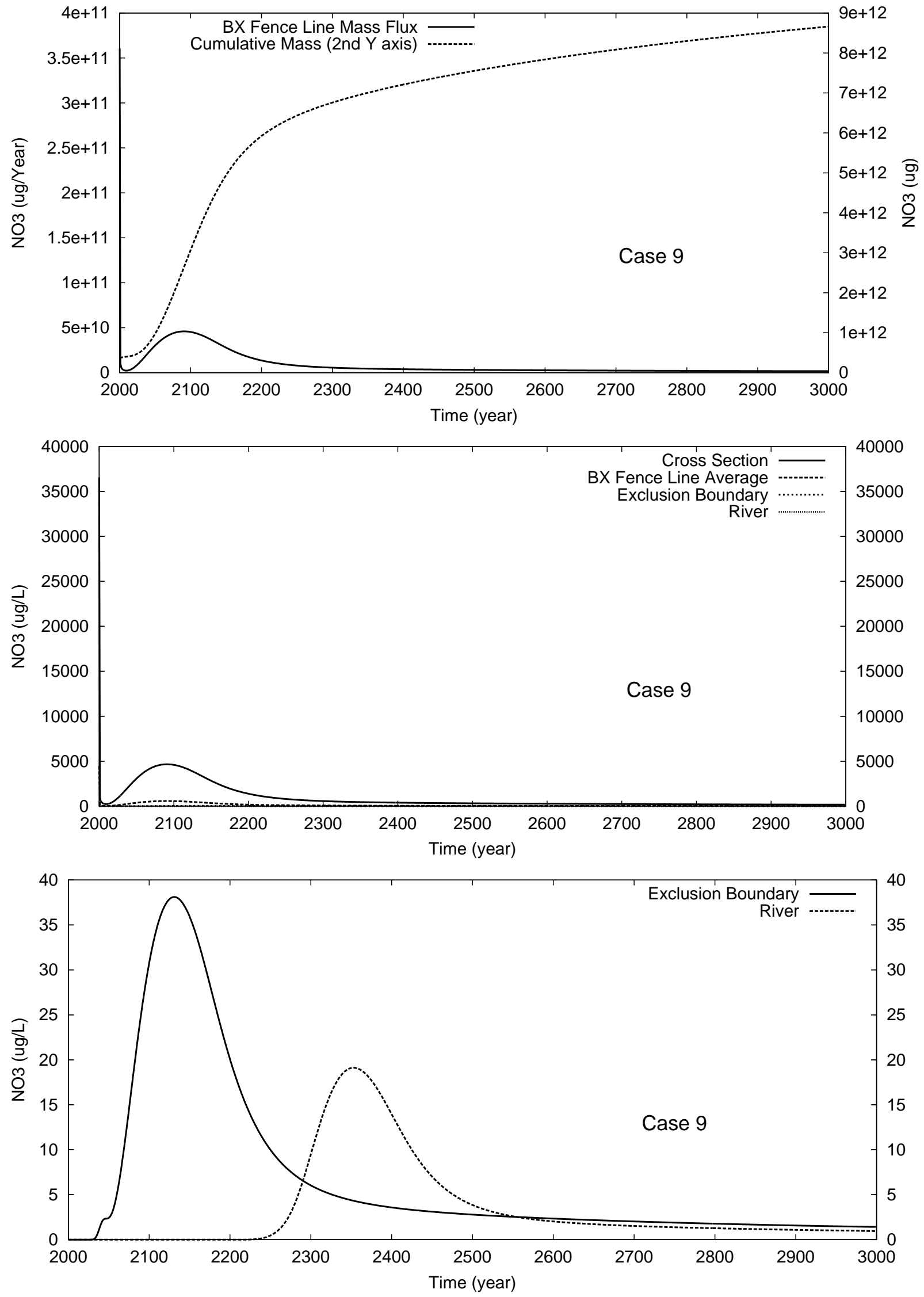

Figure C.35. Case 9 Results for NO3: Mass Flux and Breakthrough Curves

$$
\text { C-36 }
$$



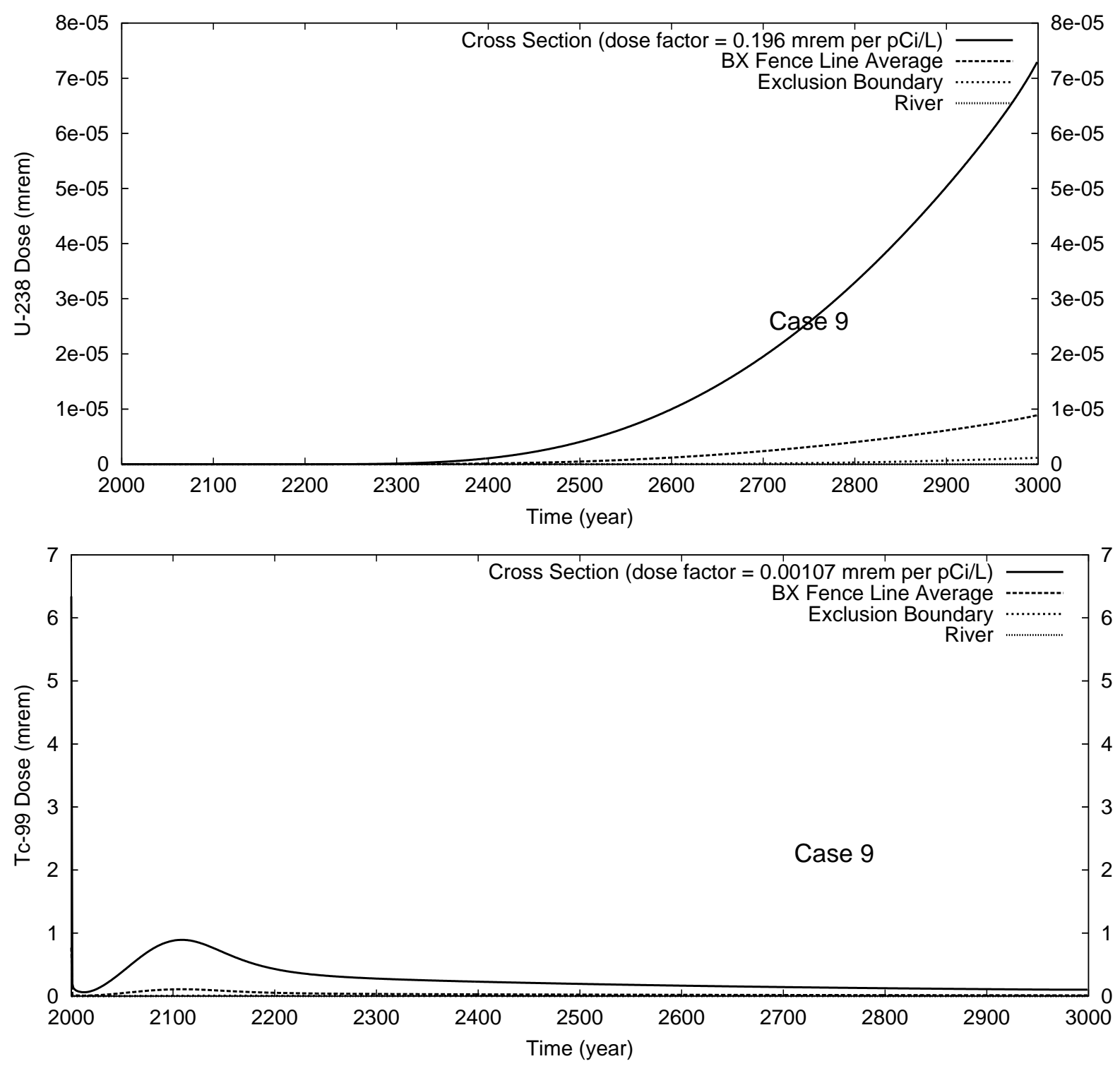

Figure C.36. Case 9 Results for U-238 and Tc-99 Dose at Compliance Points 

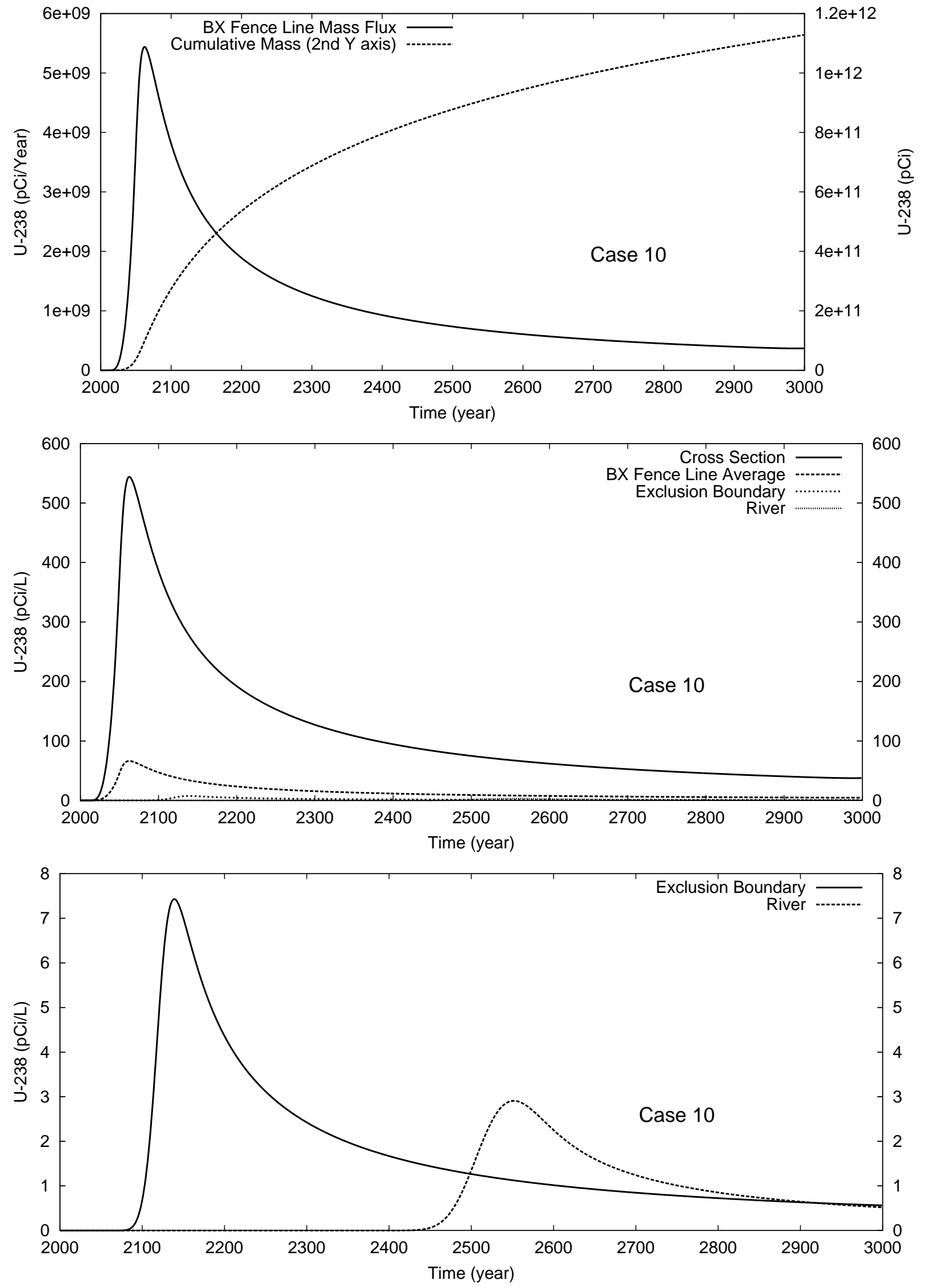

Figure C.37. Case 10 Results for U-238: Mass Flux and Breakthrough Curves C-38 


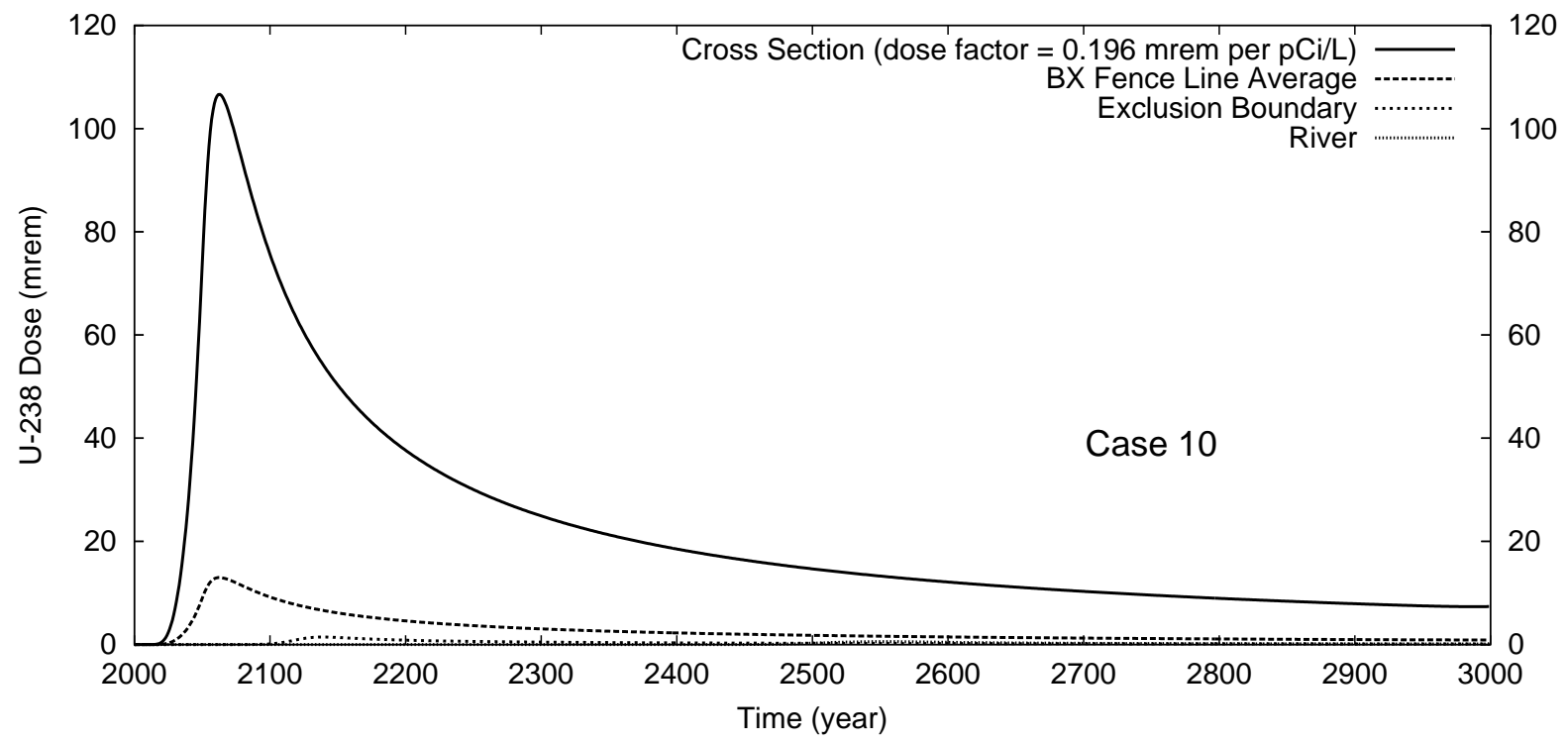

Figure C.38. Case 10 Results for U-238 Dose at Compliance Points 

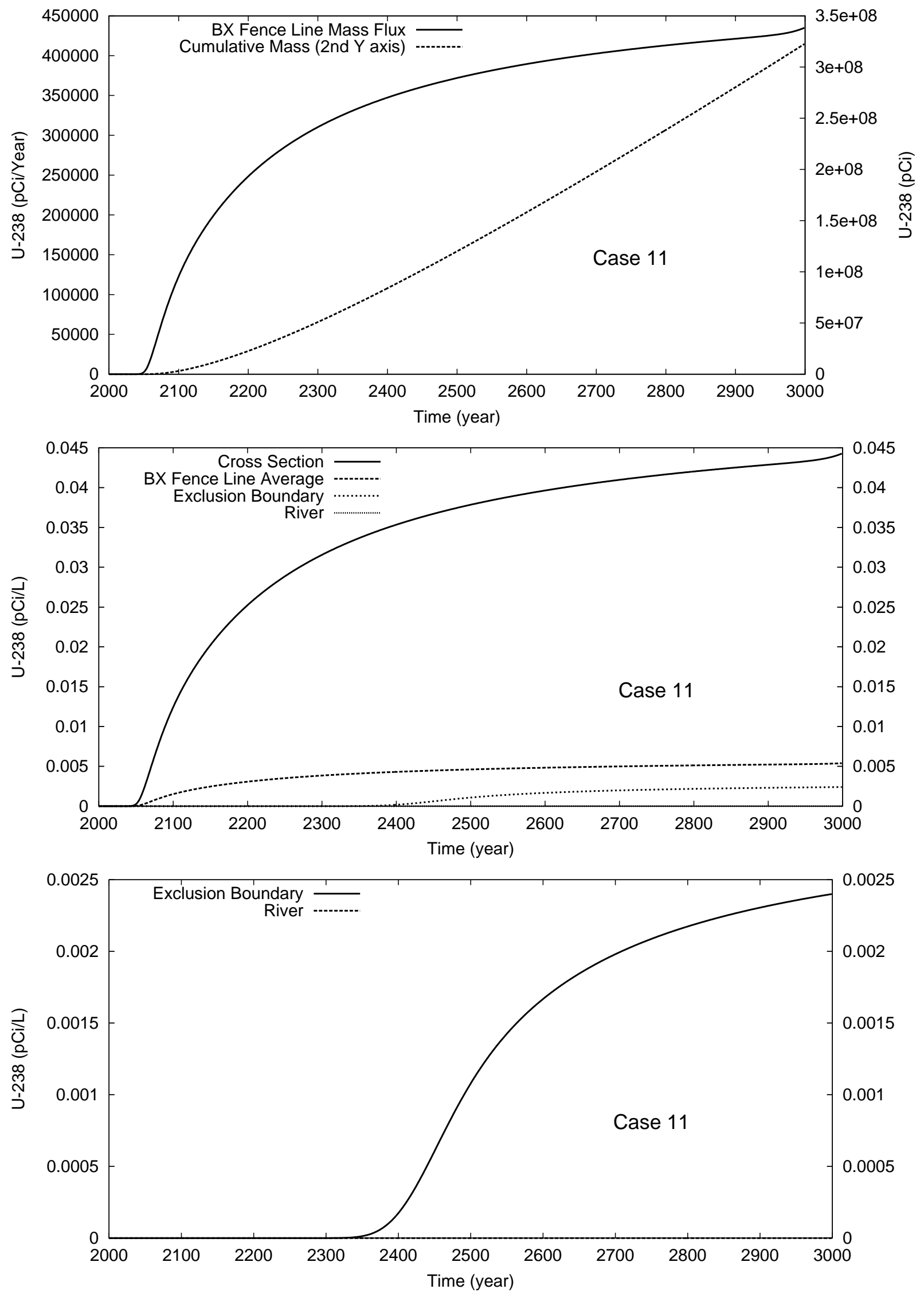

Figure C.39. Case 11 Results for U-238: Mass flux and Breakthrough Curves

$$
\text { C-40 }
$$




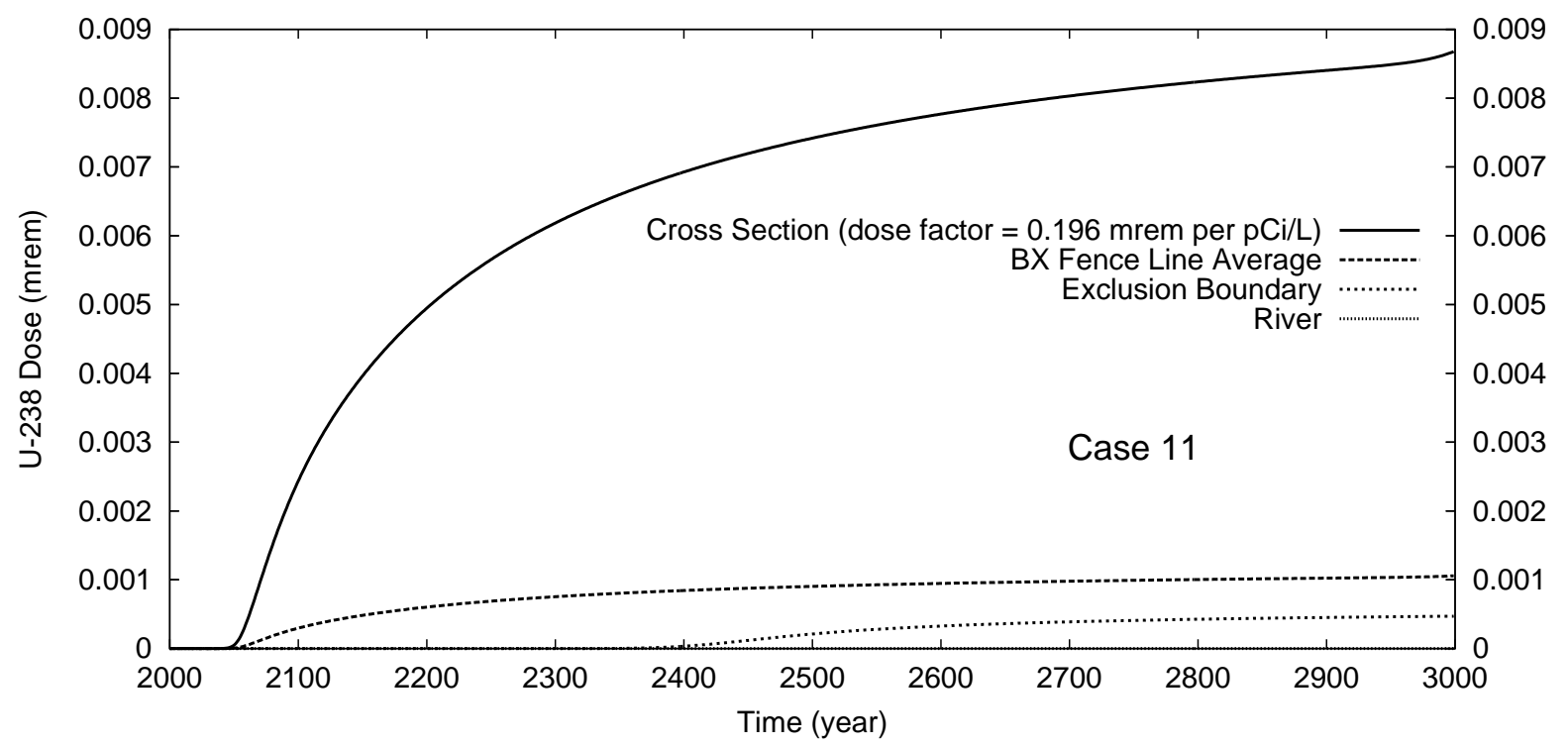

Figure C.40. Case 11 Results for U-238 Dose at Compliance Points 
Appendix D: B Trench Breathrough Curves

D-1 

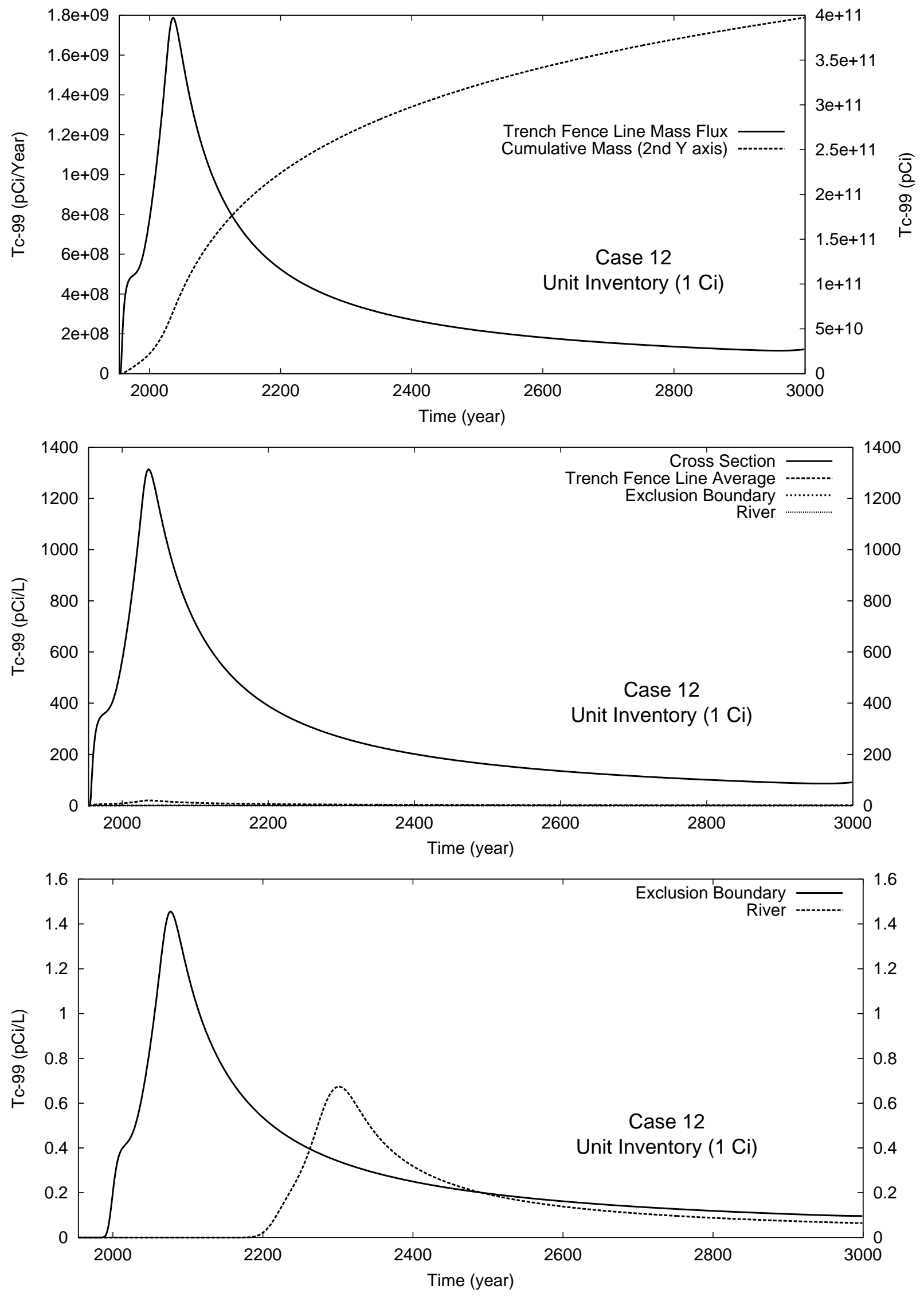

Figure D.1. Case 12 Results for Tc-99 Unit Inventory: Mass Flux and Breakthrough Curves D-2 

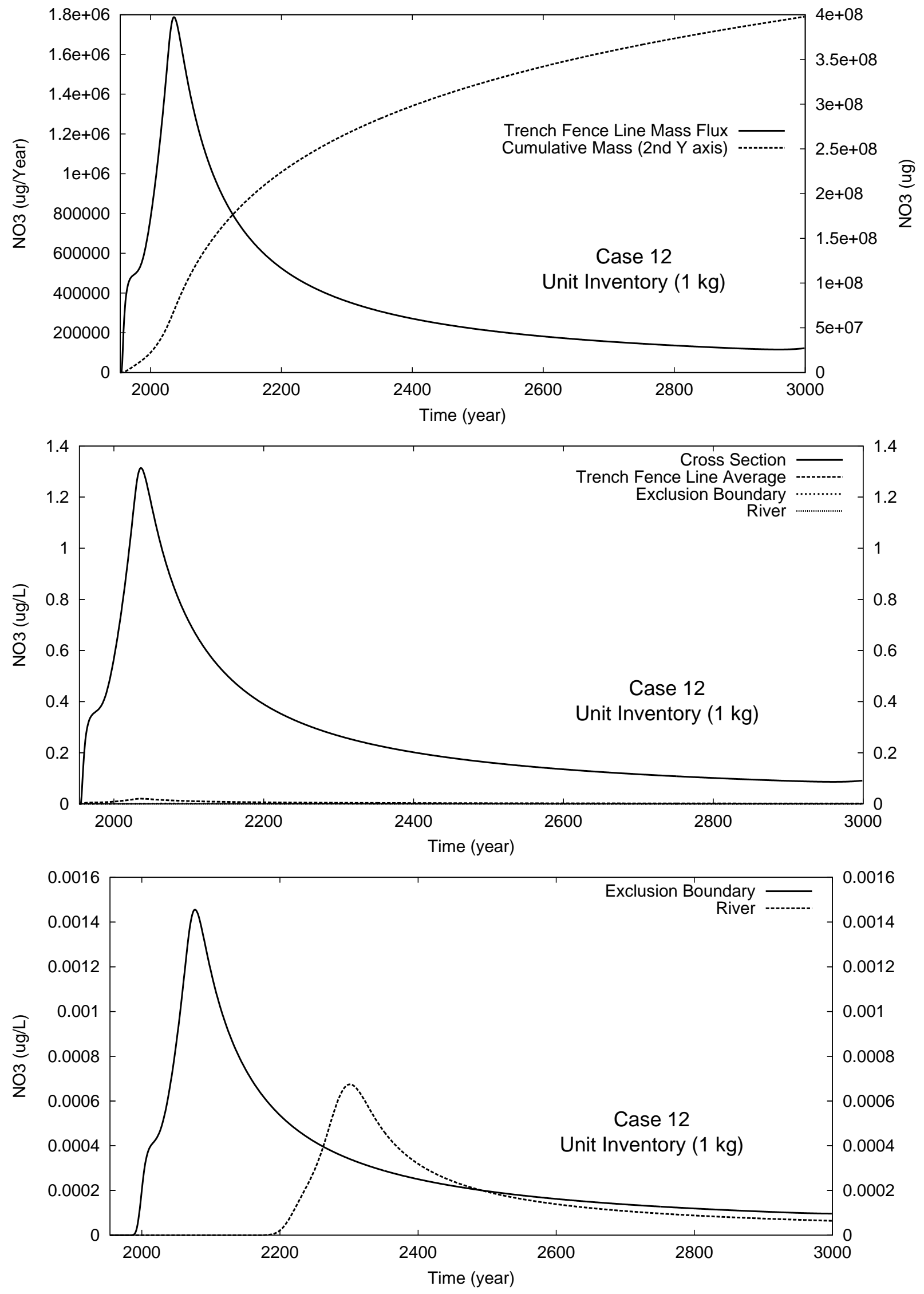

Figure D.2. Case 12 Results for NO3 Unit Inventory: Mass Flux and Breakthrough Curves D-3 


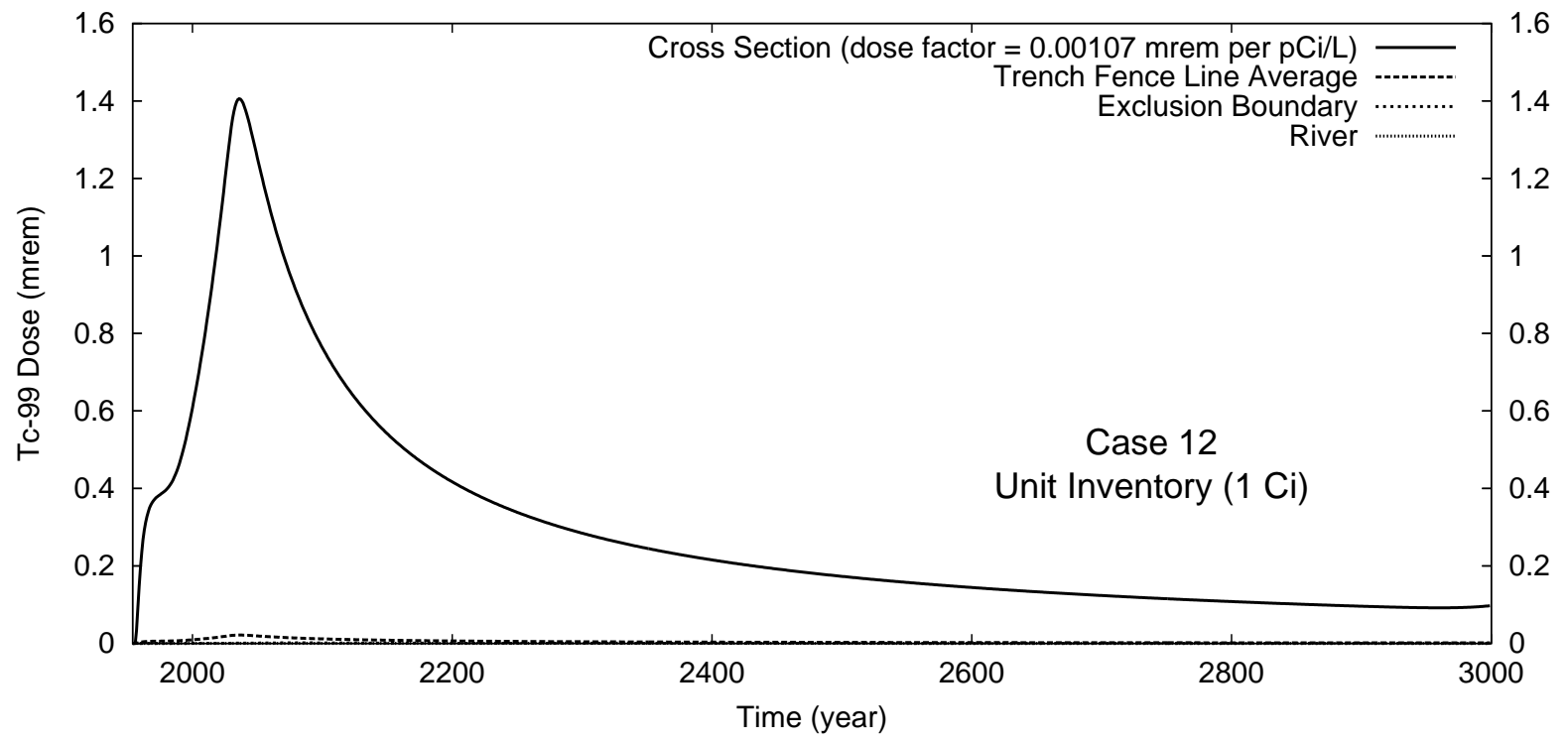

Figure D.3. Case 12 Results for U-238 and Tc-99 Unit Inventory Dose at Compliance Points 

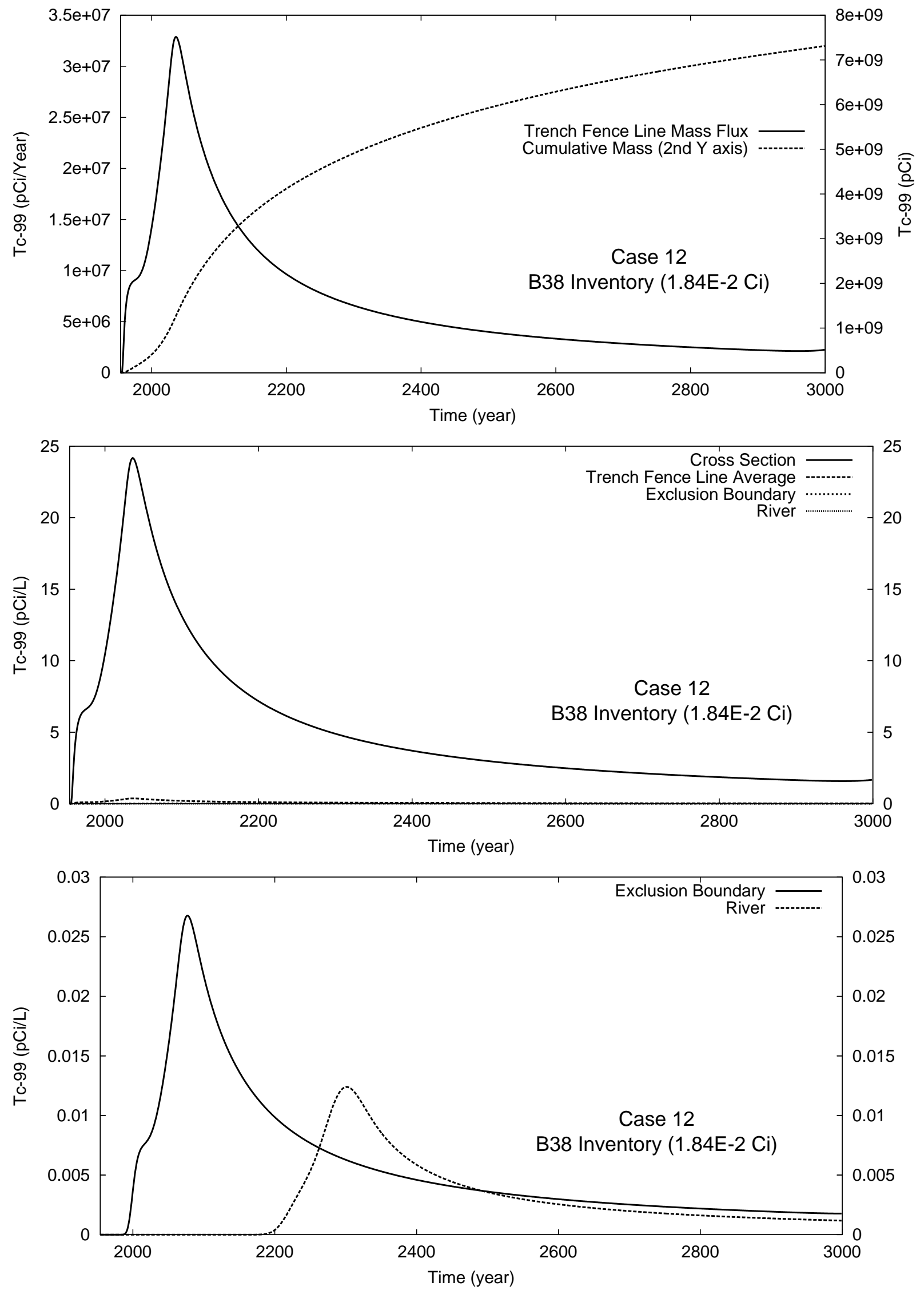

Figure D.4. Case 12 Results for Tc-99 B38 Inventory: Mass Flux and Breakthrough Curves D-5 

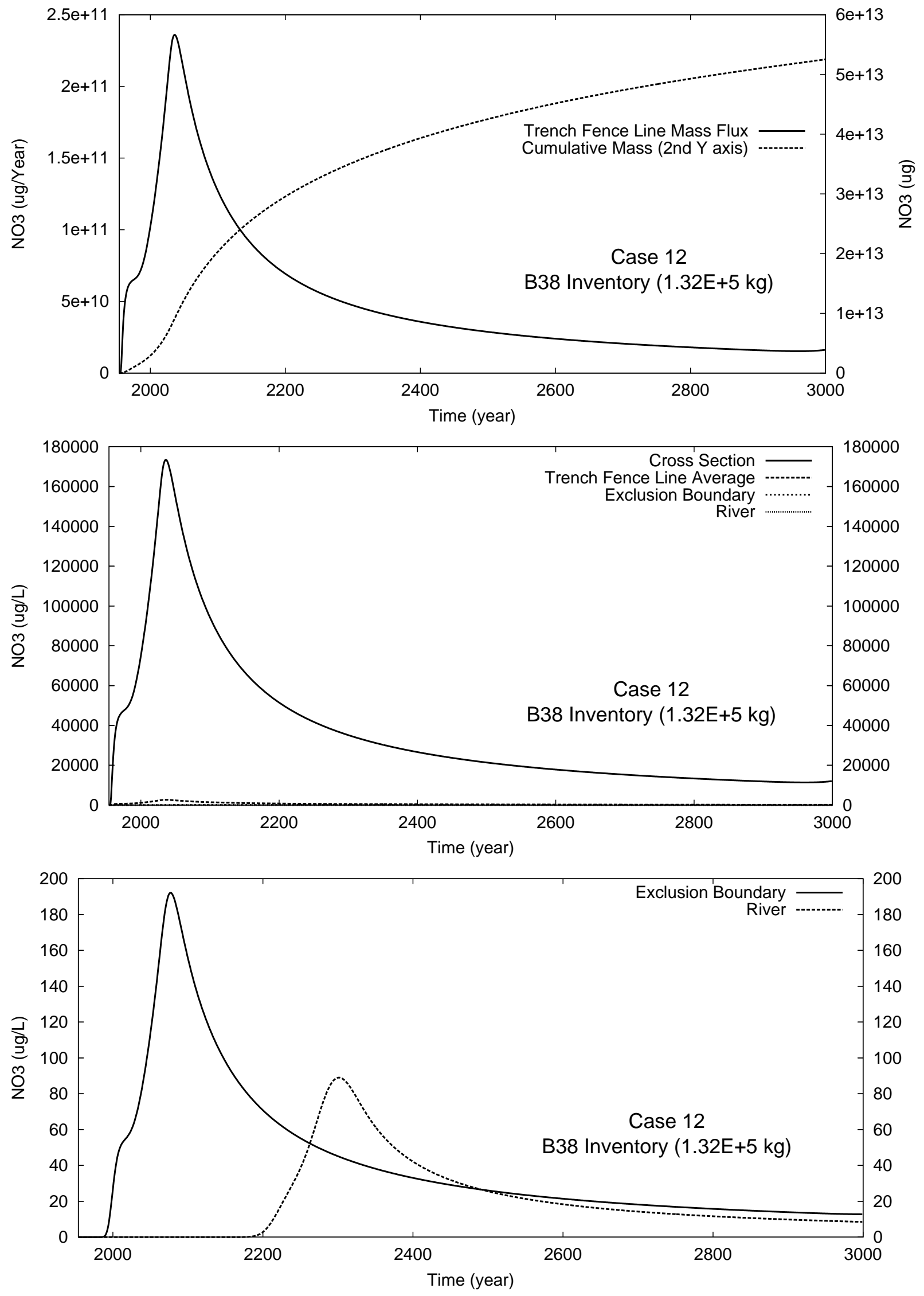

Figure D.5. Case 12 Results for NO3 B38 Inventory: Mass Flux and Breakthrough Curves D-6 


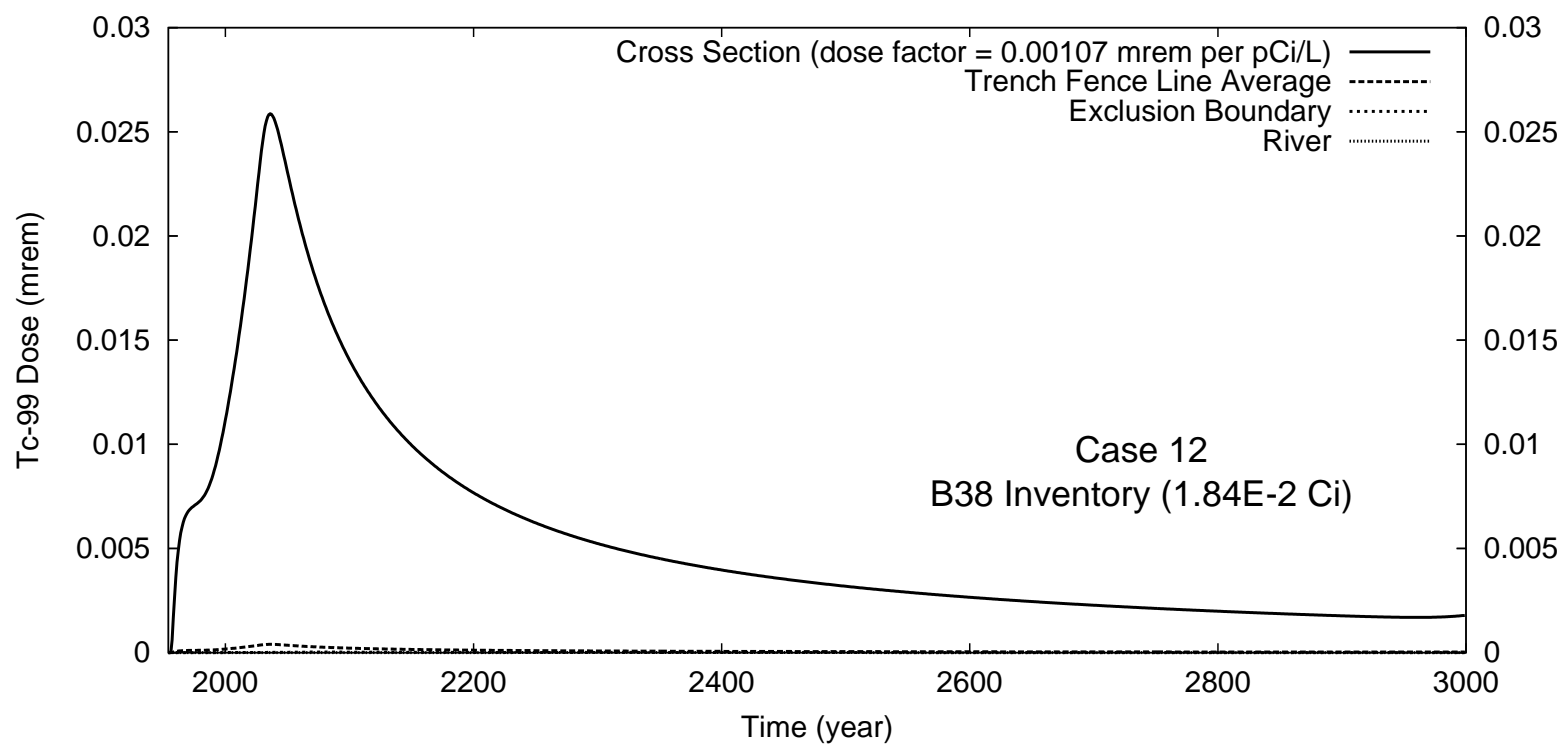

Figure D.6. Case 12 Results for U-238 and Tc-99 B38 Inventory Dose at Compliance Points 

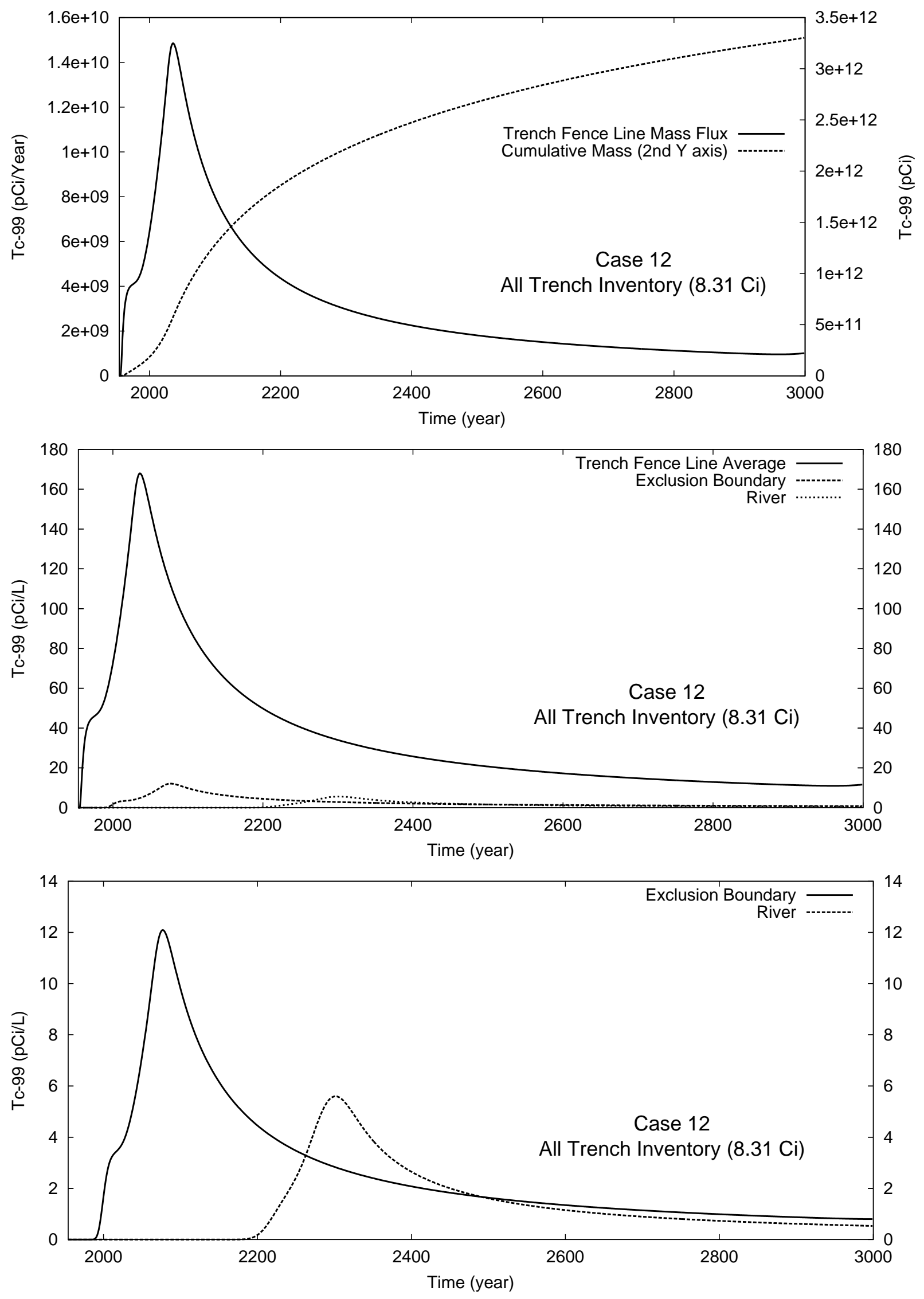

Figure D.7. Case 12 Results for Tc-99 All Trench Inventory: Mass Flux and Breakthrough Curves D-8 

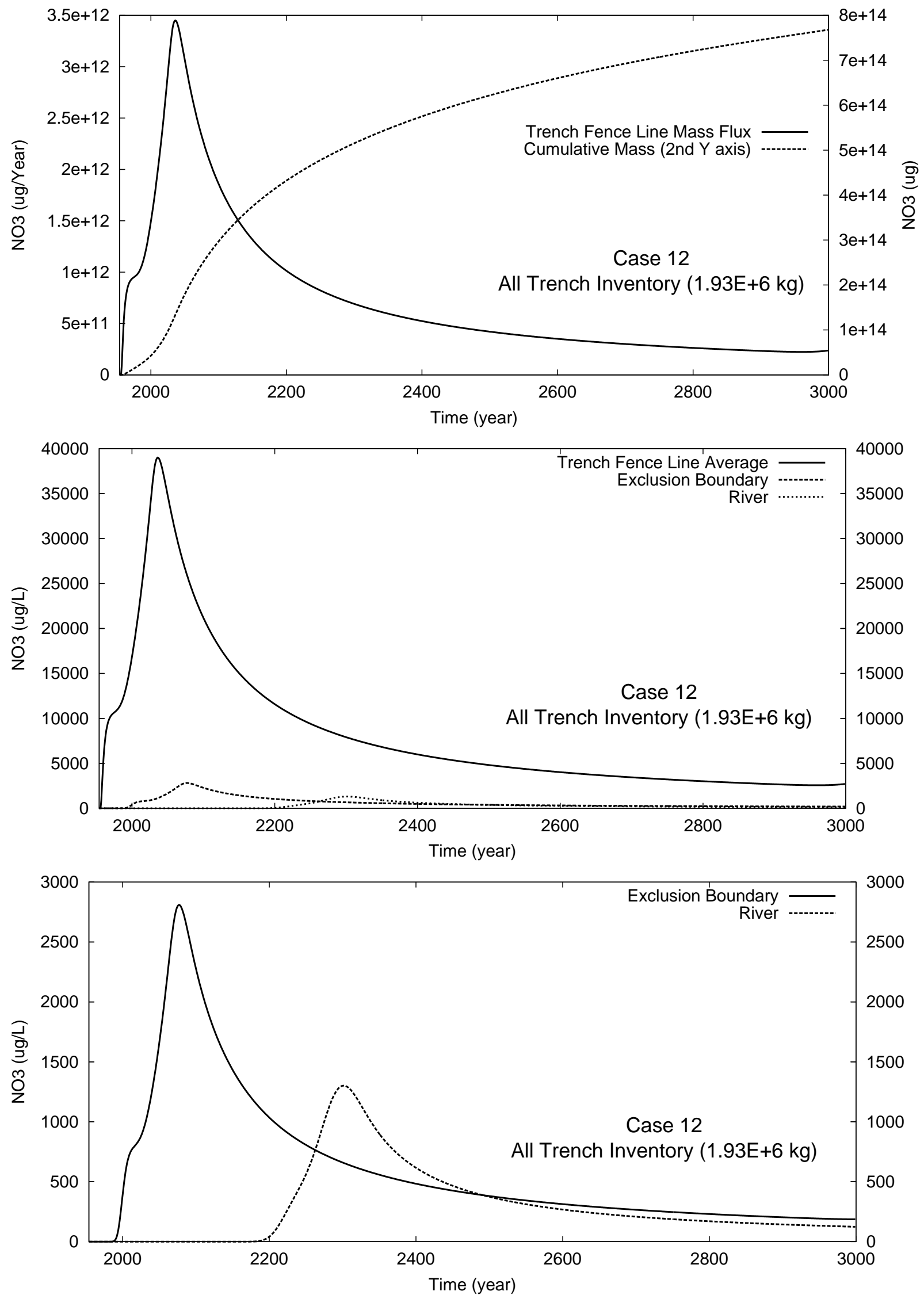

Figure D.8. Case 12 Results for NO3 All Trench Inventory: Mass Flux and Breakthrough Curves D-9 


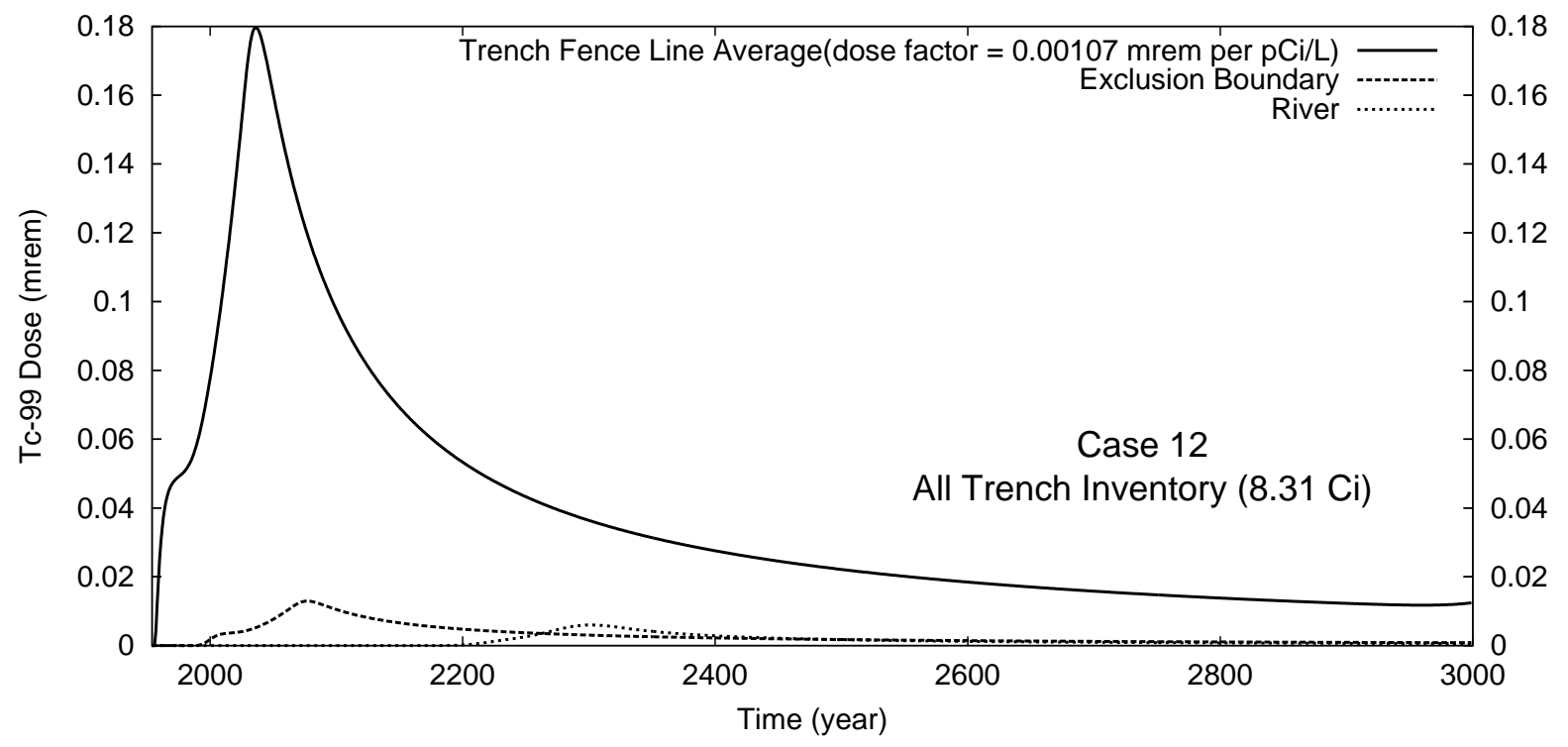

Figure D.9. Case 12 Results for U-238 and Tc-99 All Trench Inventory Dose at Compliance Points 

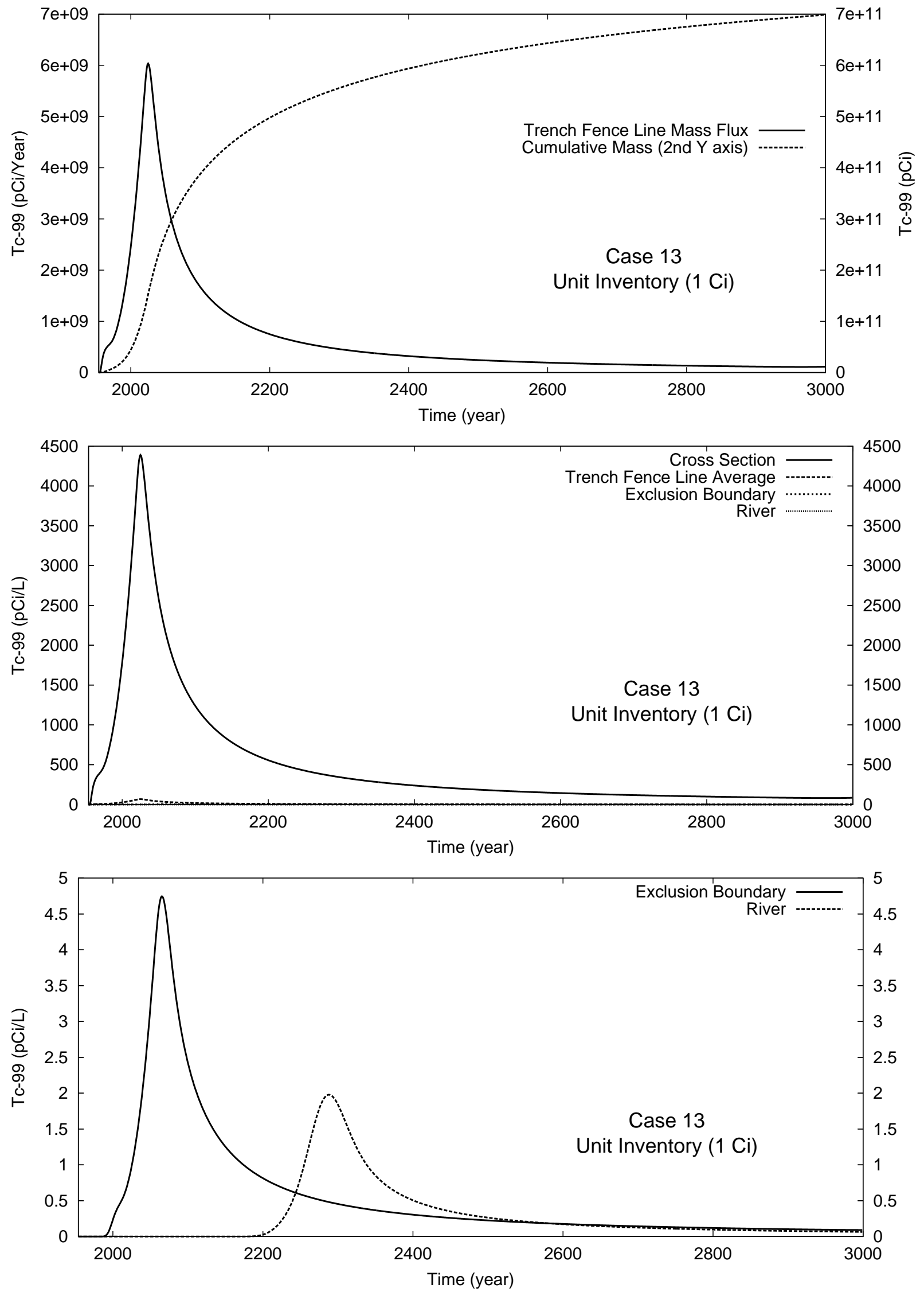

Figure D.10. Case 13 Results for Tc-99 Unit Inventory: Mass Flux and Breakthrough Curves D-11 

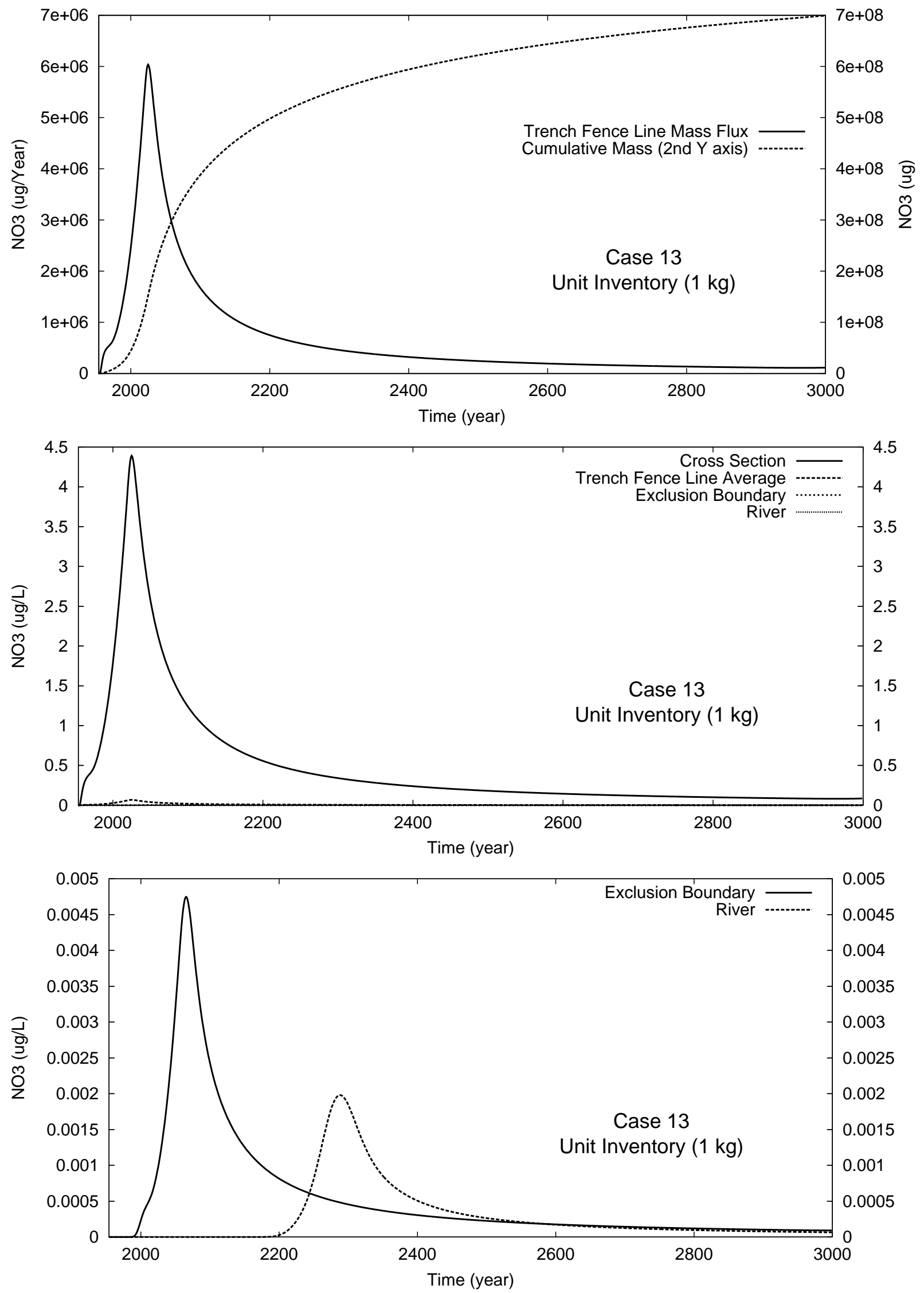

Figure D.11. Case 13 Results for NO3 Unit Inventory: Mass Flux and Breakthrough Curves D-12 


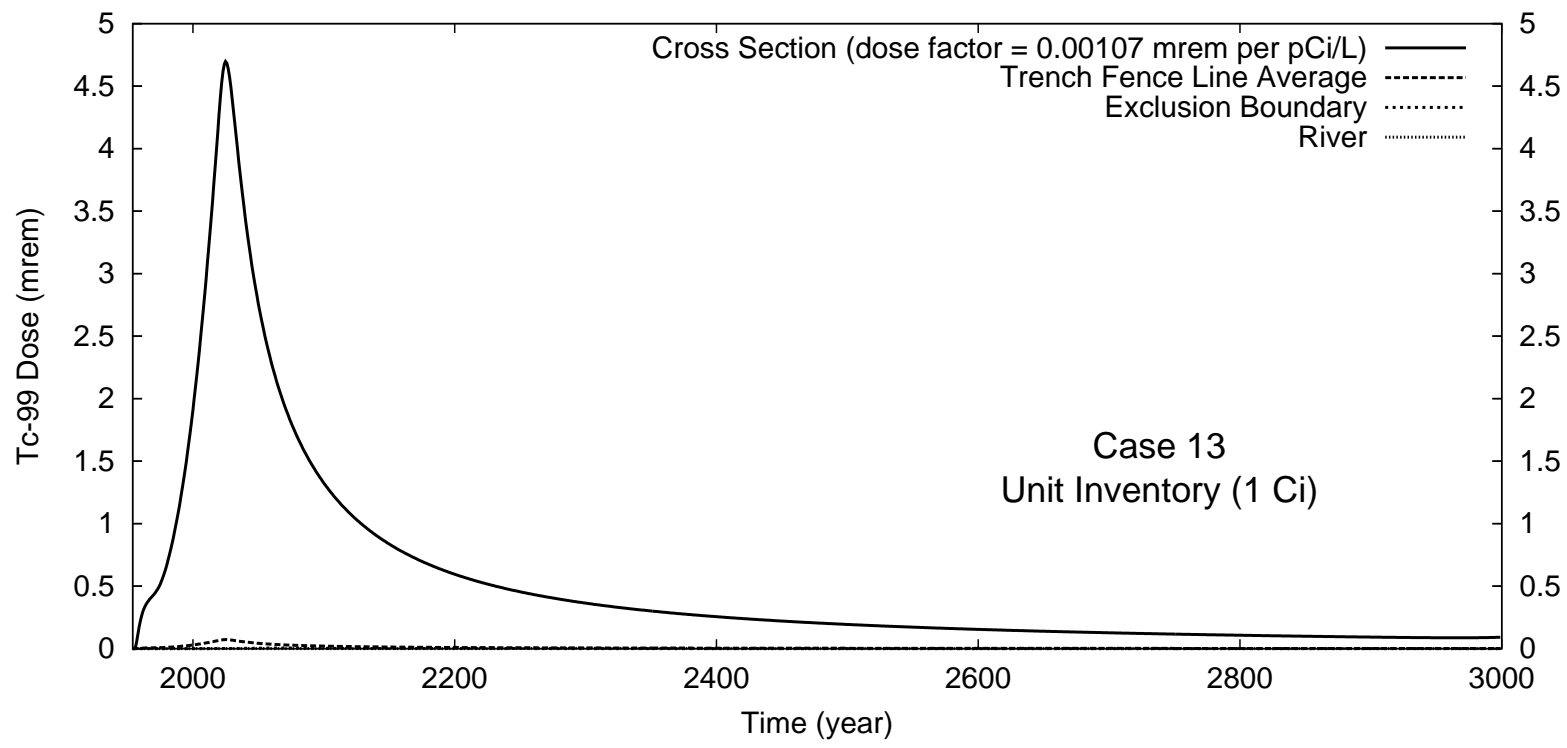

Figure D.12. Case 13 Results for U-238 and Tc-99 Unit Inventory Dose at Compliance Points 

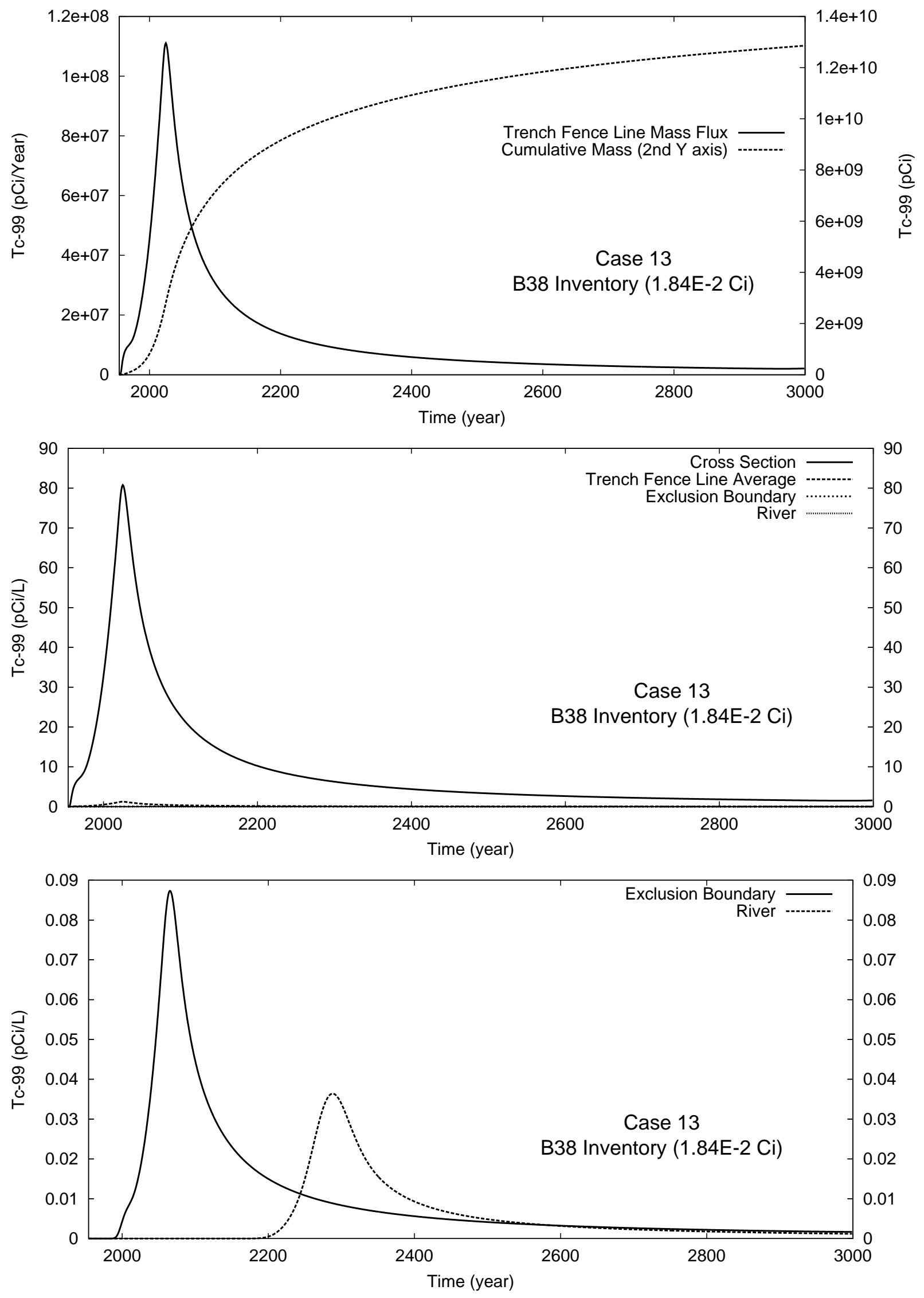

Figure D.13. Case 13 Results for Tc-99 B38 Inventory: Mass Flux and Breakthrough Curves D-14 

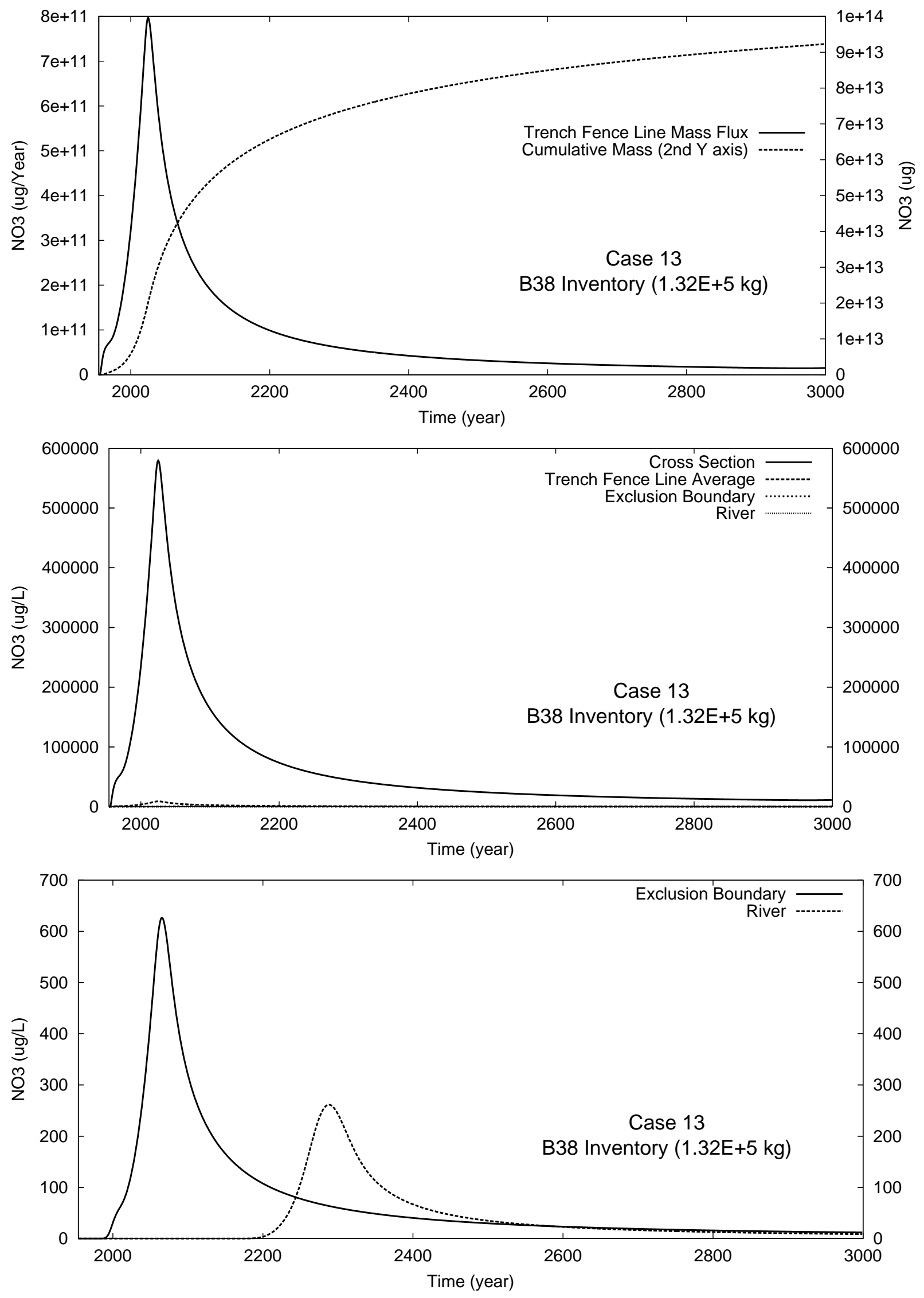

Figure D.14. Case 13 Results for NO3 B38 Inventory: Mass Flux and Breakthrough Curves D-15 


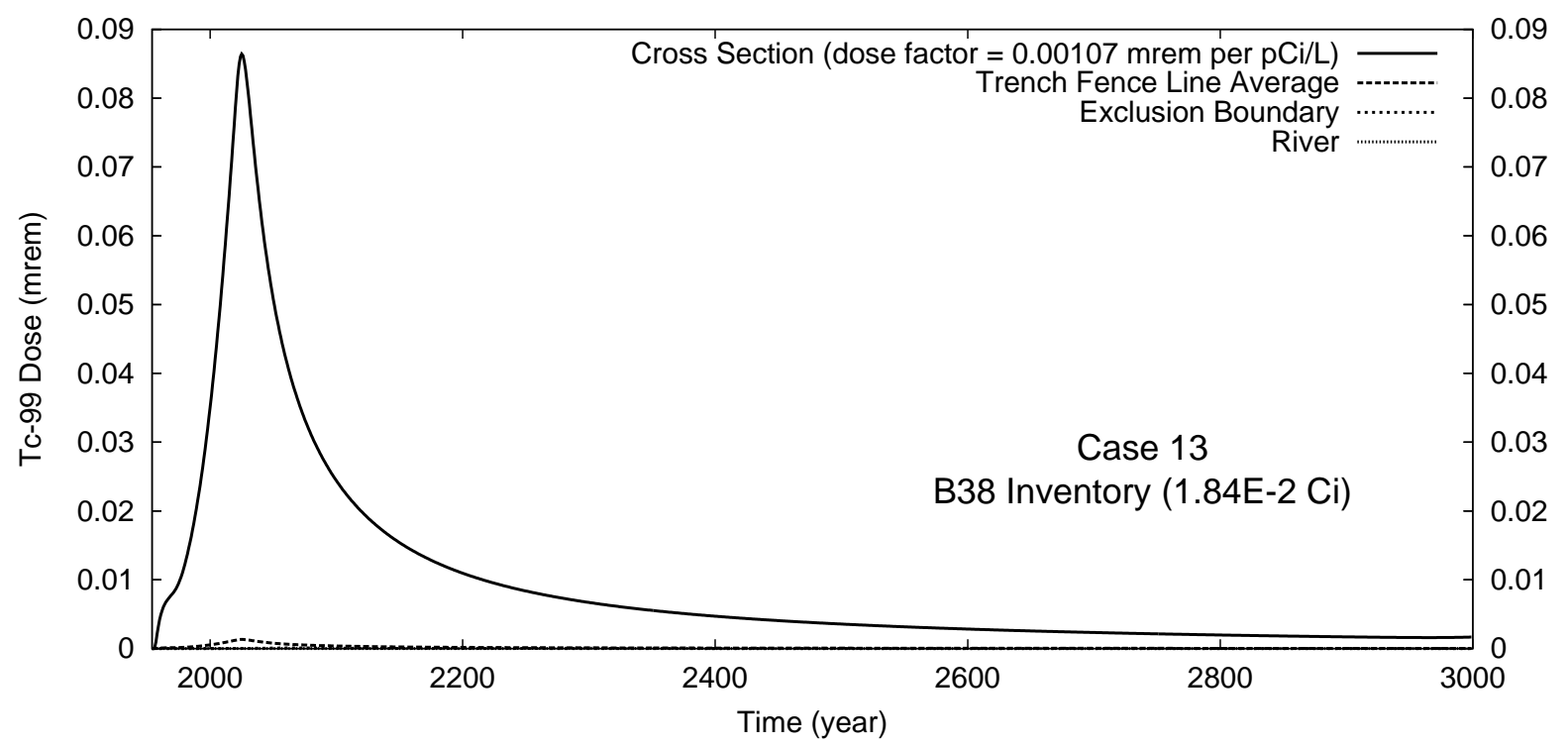

Figure D.15. Case 13 Results for U-238 and Tc-99 B38 Inventory Dose at Compliance Points 

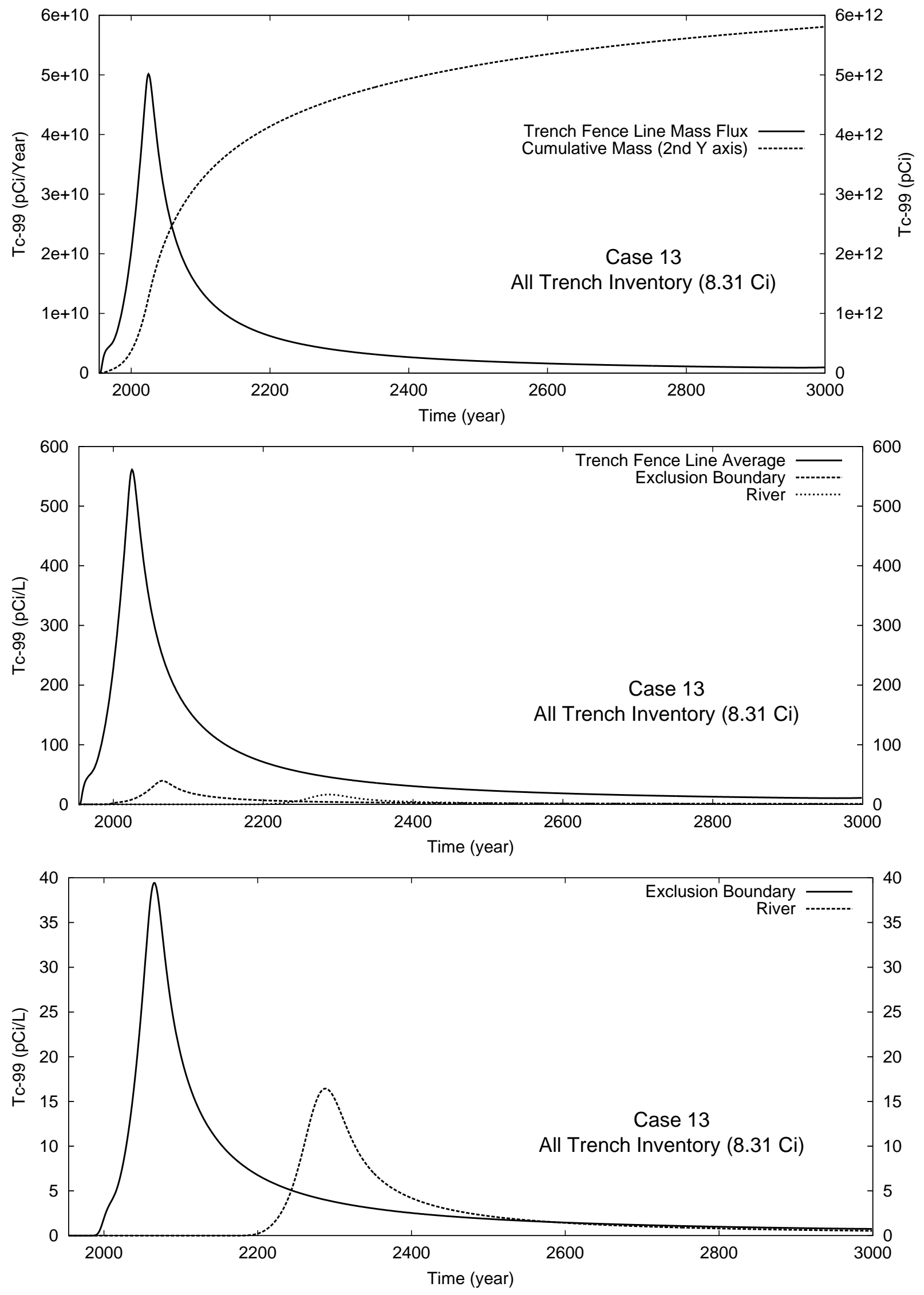

Figure D.16. Case 13 Results for Tc-99 All Trench Inventory: Mass Flux and Breakthrough Curves D-17 

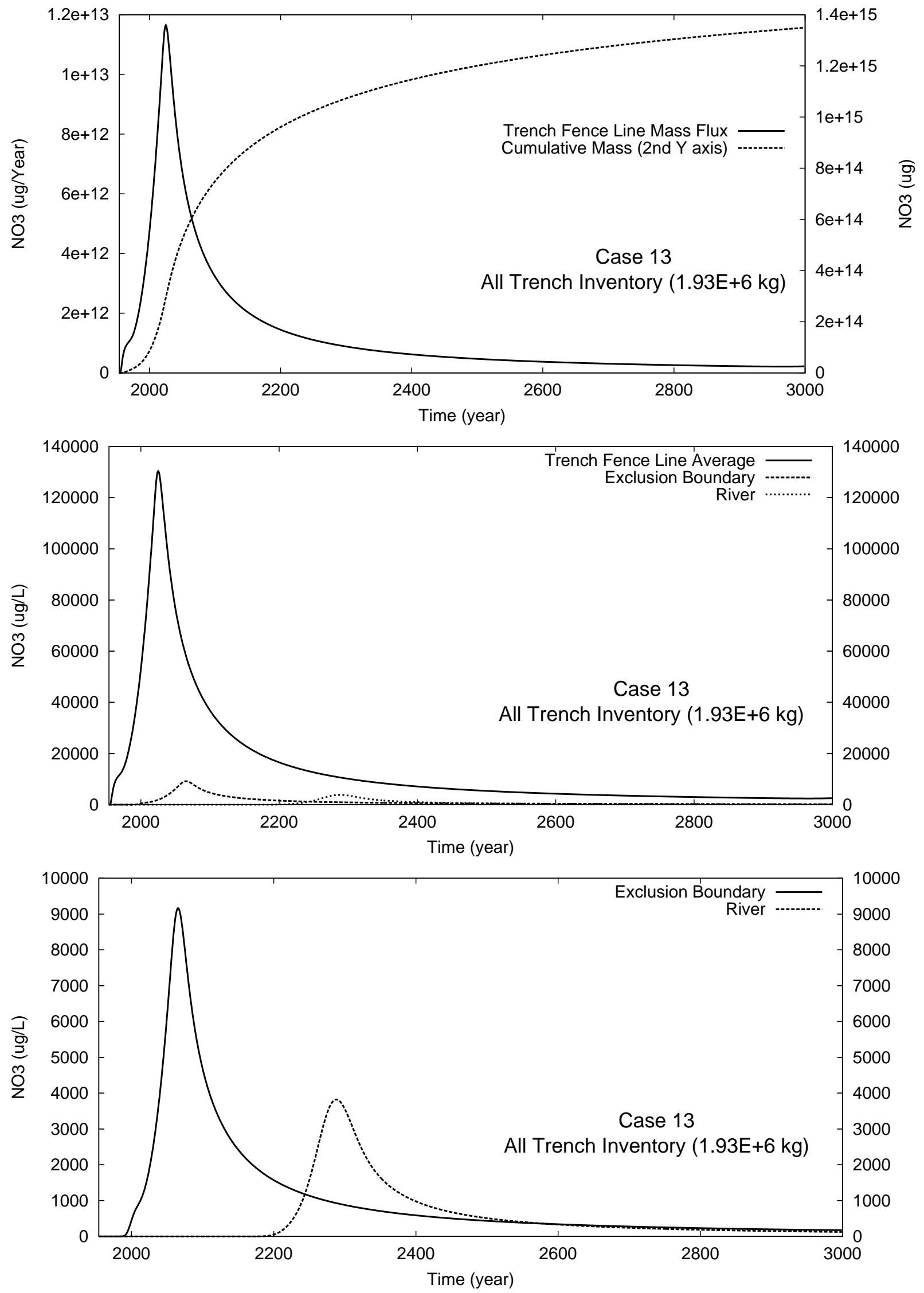

Figure D.17. Case 13 Results for NO3 All Trench Inventory: Mass Flux and Breakthrough Curves D-18 


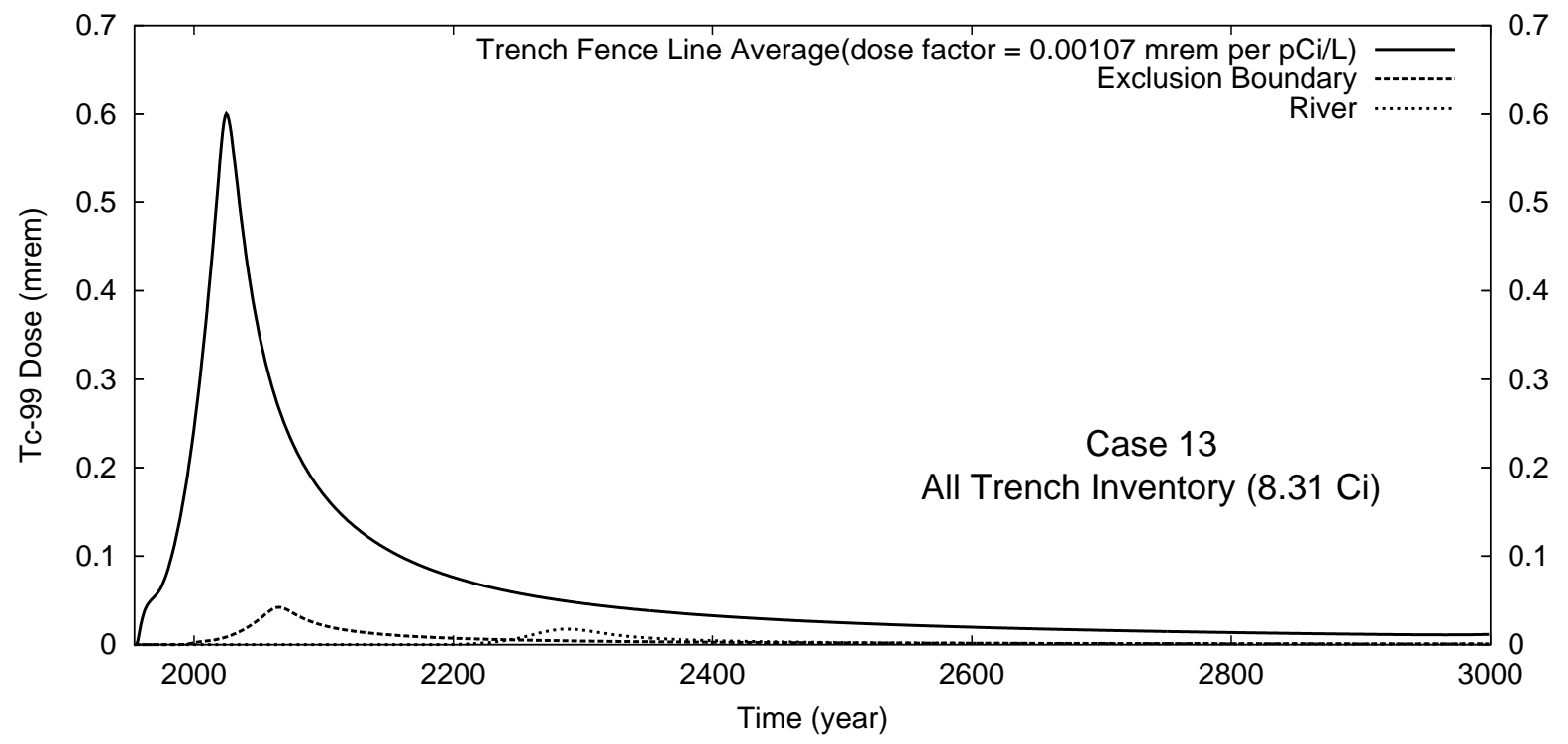

Figure D.18. Case 13 Results for U-238 and Tc-99 All Trench Inventory Dose at Compliance Points 

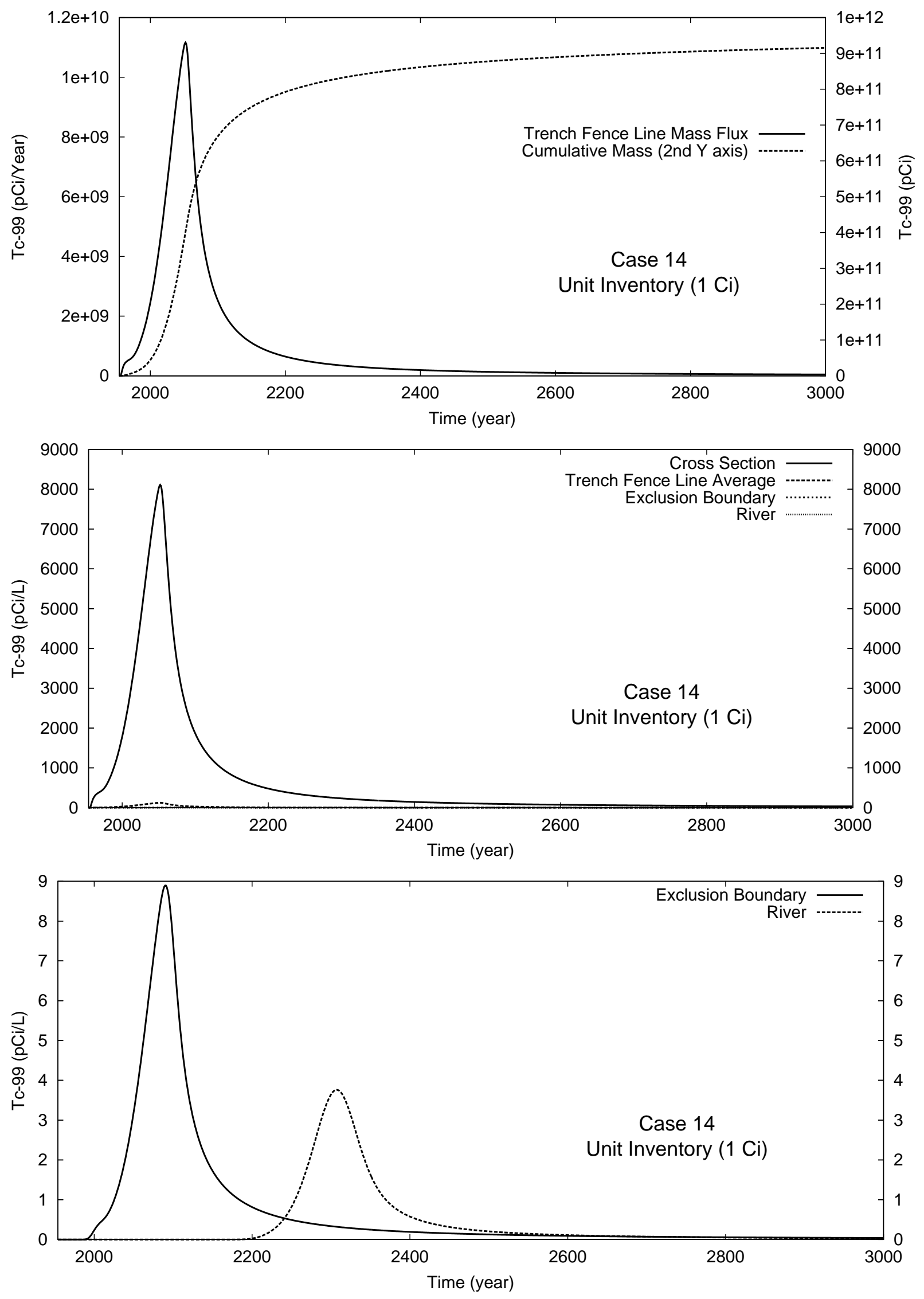

Figure D.19. Case 14 Results for Tc-99 Unit Inventory: Mass Flux and Breakthrough Curves D-20 

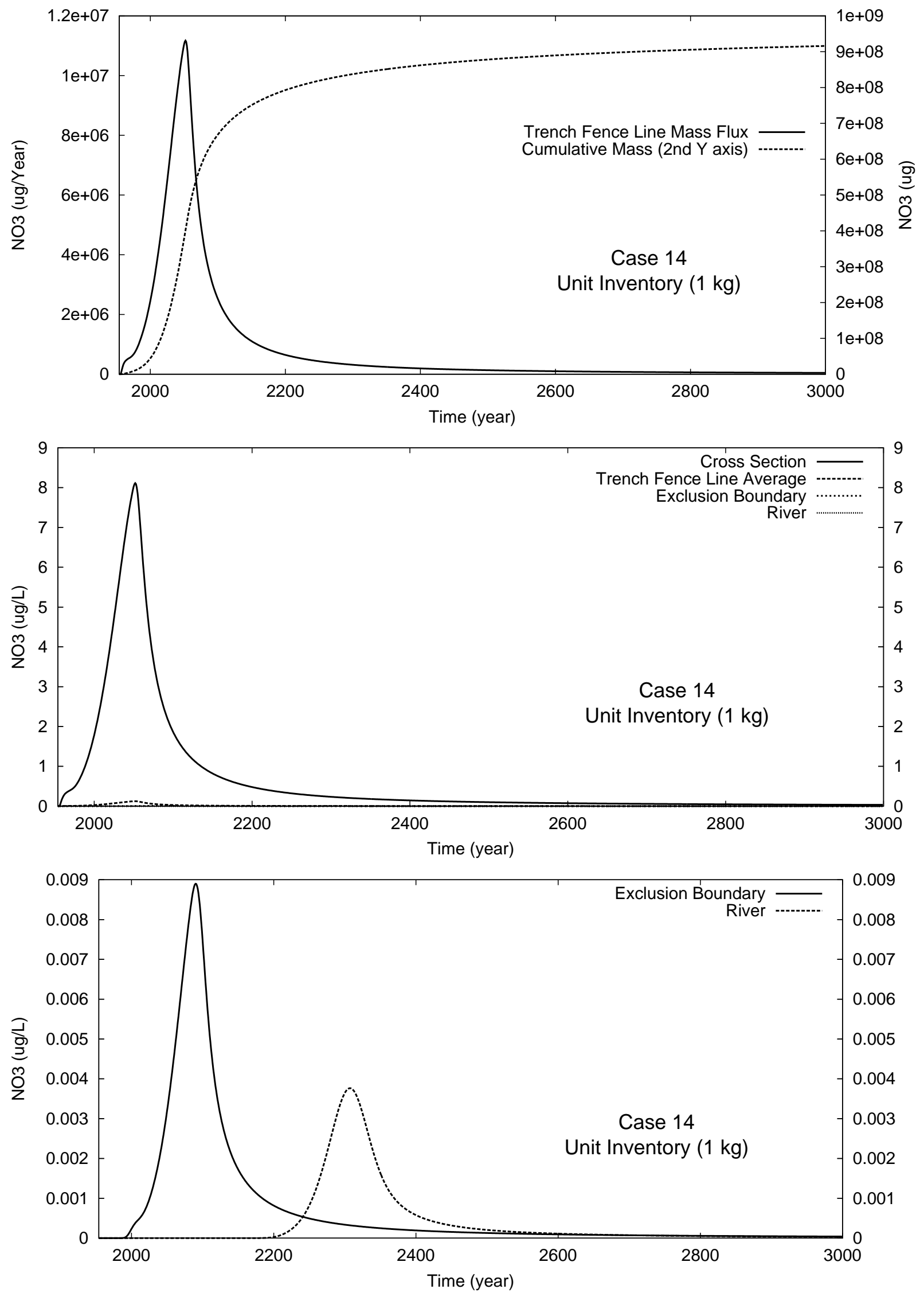

Figure D.20. Case 14 Results for NO3 Unit Inventory: Mass Flux and Breakthrough Curves D-21 


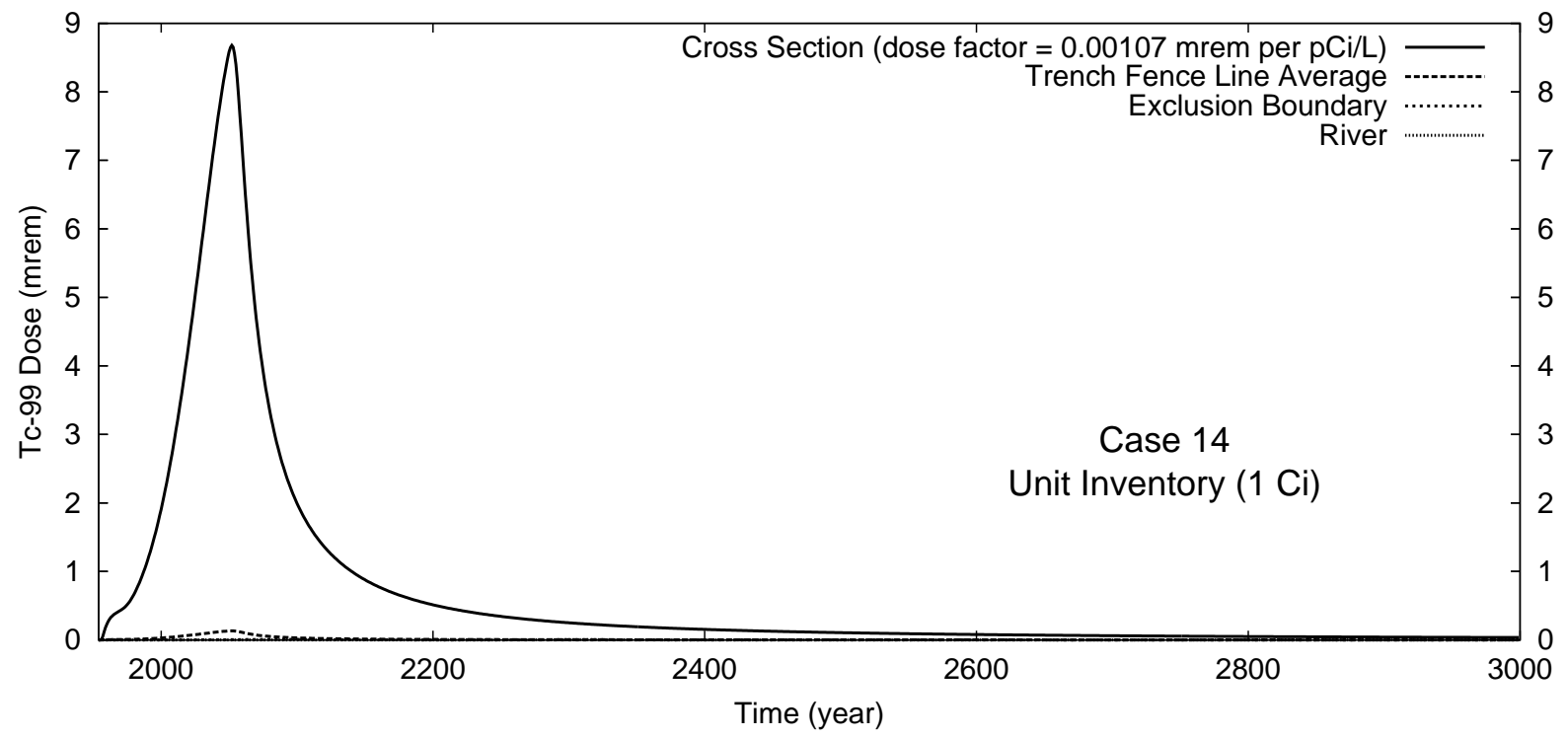

Figure D.21. Case 14 Results for U-238 and Tc-99 Unit Inventory Dose at Compliance Points 

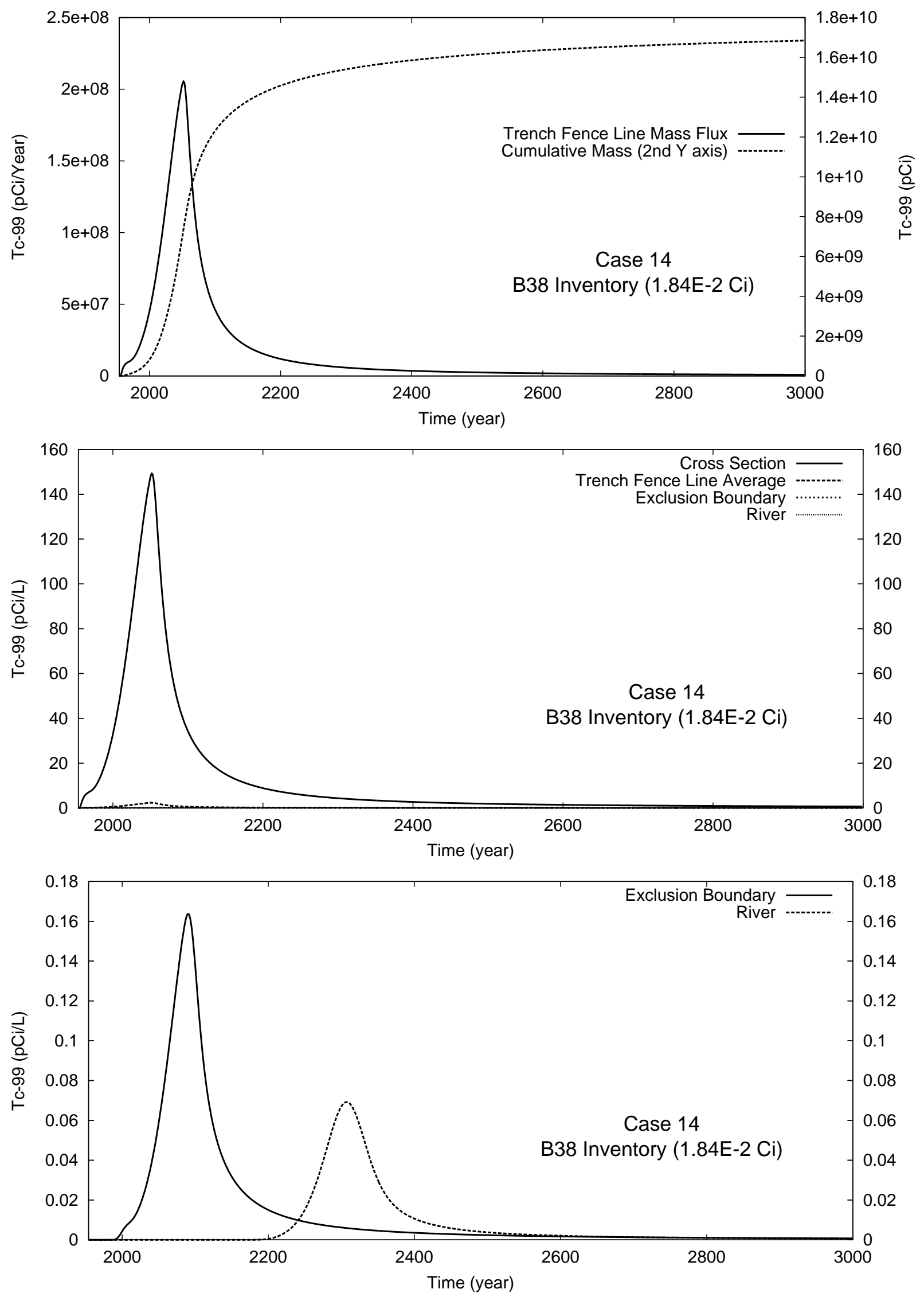

Figure D.22. Case 14 Results for Tc-99 B38 Inventory: Mass Flux and Breakthrough Curves D-23 

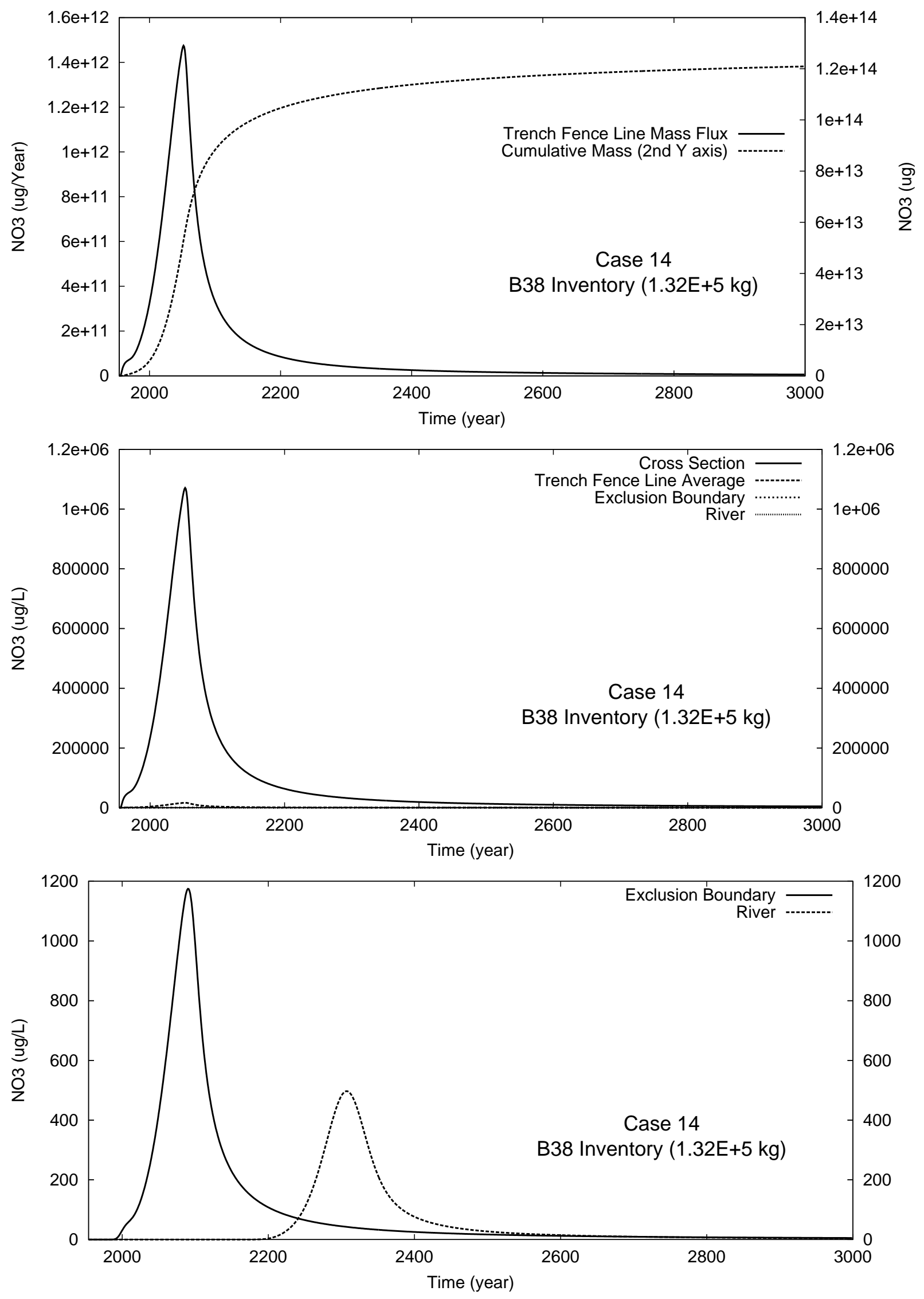

Figure D.23. Case 14 Results for NO3 B38 Inventory: Mass Flux and Breakthrough Curves D-24 


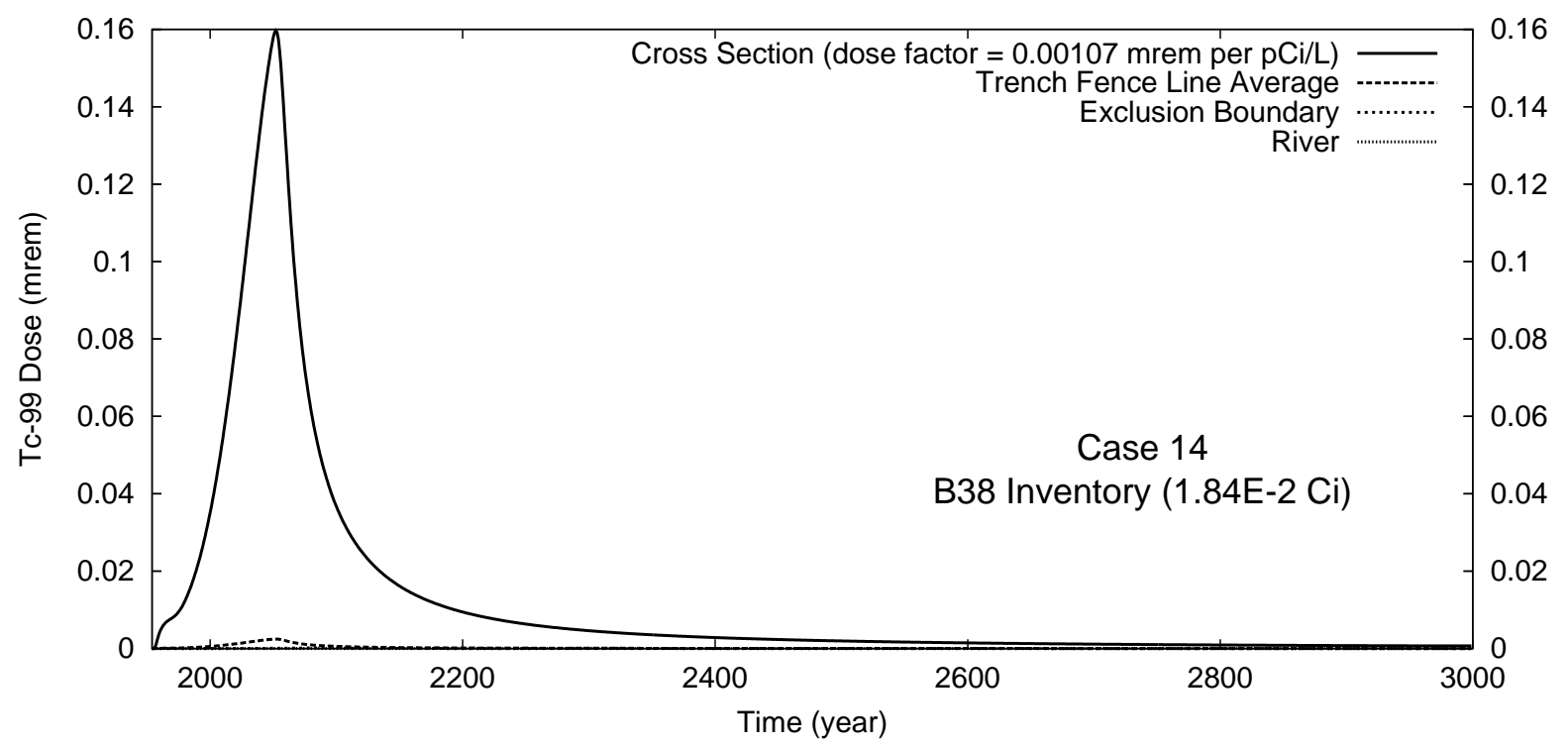

Figure D.24. Case 14 Results for U-238 and Tc-99 B38 Inventory Dose at Compliance Points 

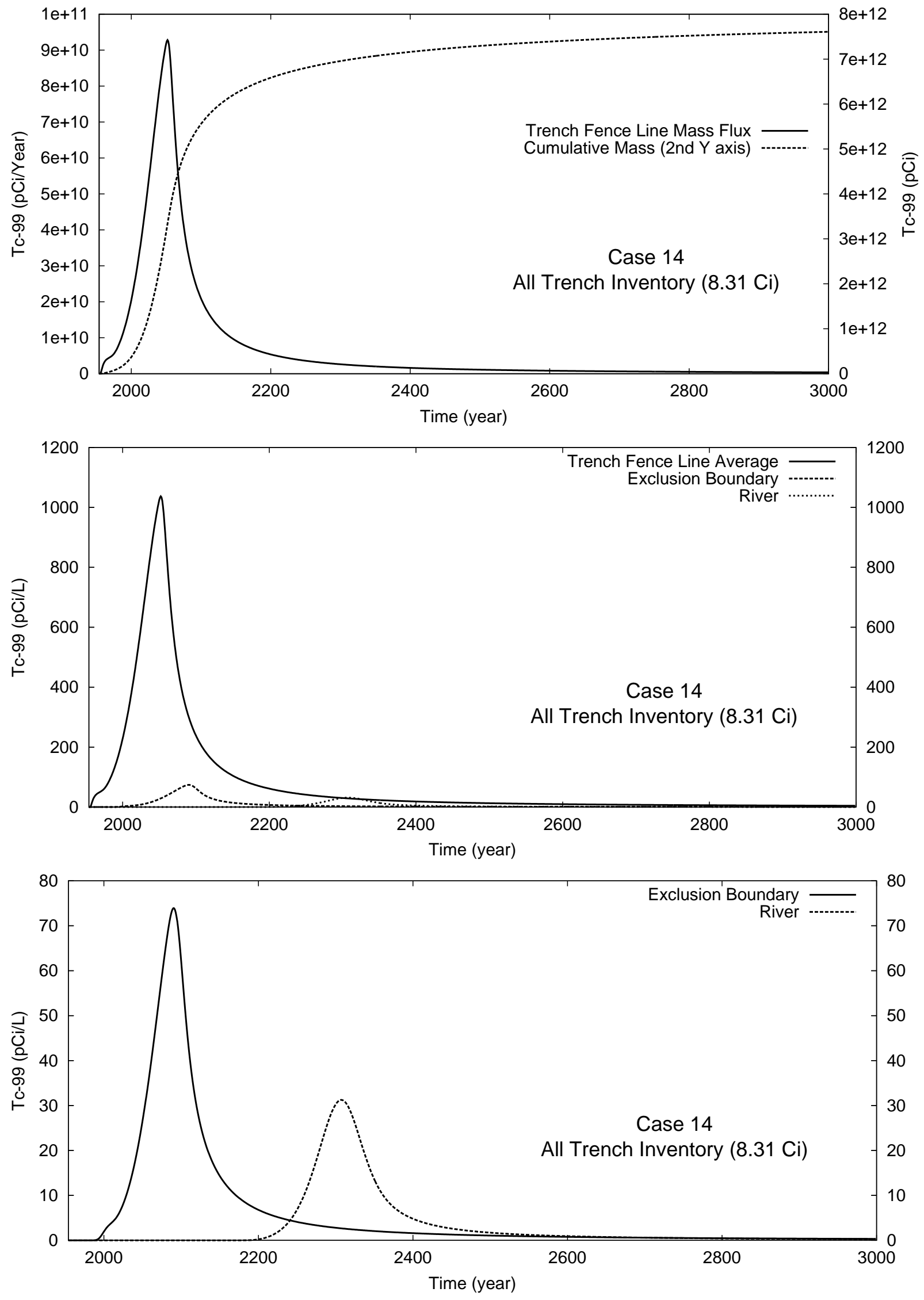

Figure D.25. Case 14 Results for Tc-99 All Trench Inventory: Mass Flux and Breakthrough Curves D-26 

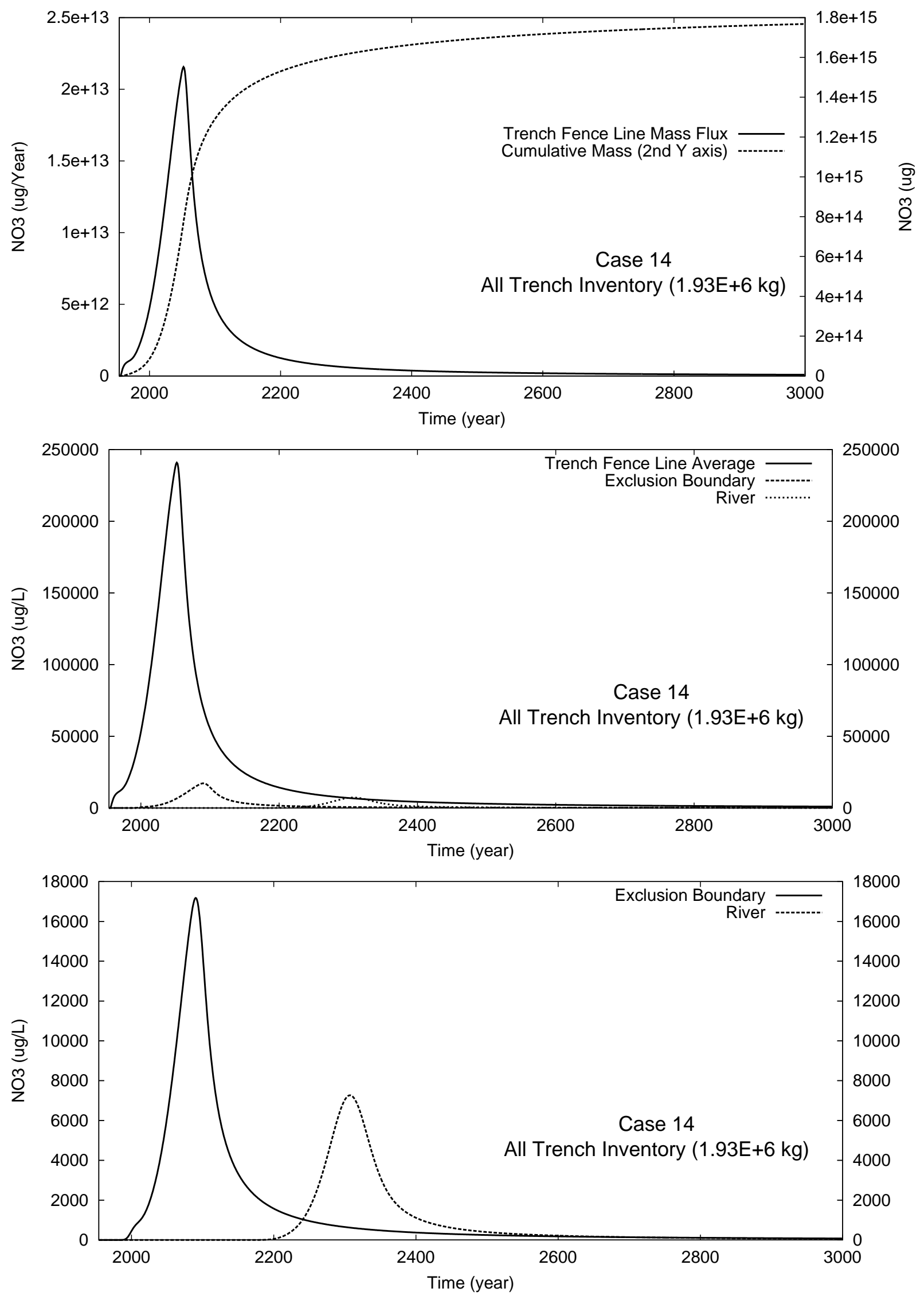

Figure D.26. Case 14 Results for NO3 All Trench Inventory: Mass Flux and Breakthrough Curves D-27 


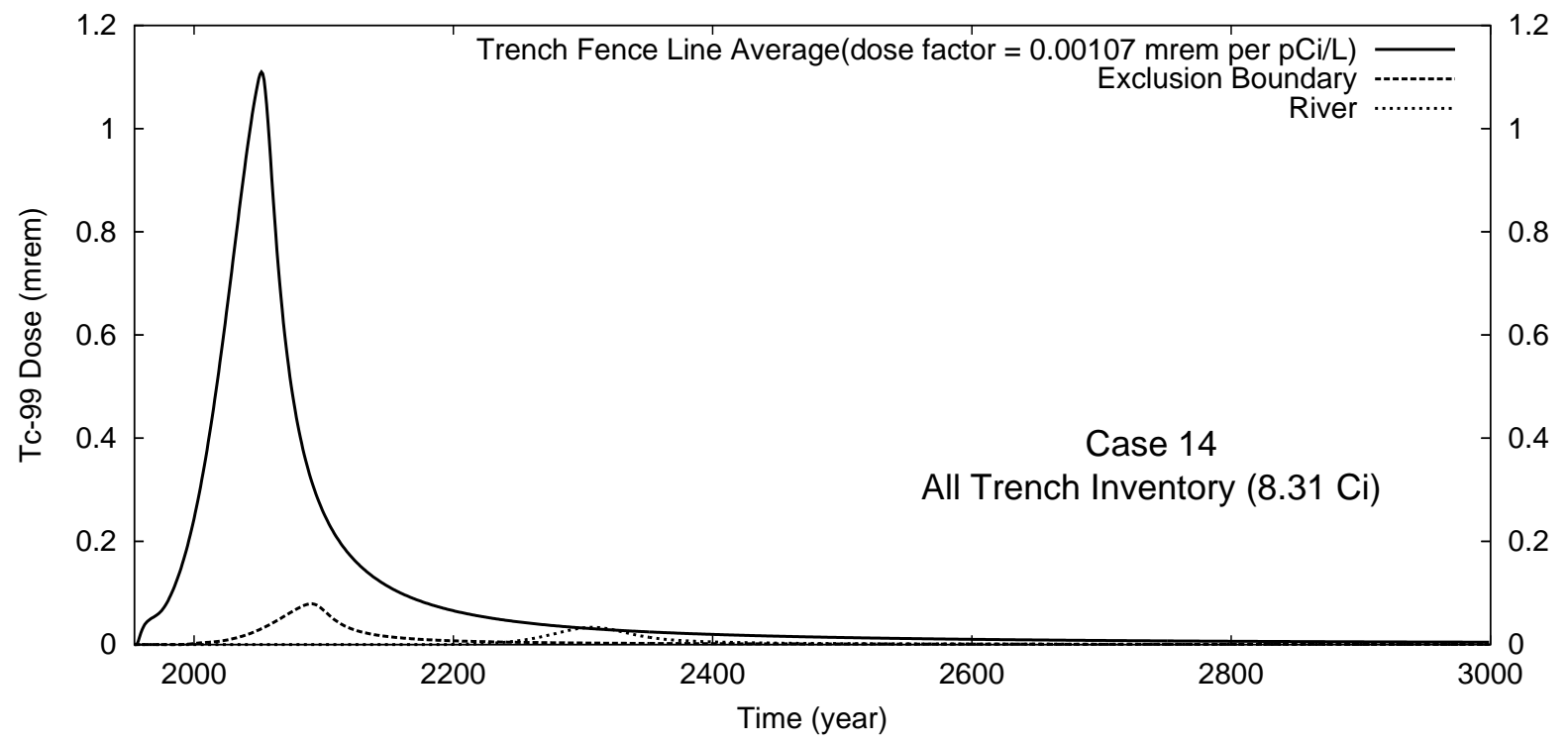

Figure D.27. Case 14 Results for U-238 and Tc-99 All Trench Inventory Dose at Compliance Points 